\title{
Feasibility Study of Secondary Heat Exchanger Concepts for the Advanced High Temperature Reactor
}

The INL is a

U.S. Department of Energy

National Laboratory

operated by

Battelle Energy Alliance

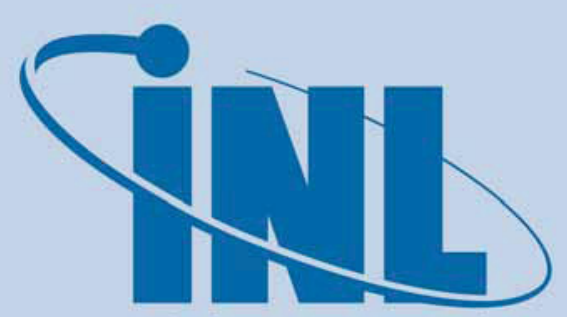

Idaho National Laboratory
Piyush Sabharwall

Eung Soo Kim

Ali Siahpush

Nolan Anderson

Michael Glazoff

Bill Phoenix

Ron Mizia

Denis Clark

Mike McKellar

M.W. Patterson

September 2011 


\section{Disclaimer}

This information was prepared as an account of work sponsored by an agency of the U.S. Government. Neither the U.S. Government nor any agency thereof, nor any of their employees, makes any warranty, expressed or implied, or assumes any legal liability or responsibility for the accuracy, completeness, or usefulness, of any information, apparatus, product, or process disclosed, or represents that its use would not infringe privately owned rights. References herein to any specific commercial product, process, or service by trade name, trade mark, manufacturer, or otherwise, does not necessarily constitute or imply its endorsement, recommendation, or favoring by the U.S. Government or any agency thereof. The views and opinions of authors expressed herein do not necessarily state or reflect those of the U.S. Government or any agency thereof. 



\title{
Feasibility Study of Secondary Heat Exchanger Concepts for the Advanced High Temperature Reactor
}

Piyush Sabharwall, Eung Soo Kim, Ali Siahpush, Nolan Anderson, Michael Glazoff, Bill Phoenix, Ron Mizia, Denis Clark, Mike McKellar, and M.W. Patterson

\author{
Idaho National Laboratory \\ Next Generation Nuclear Plant Project \\ Idaho Falls, Idaho 83415
}

http://www.inl.gov

Prepared for the

U.S. Department of Energy

Office of Nuclear Energy

Under DOE Idaho Operations Office

Contract DE-AC07-05ID14517 



\section{Feasibility Study of Secondary Heat Exchanger Concepts for the Advanced High Temperature Reactor}

INL/EXT-11-23076

Approved by:

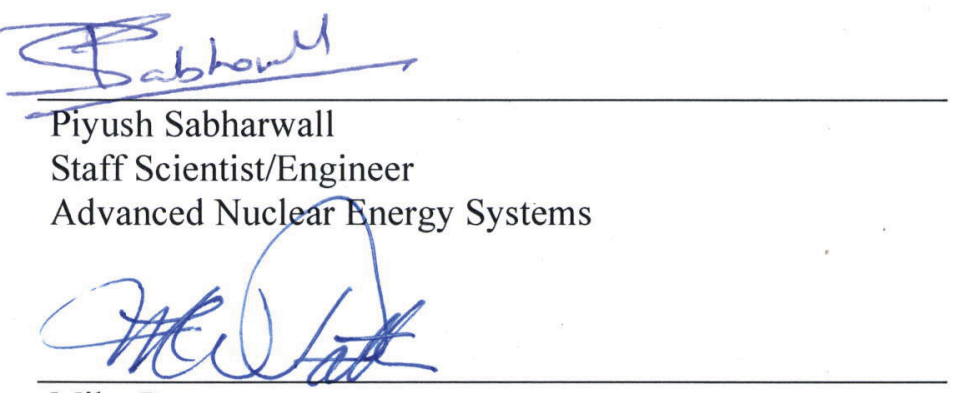

Mike Patterson

Project Manager, NGNP Process Heat Applications

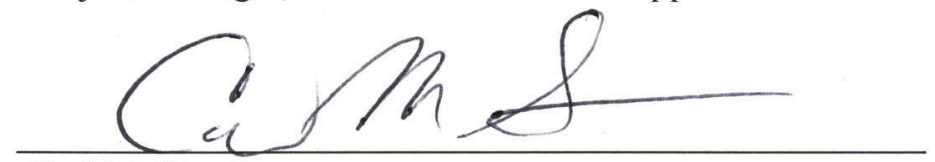

Carl M. Stoots

Department Manager, Experimental Programs
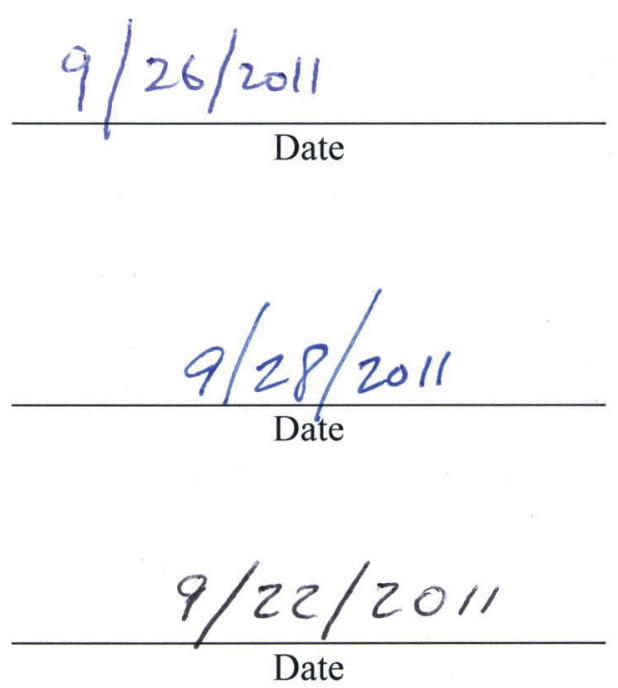



\begin{abstract}
An evaluation of viable secondary heat exchanger concepts for use with a molten salt nuclear reactor is presented based on thermal design studies using $\mathrm{KF}-\mathrm{ZrF}_{4}$ as the secondary coolant. Along with the potential issues related to materials, fabrication methods, system configuration, coolant properties and hot corrosion, a discussion of challenges associated with integrating a steam power cycle with the reactor is also presented. The reference reactor design and configuration is a $3,400 \mathrm{MW}_{\mathrm{t}}$ advanced high temperature reactor utilizing Rankine subcritical or supercritical cycles for power production.
\end{abstract}




\section{SUMMARY}

Advanced High Temperature Reactors (AHTRs) will produce high outlet temperatures $\left(704^{\circ} \mathrm{C}\right)$ using coated particle fuel, which provides for improved efficiency in power production or process heat for a variety of industrial applications. The AHTR is part of the fluoride-salt-cooled high temperature reactor (FHR) class of nuclear reactors included in the advanced reactor concept program. Early design decisions for the AHTR include use of an intermediate heat exchanger (IHX) to couple the primary loop to an intermediate loop. Heat from the IHX will be circulated in the intermediate loop through a secondary heat exchanger (SHX) and transferred to a power cycle that produces electricity or transferred to an industrial process. The feasibility of design options for the SHX is the subject of this study, and for the purposes of this study, the following preliminary decisions were made as a baseline for comparison:

- The reactor outlet temperature is $704^{\circ} \mathrm{C}$, from which the primary, secondary and tertiary fluid temperatures are derived.

- The intermediate loop fluid is $\mathrm{KF}-\mathrm{ZrF}_{4}$, which determines the SHX upstream side fluid and fluid conditions.

- A supercritical or subcritical steam cycle is connected downstream of the SHX for power production, setting the fluid conditions on the downstream side.

- The SHX is either a helically coiled tube and shell design or a printed circuit heat exchanger (PCHE) design.

- The baseline material of construction is Alloy N.

Alternative parameters are evaluated in this study and compared to the baseline based on the feasibility of their implementation.

Heat exchangers are considered key components that need to be extensively investigated because they are operated under a severe environment and their performance is directly related to the overall system efficiency and safety. Previous analysis (INL/EXT-11-21584) of the power conversion system showed that Rankine subcritical and supercritical cycles with a turbine inlet temperature of $679^{\circ} \mathrm{C}$ can yield conversion efficiencies of $42 \%$ and $44 \%$ respectively, with $\mathrm{KF}_{-} \mathrm{ZrF}_{4}$ as the secondary salt coolant.

Fluoride salts such as $\mathrm{KF}-\mathrm{ZrF}_{4}$ have highly desirable characteristics for high temperature nuclear reactor heat transport. A characteristic of molten fluoride salts is that they can easily dissolve passive oxide layers such as the chromia oxide film $\left(\mathrm{Cr}_{2} \mathrm{O}_{3}\right)$ that provides the corrosion resistance for stainless steels and nickel based alloys in many aqueous and high temperature environments. Moisture and oxide impurities in fluorides can cause corrosion (oxidation) of the metal alloy in the molten salt. Earlier work identified Hastelloy B (29\% Mo, $5 \% \mathrm{Fe}$, balance $\mathrm{Ni})$ as a material with excellent corrosion resistance, which was due to the formation of a $\mathrm{NiMoO}_{4}$ oxide layer. This alloy was dropped from consideration due to fabrication difficulties and embrittlement attributed to aging in the $650^{\circ} \mathrm{C}$ to $900^{\circ} \mathrm{C}$ temperature range.

Further alloy development resulted in the Hastelloy N composition $(15-18 \% \mathrm{Mo}, 6-8 \% \mathrm{Cr}, 5 \% \mathrm{Fe}$, balance $\mathrm{Ni}$ ) where the level of chromium addition will cause the chromia film to form. Alloy $\mathrm{N}$ will not have the oxidation resistance of higher chromium-containing nickel based alloys to postulated secondary side environments such as the environment found in supercritical steam. Therefore, the corrosion resistance of other potential SHX materials in $\mathrm{KF}-\mathrm{ZrF}_{4}$ and supercritical steam are evaluated for comparison to Alloy N. Definitive experimental data on the oxidation of these materials is generally not available; hence, the thermodynamic simulations of oxidation for Hastelloy $\mathrm{N}$ and other nickel based alloy compositions would be a good first step in understanding these reactions and guiding future experiments. High temperature alloys being considered are: Alloy $800 \mathrm{H}$, Alloy 617, Alloy N and Alloy 242. Use of ceramics in SHX should not be discounted at this early stage of design, but for thermal design studies, Alloy N properties were used.

Adapting a steam power cycle to a molten salt reactor and operating it from shutdown conditions to full operating temperature under steady-state and changing loads provide the operational parameters 
needed to develop SHX design requirements. An important engineering challenge will be preventing the molten salt from freezing in the SHX during normal and off-normal operations because of its high melting temperature $\left(390^{\circ} \mathrm{C}\right.$ for $\left.\mathrm{KF}-\mathrm{ZrF}_{4}\right)$. Applying lessons from successful operation of fossil supercritical plants and conventional light water reactors simplifies the challenge, and conceptual flowsheets with components such as condensate demineralizers and deaerators were developed.

It was determined that significant modifications will be required to existing supercritical designs, including substantial preheating of feedwater to a sufficient temperature to prevent the salt in the steam generators from freezing, and either steam-to-steam reheaters for steam exiting the high pressure turbine, or salt-to-steam reheaters. The intermediate salt loop will require at least one salt cleanup system to remove water and other impurities in case of heat exchanger leaks. The intermediate loop will also require a salt dump tank to receive salt in case of a heat exchanger rupture or certain operational occurrences such as a prolonged loss of electrical power.

The relatively high freezing point of molten salt appears best suited to a supercritical steam cycle and given the very high pressure of the supercritical steam cycle, water (inside the tube) tube and salt (outside the tube) shell steam generators will be used as the technology baseline for the SHX. However, continued development of the PCHE has the potential for significantly improved efficiency and capital cost reductions. Parametric cost estimates of the baseline steam generator and a PCHE fabricated from Alloy $\mathrm{N}$ were prepared using the cost for a boiler of a supercritical Rankine power conversion unit (PCU) that uses combustion of pulverized coal for the heat source as a basis. Total thermal duty of $3400 \mathrm{MW}$ with one, two, and three heat exchangers was evaluated and it was determined that for transfer of the entire heat load through one SHX, the capital cost of the PCHE was $38 \%$ that of the helical coil steam generator - \$116 million versus \$302 million. The estimate assumed the fabrication factors were identical and was based on an informal price for only one heat of Alloy N. Further, no attempt was made to define the uncertainty in the estimate. However, the potential for large capital cost savings justifies assuming some technical risk and expense in demonstrating PCHE technology.

Using three versus one heat exchangers increases the cost of both SHX types, but industrial experience indicates redundancy improves system reliability. Many trade studies, such as those balancing cost and reliability and others generating experimental data, will be required to design a conceptual plant and estimate its total cost. Those trade studies should be linked to design decisions for the SHX. Therefore, development of a detailed technology development roadmap is recommended for the SHX that incorporates development of materials, fabrication techniques, single effects experimentation and integral tests. To the extent practical, the roadmap should be integrated with similar work for other heat transfer system components such as the IHX, valves, piping, pumps and instrumentation.

The work reported herein represents a significant step in the preliminary design of heat exchanger options (material options, thermal design, selection and evaluation methodology with existing challenges). The efficient transfer of energy for power production or industrial applications depends on the ability to incorporate cost-effective heat exchangers between the nuclear heat transport system and the process using the heat. Ultimately, this study will aid in the development and selection of the required heat exchanger for power production. 


\section{CONTENTS}

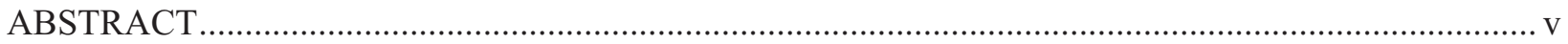

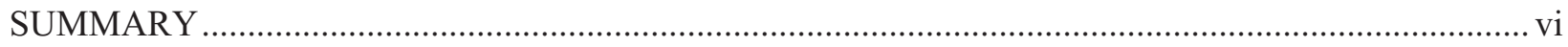

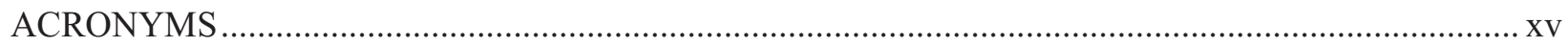

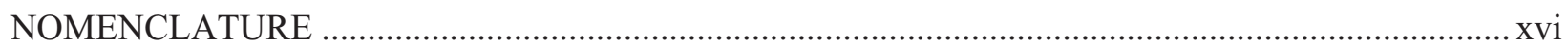

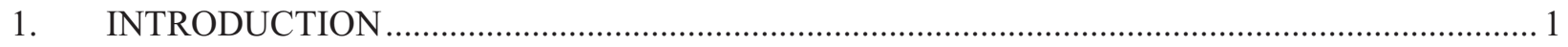

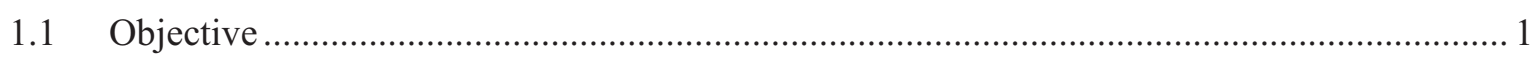

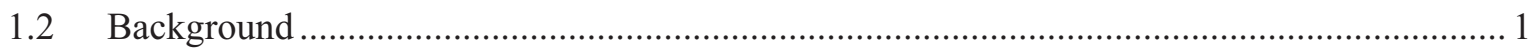

1.3 Process Applications Suited for AHTR …................................................................. 4

2. MATERIAL OPTIONS AND PROPERTIES OF THE AHTR HEAT EXCHANGERS

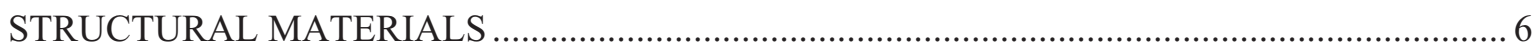

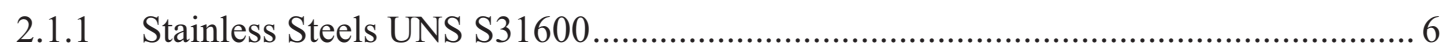

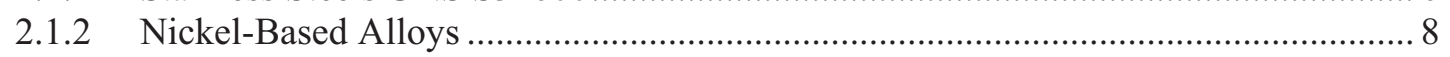

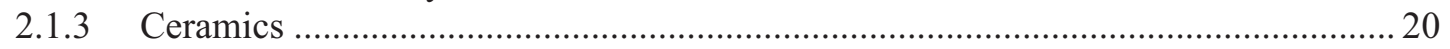

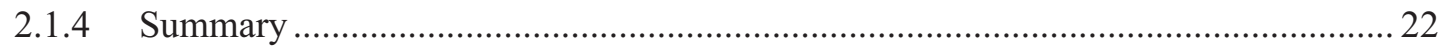

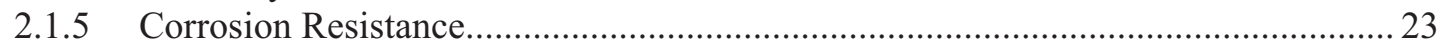

2.1.6 ASME B\&PV Acceptance (Section III, Section VIII, and Section IX) (Jetter

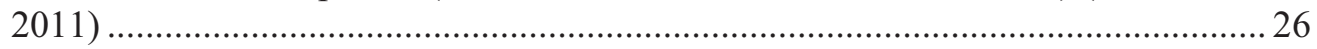

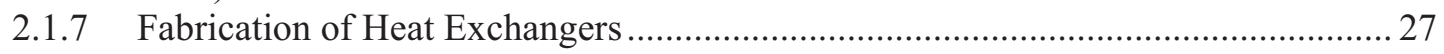

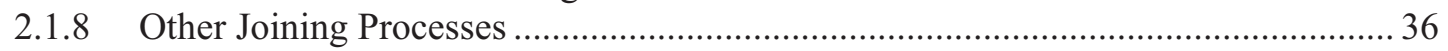

3. COMPUTATIONAL THERMODYNAMICS MODELING OF HOT CORROSION IN

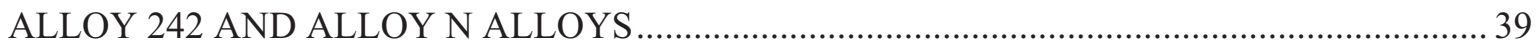

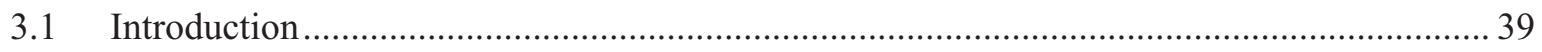

3.2 Thermodynamics and Phase Equilibria in Molten Salt Compositions................................ 41

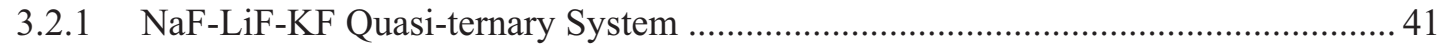

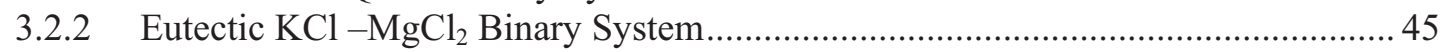

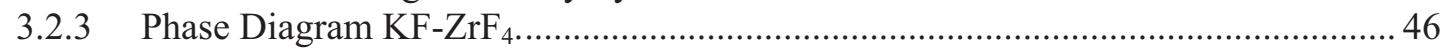

3.2.4 Carbon to Silicon Binary Phase Diagram ............................................................... 46

3.3 Chemical Compositions and Microstructure of Alloy 242 and Alloy N............................ 47

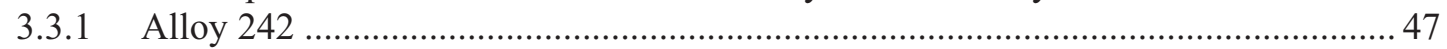

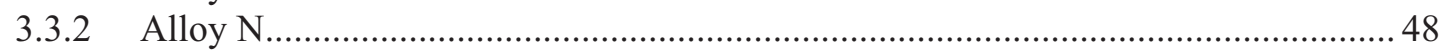

3.4 Modeling of Corrosion Behavior of Haynes-242 and Hastelloy-N in Molten Salt

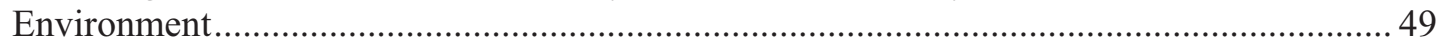

3.4.1 General Considerations on the Stability of Protective Oxide $\mathrm{Cr}_{2} \mathrm{O}_{3}$ on Alloy 242 and Alloy N Surfaces ................................................................................... 50

3.4.2 Hot Corrosion of Nickel-Based High temperature Alloys (Alloy 242 and Alloy $\mathrm{N}$ in FLiNaK) ................................................................................... 52

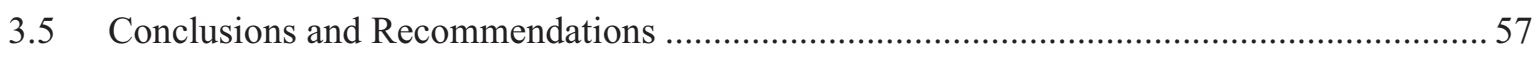

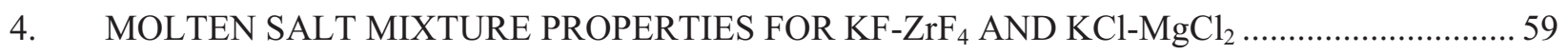

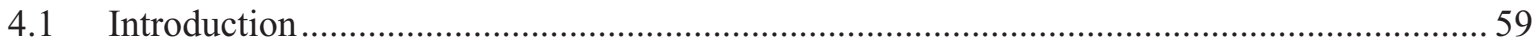




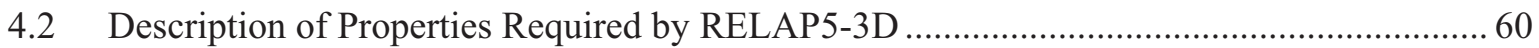

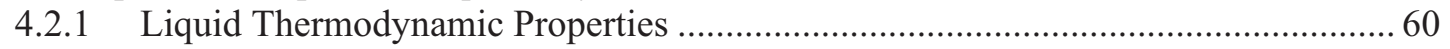

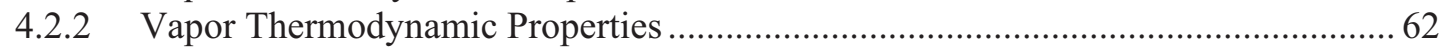

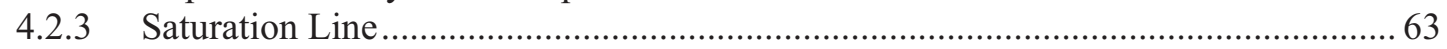

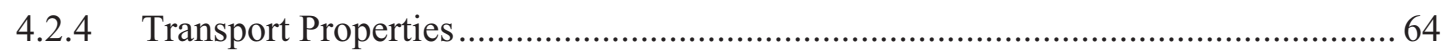

4.3 Effect of Uncertainty in Thermophysical Properties on the Nusselt Number....................... 64

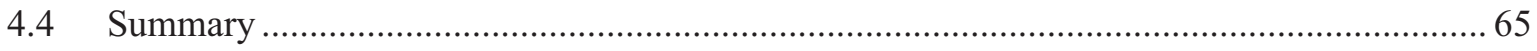

5. PRELIMINARY (THERMAL/MECHANICAL) DESIGN AND ENGINEERING

CALCULATION FOR AHTR SECONDARY HEAT EXCHANGER ....................................... 66

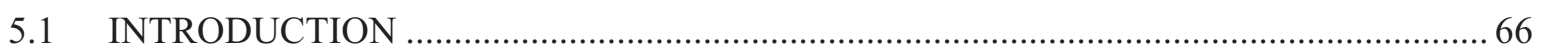

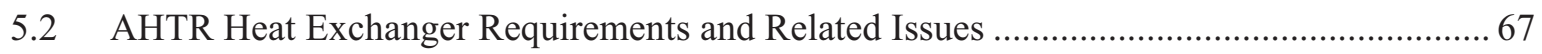

5.2.1 Basic Requirements for the AHTR Heat Exchanger Design ..................................... 67

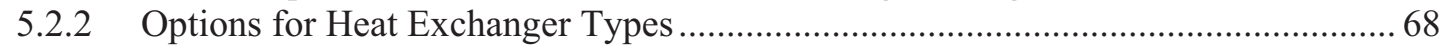

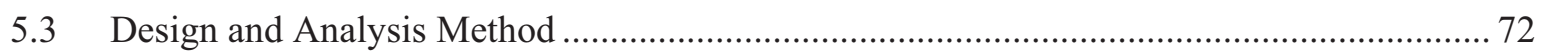

5.3.1 Mechanical Design......................................................................... 72

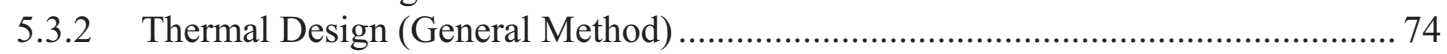

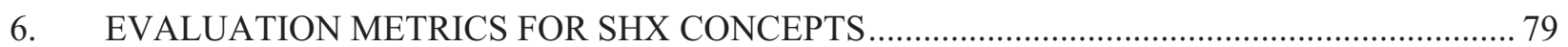

6.1 Evaluation Methodology: Analytical Hierarchy Process (AHP) ……................................ 79

6.2 Goal, Alternatives, and Criteria for AHTR SHX Selection .................................................... 80

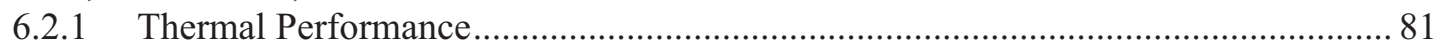

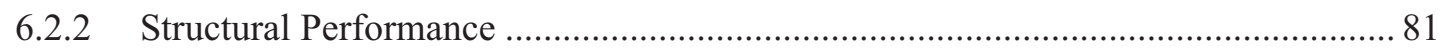

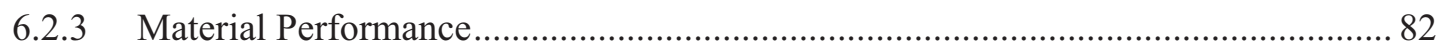

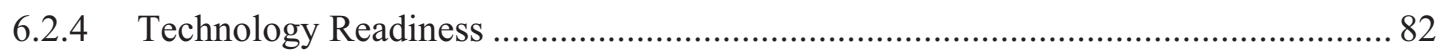

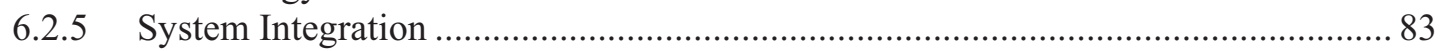

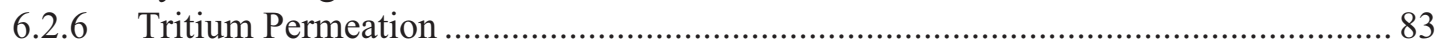

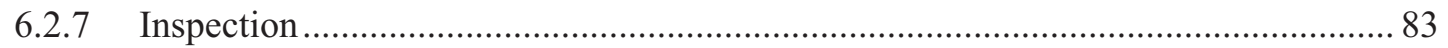

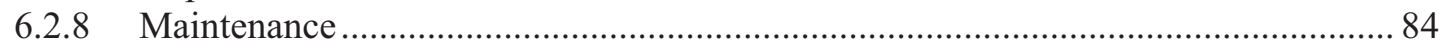

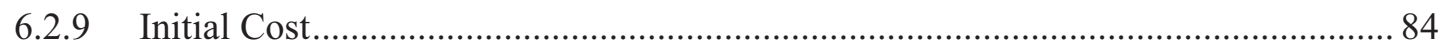

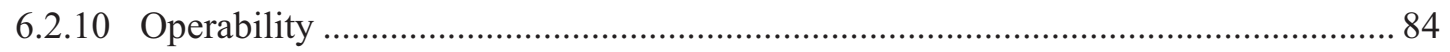

6.3 Modeling of the AHTR Heat Exchanger Selection Problem ............................................. 84

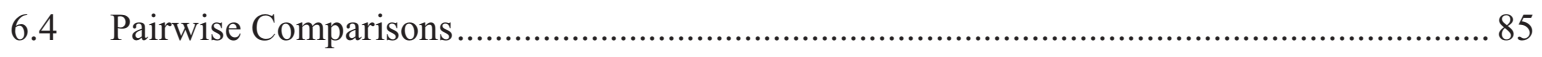

6.5 AHP Software (for Evaluation of Model): MakeItRational ................................................... 86

6.6 Results for AHTR Secondary Heat Exchanger Evaluation.............................................. 87

7. THERMAL CONSIDERATIONS FOR TRADE STUDY OF MOLTEN SALT STEAM

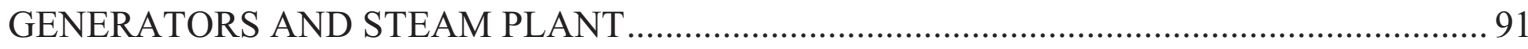

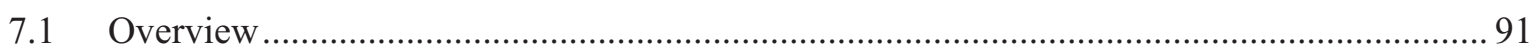

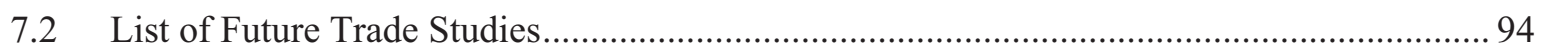

7.2.1 High Salt Freezing Temperatures and Steam Generator Fatigue Life Usage ........... 94

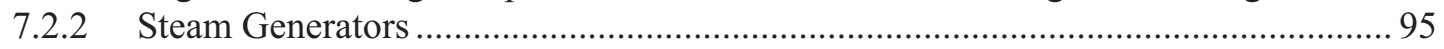

7.2.3 Frozen and Liquid Salt Properties - Conductive Heat Transfer and

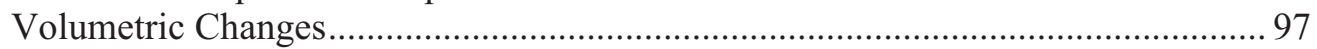

7.2.4 Frozen and Liquid Salt Properties — Water Absorption .......................................... 97

7.2.5 Salt Circuit from IHX(s) to Steam Generator(s) and Steam Generator(s) ................ 98

7.2.6 Water Chemistry Requirements and Secondary Plant Design ................................. 98

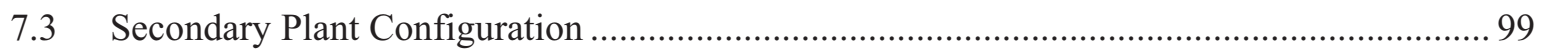




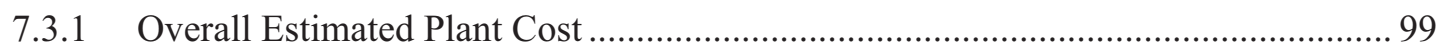

7.4 Thermodynamic Cycles and Limitations of a Molten Salt Steam Generator........................ 99

7.4.1 Example of Fossil Fired Supercritical Plant - Eddystone ...................................... 100

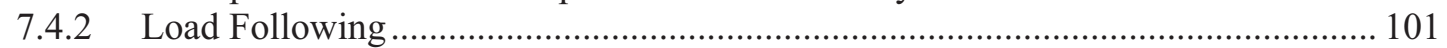

7.4.3 Supercritical Steam Cycle and Superheated Steam Cycle .................................... 101

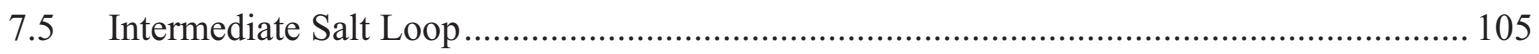

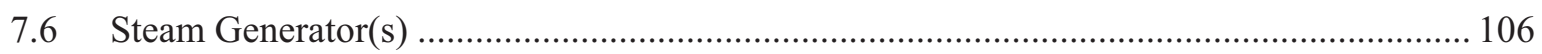

7.7 Supercritical Steam Cycle including Turbine and Associated Equipment.......................... 107

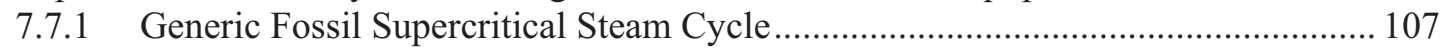

7.7.2 Nuclear Supercritical Steam Cycle with Steam-to-Steam Reheater ....................... 108

7.8 Interfacing Steam Plant with Steam Generator-Valves, Lines, and Instruments............... 111

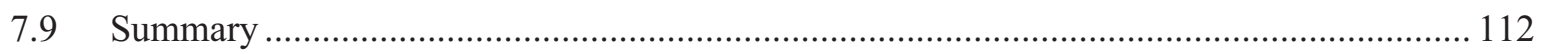

8. EQUIPMENT COST OF STEAM GENERATOR OF A POWER CONVERSION UNIT

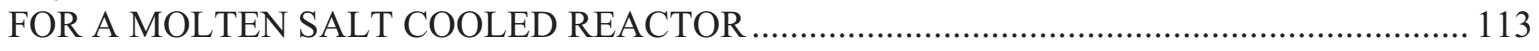

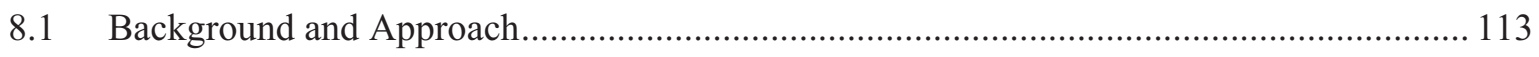

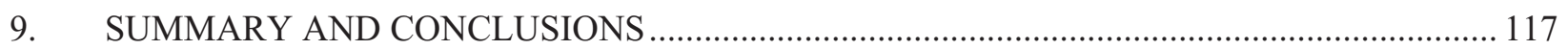

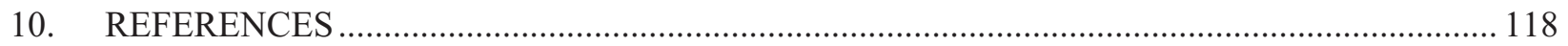

Appendix A Thermal Design of Helical Coiled Heat Exchanger for AHTR........................................ 125

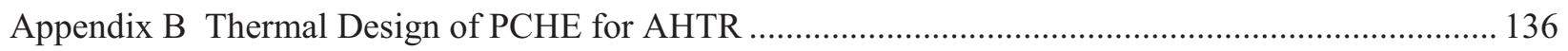

Appendix C Mechanical Design of Heat Exchanger ....................................................................... 146

\section{FIGURES}

Figure 1-1. Conceptual layout of AHTR (Ingersoll et al. 2004)............................................................. 2

Figure 1-2. Thermal energy transfer in AHTR for power production. ................................................... 3

Figure 1-3. Potential Process Applications for AHTR ........................................................................... 5

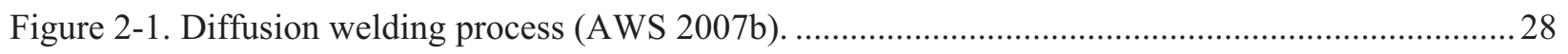

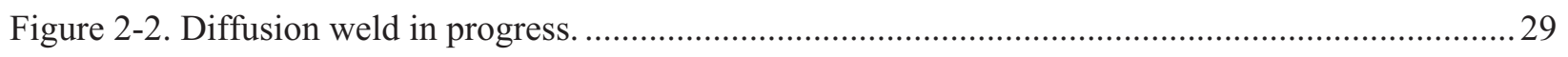

Figure 2-3. Optical micrograph of diffusion weld interface. ................................................................ 30

Figure 2-4. EBSD image of diffusion welded joint in Alloy N, showing grain growth through 15 $\mu \mathrm{m}$ nickel foil (joint is vertical near image center) ............................................................ 31

Figure 2-5. Diffusion weld in Alloy 617 with modeled and experimental compositions.......................... 34

Figure 3-1. Phase diagram LiF-KF, after (Chartrand and Pelton 2001). ................................................ 41

Figure 3-2. Quasi-binary phase diagram LiF-KF. While this diagram does not carry any additional information compared to Figure 3-1, it illustrates the computational thermodynamics capabilities developed at the INL during the last year. ................................ 42

Figure 3-3. Phase Diagram NaF-LiF, after (FactSage 2011)................................................................ 42 
Figure 3-4. ThermoCalc calculations in the present work, NaF-LiF phase diagram. Halites \#1 and \#2 correspond to solid LiF and NaF, respectively. Also see note to Figure 3-2 above. .....

Figure 3-5. The NaF-KF phase diagram, after [FactSage 2011] ............................................................. 43

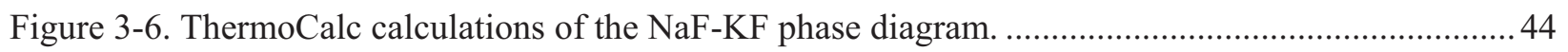

Figure 3-7. Polythermal (liquidus) projection diagram for the LiF-NaF-KF ternary system

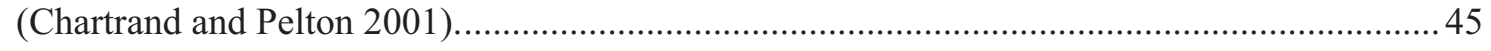

Figure 3-8. Phase diagram of the $\mathrm{KCl}-\mathrm{MgCl}_{2}$ system (FactSage 2011)............................................... 46

Figure 3-9. Phase diagram of the carbon-silicon system (Hillert 2008) ................................................ 47

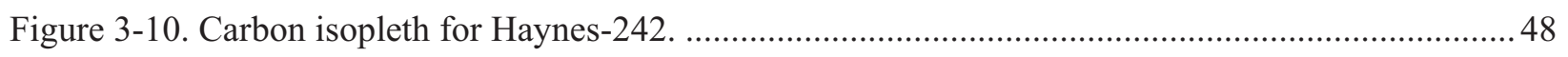

Figure 3-11. Carbtyu5^7hjn isopleth (property diagram) for Hastelloy-N. ............................................. 49

Figure 3-12. Stable phases in the $\mathrm{Cr}_{2} \mathrm{O}_{3}-$ molten salt $\mathrm{NaCl}-\mathrm{C}-\mathrm{H}-\mathrm{O}-\mathrm{N}-\mathrm{S}$ system (Shi,

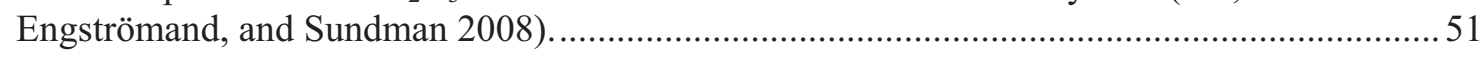

Figure 3-13. Distribution of chromium in stable phases as a function of temperature (Shi,

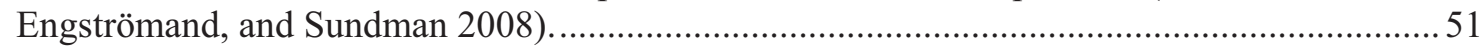

Figure 3-14. The representation of the "Fe-chromium" generic stainless steel in eutectic mixture of salts $\mathrm{KCl}$ and $\mathrm{MgCl}_{2}$ (Shi, Engströmand, and Sundman 2008)......................................52

Figure 3-15. ThermoCalc script for assessing hot corrosion of Alloy N in FLiNaK approximated

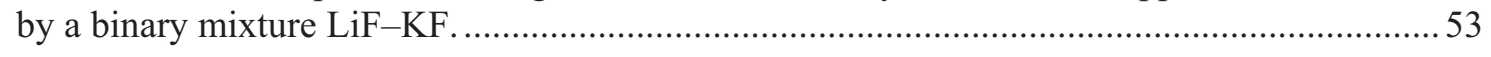

Figure 3-16. The results of a single-point calculation for $\mathrm{T}=600^{\circ} \mathrm{C}$, Alloy N ….................................. 54

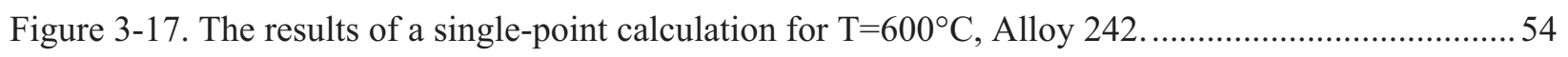

Figure 3-18. Hot corrosion of Alloy N under "mild" conditions $-\ln [\operatorname{ac}(\mathrm{F})]=-49$, accompanied by

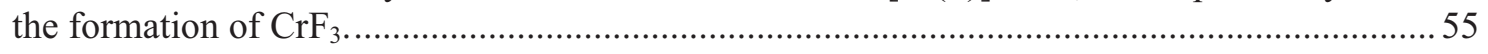

Figure 3-19. Hot corrosion of Alloy $N$ under "aggressive" conditions $-\ln [\operatorname{ac}(\mathrm{F})]=-41.5$,

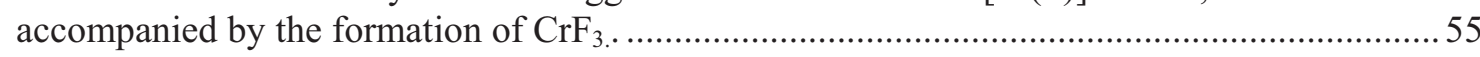

Figure 3-20. Hot corrosion of alloy 242 in "mild" conditions, $\ln [\operatorname{ac}(\mathrm{F})]=-57.5$, accompanied by the onset of formation of $\mathrm{CrF}_{2}$.

Figure 3-21. Hot corrosion of alloy 242 in "aggressive" conditions, $\ln [\operatorname{ac}(\mathrm{F})]=-45.2$, accompanied by the onset of formation of $\mathrm{CrF}_{2}$.

Figure 3-22. Computational assessment of partial pressures of different hot corrosion products for the $\mathrm{KCl}-\mathrm{ZnCl}_{2}$ eutectic mixture and generic $\mathrm{Ni}-\mathrm{Cr}-\mathrm{Fe}-\mathrm{Mo}$ alloy (Trujillo 2011). ...................57

Figure 5-1. Heat exchanger selection framework (Sabharwall et al. (i) 2011).........................................66

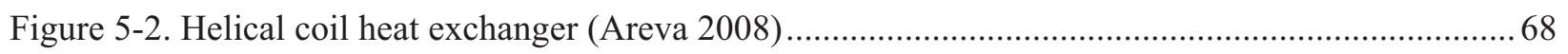

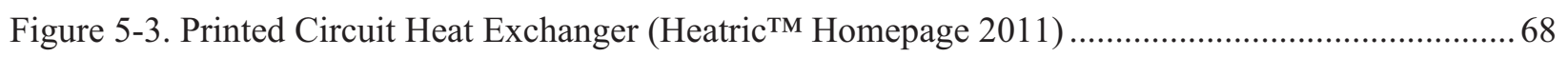

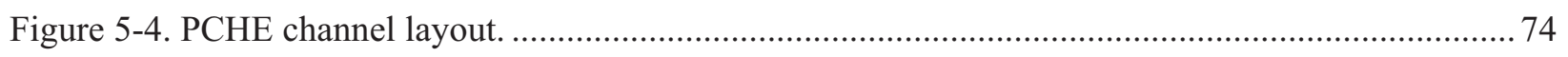

Figure 6-1. Decision hierarchy for AHTR heat exchanger selection................................................. 85

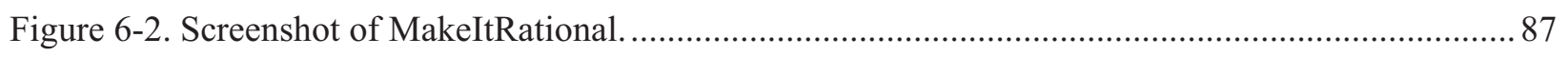

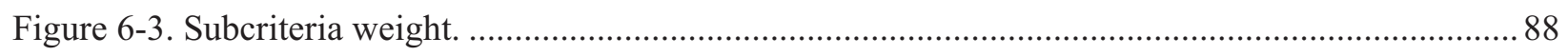

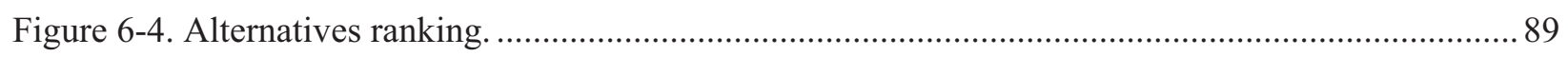


Figure 6-5. Alternatives comparisons.

Figure 7-1. Simplified molten salt nuclear reactor conceptual Rankine supercritical steam cycle with steam-to-steam reheat.

Figure 7-2. Detailed molten salt nuclear reactor conceptual Rankine supercritical steam cycle with steam-to-steam reheat.

Figure 7-3. Simplified molten salt nuclear reactor conceptual Rankine supercritical steam cycle with salt reheat. 93

Figure 7-4. Detailed molten salt nuclear reactor conceptual Rankine supercritical steam cycle with salt reheat. 93

Figure 7-5: Sketch of diagram of temperature in ${ }^{\circ} \mathrm{F}$ or ${ }^{\circ} \mathrm{C}$ versus entropy, $\mathrm{s}$, in BTU/lbm- ${ }^{\circ} \mathrm{F}$ (illustration only - not to scale).

Figure 7-6. Sketch of diagram of temperature in ${ }^{\circ} \mathrm{F}$ or ${ }^{\circ} \mathrm{C}$ versus entropy, s, in BTU/lbm- ${ }^{\circ} \mathrm{F}$ for supercritical steam cycle with $\mathrm{KF} \mathrm{ZrF}_{4}$ freezing temperature of $390^{\circ} \mathrm{C}\left(794^{\circ} \mathrm{F}\right)$ (illustration only - not to scale)

Figure 7-7. Sketch of diagram of temperature in ${ }^{\circ} \mathrm{F}$ or ${ }^{\circ} \mathrm{C}$ versus entropy, s, in BTU/lbm- ${ }^{\circ} \mathrm{F}$ for superheated steam cycle with $\mathrm{KF}-\mathrm{ZrF}_{4}$ freezing temperature of $390^{\circ} \mathrm{C}\left(794^{\circ} \mathrm{F}\right)$ (illustration only - not to scale). 104

Figure 8-1. Cross section view of the semicircular passages of a PCHE. 115

\section{TABLES}

Table 1. AHTR Design Attributes (Ingersoll et al. 2004; Wilson 2010). 3

Table 2-1. Limiting chemical composition in \%, for 316 stainless steel (316/316L Stainless Steel 2007). 6

Table 2-2. Physical constants for 316 stainless steel (316/316L Stainless Steel 2007). 7

Table 2-3. Electrical and thermal properties for 316 stainless steel (316/316L Stainless Steel 2007). 7

Table 2-4. Mechanical properties of 316 stainless steel (316/316L Stainless Steel 2007). 7

Table 2-5. Stress rupture properties of 316 stainless steel (316/316L Stainless Steel 2007). . .8

Table 2-6. Limiting chemical compositions, \%, special requirements, and special grain size requirements for alloy $800 \mathrm{H}$ (Incoloy Alloy $800 \mathrm{H}$ and $800 \mathrm{HT} 2004$ )........ 9

Table 2-7. Physical constants for alloy 800H (Incoloy Alloy 800H and 800HT 2004)..... 9

Table 2-8. Electrical and thermal properties for alloy 800H (Incoloy Alloy 800H and 800HT 2004). 9

Table 2-9. Modulus of elasticity ${ }^{\mathrm{a}}$ for alloy $800 \mathrm{H}$ (Incoloy Alloy $800 \mathrm{H}$ and 800HT 2004). 10

Table 2-10. Tensile properties and hardness of alloys $800 \mathrm{H} / 800 \mathrm{HT}$ at high temperatures (Incoloy Alloy 800H and 800HT 2004)......

Table 2-11. Room-temperature properties of cold-rolled (20\%) Alloys $800 \mathrm{H}$ and $800 \mathrm{HT}$ after high-temperature exposure (Incoloy Alloy 800H and 800HT 2004).

Table 2-12. Representative rupture-strength values for alloys 800H/800HT (Incoloy Alloy 800H and 800HT 2004). 
Table 2-13. Limiting chemical composition, \%, for Alloy 617 (Inconel Alloy 617 2005)..................... 12

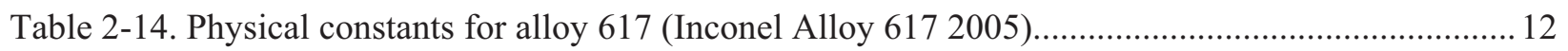

Table 2-15. Electrical and thermal properties for alloy 617 (Inconel Alloy 617 2005).......................... 13

Table 2-16. Modulus of elasticity for alloy 617 (Inconel Alloy 617 2005) ............................................ 14

Table 2-17. Typical room-temperature mechanical properties for alloy 617 (Inconel Alloy 617

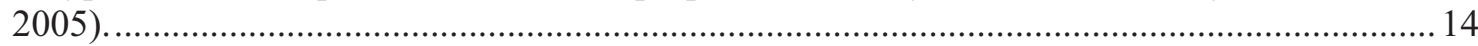

Table 2-18. Limiting chemical composition, \%, for Alloy N (Hastelloy N Alloy 2002)........................ 15

Table 2-19. Physical constants for Alloy N (Hastelloy N Alloy 2002). .................................................. 15

Table 2-20. Electrical and thermal properties for Alloy N (Hastelloy N Alloy 2002)............................. 16

Table 2-21. Alloy N short-time tensile data (Hastelloy N Alloy 2002)................................................ 17

Table 2-22. Alloy N average dynamic modulus of elasticity (Hastelloy N Alloy 2002).......................... 17

Table 2-23. Limiting chemical composition, \%, Alloy 242 (Haynes 242 Alloy 2000)........................... 18

Table 2-24. Physical constants for Alloy 242 (Haynes 242 Alloy 2000). ................................................ 18

Table 2-25. Electrical and thermal properties for Alloy 242 (Haynes 242 Alloy 2000)............................ 18

Table 2-26. Alloy 242 mechanical properties of cold-reduced sheet as cold-worked and cold-

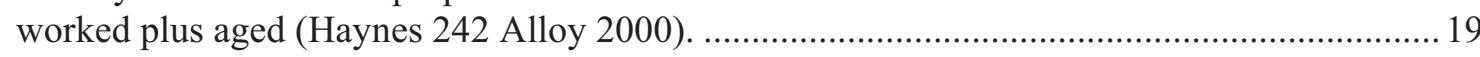

Table 2-27. Alloy 242 mechanical properties of cold-rolled sheet-annealed and aged ${ }^{\mathrm{a}}$ (Haynes

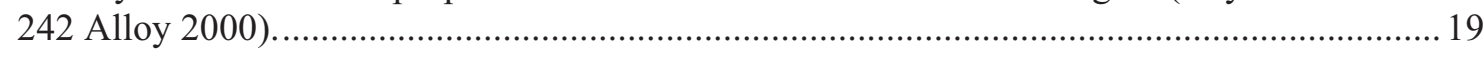

Table 2-28. Alloy 242 - dynamic modulus of elasticity (Haynes 242 Alloy 2000)................................. 20

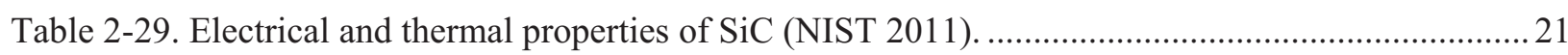

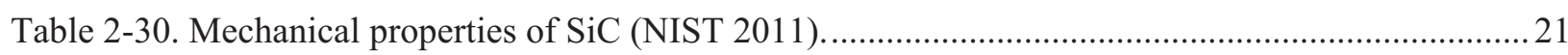

Table 2-31. Alloys potentially suited for the SHX (Ingersoll et al. 2004) ............................................... 22

Table 2-32. Alloys potentially suited for the SHX (Ingersoll et al. 2004) ............................................... 22

Table 2-33. Summary of corrosion testing results for salts without uranium...........................................2 24

Table 2-34. Braze alloys, brazing temperature, and composition.......................................................... 33

Table 3-1. Chemical composition and hot corrosion resistance of the several superalloy materials

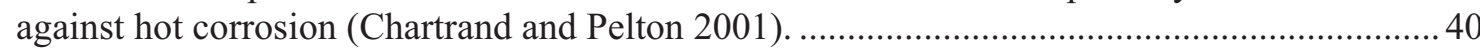

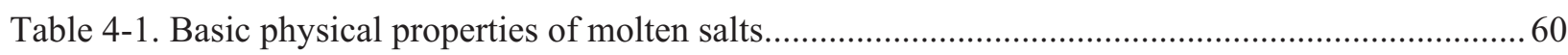

Table 4-2. Parameters for vapor components. The values for $\boldsymbol{c P \boldsymbol { i }}$ were all evaluated at $1000 \mathrm{~K}$.............62

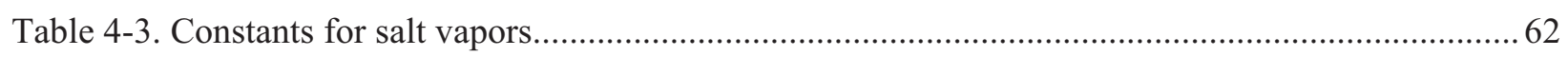

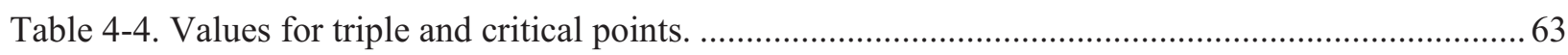

Table 4-5. Maximum deviation in the Nusselt number due to uncertainty................................................ 65

Table 5-1. SHX design requirements and basic conditions for the AHTR .............................................. 67

Table 5-2. Principal features of several types of heat exchangers (Shah 2003)......................................69

Table 5-3. Range of heat transfer coefficient values for different flow situations (Kakac and Liu 1998). 


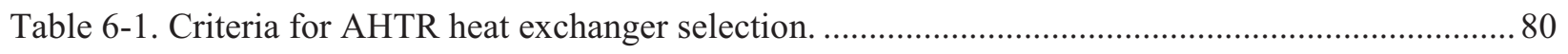

Table 6-2. Fundamental scale for pairwise comparison in AHP (Forman 2001). .................................... 86

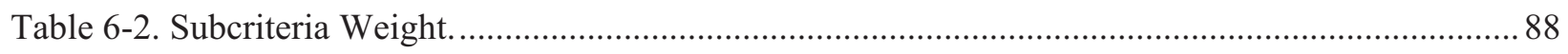

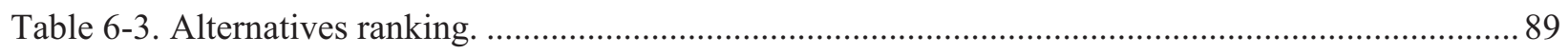

Table 8-1. Comparison of molten salt and pulverized coal heated boilers for supercritical Rankine

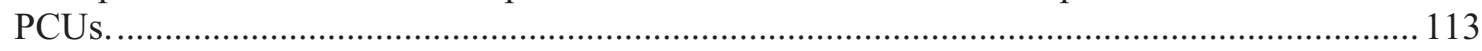

Table 8-2. Comparison of cost of pulverized coal and molten salt heated shell-and-tube heat

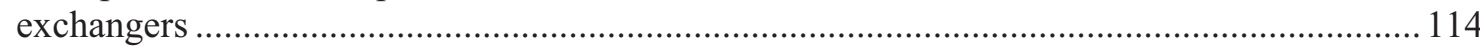

Table 8-3. Preliminary design specifications for shell-and-tube heat exchangers.................................. 115

Table 8-4. Preliminary design specification for PCHE module ................................................................ 116

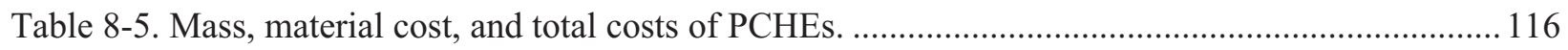




\section{ACRONYMS}

AHTR advanced high temperature reactor

ARE Aircraft Reactor Experiment

ASME American Society of Mechanical Engineers

AWS American Welding Society

BPV Boiler and Pressure Vessel

CMC ceramic matrix composition

DRACS direct reactor auxiliary cooling system

HTGR high temperature gas-cooled reactor

HTR high temperature reactor

IHX intermediate heat exchanger

INL Idaho National Laboratory

LMTD Log Mean Temperature Difference

MSR molten-salt reactor

MSRE Molten-Salt Reactor Experiment

NGNP Next Generation Nuclear Plant

ORNL Oak Ridge National Laboratory

SHX secondary heat exchanger

TEV Technical Evaluation 


\section{NOMENCLATURE}

$A_{\text {sat }} \quad$ Constant that is dependent on the molten salt

$B_{\text {sat }} \quad$ Constant that is dependent on the molten salt [K]

$M_{i} \quad$ Molecular weight of each molten salt component $[\mathrm{g} / \mathrm{mol}]$

$P_{0} \quad$ Reference pressure [triple point temperature] [Pa]

$P_{\text {sat }} \quad$ Saturation pressure at temperature $T[\mathrm{~Pa}]$

$\dot{Q} \quad$ Heat duty (W)

$\bar{R} \quad$ Universal gas constant $[\mathrm{J} / \mathrm{kg} \cdot \mathrm{K}]$

$T_{0} \quad$ Reference temperature [triple point temperature] [K]

$X_{i} \quad$ Mole fraction of each molten salt component

$c_{P_{i}} \quad$ Specific heat capacity of each molten salt component $[\mathrm{J} / \mathrm{kg} \cdot \mathrm{K}]$

$c_{P} \quad$ Specific heat capacity at constant pressure $[\mathrm{J} / \mathrm{kg} \cdot \mathrm{K}]$

$s_{g 0} \quad$ Reference vapor specific entropy [evaluated at $T_{0}$ and $\left.P_{0}\right][\mathrm{J} / \mathrm{kg} \cdot \mathrm{K}]$

$u_{g 0} \quad$ Reference vapor specific energy [evaluated at $T_{0}$ and $\left.P_{0}\right][\mathrm{J} / \mathrm{kg}$ ]

$x_{i} \quad$ Mass fraction of each molten salt component

$A_{f} \quad$ Flow area of the compact heat exchanger $\left(\mathrm{m}^{2}\right)$

$A_{s} \quad$ Surface area of the compact heat exchanger $\left(\mathrm{m}^{2}\right)$

$C_{c} \quad$ Heat capacity rate in the cold channel $(\mathrm{J} / \mathrm{K} \mathrm{s})$

$C_{h} \quad$ Heat capacity rate in the hot channel (J/K s)

$d_{h} \quad$ Hydraulic diameter of the compact heat exchanger (m)

$G \quad$ Mass velocity (m)

$h \quad$ Heat transfer coefficient $(\mathrm{W} / \mathrm{m} 2 \mathrm{~K})$

$\mathrm{k} \quad$ Thermal conductivity $[\mathrm{W} / \mathrm{m} \cdot \mathrm{K}]$

$K \quad$ Thermal conductivity of fluid (W/m K)

$L \quad$ Channel length of the compact heat exchanger (m)

$M \quad$ Total molecular weight of mixture $[\mathrm{g} / \mathrm{mol}]$

NTU Number of heat transfer unit

$\mathrm{Nu} \quad$ Nusselt number

$p \quad$ Channel pitch of the PCHE (m)

$P \quad$ Pressure $[\mathrm{Pa}]$ 


$\begin{array}{ll}P_{i} & \text { Inside pressure of the heat exchanger tube }(\mathrm{Pa}) \\ P_{i} & \text { Inside pressure of the heat exchanger tube }(\mathrm{Pa}) \\ P r & \text { Prandtl number } \\ R & \text { Gas specific gas constant }[\mathrm{J} / \mathrm{kg} \cdot \mathrm{K}] \\ R e & \text { Reynolds number } \\ R_{i} & \text { Inside radius of the heat exchanger tube }(\mathrm{m}) \\ R_{o} & \text { Outside radius of the heat exchanger tube }(\mathrm{m}) \\ R_{w} & \text { Thermal resistance in the heat exchanger tube }(\mathrm{K} / \mathrm{W}) \\ S & \text { Specific entropy }[\mathrm{J} / \mathrm{kg} \cdot \mathrm{K}] \\ T & \text { Temperature }[\mathrm{K}] \\ t_{f} & \text { Wall thickness between the channels in the PCHE }(\mathrm{m}) \\ t_{p} & \text { Plate thickness of the PCHE }(\mathrm{m}) \\ U & \text { Overall heat transfer coefficient }\left(\mathrm{W} / \mathrm{m}^{2} \mathrm{~K}\right) \\ u & \text { Specific internal energy }[\mathrm{J} / \mathrm{kg}]\end{array}$

\section{Greek symbols}

$\begin{array}{ll}v_{1} & \left.\text { Reference specific volume [evaluated at } T_{0}\right]\left[\mathrm{m}^{3} / \mathrm{kg}\right] \\ \forall & \text { Porosity of the compact heat exchanger } \\ \varepsilon & \text { Effectiveness of the heat exchanger } \\ \beta & \text { Coefficient of thermal expansion }[1 / \mathrm{K}] \\ \kappa & \text { Isothermal Compressibility [1/Pa] } \\ \mu & \text { Dynamic viscosity }[\mathrm{Pa} \cdot \mathrm{s}] \\ v & \text { Specific volume }\left[\mathrm{m}^{3} / \mathrm{kg}\right] \\ \rho & \text { Density }\left[\mathrm{kg} / \mathrm{m}^{3}\right] \\ \sigma & \text { Surface tension }[\mathrm{N} / \mathrm{m}] \\ \sigma_{\theta} & \text { Tangential stress }[\mathrm{Pa}] \\ \sigma_{D} & \text { Allowable stress of the heat exchanger material }[\mathrm{Pa}] \\ \sigma_{r} & \text { Radial stress }[\mathrm{Pa}]\end{array}$

\section{Subscripts}

$g_{0} \quad$ Vapor reference value

0 Reference value indicating triple point 


$\begin{array}{ll}1 & \text { Reference value evaluated at } P \text { and } T_{0} \\ c & \text { cold channel } \\ h & \text { hot channel } \\ i & i^{\text {th }} \text { component of molten salt } \\ m & \text { average } \\ P & \text { Constant pressure } \\ \text { sat } & \text { Saturation value }\end{array}$




\section{Feasibility Study of Secondary Heat Exchanger Concepts for the Advanced High Temperature Reactor}

\section{INTRODUCTION}

\subsection{Objective}

The work reported herein represents a significant step in the preliminary design of heat exchanger options (material options, thermal design, selection and evaluation methodology with existing challenges) for the advanced high temperature reactor (AHTR) secondary heat exchanger (SHX). The primary purpose of this study is to aid in the development and selection of the required heat exchanger for power production using either a subcritical or supercritical Rankine cycle.

\subsection{Background}

The original molten salt program began in 1950 at Oak Ridge National Laboratory (ORNL) when it initiated the Aircraft Reactor Experiment (ARE) because of its interest in liquid-fueled reactors. The ARE project planned to use circulating molten salts to power a nuclear reactor in an aircraft (MacPherson 1985), with the goal of lengthening flight times indefinitely. The Air Force saw nuclear-powered aircraft as the flying equivalent to the nuclear submarine fleet being developed by the Navy (LeBlanc 2010). ORNL launched the Molten Salt Reactor Experiment (MSRE), to develop a single-fluid molten salt test reactor that produced just $8 \mathrm{MW}$ of thermal power, in the early 1960s. The early material development work identified Hastelloy B $(29 \% \mathrm{Mo}, 5 \% \mathrm{Fe}$, balance $\mathrm{Ni})$ as a material with excellent corrosion resistance which was due to the formation of a $\mathrm{NiMoO}_{4}$ oxide layer. Consideration of this alloy was dropped due to fabrication difficulties and embrittlement from aging in the $650^{\circ} \mathrm{C}$ to $900^{\circ} \mathrm{C}$ temperature range.

Further alloy development resulted in the Hastelloy N composition (15-18\% Mo, 6-8 \% Cr, 5\% Fe, balance Ni). (Williams, D. F.et al 2006). The level of chromium addition to Alloy N causes the chromia film to form. Alloy $\mathrm{N}$ will not have the oxidation resistance of higher chromium containing nickel based alloys to postulated secondary side environments such as supercritical steam. With the creation of Alloy $\mathrm{N}$, (then called INOR-8 and currently manufactured by Haynes International as Hastelloy $\mathrm{N}^{\circledR}$ ), corrosion issues with the molten salts were mostly mitigated.

The MSRE was operated for 5 years to test material, system components, and reactor operational stability. No operational issues were encountered during the entire operating life of the MSRE (Ingersoll et al. 2004; Holcomb et al. 2006). The low corrosion rates for Hastelloy $\mathrm{N}$ were acceptable but the alloy was found to be susceptible to irradiation damage (embrittlement) and intergranular cracking due to grain boundary diffusion of the fission product tellurium. These problems were being addressed in an alloy development program at ORNL (McCoy, 1972 and $1978^{\mathrm{a}, \mathrm{b}}$ ). The technology showed enough promise during ARE and MSRE, that research was launched into harnessing those abilities for civilian nuclear power from molten salts. The knowledge gained to date has translated to an electrical-power-producing molten salt reactor with process heat application capabilities addressed in Idaho National Laboratory (INL) Technical Evaluation TEV-1160 (2011).

The advanced high temperature reactor (AHTR) is part of the fluoride-salt-cooled high temperature reactor (FHR) class of nuclear reactors included in the advanced reactor concept program and defined by

\footnotetext{
${ }^{a}$ McCoy, H.E. Chapter 7, The Development Status of Molten-Salt Breeder Reactors, ORNL-4812, August 1972

${ }^{\mathrm{b}}$ McCoy, H.E, Status of Materials Development for Molten salt Reactors, ORNL/TM-5920, January 1978
} 
high temperature fuel and low-pressure liquid coolant (Ingersoll et al. 2004). Fluoride salts have highly desirable characteristics for high temperature nuclear reactor heat transport, such as (Sabharwall et al. 2011; Wilson 2010):

- Low pressure systems

- Relatively chemically inert at high temperatures

- No exothermic chemical reactions

- Compatibility with graphite

- Low toxicity for potential process heat transfer coolants

- High heat capacity (smaller equipment)

- Good natural circulation cooling.

AHTRs will produce high outlet temperatures $\left(704^{\circ} \mathrm{C}\right)$ using coated particle fuel and can potentially improve upon the attributes of other reactors (Holcomb et al. 2009). An AHTR reactor core consists of coated particle fuel embedded within graphite fuel elements. Graphite reflectors provide additional moderation and core structure. Heat removed from the reactor is transferred to an intermediate salt that, in turn, is transferred to a tertiary side for power production and/or process heat applications.

Figure 1-1 shows the general plant layout, with the reactor containment building in the center, the turbine building on the left, and the spent fuel storage building on the right.

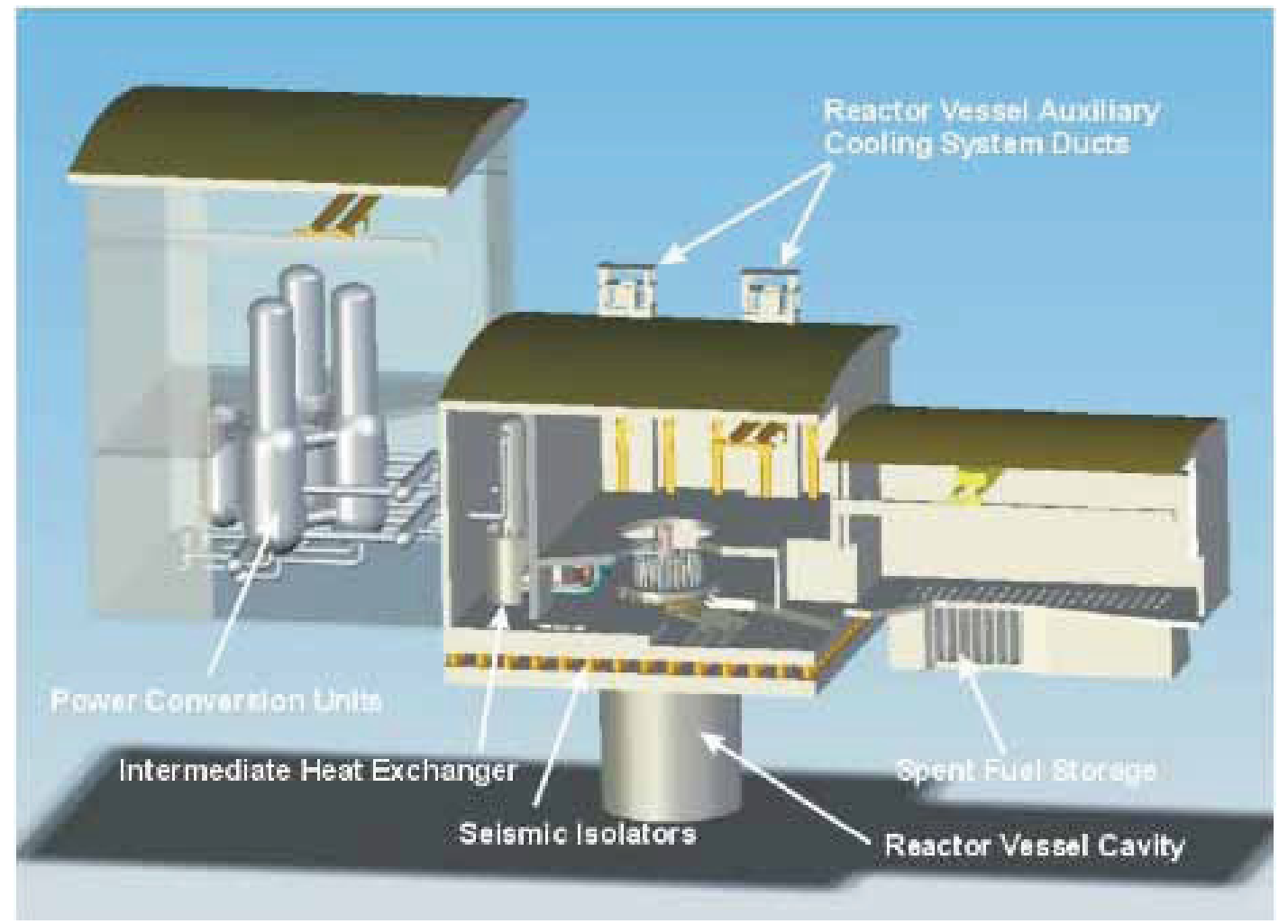

Figure 1-1. Conceptual layout of AHTR (Ingersoll et al. 2004).

While the primary system of the molten salt reactor (MSR) used molten salt with fuel material dissolved directly in the circulating salt, the AHTR uses molten salt in combination with solid, stationary fuel. However, much of the MSR-related experience is directly relevant to the AHTR. Currently, the 
primary loop reference salt for AHTR is $\mathrm{Li}_{2} \mathrm{BeF}_{4}$, referred to as "FLiBe" or "Flibe." Heat in an AHTR is transferred from the reactor core by the primary liquid-salt coolant to an intermediate heat-transfer loop through intermediate heat exchangers (IHXs). The intermediate heat-transfer loop uses an intermediate liquid-salt coolant through a secondary heat exchanger (SHX) to move the heat to a power conversion system (Rankine cycle) as shown in Figure 1-2. Previous analysis (Sabharwall et al. 2011) of the power conversion system to produce electricity showed that the Rankine subcritical and supercritical cycle with a turbine inlet temperature of $679^{\circ} \mathrm{C}$ can yield conversion efficiencies of $42 \%$ and $44 \%$ respectively, with $\mathrm{KF}-\mathrm{ZrF}_{4}$ as the secondary salt coolant. The reactor outlet temperature for a first-of-a-kind demonstration will be $704^{\circ} \mathrm{C}$. The heat exchangers are considered key components that need extensive investigation because they are operated under a severe environment and their performance is directly related to the overall system efficiency and safety.

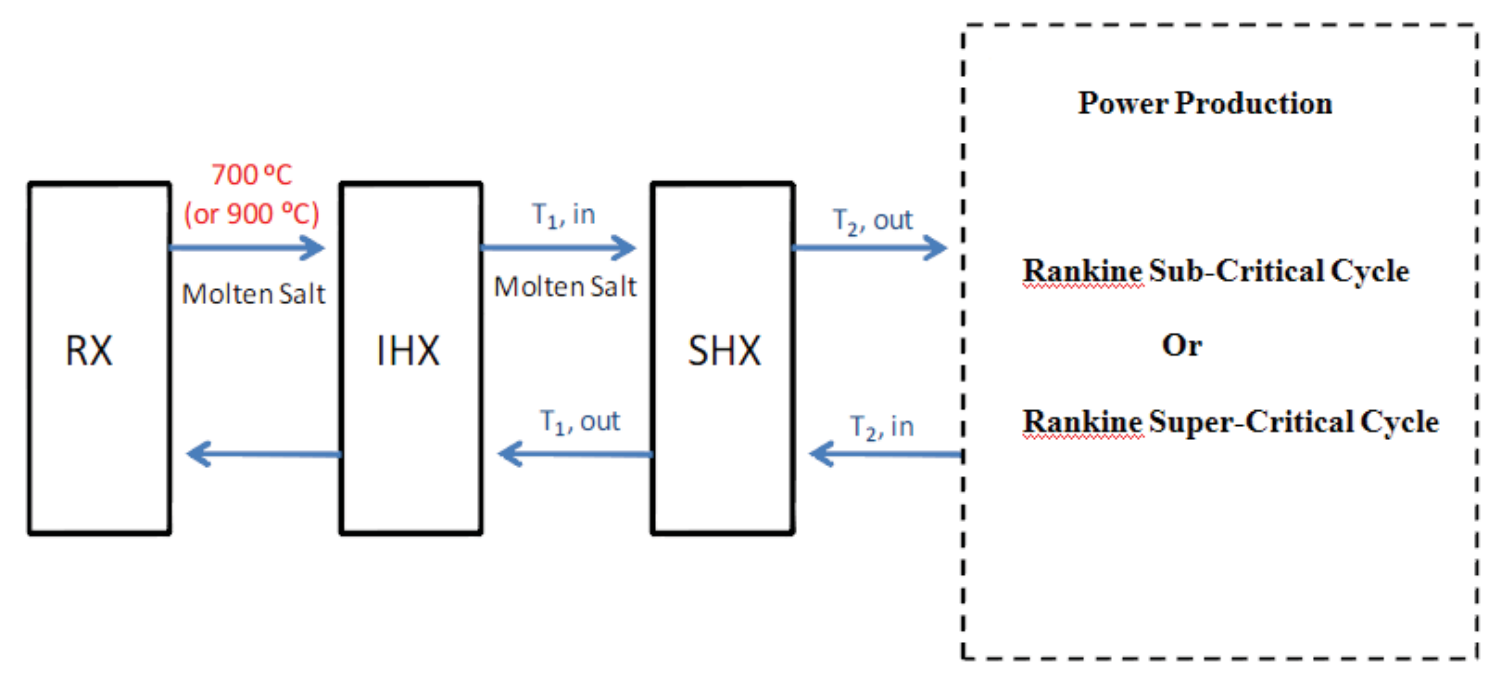

Figure 1-2. Thermal energy transfer in AHTR for power production.

AHTR, which provides high-temperature heat to increase thermal efficiency for power production and process heat applications, could be scaled to higher thermal power for better economics and still meet or exceed the safety performance of other advance reactor concepts (Ingersoll et al. 2004). AHTR design attributes that promote favorable economics are listed in Table 1.

Table 1. AHTR Design Attributes (Ingersoll et al. 2004; Wilson 2010).

\begin{tabular}{|l|l|l|}
\hline \multicolumn{1}{|c|}{ AHTR Attribute } & \multicolumn{1}{|c|}{ Phenomenological Impact(s) } & \multicolumn{1}{c|}{ Cost Implications } \\
\hline $\begin{array}{l}\text { High primary coolant volumetric heat } \\
\text { capacity }\end{array}$ & $\begin{array}{l}\text { Low fluid pumping requirements } \\
\text { Near constant temperature energy } \\
\text { transport }\end{array}$ & $\begin{array}{l}\text { Compact coolant and heat transport } \\
\text { loops (small pipes, pumps, heat } \\
\text { exchangers) }\end{array}$ \\
\hline Low primary system pressure & $\begin{array}{l}\text { Low pipe break/LOCA energetic } \\
\text { Low source term driving pressure }\end{array}$ & $\begin{array}{l}\text { Thin-walled reactor vessel and piping } \\
\text { Smaller, less complex containments }\end{array}$ \\
\hline $\begin{array}{l}\text { Transparent coolant with low } \\
\text { chemical activity }\end{array}$ & $\begin{array}{l}\text { Visible refueling operations } \\
\text { Low pipe break/LOCA efficiencies }\end{array}$ & $\begin{array}{l}\text { Efficient refueling } \\
\text { Smaller containments }\end{array}$ \\
\hline High primary system temperatures & High power conversion efficiencies & Lower fuel costs and hot refueling \\
\hline TRISO fuels & $\begin{array}{l}\text { Large fuel temperature margins } \\
\text { Good fission product containment }\end{array}$ & $\begin{array}{l}\text { Robust operating margins and safety } \\
\text { case }\end{array}$ \\
\hline
\end{tabular}


The AHTR appears to have excellent safety attributes. The combined thermal capacity of the graphite core and the molten salt coolant pool offer a large time buffer to reactor transients. The effective transfer of heat to the reactor vessel increases the effectiveness of the Reactor Vessel Auxiliary Cooling System and Direct Reactor Auxiliary Cooling System (DRACS) to remove decay heat. The excellent fission product retention characteristic of molten salt provides an extra barrier to radioactive releases. DRACS is a passive system relying on the natural convection/circulation process, and is being proposed as part of the ultimate heat sink for decay heat removal (Wang et al. 2011). Compared to a light water reactor (LWR), AHTR should be more economical as illustrated by Ingersoll et al. (2004), because of higher power conversion efficiency, low pressure containment, and absence of active safety systems. AHTR has additional advantages compared to other advance reactor concepts (such as sodium or lead cooled reactors), the fuel has a lower power density and thus generates lower rate of volumetric decay heat. A technology challenge that AHTR shares with other high-temperature designs is the availability of nuclear qualified materials for operation at higher temperatures $\left(750\right.$ to $\left.900^{\circ} \mathrm{C}\right)$. Also, most of the advance reactor concepts use graphite coated-particle fuels, which produce tritium via tertiary fission, and all nucleargrade graphite produces tritium via neutron reactions with impurities in the graphite. In the AHTR, tritium can be trapped (if required dependent upon the salt) using systems very similar to those used in the Fort St. Vain gas-cooled reactor, as discussed by Ingersoll et al. (2004).

\subsection{Process Applications Suited for AHTR}

This section briefly presents the integration of AHTR technology with conventional chemical industrial processes, for further detail refer to TEV-1160 (2011). The process heat industrial applications being considered are: hydrogen production via steam methane reforming of natural gas and high temperature steam electrolysis, substitute natural gas production, oil sands recovery via steam assisted gravity drainage, coal-to-liquid production, natural gas-to-liquids production, methanol-to-gasoline production, ammonia production, ex situ oil shale, and in situ oil shale. The temperature ranges of applications that could be coupled to the AHTR with the current reactor outlet temperature (green band) and others that could potentially be coupled if the reactor outlet temperature was raised (red band) are shown in Figure 1-3. 
Oll 8hal Gx 8thd

Oll 8han on 8tho

Oll 8nd Fecenry

HeProducten Horid 8uter

Hytrogn Produdien (B)

Hytregen Productien (AT8G)

Steom Wuthan Raterming

Kuthenel to Conelln (inc)

Ammorla Production

Stam Raridn Oyls

Hallum Eraton Cyelo

8002 OHaln
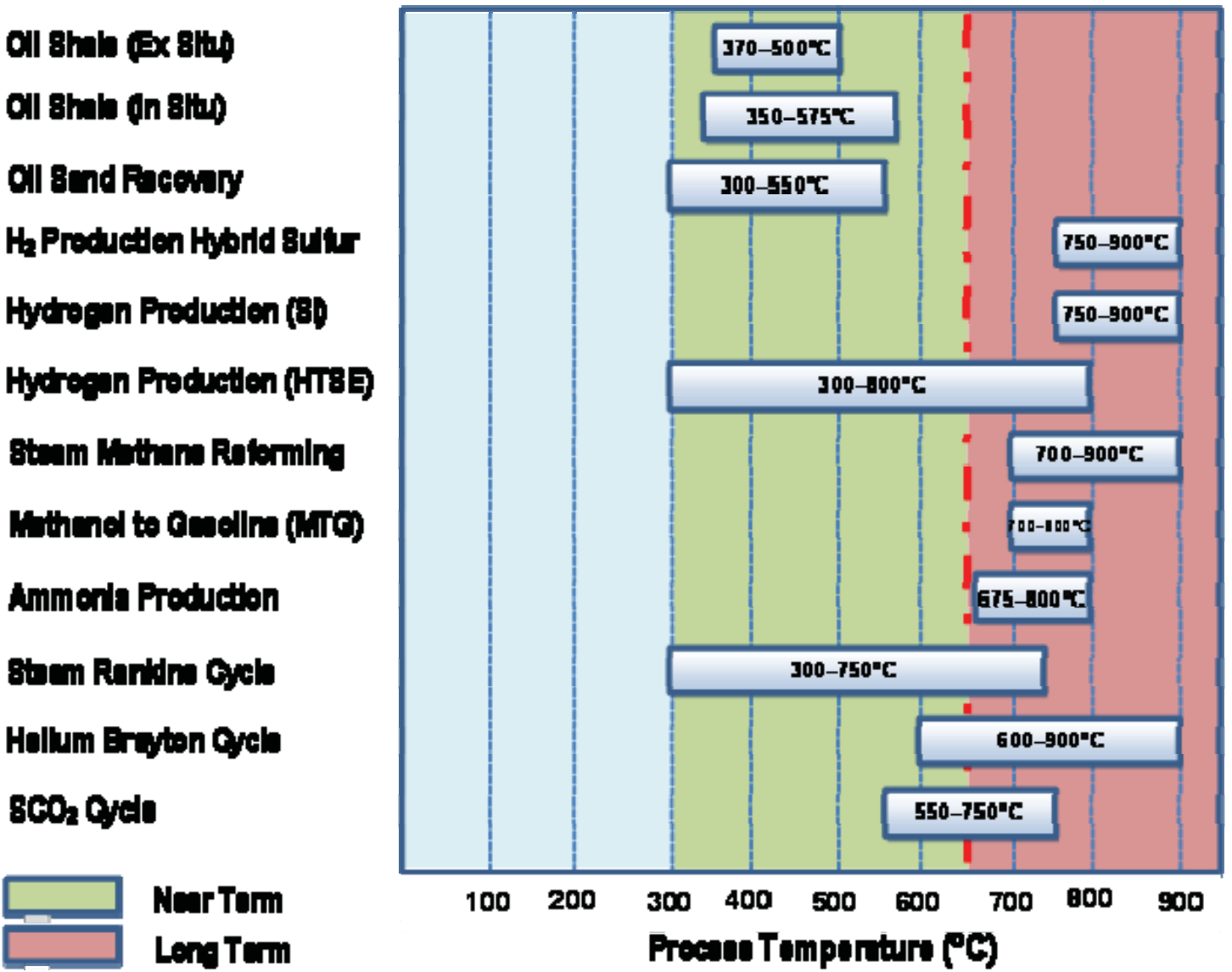

Figure 1-3. Potential Process Applications for AHTR

This report discusses the results of a preliminary design analysis of the secondary heat exchanger and explains the evaluation and selection methodology. An important engineering challenge will be to prevent the molten salt from freezing during normal and off-normal operations because of its high melting temperature $\left(390^{\circ} \mathrm{C}\right.$ for $\left.\mathrm{KF}-\mathrm{ZrF}_{4}\right)$. The efficient transfer of energy for industrial applications depends on the ability to incorporate cost-effective heat exchangers between the nuclear heat transport system and industrial process heat transport system.

The need for efficiency, compactness, and safety challenge the boundaries of existing heat exchanger technology, giving rise to this thermal design study. Descriptions of potential heat exchanger configurations or designs (such as printed circuit, spiral or helical coiled, ceramic, plate and fin, and plate type) were covered in an earlier report (Sabharwall et al. 2011). Significant work is needed before the characteristics and potential of the AHTR can be realized. Development of the integration methodology, feasibility and trade studies, and identification of research and development needs are ongoing tasks that will be covered in the future reports as work progresses. 


\section{MATERIAL OPTIONS AND PROPERTIES OF THE AHTR HEAT EXCHANGERS STRUCTURAL MATERIALS}

Some of the material options that could potentially be used in the SHX are discussed here. The SHX could have a molten salt on one side of the heat transfer barrier and an oxidizing environment such as supercritical steam on the other side. Alloy $\mathrm{N}$ is the baseline material chosen for the SHX, but other material options that are being considered include:

- Type 316 stainless steel

- Incoloy alloy $800 \mathrm{H}$

- Inconel alloy 617

- Alloy N

- Alloy 242

- $\mathrm{SiC}($ ceramic)

The general properties of these selected materials and their potential suitability are presented and discussed in this section.

\subsubsection{Stainless Steels UNS S31600}

Type 316 is an austenitic, chromium-nickel-molybdenum stainless steel with corrosion resistance superior to other chromium-nickel stainless steels (such as Type 304) in many types of aggressive chemical and high temperature environments. The molybdenum addition increases high temperature strength. The material has higher ASME Section VIII design allowable temperature - up to $725^{\circ} \mathrm{C}$ compared to 304 stainless steel (ASME BPV Code 2001).

This material is allowed for ASME Section III (Nuclear) and Section VIII, Division I components. The chemical composition for 316 stainless steel is given in Table 2-1.

Table 2-1. Limiting chemical composition in \%, for 316 stainless steel (316/316 L Stainless Steel 2007).

\begin{tabular}{|ll|}
\hline \multicolumn{1}{|c|}{ Chemical } & \multicolumn{1}{c|}{$(\%)$} \\
\hline Carbon & $0.08 \mathrm{max}$ \\
Manganese & $2.00 \mathrm{max}$ \\
Phosphorus & $0.045 \mathrm{max}$ \\
Sulfur & $0.030 \mathrm{max}$ \\
Silicon & $0.75 \mathrm{max}$ \\
Chromium & $16.00-18.00$ \\
Nickel & $10.00-14.00$ \\
Molybdenum & $2.00-3.00$ \\
Nitrogen & $0.10 \mathrm{max}$ \\
Iron & Balance \\
\hline
\end{tabular}

\section{Physical and Thermal Properties}

Physical and thermal properties of 316 stainless steel are listed in Tables 2-2 and 2-3. 
Table 2-2. Physical constants for 316 stainless steel

(316/316L Stainless Steel 2007).

\begin{tabular}{ll} 
Density & $0.29 \mathrm{lb} / \mathrm{in}^{3}\left(7.99 \mathrm{~g} / \mathrm{cm}^{3}\right)$ \\
Melting Range & $2500-2550^{\circ} \mathrm{F}\left(1371-1399^{\circ} \mathrm{C}\right)$ \\
\hline
\end{tabular}

Table 2-3. Electrical and thermal properties for 316 stainless steel (316/316L Stainless Steel 2007).

\begin{tabular}{|c|c|c|c|c|}
\hline $\begin{array}{c}\text { Temperature } \\
{ }^{\circ} \mathrm{F} \\
\end{array}$ & $\begin{array}{c}\text { Electrical Resistivity } \\
\text { Ohm-circ mil/ft }\end{array}$ & $\begin{array}{c}\text { Thermal } \\
\text { Conductivity } \\
\text { Btu-in/ft }-\mathrm{h}-{ }^{\circ} \mathrm{F}\end{array}$ & $\begin{array}{c}\text { Coefficient of } \\
\text { Expansion } \\
10^{-6} \mathrm{in} / \mathrm{in} /{ }^{\circ} \mathrm{F} \\
\end{array}$ & $\begin{array}{c}\text { Specific Heat } \\
\text { Btu/lb- }{ }^{\circ} \mathrm{F}\end{array}$ \\
\hline 32 & - & - & - & 0.12 \\
\hline 68 & 449.2 & - & - & - \\
\hline 212 & - & - & $8.9 \times 10^{-6}$ & 0.12 \\
\hline 600 & - & - & $9.0 \times 10^{-6}$ & - \\
\hline 1000 & - & - & $9.7 \times 10^{-6}$ & - \\
\hline 1200 & - & - & $10.3 \times 10^{-6}$ & - \\
\hline 1500 & - & - & $11.1 \times 10^{-6}$ & - \\
\hline${ }^{\circ} \mathrm{C}$ & $\mu \Omega-\mathrm{m}$ & $\mathrm{W} / \mathrm{m}-{ }^{\circ} \mathrm{C}$ & $\mu \mathrm{m} / \mathrm{m}-{ }^{\circ} \mathrm{C}$ & $\mathrm{J} / \mathrm{kg}-{ }^{\circ} \mathrm{C}$ \\
\hline 0 & - & - & - & 0.50 \\
\hline 20 & 0.74 & - & - & \\
\hline 100 & - & - & 16.0 & 0.50 \\
\hline 315 & - & - & 16.2 & - \\
\hline 538 & - & - & 17.5 & - \\
\hline 649 & - & - & 18.5 & - \\
\hline 871 & - & - & 19.9 & - \\
\hline
\end{tabular}

\section{Mechanical Properties}

Mechanical properties of 316 stainless steel are listed in Tables 2-4 and 2-5.

Table 2-4. Mechanical properties of 316 stainless steel (316/316L Stainless Steel 2007).

\begin{tabular}{|cccc|}
\hline $\begin{array}{c}\text { Temperature } \\
{ }^{\circ} \mathrm{F}\left({ }^{\circ} \mathrm{C}\right)\end{array}$ & $\begin{array}{c}\text { Ultimate Tensile Stress } \\
\mathrm{ksi}(\mathrm{MPa})\end{array}$ & $\begin{array}{c}0.2 \% \text { Yield Strength ksi } \\
(\mathrm{MPa})\end{array}$ & $\begin{array}{c}\text { Elongation \% in 2” } \\
(50.8 \mathrm{~mm})\end{array}$ \\
\hline $75(24)$ & $84.0(579)$ & $42.0(290)$ & 50 \\
$400(204)$ & $81.0(558)$ & $35.0(241)$ & 51 \\
$600(316)$ & $78.0(538)$ & $31.0(214)$ & 48 \\
$800(427)$ & $76.0(524)$ & $27.5(190)$ & 47 \\
$1000(538)$ & $70.0(483)$ & $24.0(165)$ & 44 \\
$1200(649)$ & $57.0(393)$ & $21.0(145)$ & 40 \\
$1400(760)$ & $35.0(241)$ & $18.0(124)$ & 37 \\
$1600(871)$ & $24.0(165)$ & $16.0(110)$ & 44 \\
\hline
\end{tabular}


Table 2-5. Stress rupture properties of 316 stainless steel (316/316L Stainless Steel 2007).

\begin{tabular}{|cccc|}
\hline \multirow{2}{*}{$\begin{array}{c}\text { Test Temperature } \\
{ }^{\circ} \mathrm{F}\left({ }^{\circ} \mathrm{C}\right)\end{array}$} & \multicolumn{3}{c|}{ Stress, ksi (MPa) for rupture in: } \\
\cline { 2 - 4 } $1100(593)$ & $36.0(248)$ & $10,000 \mathrm{hrs}$ & $100,000 \mathrm{hrs}$ \\
$1200(649)$ & $24.0(165)$ & $28.0(193)$ & $25.0(172)$ \\
$1300(704)$ & $15.5(106)$ & $16.5(114)$ & $13.5(94)$ \\
$1400(760)$ & $10.0(69)$ & $10.0(69)$ & $7.0(48)$ \\
$1500(816)$ & $6.0(41)$ & $6.0(41)$ & $3.5(24)$ \\
$1600(871)$ & $3.5(24)$ & $3.5(24)$ & $2.0(14)$ \\
\hline
\end{tabular}

\subsubsection{Nickel-Based Alloys}

The nickel-based alloys presented in this section are mainly high temperature alloys. The alloys studied are:

- Alloy $800 \mathrm{H}$

- Alloy 617

- Alloy N

- Alloy 242.

\subsubsection{Alloy 800H - UNS N08810}

Alloy $800 \mathrm{H}$ is an iron-nickel-chromium material that is designed for high temperature service where resistance to creep and rupture is required. Alloy $800 \mathrm{H}$ is one of three grades of $33 \mathrm{Ni}-42 \mathrm{Fe}-21 \mathrm{Cr}$ alloy that are listed in ASME Section II and approved for construction of pressure boundary components. These are identified as UNS N08800, UNS N08810, and UNS N08811 for Alloys 800, 800H, and 800HT respectively. The 800 series of alloys were developed for high temperature strength and resistance to oxidation, carburization, and other forms of high temperature corrosion. Alloys $800 \mathrm{H}$ and $800 \mathrm{HT}$ have the same basic composition as INCOLOY Alloy 800, but have significantly higher creep-rupture strength. The higher strength results from close control of the carbon, aluminum, and titanium contents in conjunction with a high-temperature anneal. Alloys $800 \mathrm{H}$ and $800 \mathrm{HT}$ are used in chemical and petrochemical processing, power plants for super-heater and reheater tubing, industrial furnaces, and heat treating equipment. Alloy $800 \mathrm{HT}$ has a more restrictive chemistry and grain size requirement compared to Alloy $800 \mathrm{H}$; however, Alloy $800 \mathrm{HT}$ is within the specifications of Alloy $800 \mathrm{H}$. It appears that current practice for all of the major alloy vendors is to produce only Alloy $800 \mathrm{HT}$, rather than provide all three variants of the material.

The chemical composition and special requirements for $800 \mathrm{H}$ are given in Table 2-6. 
Table 2-6. Limiting chemical compositions, \%, special requirements, and special grain size requirements for alloy $800 \mathrm{H}$ (Incoloy Alloy $800 \mathrm{H}$ and $800 \mathrm{HT}$ 2004).

\begin{tabular}{|lc|}
\hline \multicolumn{1}{c}{ INCOLOY alloys } & $800 \mathrm{H}$ \\
\hline Nickel & $30.0-35.0$ \\
Chromium & $19.0-23.0$ \\
Iron & $39.5 \mathrm{~min}$ \\
Carbon & $0.05-0.10$ \\
Aluminum & $0.15-0.60$ \\
Titanium & $0.15-0.60$ \\
Aluminum + Titanium & $0.30-1.20$ \\
ASTM grain size & 5 or coarser \\
\hline \multicolumn{2}{|c|}{ Special Requirements for INCOLOY Alloy $800 \mathrm{H}$} \\
\hline Carbon & 0.08 max \\
Aluminum + Titanium & $0.4-0.7$ \\
ASTM grain size & Special \\
\hline Special Grain Size Requirements for INCOLOY Alloys $800 \mathrm{H}$ and $800 \mathrm{HT}$ \\
\hline Plate & ASTM 1-5 \\
Tube/Pipe & ASTM 1-5 \\
Sheet & ASTM 2-5 \\
\hline
\end{tabular}

\section{Physical and Thermal Properties}

Physical and thermal properties of Incoloy $800 \mathrm{H} / 800 \mathrm{HT}$ are listed in Tables 2-7 and 2-8.

Table 2-7. Physical constants for alloy $800 \mathrm{H}$ (Incoloy Alloy $800 \mathrm{H}$ and $800 \mathrm{HT}$ 2004).

\begin{tabular}{|ll|}
\hline Density & $0.287 \mathrm{lb} / \mathrm{in}^{3}\left(7.94 \mathrm{~g} / \mathrm{cm}^{3}\right)$ \\
Melting Range & $2475-2525^{\circ} \mathrm{F}\left(1357-1385^{\circ} \mathrm{C}\right)$ \\
\hline
\end{tabular}

Table 2-8. Electrical and thermal properties for alloy $800 \mathrm{H}$ (Incoloy Alloy $800 \mathrm{H}$ and $800 \mathrm{HT} 2004$ ).

\begin{tabular}{|c|c|c|c|}
\hline $\begin{array}{c}\text { Temperature } \\
{ }^{\circ} \mathrm{F}\end{array}$ & $\begin{array}{c}\text { Electrical Resistivity } \\
\text { Ohm-circ mil/ft }\end{array}$ & $\begin{array}{c}\text { Thermal Conductivity } \\
\text { Btu-in } / \mathrm{ft}^{2}-\mathrm{h}-{ }^{\circ} \mathrm{F}\end{array}$ & $\begin{array}{c}\text { Coefficient of Expansion } \\
10^{-6} \mathrm{in} / \mathrm{in} /{ }^{\circ} \mathrm{F}\end{array}$ \\
\hline 70 & 595 & 80 & - \\
\hline 100 & 600 & 83 & - \\
\hline 200 & 620 & 89 & 7.9 \\
\hline 400 & 657 & 103 & 8.8 \\
\hline 600 & 682 & 115 & 9.0 \\
\hline 800 & 704 & 127 & 9.2 \\
\hline 1000 & 722 & 139 & 9.4 \\
\hline 1200 & 746 & 152 & 9.6 \\
\hline 1400 & 758 & 166 & 9.9 \\
\hline 1600 & 770 & 181 & 10.2 \\
\hline 1800 & 776 & 214 & - \\
\hline 2000 & 788 & - & - \\
\hline
\end{tabular}




\begin{tabular}{|cccc|}
\hline $\begin{array}{c}\text { Temperature } \\
{ }^{\circ} \mathrm{F}\end{array}$ & $\begin{array}{c}\text { Electrical Resistivity } \\
\text { Ohm-circ mil/ft }\end{array}$ & $\begin{array}{c}\text { Thermal Conductivity } \\
\text { Btu-in/ } / \mathrm{ft}^{2}-\mathrm{h}-{ }^{\circ} \mathrm{F}\end{array}$ & $\begin{array}{c}\text { Coefficient of Expansion } \\
10^{\mathrm{a}} \mathrm{in} / \mathrm{in} /{ }^{\circ} \mathrm{F}\end{array}$ \\
\hline${ }^{\circ} \mathrm{C}$ & $\mu \Omega \cdot \mathrm{m}$ & $\mathrm{W} / \mathrm{m}^{\circ} \mathrm{C}$ & $\mu \mathrm{m} / \mathrm{m} /{ }^{\circ} \mathrm{C}$ \\
20 & 0.989 & 11.5 & - \\
100 & 1.035 & 13.0 & 14.4 \\
200 & 1.089 & 14.7 & 15.9 \\
300 & 1.127 & 16.3 & 16.2 \\
400 & 1.157 & 17.9 & 16.5 \\
500 & 1.191 & 19.5 & 16.8 \\
600 & 1.223 & 21.1 & 17.1 \\
700 & 1.251 & 22.8 & 17.5 \\
800 & 1.266 & 24.7 & - \\
900 & 1.283 & 27.1 & - \\
1000 & 1.291 & 31.9 & \\
\hline
\end{tabular}

\section{Mechanical Properties}

Mechanical properties of Incoloy 800H/800HT are listed in Tables 2-9 through 2-12.

Table 2-9. Modulus of elasticity ${ }^{a}$ for alloy $800 \mathrm{H}$ (Incoloy Alloy $800 \mathrm{H}$ and $800 \mathrm{HT} 2004$ ).

\begin{tabular}{cccc}
\hline $\begin{array}{c}\text { Temperature } \\
{ }^{\circ} \mathrm{F}\end{array}$ & $\begin{array}{c}\text { Tensile Modulus } \\
10^{3} \mathrm{ksi}\end{array}$ & $\begin{array}{c}\text { Shear Modulus } \\
10^{3} \mathrm{ksi}\end{array}$ & Poisson's Ratio $^{\mathrm{b}}$ \\
\hline 75 & 28.50 & 10.64 & 0.339 \\
200 & 27.82 & 10.37 & 0.341 \\
400 & 26.81 & 9.91 & 0.353 \\
600 & 25.71 & 9.47 & 0.357 \\
800 & 24.64 & 9.04 & 0.363 \\
1000 & 23.52 & 8.60 & 0.367 \\
1200 & 22.37 & 8.12 & 0.377 \\
1400 & 21.06 & 7.58 & 0.389 \\
1600 & 19.20 & 6.82 & 0.408 \\
${ }^{\circ} \mathrm{C}$ & $\mathrm{GPa}$ & $\mathrm{GPa}$ & 0.339 \\
20 & 196.5 & 73.4 & 0.343 \\
100 & 191.3 & 71.2 & 0.349 \\
200 & 184.8 & 68.5 & 0.357 \\
300 & 178.3 & 66.1 & 0.362 \\
400 & 171.6 & 63.0 & 0.367 \\
500 & 165.0 & 60.3 & 0.373 \\
600 & 157.7 & 57.4 & 0.381 \\
700 & 150.1 & 54.3 & 0.394 \\
800 & 141.3 & 50.7 & \\
& & & \\
\hline a. Determined by dynamic method. & & & \\
\hline balculated from moduli of elasticity. & & & \\
\hline
\end{tabular}


Table 2-10. Tensile properties and hardness of alloys $800 \mathrm{H} / 800 \mathrm{HT}$ at high temperatures (Incoloy Alloy $800 \mathrm{H}$ and $800 \mathrm{HT}$ 2004).

\begin{tabular}{|c|c|c|c|c|c|c|}
\hline \multicolumn{2}{|c|}{ Temperature } & \multirow{2}{*}{$\begin{array}{c}\text { Hardness } \\
\text { BHN }\end{array}$} & \multicolumn{2}{|c|}{ Tensile Strength } & \multicolumn{2}{|c|}{$\begin{array}{l}\text { Yield Strength } \\
(0.2 \% \text { Offset })\end{array}$} \\
\hline${ }^{\circ} \mathrm{F}$ & ${ }^{\circ} \mathrm{C}$ & & ksi & $\mathrm{MPa}$ & ksi & $\mathrm{MPa}$ \\
\hline 80 & 27 & 126 & 77.8 & 536 & 21.7 & 150 \\
\hline 800 & 425 & 一 & 67.5 & 465 & 18.8 & 130 \\
\hline 1000 & 540 & 90 & 62.7 & 432 & 13.0 & 90 \\
\hline 1200 & 650 & 84 & 54.8 & 378 & 13.5 & 93 \\
\hline 1300 & 705 & 82 & 47.7 & 329 & 15.8 & 109 \\
\hline 1400 & 760 & 74 & 34.2 & 236 & 13.1 & 90 \\
\hline
\end{tabular}

Table 2-11. Room-temperature properties of cold-rolled (20\%) Alloys $800 \mathrm{H}$ and $800 \mathrm{HT}$ after high-temperature exposure (Incoloy Alloy 800H and 800HT 2004).

\begin{tabular}{|c|c|c|c|c|c|c|c|c|c|c|}
\hline \multicolumn{2}{|c|}{$\begin{array}{c}\text { Exposure } \\
\text { Temperature } \\
\end{array}$} & \multirow{2}{*}{$\begin{array}{c}\text { Exposure } \\
\text { Time } \\
\text { Hours } \\
\end{array}$} & \multicolumn{2}{|c|}{ Impact Strength $^{\mathrm{a}}$} & \multicolumn{2}{|c|}{$\begin{array}{l}\text { Yield Strength } \\
(0.2 \% \text { Offset })\end{array}$} & \multicolumn{2}{|c|}{$\begin{array}{l}\text { Tensile } \\
\text { Strength }\end{array}$} & \multirow{2}{*}{$\begin{array}{c}\text { Elongation } \\
\% \\
\end{array}$} & \multirow{2}{*}{$\begin{array}{c}\text { Reduction of } \\
\text { Area } \\
\% \\
\end{array}$} \\
\hline${ }^{\circ} \mathrm{F}$ & ${ }^{\circ} \mathrm{C}$ & & $\mathrm{ft} \bullet \mathrm{lbf}$ & $\mathrm{J}$ & ksi & $\mathrm{MPa}$ & ksi & $\mathrm{MPa}$ & & \\
\hline \multicolumn{2}{|c|}{ No exposure } & - & 112 & 152 & 113.0 & 779 & 114.0 & 786 & 15.5 & 58.0 \\
\hline \multirow[t]{4}{*}{1000} & 540 & 1,000 & 63 & 85 & 114.5 & 789 & 127.5 & 879 & 18.5 & 50.5 \\
\hline & & 4,000 & 78 & 106 & 112.5 & 776 & 125.5 & 865 & 20.0 & 52.5 \\
\hline & & 8,000 & 61 & 83 & 113.5 & 783 & 128.5 & 886 & 20.0 & 47.0 \\
\hline & & 12,000 & 61 & 83 & 113.5 & 783 & 128.5 & 886 & 20.0 & 52.0 \\
\hline \multirow[t]{4}{*}{1200} & 650 & 1,000 & 87 & 118 & 90.5 & 624 & 109.0 & 752 & 23.0 & 46.5 \\
\hline & & 4,000 & 65 & 88 & 79.4 & 547 & 107.0 & 738 & 21.5 & 43.0 \\
\hline & & 8,000 & 62 & 84 & 81.4 & 561 & 106.5 & 734 & 25.5 & 52.5 \\
\hline & & 12,000 & 63 & 85 & 78.9 & 544 & 105.0 & 724 & 24.0 & 50.0 \\
\hline
\end{tabular}

Table 2-12. Representative rupture-strength values for alloys $800 \mathrm{H} / 800 \mathrm{HT}$ (Incoloy Alloy $800 \mathrm{H}$ and $800 \mathrm{HT}$ 2004).

\begin{tabular}{|c|c|c|c|c|c|c|c|c|c|}
\hline \multicolumn{2}{|c|}{ Temperature } & \multicolumn{2}{|c|}{$10,000 \mathrm{~h}$} & \multicolumn{2}{|c|}{$30,000 \mathrm{~h}$} & \multicolumn{2}{|c|}{$50,000 \mathrm{~h}$} & \multicolumn{2}{|c|}{$100,000 \mathrm{~h}$} \\
\hline${ }^{\circ} \mathrm{F}$ & ${ }^{\circ} \mathrm{C}$ & $\mathrm{ksi}$ & $\mathrm{MPa}$ & $\mathrm{ksi}$ & $\mathrm{MPa}$ & $\mathrm{ksi}$ & $\mathrm{MPa}$ & $\mathrm{ksi}$ & $\mathrm{MPa}$ \\
\hline 1200 & 650 & 17.5 & 121 & 15.0 & 103 & 14.0 & 97 & 13.0 & 90 \\
\hline 1300 & 705 & 11.0 & 76 & 9.5 & 66 & 8.8 & 61 & 8.0 & 55 \\
\hline 1400 & 760 & 7.3 & 50 & 6.3 & 43 & 5.8 & 40 & 5.3 & 37 \\
\hline 1500 & 815 & 5.2 & 36 & 4.4 & 30 & 4.1 & 28 & 3.7 & 26 \\
\hline 1600 & 870 & 3.5 & 24 & 3.0 & 21 & 2.8 & 19 & 2.5 & 17 \\
\hline 1700 & 925 & 1.9 & 13 & 1.6 & 11 & 1.4 & 10 & 1.2 & 8.3 \\
\hline 1800 & 980 & 1.2 & 8.3 & 1.0 & 6.9 & 0.9 & 6.2 & 0.8 & 5.5 \\
\hline
\end{tabular}




\subsubsection{Alloy 617-UNS N06617}

Alloy 617 (Inconel $617^{\circledR}$ ) was initially developed for high temperature applications above $800^{\circ} \mathrm{C}$. It is often considered for use in aircraft and land-based gas turbines, chemical manufacturing components, metallurgical processing facilities, and power generation structures. The alloy was also considered and investigated for the HTGR programs in the United States and Germany in the late 1970s and early 1980s. Alloy 617 is not currently qualified for use in ASME Boiler and Pressure Vessel (BPV) Code Section III, although it is allowed in Section I and Section VIII, Division 1 (non-nuclear service).

The ASTM specified chemical composition of Alloy 617 is shown in Table 2-13. The high nickel and chromium contents provide the alloy with high resistance to a variety of reducing and oxidizing environments. The aluminum, in conjunction with chromium, offers oxidation resistance at high temperatures. The aluminum added can also result in precipitation strengthening on top of the solid solution strengthening imparted by the cobalt and molybdenum. Strengthening is also derived from $\mathrm{M} 23 \mathrm{C} 6, \mathrm{M} 6 \mathrm{C}, \mathrm{Ti}(\mathrm{C}, \mathrm{N})$ and other precipitates when in appropriate sizes, distributions, and volume fractions.

Table 2-13. Limiting chemical composition, \%, for Alloy 617 (Inconel Alloy 617 2005).

\begin{tabular}{|ll|}
\hline Nickel & $44.5 \mathrm{~min}$ \\
Chromium & $20.0-24.0$ \\
Mobalt & $10.0-15.0$ \\
Aluminum & $8.0-10.0$ \\
Carbon & $0.8-1.5$ \\
Iron & $0.05-0.15$ \\
Manganese & $3.0 \max$ \\
Silicon & $1.0 \max$ \\
Sulfur & $1.0 \max$ \\
Titanium & $0.015 \max$ \\
Copper & $0.6 \max$ \\
Boron & $0.5 \max$ \\
\hline
\end{tabular}

\section{Physical and Thermal Properties}

Physical and thermal properties of Inconel 617 are listed in Tables 2-14 and 2-15.

Table 2-14. Physical constants for alloy 617 (Inconel Alloy 617 2005).

\begin{tabular}{ll} 
Density & $0.302, \mathrm{lb} / \mathrm{in}^{3}\left(8.36 \mathrm{~g} / \mathrm{cm}^{3}\right)$ \\
Melting Range & $2430-2510^{\circ} \mathrm{F}\left(1332-1380^{\circ} \mathrm{C}\right.$ \\
\hline
\end{tabular}


Table 2-15. Electrical and thermal properties for alloy 617 (Inconel Alloy 6172005 ).

\begin{tabular}{|c|c|c|c|c|}
\hline $\begin{array}{l}\text { Temperature } \\
{ }^{\circ} \mathrm{F}\end{array}$ & $\begin{array}{l}\text { Electrical Resistivity } \\
\text { Ohm-circ mil/ft }\end{array}$ & $\begin{array}{l}\text { Thermal } \\
\text { Conductivity } \\
\text { Btu-in } / \mathrm{ft}^{2}-\mathrm{h}-{ }^{\circ} \mathrm{F}\end{array}$ & $\begin{array}{l}\text { Coefficient of } \\
\text { Expansion }^{\mathrm{b}} \\
10^{-6} \mathrm{in} / \mathrm{in}^{\circ} \mathrm{F}\end{array}$ & $\begin{array}{c}\text { Specific Heat }^{\mathrm{c}} \\
\text { Btu/lb- }{ }^{\circ} \mathrm{F}\end{array}$ \\
\hline 78 & 736 & 94 & - & 0.100 \\
\hline 200 & 748 & 101 & 7.0 & 0.104 \\
\hline 400 & 757 & 113 & 7.2 & 0.111 \\
\hline 600 & 764 & 125 & 7.4 & 0.117 \\
\hline 800 & 770 & 137 & 7.6 & 0.124 \\
\hline 1000 & 779 & 149 & 7.7 & 0.131 \\
\hline 1200 & 793 & 161 & 8.0 & 0.137 \\
\hline 1400 & 807 & 173 & 8.4 & 0.144 \\
\hline 1600 & 803 & 185 & 8.7 & 0.150 \\
\hline 1800 & 824 & 197 & 9.0 & 0.157 \\
\hline 2000 & - & 209 & 9.2 & 0.163 \\
\hline${ }^{\circ} \mathrm{C}$ & $\mu \Omega-\mathrm{m}$ & $\mathrm{W} / \mathrm{m}-{ }^{\circ} \mathrm{C}$ & $\mu \mathrm{m} / \mathrm{m}-{ }^{\circ} \mathrm{C}$ & $\mathrm{J} / \mathrm{kg}-{ }^{\circ} \mathrm{C}$ \\
\hline 20 & 1.222 & 13.4 & - & 419 \\
\hline 100 & 1.245 & 14.7 & 11.6 & 440 \\
\hline 200 & 1.258 & 16.3 & 12.6 & 465 \\
\hline 300 & 1.268 & 17.7 & 13.1 & 490 \\
\hline 400 & 1.278 & 19.3 & 13.6 & 515 \\
\hline 500 & 1.290 & 20.9 & 13.9 & 536 \\
\hline 600 & 1.308 & 22.5 & 14.0 & 561 \\
\hline 700 & 1.332 & 23.9 & 14.8 & 586 \\
\hline 800 & 1.342 & 25.5 & 15.4 & 611 \\
\hline 900 & 1.338 & 27.1 & 15.8 & 636 \\
\hline 1000 & 1.378 & 28.7 & 16.3 & 662 \\
\hline \multicolumn{5}{|c|}{$\begin{array}{l}\text { a. Calculated from electrical resistivity. } \\
\text { b. Mean Coefficient of linear expansion between } 78^{\circ} \mathrm{F}\left(26^{\circ} \mathrm{C}\right) \text { and temperature shown. } \\
\text { c. Calculated values. }\end{array}$} \\
\hline
\end{tabular}

\section{Mechanical Properties}

Mechanical properties of Inconel 617 are listed in Tables 2-16 and 2-17. 
Table 2-16. Modulus of elasticity for alloy 617 (Inconel Alloy 617 2005).

\begin{tabular}{|c|c|c|c|}
\hline $\begin{array}{c}\text { Temperature } \\
{ }^{\circ} \mathrm{F}\end{array}$ & $\begin{array}{c}\text { Tensile Modulus } \\
10^{3} \mathrm{ksi}\end{array}$ & $\begin{array}{l}\text { Shear Modulus } \\
10^{3} \mathrm{ksi}\end{array}$ & Poisson's Ratio \\
\hline 74 & 30.6 & 11.8 & 0.30 \\
\hline 200 & 30.0 & 11.6 & 0.30 \\
\hline 400 & 29.0 & 11.2 & 0.30 \\
\hline 600 & 28.0 & 10.8 & 0.30 \\
\hline 800 & 26.9 & 10.4 & 0.30 \\
\hline 1000 & 25.8 & 9.9 & 0.30 \\
\hline 1200 & 24.6 & 9.5 & 0.30 \\
\hline 1400 & 23.3 & 9.0 & 0.30 \\
\hline 1600 & 21.9 & 8.4 & 0.30 \\
\hline 1800 & 20.5 & 7.8 & 0.31 \\
\hline 2000 & 18.8 & 7.1 & 0.32 \\
\hline${ }^{\circ} \mathrm{C}$ & $\mathrm{GPa}$ & $\mathrm{GPa}$ & Poisson's Ratiob \\
\hline 25 & 211 & 81 & 0.30 \\
\hline 100 & 206 & 80 & 0.30 \\
\hline 200 & 201 & 77 & 0.30 \\
\hline 300 & 194 & 75 & 0.30 \\
\hline 400 & 188 & 72 & 0.30 \\
\hline 500 & 181 & 70 & 0.30 \\
\hline 600 & 173 & 66 & 0.30 \\
\hline 700 & 166 & 64 & 0.30 \\
\hline 800 & 157 & 61 & 0.30 \\
\hline 900 & 149 & 57 & 0.30 \\
\hline 1000 & 139 & 53 & 0.31 \\
\hline 1100 & 129 & 49 & 0.32 \\
\hline
\end{tabular}

Table 2-17. Typical room-temperature mechanical properties for alloy 617 (Inconel Alloy 617 2005).

\begin{tabular}{|c|c|c|c|c|c|c|c|c|}
\hline \multirow{2}{*}{$\begin{array}{l}\text { Production } \\
\text { Form }\end{array}$} & \multirow{2}{*}{$\begin{array}{l}\text { Production } \\
\text { Method }\end{array}$} & \multicolumn{2}{|c|}{$\begin{array}{l}\text { Yield Strength } \\
(0.2 \% \text { Offset })\end{array}$} & \multicolumn{2}{|c|}{$\begin{array}{l}\text { Tensile } \\
\text { Strength }\end{array}$} & \multirow[b]{2}{*}{ Elongation, \% } & \multirow{2}{*}{$\begin{array}{c}\text { Reduction of } \\
\text { Area, } \%\end{array}$} & \multirow{2}{*}{$\begin{array}{c}\text { Hardness } \\
\text { BHN }\end{array}$} \\
\hline & & ksi & $\mathrm{MPa}$ & Ksi & $\mathrm{MPa}$ & & & \\
\hline Plate & Hot Rolling & 46.7 & 322 & 106.5 & 734 & 62 & 56 & 172 \\
\hline Bar & Hot Rolling & 46.1 & 318 & 111.5 & 769 & 56 & 50 & 181 \\
\hline Tubing & Cold Drawing & 55.6 & 383 & 110.0 & 758 & 56 & - & 193 \\
\hline Sheet or Strip & Cold Rolling & 50.9 & 351 & 109.5 & 755 & 58 & - & 173 \\
\hline
\end{tabular}




\subsubsection{Alloy N-UNS N10003}

Alloy $\mathrm{N}$ alloy is a nickel-based alloy invented at ORNL (Hastelloy N, 2002) as a container material for molten fluoride salts. Alloy $\mathrm{N}$ was formerly called INOR-8. It has good oxidation resistance to hot fluoride salts in the temperature range of 1300 to $1600^{\circ} \mathrm{F}\left(704\right.$ to $\left.871^{\circ} \mathrm{C}\right)$. Alloy $\mathrm{N}$ alloy has good oxidation resistance in air. It shows promise for continuous operations at temperatures up to $1800^{\circ} \mathrm{F}$ $\left(982^{\circ} \mathrm{C}\right)$. Intermittent use at temperatures up to $1900^{\circ} \mathrm{F}\left(1038^{\circ} \mathrm{C}\right)$ may also be possible (Hastelloy $\mathrm{N}$ Alloy, 2002). No discernible oxidation could be measured for the alloy at temperatures up to $1200^{\circ} \mathrm{F}$ $\left(649^{\circ} \mathrm{C}\right)$. The chemical composition of Alloy N (UNS N10003) is shown in Table 2-18.

Table 2-18. Limiting chemical composition, \%, for Alloy N (Hastelloy N Alloy 2002).

\begin{tabular}{|ll|}
\hline Chromium & $6.0-8.0$ \\
Iron & $5.0 \mathrm{max}$ \\
Carbon & $0.04-0.08$ \\
Silicon & $1.00 \mathrm{max}$ \\
Cobalt & $0.20 \mathrm{max}$ \\
Tungangten & $1.00 \mathrm{max}$ \\
Vanadium & $0.50 \mathrm{max}$ \\
Molybdenum & $0.50 \mathrm{max}$ \\
Phosphorus & $15.0-18.0$ \\
Sulfur & $0.015 \mathrm{max}$ \\
Aluminum plus titanium & $0.020 \mathrm{max}$ \\
Copper & $0.35 \mathrm{max}$ \\
Boron & $0.010 \mathrm{max}$ \\
Nickel & remainder \\
Aluminum & - \\
\hline
\end{tabular}

\section{Physical and Thermal Properties}

Physical and thermal properties for Alloy $\mathrm{N}$ are listed in Tables 2-19 and 2-20.

Table 2-19. Physical constants for Alloy N (Hastelloy N Alloy 2002).

\begin{tabular}{ll} 
Density & $0.32 \mathrm{lb} / \mathrm{in}^{3}\left(8.86 \mathrm{~g} / \mathrm{cm}^{3}\right)$ \\
Melting Range & $2375-2550^{\circ} \mathrm{F}\left(1300-1400^{\circ} \mathrm{C}\right)$ \\
\hline
\end{tabular}


Table 2-20. Electrical and thermal properties for Alloy N (Hastelloy N Alloy 2002).

\begin{tabular}{|c|c|c|c|c|c|}
\hline $\begin{array}{c}\text { Temperature } \\
{ }^{\circ} \mathrm{F} \\
\end{array}$ & $\begin{array}{c}\text { Thermal } \\
\text { Conductivity } \\
\text { Btu-in } / \mathrm{ft}^{2}-\mathrm{h}-{ }^{\circ} \mathrm{F}\end{array}$ & $\begin{array}{c}\text { Specific Heat } \\
\text { Btu/lb- }{ }^{\circ} \mathrm{F} \\
\end{array}$ & $\begin{array}{c}\text { Temperature } \\
{ }^{\circ} \mathrm{F} \\
\end{array}$ & $\begin{array}{c}\text { Coefficient of } \\
\text { Thermal } \\
\text { Expansion } \\
10^{-6} \mathrm{in} / \mathrm{in} /{ }^{\circ} \mathrm{F} \\
\end{array}$ & $\begin{array}{c}\text { Electrical } \\
\text { Resistivity } \\
\text { Ohm-cir mil/ft }\end{array}$ \\
\hline 212 & 79 & 0.1 & 70 & - & 725.7 \\
\hline 392 & 88 & 0.105 & 400 & 6.4 & - \\
\hline 572 & 99 & 0.109 & 600 & 6.7 & - \\
\hline 752 & 109 & 0.112 & 800 & 7 & - \\
\hline 896 & - & 0.114 & 1000 & 7.4 & - \\
\hline 932 & 124 & - & 1200 & 7.8 & - \\
\hline 1004 & - & 0.116 & 1300 & - & 757.8 \\
\hline 1058 & - & 0.125 & 1400 & 8.1 & - \\
\hline 1094 & - & 0.135 & 1500 & - & 745.6 \\
\hline 1112 & 140 & - & 1600 & 8.5 & - \\
\hline 1148 & - & 0.14 & 1800 & 8.8 & - \\
\hline 1220 & - & 0.139 & - & - & - \\
\hline 1292 & 162 & 0.138 & - & - & - \\
\hline${ }^{\circ} \mathrm{C}$ & $\mathrm{W} / \mathrm{m}-{ }^{\circ} \mathrm{C}$ & $\mathrm{J} / \mathrm{kg}-{ }^{\circ} \mathrm{C}$ & ${ }^{\circ} \mathrm{C}$ & $\mu \mathrm{m} / \mathrm{m}-{ }^{\circ} \mathrm{C}$ & $\mu \Omega-\mathrm{m}$ \\
\hline 100 & 11.5 & 419 & 20 & - & 1.2 \\
\hline 200 & 13.1 & 440 & 204 & 11.6 & - \\
\hline 300 & 14.4 & 456 & 316 & 12.3 & - \\
\hline 400 & 16.5 & 469 & 427 & 12.7 & - \\
\hline 480 & - & 477 & 538 & 13.4 & - \\
\hline 500 & 18.0 & - & 649 & 14.0 & - \\
\hline 540 & - & 485 & 705 & - & 1.26 \\
\hline 570 & - & 523 & 760 & 14.7 & - \\
\hline 590 & - & 565 & 815 & - & 1.24 \\
\hline 600 & 20.3 & - & 871 & 15.3 & - \\
\hline 620 & - & 586 & 982 & 15.8 & - \\
\hline 660 & - & 582 & - & - & - \\
\hline 700 & 23.6 & 578 & - & - & - \\
\hline
\end{tabular}

\section{Mechanical Properties}

Mechanical properties for Alloy $\mathrm{N}$ are listed in Table 2-21 through Table 2-22. 
Table 2-21. Alloy N short-time tensile data (Hastelloy N Alloy 2002).

\begin{tabular}{|c|c|c|c|c|c|c|c|}
\hline \multirow[b]{2}{*}{ Form } & \multirow[b]{2}{*}{ Condition } & \multicolumn{2}{|c|}{ Aging } & \multirow[b]{2}{*}{$\begin{array}{l}\text { Test Temp., } \\
{ }^{\circ} \mathrm{F}\left({ }^{\circ} \mathrm{C}\right)\end{array}$} & \multirow[b]{2}{*}{$\begin{array}{l}\text { Ultimate } \\
\text { Tensile } \\
\text { Strength, psi }\end{array}$} & \multirow{2}{*}{$\begin{array}{c}\text { Yield } \\
\text { Strength } \\
\text { at } 0.2 \% \\
\text { offset, psi }\end{array}$} & \multirow[b]{2}{*}{$\begin{array}{c}\text { Elongation } \\
\text { in } 2 \text { in., } \\
\%\end{array}$} \\
\hline & & $\begin{array}{l}\text { Temp., } \\
{ }^{\circ} \mathrm{F}\left({ }^{\circ} \mathrm{C}\right)\end{array}$ & $\begin{array}{l}\text { Time } \\
\text { Hrs. }\end{array}$ & & & & \\
\hline \multirow{10}{*}{$\begin{array}{l}\text { Sheet, } \\
0.063 \text {-inch } \\
\text { thick }\end{array}$} & & - & - & Room & 115,100 & 45,500 & 50.7 \\
\hline & Heat-treated at & - & - & $1100(593)$ & 86,900 & 32,900 & 45.3 \\
\hline & $2150^{\circ} \mathrm{F}$ & - & - & $1300(764)$ & 69,600 & 31,600 & 30.0 \\
\hline & $\left(1177^{\circ} \mathrm{C}\right), \mathrm{RAC}$ & - & - & $1500(816)$ & 55,900 & 29,500 & 24.3 \\
\hline & & - & - & $1700(927)$ & 34,000 & 25,900 & 30.0 \\
\hline & \multirow{5}{*}{$\begin{array}{l}\text { Heat-treated at } \\
2150^{\circ} \mathrm{F} \\
\left(1177^{\circ} \mathrm{C}\right) \text {, then } \\
\text { welded and } \\
\text { tested as-welded }{ }^{2}\end{array}$} & 1500 & 128 & Room & 115,400 & 49,300 & 46.8 \\
\hline & & - & - & Room & 116,100 & - & 37.5 \\
\hline & & - & - & $1200(649)$ & 71,500 & - & 17.0 \\
\hline & & - & - & $1300(704)$ & 63,500 & - & 10.5 \\
\hline & & - & - & $1500(816)$ & 52,000 & - & 8.5 \\
\hline
\end{tabular}

Table 2-22. Alloy N average dynamic modulus of elasticity (Hastelloy N Alloy 2002).

\begin{tabular}{|c|c|c|c|}
\hline Form & Condition & $\begin{array}{c}\text { Test } \\
\text { Temperature, } \\
{ }^{\circ} \mathrm{F}\end{array}$ & $\begin{array}{l}\text { Dynamic Modulus of } \\
\text { Elasticity, psi } \times 10^{6}\end{array}$ \\
\hline Sheet & $\begin{array}{l}\text { Heat-treated at } \\
2150^{\circ} \mathrm{F}\left(1177^{\circ} \mathrm{C}\right), \mathrm{RAC}\end{array}$ & $\begin{array}{r}57 \\
430 \\
770 \\
930 \\
1070 \\
1170 \\
1290 \\
1470 \\
1570 \\
1660 \\
1750 \\
1830 \\
1920 \\
\end{array}$ & $\begin{array}{l}31.7 \\
29.3 \\
27.8 \\
27.1 \\
26.3 \\
26.2 \\
24.8 \\
23.7 \\
22.7 \\
21.9 \\
20.7 \\
19.7 \\
17.7 \\
\end{array}$ \\
\hline
\end{tabular}

\subsubsection{Alloy 242-UNS N10242}

Haynes ${ }^{\circledR} 242^{\circledR}$ alloy (UNS N10242) is an age-hardenable, nickel-molybdenum, chromium alloy that derives its strength from a long-range ordering reaction upon aging. It has tensile and creep strength properties up to $1300^{\circ} \mathrm{F}\left(705^{\circ} \mathrm{C}\right)$, which are as much as double those for solid solution strengthened alloys but with high ductility in the aged condition. The thermal expansion characteristics of Alloy 242 are much lower than those for most other alloys, and it has very good oxidation resistance up to $1500^{\circ} \mathrm{F}\left(815^{\circ} \mathrm{C}\right)$. Other attractive features include excellent low cycle fatigue properties, very good thermal stability, and resistance to high-temperature fluorine and fluoride environments. The chemical composition of Alloy 242 is shown in Table 2-23. 
Table 2-23. Limiting chemical composition, \%, Alloy 242

(Haynes 242 Alloy 2000).

\begin{tabular}{|ll|}
\hline Nickel & $65.0^{\mathrm{a}}$ \\
Molybdenum & $24.0-26.0$ \\
Chromium & $7.0-9.0-$ \\
Iron & $2.0 \mathrm{max}$ \\
Cobalt & $2.5 \mathrm{max}$ \\
Manganese & $0.8 \mathrm{max}$ \\
Silicon & $0.8 \mathrm{max}$ \\
Aluminum & $0.5 \mathrm{max}$ \\
Carbon & $0.03 \mathrm{max}$ \\
Boron & $0.006 \mathrm{max}$ \\
Copper & $0.2 \mathrm{max}$ \\
\hline a. As balance & \\
\hline
\end{tabular}

\section{Physical and Thermal Properties}

Physical and thermal properties of Alloy 242 are listed in Tables 2-24 and 2-25.

Table 2-24. Physical constants for Alloy 242 (Haynes 242 Alloy 2000).

\begin{tabular}{|ll|}
\hline Density & $0.327 \mathrm{lb} / \mathrm{in}^{3}\left(9.05 \mathrm{~g} / \mathrm{cm}^{3}\right)$ \\
Melting Range & $2350-2510^{\circ} \mathrm{F}\left(1290-1375^{\circ} \mathrm{C}\right)$ \\
\hline
\end{tabular}

Table 2-25. Electrical and thermal properties for Alloy 242 (Haynes 242 Alloy 2000).

\begin{tabular}{|ccccc|}
\hline $\begin{array}{c}\text { Temperature } \\
{ }^{\circ} \mathrm{F}\end{array}$ & $\begin{array}{c}\text { Electrical } \\
\text { Resistivity } \\
\text { Ohm-circ mil/ft }\end{array}$ & $\begin{array}{c}\text { Thermal } \\
\text { Conductivity } \\
\text { Btu-in/ } \mathrm{ft}^{2}-\mathrm{h}-{ }^{\circ} \mathrm{F}\end{array}$ & $\begin{array}{c}\text { Coefficient of } \\
\text { Expansion } \\
10^{-6} \mathrm{in} / \mathrm{in} /{ }^{\circ} \mathrm{F}\end{array}$ & $\begin{array}{c}\text { Specific Heat } \\
\text { Btu/lb- }{ }^{\circ} \mathrm{F}\end{array}$ \\
\hline 70 & 733.4 & 75.7 & - & 0.092 \\
200 & 741.0 & 83.6 & 6.0 & 0.097 \\
400 & 753.2 & 96.1 & 6.3 & 0.10 \\
600 & 763.9 & 108.5 & 6.5 & 0.103 \\
800 & 773.1 & 120.9 & 6.7 & 0.106 \\
1000 & 780.8 & 133.3 & 6.8 & 0.11 \\
1200 & 789.9 & 145.7 & 6.8 & 0.118 \\
1400 & 800.6 & 158.2 & 6.9 & 0.144 \\
1600 & 783.8 & 170.6 & 7.7 & 0.146 \\
1800 & 770.1 & 183 & 8.0 & 0.15 \\
${ }^{\circ} \mathrm{C}$ & $\mu \Omega-\mathrm{m}$ & $\mathrm{W} / \mathrm{m}-{ }^{\circ} \mathrm{C}$ & $\mu \mathrm{m} / \mathrm{m}-{ }^{\circ} \mathrm{C}$ & $\mathrm{J} / \mathrm{kg}^{\circ}{ }^{\circ} \mathrm{C}$ \\
20 & 1.22 & 11.3 & - & 386 \\
100 & 1.234 & 12.6 & 10.8 & 405 \\
200 & 1.251 & 14.2 & 11.3 & 419 \\
300 & 1.267 & 15.9 & 11.6 & 431 \\
400 & 1.28 & 17.5 & 11.9 & 439
\end{tabular}




\begin{tabular}{|ccccc|}
\hline $\begin{array}{c}\text { Temperature } \\
{ }^{\circ} \mathrm{F}\end{array}$ & $\begin{array}{c}\text { Electrical } \\
\text { Resistivity } \\
\text { Ohm-circ mil/ft }\end{array}$ & $\begin{array}{c}\text { Thermal } \\
\text { Conductivity } \\
\text { Btu-in } / \mathrm{ft}^{2}-\mathrm{h}^{\circ} \mathrm{F}\end{array}$ & $\begin{array}{c}\text { Coefficient of } \\
\text { Expansion } \\
10^{-6} \text { in } / \mathrm{in} /{ }^{\circ} \mathrm{F}\end{array}$ & $\begin{array}{c}\text { Specific Heat } \\
\text { Btu/lb- }{ }^{\circ} \mathrm{F}\end{array}$ \\
\hline 500 & 1.295 & 19.2 & 12.2 & 451 \\
600 & 1.306 & 20.9 & 12.3 & 470 \\
700 & 1.32 & 22.5 & 13.0 & 595 \\
800 & 1.324 & 24.2 & 14.0 & 605 \\
900 & 1.298 & 25.8 & 14.5 & 610 \\
1000 & 1.276 & 27.5 & 15.0 & 627 \\
\hline
\end{tabular}

\section{Mechanical Properties}

Mechanical properties of Alloy 242 are listed in Table 2-26 through 2-28.

Table 2-26. Alloy 242 mechanical properties of cold-reduced sheet as cold-worked and cold-worked plus aged (Haynes 242 Alloy 2000).

\begin{tabular}{|c|c|c|c|c|c|c|}
\hline & \multirow{2}{*}{$\begin{array}{c}\text { Test } \\
\text { Temperature } \\
{ }^{\circ} \mathrm{F}\left({ }^{\circ} \mathrm{C}\right)\end{array}$} & \multicolumn{2}{|c|}{$\begin{array}{l}\text { Ultimate Tensile } \\
\text { Strength }\end{array}$} & \multirow{2}{*}{$\begin{array}{c}0.2 \% \text { Yield } \\
\text { Strength }\end{array}$} & \multicolumn{2}{|c|}{$\begin{array}{l}\text { Elongation } \\
\text { in } 2 \text { in. }(50 \mathrm{~mm})\end{array}$} \\
\hline & & Ksi & $\mathrm{MPa}$ & & $\mathrm{MPa}$ & $\%$ \\
\hline M.A. & Room & 137.6 & 950 & 65.3 & 450 & 47 \\
\hline M.A. $+20 \%$ C.W. & Room & 169.6 & 1170 & 139.5 & 960 & 20 \\
\hline M.A. $+40 \%$ C.W. & Room & 217.9 & 1500 & 181.3 & 1250 & 8 \\
\hline M.A. + Age & Room & 192.0 & 1325 & 130.0 & 895 & 32 \\
\hline M.A. $+20 \%$ C.W. + Age & Room & 209.5 & 1445 & 173.0 & 1195 & 21 \\
\hline M.A. $+40 \%$ C.W. + Age & Room & 244.7 & 1685 & 219.7 & 1515 & 11 \\
\hline M.A. $+40 \%$ C.W. + Age & $1100(595)$ & 201.9 & 1390 & 191.4 & 1320 & 11 \\
\hline M.A. $+40 \%$ C.W. + Age & $1200(650)$ & 198.7 & 1370 & 145.9 & 1005 & 8 \\
\hline M.A. $+40 \%$ C.W. + Age & $1300(705)$ & 183.7 & 1265 & 134.3 & 925 & 11 \\
\hline M.A. $+40 \%$ C.W. + Age & $1400(760)$ & 156.0 & 1075 & 94.1 & 650 & 32 \\
\hline
\end{tabular}

Table 2-27. Alloy 242 mechanical properties of cold-rolled sheet-annealed and aged ${ }^{a}$ (Haynes 242 Alloy 2000).

\begin{tabular}{|c|c|c|c|c|c|c|}
\hline \multirow{2}{*}{$\begin{array}{c}\text { Test } \\
\text { Temperature } \\
{ }^{\circ} \mathrm{F}\left({ }^{\circ} \mathrm{C}\right)\end{array}$} & \multicolumn{2}{|c|}{$\begin{array}{l}\text { Ultimate } \\
\text { Tensile } \\
\text { Strength } \\
\end{array}$} & \multicolumn{2}{|c|}{$\begin{array}{c}0.2 \% \text { Yield } \\
\text { Strength }\end{array}$} & \multirow{2}{*}{$\begin{array}{c}\begin{array}{c}\text { Elongation } \\
\text { in 4D }\end{array} \\
\% \\
\end{array}$} & \multirow{2}{*}{$\begin{array}{c}\text { Reduction } \\
\text { in Area } \\
\%\end{array}$} \\
\hline & Ksi & $\mathrm{MPa}$ & Ksi & $\mathrm{MPa}$ & & \\
\hline $75(25)$ & 187 & 1288 & 120 & 827 & 38 & - \\
\hline $1000(540)$ & 165 & 1137 & 106 & 730 & 31 & - \\
\hline $1100(595)$ & 150 & 1034 & 102 & 703 & 18 & - \\
\hline $1200(650)$ & 135 & 930 & 96 & 661 & 14 & - \\
\hline $1300(705)$ & 109 & 751 & 83 & 572 & 10 & - \\
\hline
\end{tabular}


Table 2-28. Alloy 242 - dynamic modulus of elasticity (Haynes 242 Alloy 2000).

\begin{tabular}{cccc}
$\begin{array}{c}\text { Temp. } \\
{ }^{\circ} \mathrm{F}\end{array}$ & $\begin{array}{c}\text { Dynamic Modulus of } \\
\text { Elasticity } \\
10^{6} \mathrm{psi}\end{array}$ & $\begin{array}{c}\text { Temp. } \\
{ }^{\circ} \mathrm{C}\end{array}$ & $\begin{array}{c}\text { Dynamic Modulus of } \\
\text { Elasticity } \\
\text { GPa }\end{array}$ \\
\hline Room & 33.2 & Room & 229 \\
200 & 32.7 & 100 & 225 \\
400 & 31.8 & 200 & 219 \\
600 & 30.8 & 300 & 213 \\
800 & 29.7 & 400 & 206 \\
1000 & 28.6 & 500 & 199 \\
1200 & 27.6 & 600 & 193 \\
1400 & 25.7 & 700 & 185 \\
1600 & 24.0 & 800 & 172 \\
1800 & 22.4 & 900 & 163 \\
& & 1000 & 152 \\
\hline
\end{tabular}

\subsubsection{Ceramics}

\subsubsection{Silicon Carbide}

Ceramic materials are also being considered for use in the SHX. One of the most promising ceramic materials for use as a heat exchanger is silicon carbide (SiC). SiC maintains its flexural strength at elevated temperatures and shows good thermal shock resistance. SiC is chemically inert in many environments and possesses high thermal conductivity (about four times that of steel) (Sommers et al. 2010). $\mathrm{SiC}$ is able to operate safely at higher temperatures $\left(\sim 1300^{\circ} \mathrm{C}\right)$ than metallic alloys (Heat Transfer International Homepage 2011). A shell-and-tube type ceramic heat exchanger can operated at about 1.3 MPa (Heat Transfer International Homepage 2011). However, leakage between the primary and secondary fluids can be a significant issue if the pressure difference between the fluids is large. In some cases of high-temperature exposure, the helium permeability through $\mathrm{SiC}$ ceramics can increase by at least three orders of magnitude with a pressure difference of $520 \mathrm{kPa}$ across the tube walls (Taborek 1983).

Various fabrication techniques are implemented for the synthesis of $\mathrm{SiC}$ such as sintering, direct conversion, gas phase reaction, and polymer pyrolysis (Snead et al. 2007). The atomic structure of SiC can be arranged in various crystalline structures, each of which has different properties. The properties of sintered $\mathrm{SiC}$ with a hexagonal crystal system are included here.

An excellent review of the performance of $\mathrm{SiC}$ composites for application in molten salt environments was performed by Katoh, Wilson, and Forsberg (2007). The report focused on the possible use of $\mathrm{SiC}$ for reactor components such as fuel element cladding, control rods, and intermediate heat exchangers. However, little data was found to be available on the corrosion of silicon carbide in fluoride salts such as $\mathrm{KF}-\mathrm{ZrF}_{4}$. This lack of information will need to be addressed by thermodynamic modeling of the interaction of $\mathrm{KF}-\mathrm{ZrF}_{4}$ with $\mathrm{SiC}$ at various redox potentials and temperatures, which will have to be confirmed by a corrosion test program.

\section{Physical and Thermal Properties}

Temperature dependent thermal properties of $\mathrm{SiC}$ are presented in Table 2-29. The properties are presented with the accompanying percentage of uncertainty. 
Table 2-29. Electrical and thermal properties of SiC (NIST 2011).

\begin{tabular}{|ccccc|}
\hline $\begin{array}{c}\text { Temperature } \\
{ }^{\circ} \mathrm{C}\end{array}$ & $\begin{array}{c}\text { Density } \\
\mathrm{g} / \mathrm{cm}^{3}\end{array}$ & $\begin{array}{c}\text { Thermal } \\
\text { Conductivity } \\
\mathrm{W} / \mathrm{m}^{\circ}{ }^{\circ} \mathrm{C}\end{array}$ & $\begin{array}{c}\text { Coefficient of } \\
\text { Expansion } \\
\mu \mathrm{m} / \mathrm{m}-{ }^{\circ} \mathrm{C}\end{array}$ & $\begin{array}{r}\text { Specific Heat } \\
\mathrm{J} / \mathrm{kg}-{ }^{\circ} \mathrm{C}\end{array}$ \\
\hline 20 & $3.16(1 \%)$ & $114(8 \%)$ & $1.1(10 \%)$ & $715(5 \%)$ \\
500 & $3.14(1 \%)$ & $55.1(8 \%)$ & $4.4(10 \%)$ & $1086(5 \%)$ \\
1000 & $3.11(1 \%)$ & $35.7(8 \%)$ & $5.0(10 \%)$ & $1240(5 \%)$ \\
1200 & $3.10(1 \%)$ & $31.3(8 \%)$ & $5.2(10 \%)$ & $1282(5 \%)$ \\
1400 & $3.09(1 \%)$ & $27.8(8 \%)$ & $5.4(10 \%)$ & $1318(5 \%)$ \\
1500 & $3.08(1 \%)$ & $26.3(8 \%)$ & $5.5(10 \%)$ & $1336(5 \%)$ \\
\hline
\end{tabular}

The density of $\mathrm{SiC}$ is nearly three times less than the steel alloys. In comparison to a steel alloy of equal volume this results in a large reduction in weight. At lower temperatures, the thermal conductivity of $\mathrm{SiC}$ is much greater than the steel alloys; however at around $1000^{\circ} \mathrm{C}$ the thermal conductivity of $\mathrm{SiC}$ is nearly the same as a steel alloy. The coefficient of thermal expansion of SiC is significantly less than the steel alloys. SiC has good thermal shock resistance because of the lower coefficient of thermal expansion. The specific heat of $\mathrm{SiC}$ is nearly twice as large as that of the steel alloys.

\section{Mechanical Properties}

Ceramic materials tend to fracture before any plastic deformation takes place, resulting in poor toughness. The mechanical properties of $\mathrm{SiC}$ material are dependent on factors such as porosity and the impurity concentration (Snead et al. 2007). High porosity and/or impurity concentration will further decrease the toughness and reduce the tensile strength of the ceramic.

Temperature dependent mechanical properties for $\mathrm{SiC}$ are presented in Table 2-30; properties are presented with the accompanying percentage of uncertainty.

Table 2-30. Mechanical properties of SiC (NIST 2011).

\begin{tabular}{|cccc|}
\hline $\begin{array}{c}\text { Temperature } \\
{ }^{\circ} \mathrm{C}\end{array}$ & $\begin{array}{c}\text { Tensile Modulus } \\
\mathrm{GPa}\end{array}$ & $\begin{array}{c}\text { Shear Modulus } \\
\text { GPa }\end{array}$ & Poisson's Ratio \\
\hline 20 & $415(3 \%)$ & $179(3 \%)$ & $0.160(25 \%)$ \\
500 & $404(3 \%)$ & $174(3 \%)$ & $0.159(25 \%)$ \\
1000 & $392(3 \%)$ & $169(3 \%)$ & $0.157(25 \%)$ \\
1200 & $387(3 \%)$ & $167(3 \%)$ & $0.157(25 \%)$ \\
1400 & $383(3 \%)$ & $166(3 \%)$ & $0.156(25 \%)$ \\
1500 & $380(3 \%)$ & $165(3 \%)$ & $0.156(25 \%)$ \\
\hline
\end{tabular}

The tensile strength of sintered $\mathrm{SiC}$ was reported as $250 \pm 15 \mathrm{MPa}$ (NIST 2011) and was constant over the range of 20 to $1500^{\circ} \mathrm{C}$. Overall, ceramics are much more brittle then steel alloys, as they essentially have no plasticity region so the strain imposed on a ceramic SHX would need to be minimal.

\subsubsection{Ceramic Matrix Composites}

Each ceramic material has benefits and shortcomings. These materials can be tailored to meet specific requirements of an application. Ceramic matrix composites (CMCs) were developed to overcome the intrinsic brittleness and lack of reliability of monolithic ceramics (Sommers et al. 2010). 
CMCs combine reinforcing ceramic phases within a ceramic matrix to create materials with improved properties. The desirable characteristics of CMCs include high-temperature stability, high thermal shock resistance, high hardness, high corrosion resistance, nonmagnetic and nonconductive properties, and greater versatility in providing unique engineering solutions (Sommers et al. 2010). CMCs can be specialized to meet the physical and thermal stresses of the SHX, which makes them an attractive option. However, ceramic materials must be tested in an SHX environment and be ASME Code qualified to be used in constructing an SHX.

\subsubsection{Summary}

The metallic materials used in the SHX environment must demonstrate adequate strength (long term and short term), good thermal-aging properties, resistance to irradiation degradation, fabricability, and good corrosion resistance (Ingersoll et al. 2004). Ingersoll et al. (2004) reported on some of the alloys that are considered for use in the SHX, and their suitability. Their results are summarized in Tables 2-31 and 2-32 for long term strength at 500 and $1000^{\circ} \mathrm{C}$ respectively.

Table 2-31. Alloys potentially suited for the SHX (Ingersoll et al. 2004).

\begin{tabular}{|c|c|c|c|c|c|c|}
\hline & $\begin{array}{l}\text { Candidate } \\
\text { Materials }\end{array}$ & $\begin{array}{c}\text { Salt Corrosion } \\
\text { Resistance }\end{array}$ & $\begin{array}{c}\text { Air } \\
\text { Corrosion } \\
\text { Resistance }\end{array}$ & $\begin{array}{l}\text { Long-Term } \\
\text { Strength at } \\
\mathbf{5 0 0}^{\circ} \mathrm{C} \\
\end{array}$ & $\begin{array}{c}\text { Highest } \\
\text { Usage } \\
\text { Temperature } \\
\left({ }^{\circ} \mathrm{C}\right) \\
\end{array}$ & \\
\hline \multirow{5}{*}{$\begin{array}{l}\text { Coated } \\
\text { Monolithic }\end{array}$} & Alloy $800 \mathrm{H}$ or HT & Poor-Fair & Good & Very good & 980 & \\
\hline & Alloy N & Excellent & Good & Very good & 730 & \\
\hline & Alloy 242 & Very good & Good & Very good & 540 & \\
\hline & Alloy $800 \mathrm{H}$ or HT & Poor-Fair & Good & Very good & 980 & \\
\hline & Candidate materials & $\begin{array}{c}\text { Metallurgical } \\
\text { Stability }\end{array}$ & $\begin{array}{c}\text { Irradiation } \\
\text { Resistance }\end{array}$ & Fabricability & Maturity & Codified \\
\hline \multirow{4}{*}{$\begin{array}{l}\text { Coated } \\
\text { Monolithic }\end{array}$} & Alloy $800 \mathrm{H}$ or HT & Good & Good & Good & High & Sect. I, III, VIII \\
\hline & Alloy N & Good & Good & Good & High & Sect. III, VIII \\
\hline & Alloy 242 & Good & Adequate & Good & Low & Sect. VIII \\
\hline & Alloy $800 \mathrm{H}$ or HT & Good & Good & Good & High & Sect. III, VIII \\
\hline
\end{tabular}

Table 2-32. Alloys potentially suited for the SHX (Ingersoll et al. 2004).

\begin{tabular}{|c|c|c|c|c|c|c|}
\hline & $\begin{array}{l}\text { Candidate } \\
\text { Materials }\end{array}$ & $\begin{array}{c}\text { Salt Corrosion } \\
\text { Resistance } \\
\end{array}$ & $\begin{array}{c}\text { Air } \\
\text { Corrosion } \\
\text { Resistance } \\
\end{array}$ & $\begin{array}{c}\text { Long-Term } \\
\text { Strength at } \\
1000^{\circ} \mathrm{C} \\
\end{array}$ & $\begin{array}{c}\text { Highest Usage } \\
\text { Temperature } \\
\left({ }^{\circ} \mathrm{C}\right) \\
\end{array}$ & \\
\hline \multirow{3}{*}{ Coated } & Inconel 617 & Needs evaluation & Good & Very good & 1000 & \\
\hline & Alloy $800 \mathrm{H}$ & Needs evaluation & Poor & Good & 1000 & \\
\hline & $\begin{array}{l}\text { Candidate } \\
\text { Materials }\end{array}$ & $\begin{array}{c}\text { Metallurgical } \\
\text { Stability }\end{array}$ & $\begin{array}{c}\text { Irradiation } \\
\text { Resistance } \\
\end{array}$ & Fabricability & Maturity & Codified \\
\hline \multirow{2}{*}{ Coated } & Inconel 617 & Good & Good & Good & High & Sect. VIII \\
\hline & Alloy $800 \mathrm{H}$ & Good & N/A & Good & High & Sect. I, III, VIII \\
\hline
\end{tabular}

There are various materials options for use in the SHX. The materials discussed in this section include stainless steel type 316, Incoloy Alloy 800H, Inconel ${ }^{\circledR}$ Alloy 617, Alloy N, Alloy 242, and SiC ceramic. These materials must exhibit corrosion resistance to the molten salt coolants and be able to effectively 
transfer heat to the tertiary system. The material that best fits the needs of the AHTR will be used in the SHX.

\subsubsection{Corrosion Resistance}

\subsubsection{Primary Molten Salt Primary System Materials Degradation}

There has been a large amount of corrosion data generated by ORNL and others on molten fuel salt corrosion for application in molten salt reactors such as the ARE, MSRE, and the Molten Salt Breeder Reactor (MSBR) with review articles that summarize the results (Grimes et al. 1972; McCoy 1978; Williams, Toth, and Clarno 2006).

The ARE used a fuel salt composition of $\mathrm{NaF}_{-} \mathrm{ZrF}_{4}-\mathrm{UF}_{4}(53.09-40.73-6.18 \mathrm{~mol} \%)$. The containment material was Inconel and the stated alloy chemistry (15\% chromium, 7\% iron, balance nickel) would correspond to the present nomenclature of Inconel Alloy 600 (UNS N06600). Alloy 600 was not shown to have the required corrosion resistance. The work progressed to the study of nickel-molybdenum alloy chemistries Hastelloy B ${ }^{\circledR}$ (Ni-28 \% Mo-5\%Fe) and Hastelloy $\mathrm{W}^{\circledR}(\mathrm{Ni}-25 \% \mathrm{Mo}-5.5 \% \mathrm{Fe}-5 \%$ chromium) were also tested and showed good corrosion performance (Grimes et al. 1972). There were problems identified with fabricability of the Hastelloy B alloy and embrittlement of both alloys in the temperature range of $650^{\circ} \mathrm{C}$ to $815^{\circ} \mathrm{C}$ because of formation of nickel-molybdenum intermetallic compounds. The Hastelloy $\mathrm{B}^{\circledR}$ development has progressed to the development of the current Hastelloy B-3 ${ }^{\circledR}$ (UNS N10675) composition which has eliminated the fabrication issues observed in Hastelloy B such as weldability and reduction of precipitation of deleterious phases.

An alloy development program identified a molybdenum addition and a decreased chromium level as necessary attributes of an improved alloy, which resulted in the formulation and production of INOR-8 (17\% molybdenum, $7 \%$ chromium, $5 \%$ iron, $71 \%$ nickel). This composition is now designated as Alloy $\mathrm{N}$ (UNS N 10003). The early versions of this material may not have been optimized because of some of the melt practices in place at the time, but the Alloy $\mathrm{N}$ recently supplied by Haynes International was produced by a vacuum induction melting primary melt practice with secondary refining step using electroslag remelting (Mizia 2011). This melt and refining process will give a clean microstructure because of reduction of tramp elements that will cause development of deleterious second phases that reduce corrosion resistance and high temperature mechanical properties.

The fuel for the MSRE had the composition LiF-BeF $-\mathrm{ZrF}_{4}-\mathrm{UF}_{4}$ (64-30-5-1 mol \%). The general corrosion resistance of Alloy $\mathrm{N}$ was found to be acceptable during exposure in the MSRE. However, during post reactor operation inspection, it was found that Alloy $\mathrm{N}$ suffered radiation embrittlement from exposure to thermal neutrons and environmental (intergranular) cracking because of exposure to fission products where tellurium is the main embrittling element. To avoid these modes of degradation, investigations were performed that resulted in modifications to the basic Alloy $\mathrm{N}$ chemistry (Williams, Toth, and Clarno 2006). Titanium was added to improve the post irradiation creep properties and niobium was added for improved resistance.

It was found that alloying additions were partially effective. The extent of tellurium embrittlement can be reduced by controlling the molten salt oxidizing potential.

\subsubsection{Molten Salt Reactor Secondary System Materials}

The issues of radiation embrittlement and intergranular cracking will not be a major concern for the secondary loop, except where the primary to secondary heat transfer takes place. An issue will be the diffusion of tritium from the primary loop to the secondary loop. Tritium from the fission of the uranium and migrating to the salt can diffuse through the tube walls of the steam generator, resulting in tritium

contaminated water. This may result in worker exposure and create a waste management issue (Forsberg, 
Peterson, and Zhao 2004). This is also an issue with the very high temperature reactor (VHTR) and is presently being investigated. The molten salt coolants considered for use in (Oh 2009; Oh and Kim 2008; Oh, Kim, and Patterson 2011) the intermediate coolant loop are LiF-NaF-KF (FLiNaK), $\mathrm{KF}_{-2} \mathrm{ZF}_{4}$, and $\mathrm{KCl}-\mathrm{MgCl}_{2}$ (Sabharwall et al. 2011). The molten salt that will be evaluated for corrosion effects will be $\mathrm{KF}-\mathrm{ZrF}_{4}{ }^{\mathrm{c}}{ }^{\mathrm{A}} \mathrm{A}$ feature of molten fluoride salts is that they can easily dissolve passive oxide layers such as the chromia oxide film $\left(\mathrm{Cr}_{2} \mathrm{O}_{3}\right)$ that provides the corrosion resistance for stainless steels and nickel based alloys in many aqueous and high temperature environments. Moisture and oxide impurities in fluorides can cause corrosion (oxidation) of the metal alloy in the molten salt. The materials such as Alloy $\mathrm{N}$ that resist the molten salts will not have a chromia layer. However, not having a chromia layer leaves Alloy $\mathrm{N}$ vulnerable to the corrosive conditions on the secondary side such as supercritical steam. The secondary system will have to have an adequately corrosion resistant material for fabrication of heat exchangers that will transfer heat to other molten salt, helium, and supercritical fluid systems. A possible solution to this problem is bimetallic construction or the use of coatings. This idea will need further development.

Table 2-33 is a compilation of corrosion data on materials for molten salts without a uranium addition, which reflect choices for the secondary system. It generally shows that INOR-8 (Alloy N) is a suitable choice for theses salts; however, the table shows no data for KF-ZrF4. As an initial approximation, the data for $\mathrm{NaF}-\mathrm{Zr}_{4}$ could be used to recommend the choice of Alloy $\mathrm{N}$ in a corrosion testing program for $\mathrm{KF}-\mathrm{ZrF}_{4}$.

Table 2-33. Summary of corrosion testing results for salts without uranium.

\begin{tabular}{|c|c|c|c|c|c|c|}
\hline Loop \# & Alloy & Salt & $\begin{array}{l}\text { Duration } \\
\text { (h) }\end{array}$ & $\begin{array}{l}\mathrm{T}_{\max } \\
\left({ }^{\circ} \mathrm{C}\right)\end{array}$ & $\begin{array}{l}\text { Corrosion } \\
\text { Depth } \\
(\mathrm{mm})\end{array}$ & $\begin{array}{c}\text { ORNL } \\
\text { (Report \# or } \\
\text { Reference) }\end{array}$ \\
\hline 116 & $316 \mathrm{SS}$ & FLiNaK & 500 & 815 & 4 & 1294 \\
\hline 119 & $316 \mathrm{SS}$ & $\mathrm{FLiNaK}+\mathrm{NaK}$ & 500 & 815 & 2 & 1294 \\
\hline 347 & Inconel & $50 \mathrm{NaF}-50 \mathrm{ZrF}_{4}$ & 3000 & 815 & 11 & 1692 \\
\hline 518 & Inconel & $\mathrm{NaF}-\mathrm{ZrF}_{4}$ & 3000 & 815 & 11 & 2338 \\
\hline 346 & Inconel & $50 \mathrm{NaF}-50 \mathrm{ZrF}_{4}$ & 2000 & 815 & 9 & 1692 \\
\hline 519 & Inconel & $\mathrm{NaF}-\mathrm{ZrF}_{4}$ & 2000 & 815 & 12.5 & 1692 \\
\hline \multirow[t]{2}{*}{78} & Inconel & FLiNaK & 1000 & 815 & 13 & 1294,2337 \\
\hline & Inconel & $\mathrm{NaF}-\mathrm{ZrF}_{4}$ & 1000 & 815 & 3 & {$[76]$} \\
\hline 278 & Inconel & $\mathrm{NaF}-\mathrm{ZrF}_{4}$ & 1000 & 815 & 5 & 2338 \\
\hline \multirow[t]{7}{*}{399} & Inconel & $\mathrm{NaF}-\mathrm{ZrF}_{4}$ & 1000 & 815 & 10 & 2338 \\
\hline & Inconel & $60 \mathrm{NaF}-40 \mathrm{ZrF}_{4}$ & 1000 & 815 & 5 & $C F-57-9-35$ \\
\hline & Inconel & $50 \mathrm{NaF}-5 \mathrm{OBe}_{2}$ & 1000 & 815 & 8 & $C F-57-9-35$ \\
\hline & Inconel & $70 \mathrm{NaF}-30 \mathrm{BeF}_{2}$ & 1000 & 815 & 6 & $C F-57-9-35$ \\
\hline & Inconel & $24 \mathrm{LiF}-53 \mathrm{NaF}-23 \mathrm{BeF}_{2}$ & 1000 & 815 & 5 & $C F-57-9-35$ \\
\hline & Inconel & $36 \mathrm{LiF}-49 \mathrm{NaF}-15 \mathrm{BeF}_{2}$ & 1000 & 815 & 3 & $C F-57-9-35$ \\
\hline & Inconel & $74 \mathrm{LiF}-26 \mathrm{ThF}_{4}$ & 1000 & 815 & 6 & $C F-57-9-35$ \\
\hline 517 & Inconel & $\mathrm{NaF}-\mathrm{ZrF}_{4}$ & 822 & 815 & 5.5 & 2338 \\
\hline 337 & Inconel & $\mathrm{NaF}-\mathrm{ZrF}_{4}$ & 575 & 815 & 8 & 2338 \\
\hline 214 & Inconel & $\mathrm{FLiNaK}+\mathrm{NaK}$ & 500 & 815 & 3 & 1294 \\
\hline 230 & Inconel & $36 \mathrm{NaF}-18 \mathrm{KF}-46 \mathrm{ZrF}_{4}$ & 500 & 815 & 10 & 1375 \\
\hline \multirow[t]{2}{*}{348} & Inconel & $50 \mathrm{NaF}-50 \mathrm{ZrF}_{4}$ & 500 & 815 & 5.5 & 1692 \\
\hline & Inconel & FLiNaK & 500 & 815 & 7 & 1816 \\
\hline
\end{tabular}

c Personal Communication, Piyush Sabharwall to R.E. Mizia, 08-22-11. 


\begin{tabular}{|c|c|c|c|c|c|c|}
\hline Loop \# & Alloy & Salt & $\begin{array}{c}\text { Duration } \\
\text { (h) }\end{array}$ & $\begin{array}{l}\mathrm{T}_{\max } \\
\left({ }^{\circ} \mathrm{C}\right)\end{array}$ & $\begin{array}{l}\text { Corrosion } \\
\text { Depth } \\
\text { (mm) }\end{array}$ & $\begin{array}{c}\text { ORNL } \\
\text { (Report \# or } \\
\text { Reference) }\end{array}$ \\
\hline 934 & Inconel & $60 \mathrm{NaF}-40 \mathrm{ZrF}_{4}$ & 500 & 815 & 5 & 2157 \\
\hline \multirow[t]{3}{*}{935} & Inconel & $60 \mathrm{NaF}-40 \mathrm{ZrF}_{4}$ & 500 & 815 & 5 & 2157 \\
\hline & Inconel & $\mathrm{NaF}-\mathrm{BeF}_{2}$ & 500 & 815 & 10 & {$[76]$} \\
\hline & Inconel & $\mathrm{LiF}-\mathrm{NaF}-\mathrm{BeF}_{2}$ & 500 & 815 & 5 & {$[76]$} \\
\hline 246 & Inconel & $52 \mathrm{NaF}-48 \mathrm{ZrF}_{4}$ & 500 & 815 & 8 & 2337 \\
\hline 262 & Inconel & $57 \mathrm{NaF}-43 \mathrm{BeF}_{2}$ & 500 & 815 & 9 & 2337 \\
\hline 277 & Inconel & $50 \mathrm{NaF}-50 \mathrm{ZrF}_{4}$ & 500 & 815 & 5 & 2337 \\
\hline 276 & Inconel & $\mathrm{NaF}-\mathrm{ZrF}_{4}$ & 500 & 815 & 8 & 2338 \\
\hline 277 & Inconel & $\mathrm{NaF}-\mathrm{ZrF} \mathrm{F}_{4}$ & 500 & 815 & 4 & 2338 \\
\hline 336 & Inconel & $\mathrm{NaF}-\mathrm{ZrF}_{4}$ & 500 & 815 & 6 & 2338 \\
\hline 341 & Inconel & $\mathrm{NaF}-\mathrm{ZrF}_{4}$ & 500 & 815 & 5.5 & 2338 \\
\hline 342 & Inconel & $\mathrm{NaF}-\mathrm{ZrF}_{4}$ & 500 & 815 & 6 & 2338 \\
\hline 516 & Inconel & $\mathrm{NaF}-\mathrm{ZrF} \mathrm{F}_{4}$ & 500 & 815 & 6 & 2338 \\
\hline 338 & Inconel & $\mathrm{NaF}-\mathrm{ZrF}_{4}$ & 500 & 815 & 6 & 2338 \\
\hline 411 & Inconel & $\mathrm{NaF}-\mathrm{ZrF} \mathrm{F}_{4}$ & 250 & 815 & 4.5 & 2338 \\
\hline 410 & Inconel & $\mathrm{NaF}-\mathrm{ZrF} \mathrm{F}_{4}$ & 100 & 815 & 4 & 2338 \\
\hline 400 & Inconel & $\mathrm{NaF}-\mathrm{ZrF}_{4}$ & 50 & 815 & 3 & 2338 \\
\hline 1181 & Inconel & 71LiF-29 $\mathrm{ThF}_{4}$ & 8760 & 732 & 6.5 & 2684 \\
\hline 1239 & Inconel & $71 \mathrm{LiF}-16 \mathrm{BeF}_{2}-13 \mathrm{ThF}_{4}$ & 8760 & 732 & 7.5 & 2973 \\
\hline $9377-6$ & Inconel & $71 \mathrm{LiF}-16 \mathrm{BeF}_{2} 13 \mathrm{ThF}_{4}$ & 13155 & 704 & 13 & 3215 \\
\hline 1188 & Inconel & $35 \mathrm{LiF}-27 \mathrm{NaF}-38 \mathrm{BeF}_{2}$ & 8760 & 677 & 9 & 2723 \\
\hline 1210 & Inconel & 71LiF-29ThF 4 & 8760 & 677 & 5 & 2799 \\
\hline 1235 & Inconel & $71 \mathrm{LiF}-16 \mathrm{BeF}_{2}-13 \mathrm{ThF}_{4}$ & 7789 & 677 & 4 & 2973 \\
\hline 1214 & Inconel & FLiNaK & 4673 & 677 & 13 & 2684 \\
\hline 1169 & Inconel & 71LiF-29 $\mathrm{ThF}_{4}$ & 1000 & 677 & 1 & 2474 \\
\hline 1177 & Inconel & 71LiF-29ThF 4 & 1000 & 677 & 1.5 & 2474 \\
\hline 1173 & Inconel & $58 \mathrm{NaF}-35 \mathrm{BeF}_{2}-7 \mathrm{ThF}_{4}$ & 1000 & 677 & 4 & 2474 \\
\hline 1176 & Inconel & $58 \mathrm{LiF}-35 \mathrm{BeF}_{2}-7 \mathrm{ThF}_{4}$ & 1000 & 677 & 1 & 2474 \\
\hline 1234 & Inconel & $71 \mathrm{LiF}-16 \mathrm{BeF}_{2}-13 \mathrm{ThF}_{4}$ & 1000 & 677 & 1 & 2799 \\
\hline $9344-2$ & Inconel & FLiNaK & 8760 & 649 & 8 & 2890 \\
\hline $9344-2$ & Inconel & FLiNaK & 8735 & 649 & 8 & 3215 \\
\hline 1172 & Inconel & $35 \mathrm{LiF}-27 \mathrm{NaF}-38 \mathrm{BeF}_{2}$ & 1000 & 607 & 2 & 2474 \\
\hline 1175 & Inconel & FLiNaK & 1000 & 607 & 1 & 2474 \\
\hline LDRD & INOR-8 & FLiNaK & 3048 & 815 & 0.1 & {$[77]$} \\
\hline 1209 & INOR-8 & 71LiF-29ThF 4 & 8760 & 732 & 0 & 2799 \\
\hline 1216 & INOR-8 & $58 \mathrm{LiF}-35 \mathrm{BeF}_{2}-7 \mathrm{ThF}_{4}$ & 8760 & 732 & 1 & 2973 \\
\hline 1240 & INOR-8 & $71 \mathrm{LiF}-16 \mathrm{BeF}_{2}-13 \mathrm{ThF}_{4}$ & 8760 & 732 & 0 & 2973 \\
\hline MSRP7 & INOR-8 & $71 \mathrm{LiF}-16 \mathrm{BeF}_{2}-13 \mathrm{ThF}_{4}$ & 20000 & 704 & 1 & 3215 \\
\hline MSRP8 & INOR-8 & $58 \mathrm{LiF}-35 \mathrm{BeF}_{2}-7 \mathrm{ThF}_{4}$ & 9633 & 704 & 0 & 3215 \\
\hline $15 \mathrm{~A}$ & INOR-8 & $73 \mathrm{LiF}-2 \mathrm{BeF}_{2}-25 \mathrm{ThF}_{4}$ & 39476 & 677 & 0.05 & $T M-4286$ \\
\hline 1208 & INOR-8 & FLiNaK & 8760 & 677 & 1 & 2799 \\
\hline
\end{tabular}




\begin{tabular}{|c|c|c|c|c|c|c|}
\hline Loop \# & Alloy & Salt & $\begin{array}{c}\text { Duration } \\
\text { (h) }\end{array}$ & $\begin{array}{l}\mathrm{T}_{\max } \\
\left({ }^{\circ} \mathrm{C}\right)\end{array}$ & $\begin{array}{l}\text { Corrosion } \\
\text { Depth } \\
(\mathrm{mm})\end{array}$ & $\begin{array}{c}\text { ORNL } \\
\text { (Report \# or } \\
\text { Reference) }\end{array}$ \\
\hline 1190 & INOR-8 & $58 \mathrm{NaF}-35 \mathrm{BeF}_{2}-7 \mathrm{ThF}_{4}$ & 8760 & 677 & 1 & 2799 \\
\hline 1233 & INOR-8 & $71 \mathrm{LiF}-16 \mathrm{BeF}_{2}-13 \mathrm{ThF}_{4}$ & 8760 & 677 & 0 & 2973 \\
\hline 1213 & INOR-8 & 71LiF-29ThF 4 & 3114 & 677 & 0 & 2626 \\
\hline 15 & INOR-8 & $73 \mathrm{LiF}-2 \mathrm{BeF}_{2}-25 \mathrm{ThF}_{4}$ & 2003 & 677 & 0 & $T M-4286$ \\
\hline 1165 & INOR-8 & FLiNaK & 1340 & 677 & 0 & 2551 \\
\hline 1164 & INOR-8 & $58 \mathrm{NaF}-35 \mathrm{BeF}_{2}-7 \mathrm{ThF}_{4}$ & 1000 & 677 & 0 & 2551 \\
\hline 1221 & INOR-8 & 71LiF-29ThF 4 & 1000 & 677 & 0 & 2626 \\
\hline 1228 & INOR-8 & $71 \mathrm{LiF}-16 \mathrm{BeF}_{2}-13 \mathrm{ThF}_{4}$ & 1000 & 677 & 0 & 2723 \\
\hline MSRE & INOR-8 & $67 \mathrm{LiF}-33 \mathrm{BeF}_{2}$ & 26000 & 649 & 0 & $T M-4174$ \\
\hline $9354-3$ & INOR-8 & $35 \mathrm{LiF}-27 \mathrm{NaF}-38 \mathrm{BeF}_{2}$ & 19942 & 649 & 0 & 3215 \\
\hline 1194 & INOR-8 & FLiNaK & 1000 & 607 & 0 & 2551 \\
\hline 1195 & INOR-8 & $35 \mathrm{LiF}-27 \mathrm{NaF}-28 \mathrm{BeF}_{2}$ & 1000 & 607 & 0 & 2551 \\
\hline
\end{tabular}

\subsubsection{ASME B\&PV Acceptance (Section III, Section VIII, and Section IX) (Jetter 2011)}

This section will briefly discuss the requirements for an American Society of Mechanical Engineers ASME BPV Code, Section III nuclear code designed IHX used as a transfer heat from the primary (reactor side) heat transport system to the secondary heat transport system. Our focus will be on the Section VIII requirements of the SHX designed to the requirements of ASME Section VIII, which will transfer this heat to downstream applications such as hydrogen production, process heat, and electricity generation. Sections III and VIII have subtier documents with specific scope and applicability. Each of these subtier documents has its own unique features with respect to design rules and their implementation.

Section III covers all phases of construction, which are defined as materials, design, fabrication, installation, examination, testing, over pressure protection, name plates, stamping, and reports. Section III also provides rules for different classes of components, depending upon their safety significance; Class 1 being the most significant, followed by Class 2 and Class 3. In the new Section III Div. 5 for high temperature reactors such as the AHTR, Class 1 corresponds to Class A and Class 2 corresponds to Class B. The IHX in the AHTR would be considered Class 1.

At temperatures below the creep range, the rules for Class 1 construction are in Subsection NB. At elevated temperatures, where creep is (or might be) significant, the rules for Class 1 construction, including vessels, pumps, valves, and piping, are in Subsection NH. The upper temperature limit for Subsection NB is $700^{\circ} \mathrm{F}$ for ferritic materials such as $2.25 \mathrm{Cr}-1 \mathrm{Mo}$ and $800^{\circ} \mathrm{F}$ for austenitic materials such as 316 stainless steel. Above these temperatures, Subsection NH applies for Class 1 components.

The allowable stress values $\left(\mathrm{S}_{\mathrm{m}}\right)$ for NB are in Table 2 of Section II Part D of the ASME BPV Code. The allowable stresses for Subsection NH are in an appendix to Subsection NH. There are many material choices for Subsection NB construction. The only currently approved materials for Subsection NH construction are 304 and 316 stainless steels, Alloy 800H, 2.25 Cr-1Mo Grade 22 Class 1, and 9 Cr-1MoV Grade 91.

Section VIII has three divisions: Div. 1, 2, and 3. Section VIII, Div. 1 is the classical, long standing code used for vessels that neither fall under the auspices of Section III nor fired power boilers covered in Section I. Section VIII Div, 1 covers all aspects of construction, but only applies to vessels. The SHX 
would fall under Section VIII. Many Section VIII vessels, mostly Div. 1, are used in the petrochemical industry, but the use of Div. 2 vessels is increasing to take advantage of the higher allowable stress values for some materials.

Section VIII Div. 1 covers the temperature range from cryogenic to very high creep temperatures. The design approach for Div. 1 is referred to as design-by-rule, wherein formulas are provided to calculate required wall thicknesses based on the allowable stress, loading, and pertinent geometric parameters for the particular shape under consideration. There are no rules in Div. 1 to assess cyclic life and fatigue, but it is assumed that for many configurations, fatigue will not be critical for modest cyclic service.

The allowable stress criteria for Section VIII Div. 1 are equal to or more conservative than allowable stress criteria for Class 1 Subsection NB components below the creep regime. In the creep regime, the allowable stress criteria for Section VIII Div. 1 is the lesser of $2 / 3$ of the average ${ }^{\mathrm{d}}$ or $80 \%$ of the minimum creep rupture strength in 100,000 hours or $100 \%$ of the average stress to produce a creep rate of $0.01 \% / 1,000$ hours. Nominally, for many materials, it is the minimum creep rupture strength that governs the allowable stress in the creep regime. Thus, at 100,000 hours, the allowable stress in Section III, Subsection NH will be a factor of $(2 / 3) /(0.8)$ or 0.83 lower than the corresponding allowable stress in Section VIII Div. 1. However, this difference is tempered by the observation that the Section VIII Div. 1 allowable stress is applied to design conditions while the $\mathrm{NH}$ allowable stress is applied to the lower service level conditions.

Section VIII Div. 2 more closely aligns with Section III Subsection NB for Class 1 components although Div. 2 only covers vessels. Div. 2 provides two routes for design; design-by-analysis similar to Subsection NB, and design by rule similar to Div. 1. However, even when using the design-by-rule procedures, the fatigue life must be considered explicitly. This can be accomplished by using the designby-analysis rules or by meeting certain screening criteria.

Section VIII Div. 3 is specifically for very high pressure service. A key feature of Div. 3 is that the allowable stress is limited to $2 / 3$ of the yield strength without any limit on the tensile strength. However, except as discussed below, the maximum design temperature is limited to the traditional 700 and $800^{\circ} \mathrm{F}$ or lower. The exception is A-286, which is limited to $900^{\circ} \mathrm{F}$ for Section VIII Div. 3 construction.

\subsubsection{Fabrication of Heat Exchangers}

\subsubsection{Diffusion Welding}

Diffusion welding is an ancient welding process; in its modern technical incarnation, it has been in use for many decades, joining modern materials such as stainless steels, titanium alloys, and iron-, nickel-, and cobalt-based superalloys (AWS 2007a).

\section{Principles}

If atomically clean, perfectly flat metallic surfaces were brought into close contact, the valence electrons of the separate pieces would interact, and, subject to crystallographic constraints, would instantly form a single crystal or a grain boundary at room temperature. This would be an ideal weld, producing one piece from two with no application of heat.

In the real world at macro scales, surfaces are typically rough on the atomic scale (are said to contain asperities) and very seldom atomically clean (being typically covered by oxide layers or adsorbed material), and it is only with the aid of diffusion that useful welds can be formed. With the application of pressure (not enough to cause macro deformation), the asperities are deformed, and metal-to-metal atomic

d. The average value of the creep rupture strength is obtained from a best fit model correlation of the data. 
contact is achieved as surface contaminants are displaced. Over time, the surface contaminants diffuse away through the microstructure, and since diffusion is a strong function of temperature, the production of welds in realistic times requires elevated temperatures, typically in excess of $60 \%$ of the melting temperature $\left(>0.6 \mathrm{~T}_{\mathrm{M}}\right)$, often within $100-200^{\circ} \mathrm{C}$ of the melting range. The process is illustrated in Figure 2-1.

Diffusion welding is a relatively capital-intensive, high-precision process that is used mainly for high value-added parts; clean, precision surfaces are required, and in order to properly align the workpieces, extensive fixturing is typical. Vacuum or inert atmospheres are required to avoid oxidation at the high temperatures needed for rapid diffusion. Diffusion welding cycles are long, often measured in hours.

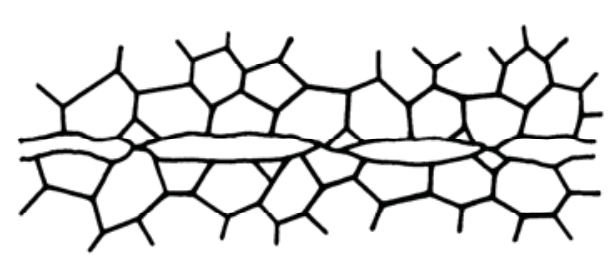

Initial Asperity Contact

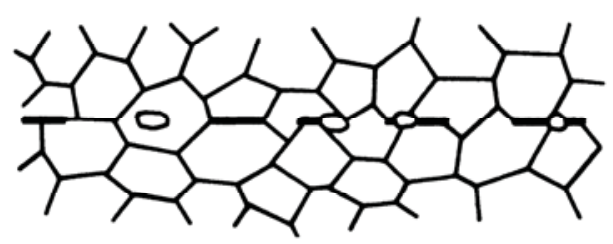

(B) Second Stage-Grain Boundary Migration and Pore Elimination

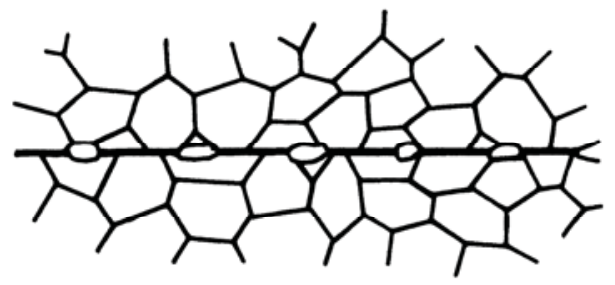

(A) First Stage-Deformation and Interfacial Boundary Formation

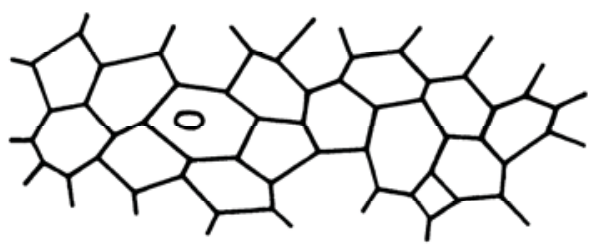

(C) Third Stage-Volume Diffusion Pore Elimination

Figure 2-1. Diffusion welding process (AWS 2007b).

\section{Applications}

Diffusion welding is extensively used in the aerospace industry (AWS 2007a). It is especially suited to joining metals that have high solubilities for their own oxides, such as copper and titanium alloys. It can also join the chromium-containing alloys typically used for high temperature service in oxidizing environments, or in other aggressive corrosion applications; in this case the chromium oxide that is responsible for the alloys' usefulness must be overcome in the diffusion welding process, and various methods have been developed for promoting this.

\section{Applicability to Compact Heat Exchangers}

Compact heat exchangers are an excellent candidate for diffusion welding, and in fact are made in this way for current applications at lower temperatures (AWS 2007c \& d). It is suitable for welding a fairly thick stack (many inches) of sheet material in which fluid flow passages have been machined or etched. Stainless steel compact heat exchangers - thick stacks of channeled sheet material — for use at temperatures below $600^{\circ} \mathrm{C}$ have been constructed in this way.

The present work is addressing several extensions of these issues, including the diffusion welding of alloys suitable for heat exchangers with different working fluids (molten salts, helium, water/steam), implications of the diffusion welding of dissimilar alloys, and exposure of diffusion welds to the anticipated heat transfer media to develop an approach to extending the service life of actual components. 


\section{Experimental Approach}

Diffusion welding typically requires a vacuum hot press or Hot Isostatic Press (HIP) large enough for the anticipated components being welded. Compact heat exchangers may be up to $0.5 \mathrm{~m}$ in size, or composed of subunits of that size. The Gleeble ${ }^{\circledR}$ (AWS 2007e) a high temperature thermomechanical testing machine, was used for applying the appropriate time, temperature, and pressure cycles to explore alloys of interest, including Alloys $617,800 \mathrm{H}$, and $\mathrm{N}$. The Gleeble is capable of diffusion welding parts with a final size of up to 6 inches in length and 1 inch in diameter; a typical welded specimen is 0.5 in. in diameter and 6 in. long, suitable for tensile testing, metallographic examination, and exposure in environmental test loops. Figure 2-2 shows such a specimen during diffusion welding.

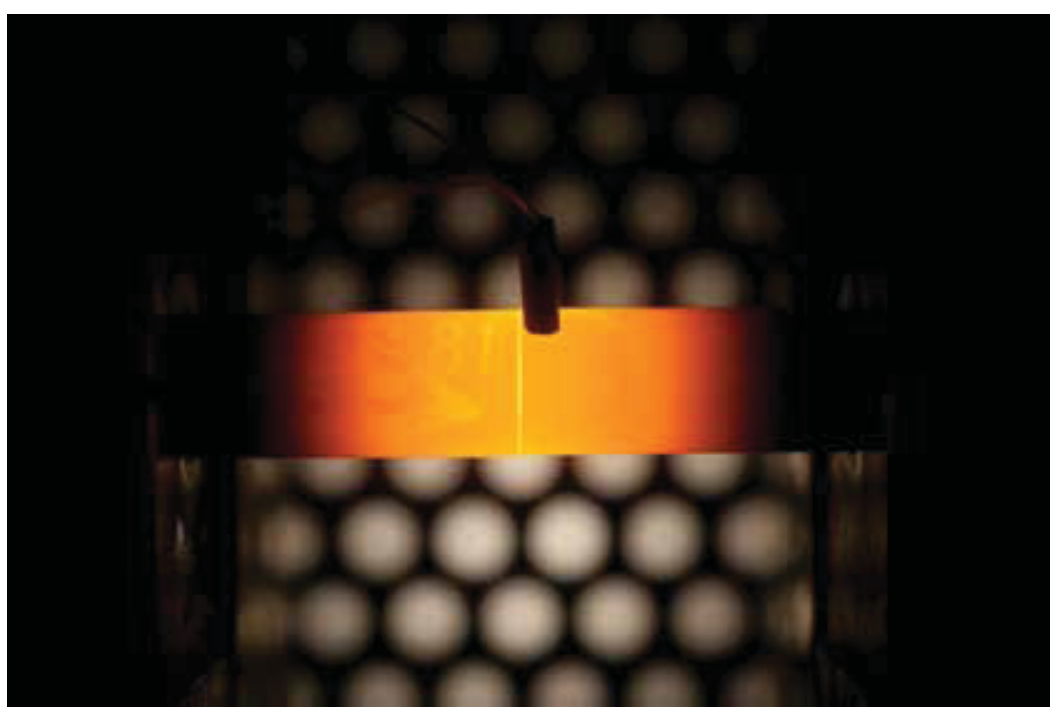

Figure 2-2. Diffusion weld in progress.

\section{Parameter Development}

Although diffusion welding fairly well covered in literature, specific recipes for welding given alloys in a given geometry still require some trial and error. Time, temperature, and pressure are critical parameters, as are the particular surface preparation and condition at the start of welding.

\section{Time, Temperature, and Pressure}

An extensive test matrix was developed for Alloy $800 \mathrm{H}$, involving times of $1,1.5,3,5$, and 7 hours and temperatures of 1000 to $1150^{\circ} \mathrm{C}$. It rapidly became apparent, from both metallographic examination and tensile testing, that temperatures from 1000 to $1100^{\circ} \mathrm{C}$ produced unreliable results, as did times of 1 and 1.5 hours. The "standard conditions" for diffusion welding thus became 3 hours at $1150^{\circ} \mathrm{C}$.

Previous INL experience with diffusion welding of Alloy 617 in the Gleeble suggest that a pressure of 3 to $5 \mathrm{MPa}$ was sufficient to promote intimate contact at the surfaces being joined, but not so much as to produce macroscopic creep. This was the goal, though pressures of 3 to $7 \mathrm{MPa}$ were finally used.

A typical diffusion weld microstructure is shown in Figure 2-3. 


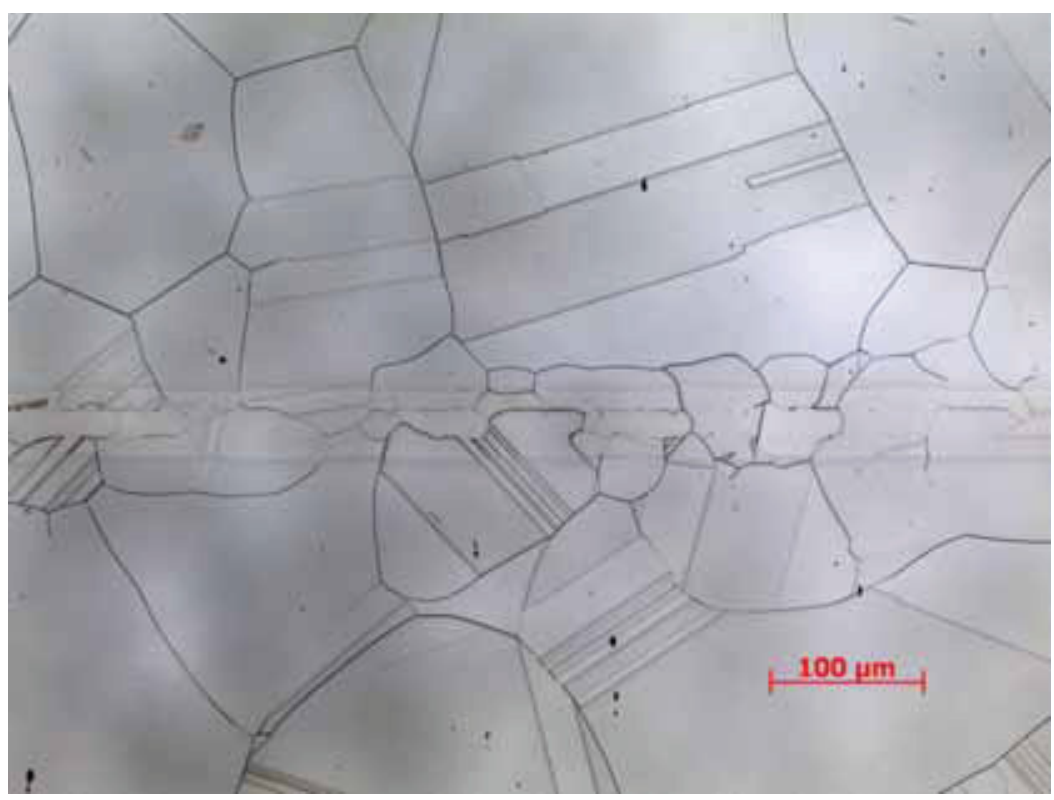

Figure 2-3. Optical micrograph of diffusion weld interface.

\section{Surface Preparation}

A standard metallographic grind of 600 grit was chosen for preparing the ends of the cylindrical specimens. All the alloys of interest here are alloyed with chromium for oxidation resistance; a chromium oxide forms almost instantly on any fresh surface. Electroplating about $0.5 \mu \mathrm{m}$ of nickel on the surfaces after the oxide was reduced in the electroplating bath meant that only pure nickel was exposed to the air; it does not form an oxide as chromium does, diffuses away fairly quickly at elevated temperatures, and is compatible with the nickel based alloys used here.

\section{Interlayer}

A filler metal or interlayer is sometimes used in diffusion welding because it fills in asperities and improves the macro-scale fitup of the joint. Depending on the material chosen, diffusion can be enhanced. The technique of "transient liquid phase bonding" is an extension of this, where a thin interlayer, often containing boron, actually melts at the diffusion temperature, then re-solidifies as the readily-diffusible boron diffuses away.

In the present work, nickel foil either 5 or $15 \mu \mathrm{m}$ thick was used as an interlayer on some joints. The electron backscatter diffraction (EBSD) image in Figure 2-4 shows that grain growth has crossed the prior interface through the $15 \mu \mathrm{m}$ foil, essentially forming a monolithic work piece. 


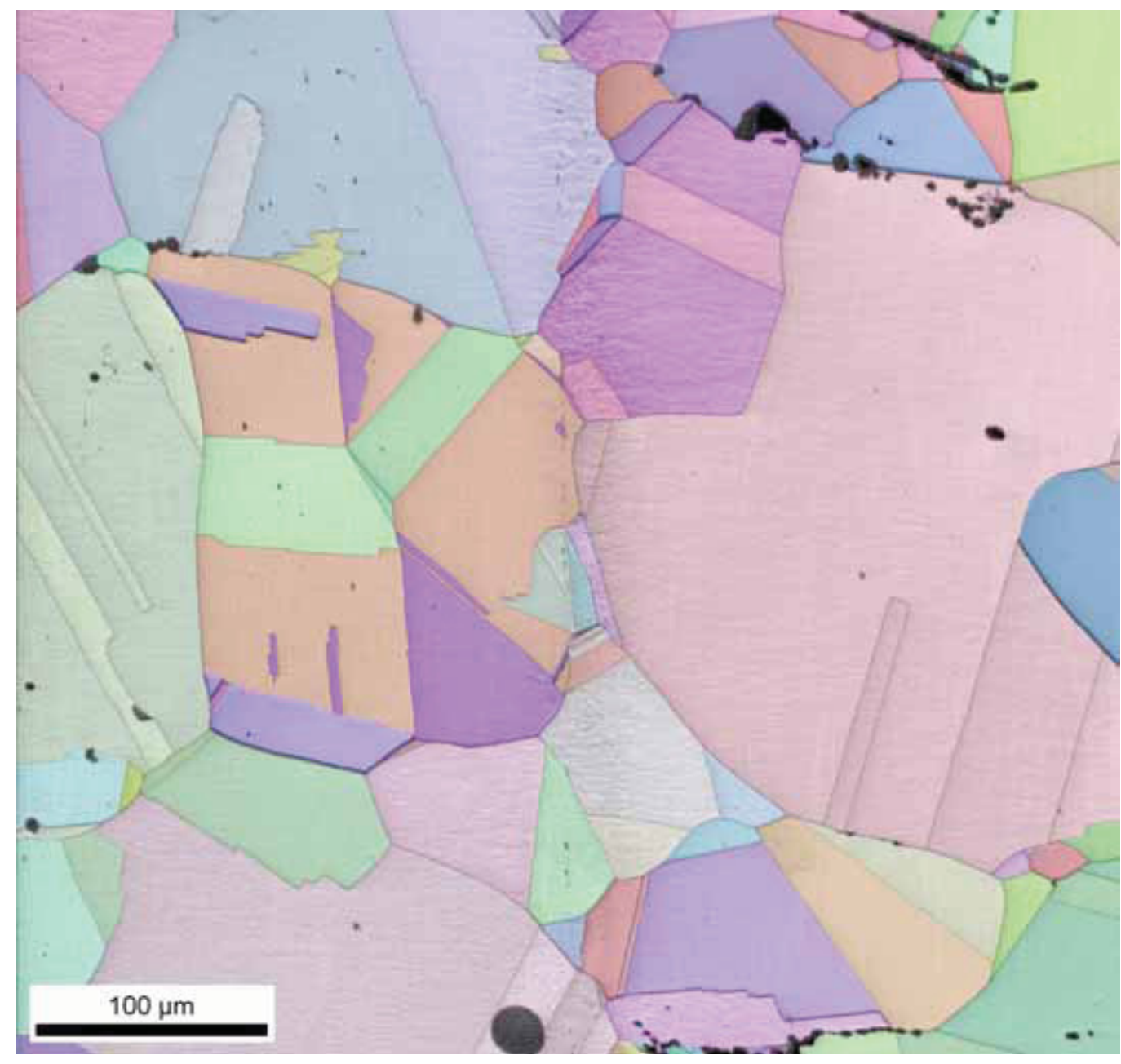

Figure 2-4. EBSD image of diffusion welded joint in Alloy N, showing grain growth through $15 \mu \mathrm{m}$ nickel foil (joint is vertical near image center).

\section{Vacuum Hot Press}

It was recognized that parts with a greater than $1 \mathrm{in}$. diameter must be produced to actually fabricate compact heat exchangers and to meet code requirements for qualifying the process for materials of interest. To that end, a contract was established with Oregon State University, which has the capability and experience to diffusion weld parts with up to a $3 \mathrm{in.}$ in diameter and several inches high.

\subsubsection{Brazing}

Brazing is the permanent joining of two base metals (either similar or dissimilar) with a braze alloy that has a melting point lower than those of the base metals. Brazing is a joining process where a metallic filler material is heated to melting temperature and distributed between closely fitted surfaces to be joined by capillary action. The filler metal must have a lower melting temperature than the parent material. The requirements for a successful fabrication of a brazed joint are that the braze metal or alloy must melt and flow over the surfaces of the components to be joined, form a fillet or fill a narrow gap between the components, and then form a permanent bond by remaining adherent while solidifying. 
Brazing has the following advantages in the joining area (ASM 1983):

- Economical fabrication of complex and multi-component assemblies

- Simple method to obtain extensive joint area or joint length

- Joint temperature capability approaching that of base metal

- Excellent stress distribution and heat-transfer properties

- Ability to preserve protective metal coating or cladding

- Ability to join cast materials to wrought metals

- Ability to join nonmetals to metals

- Ability to join metal thicknesses that vary widely in size

- Ability to join dissimilar metals

- Ability to join porous metal components

- Ability to fabricate large assemblies in a stress-free condition

- Ability to preserve special metallurgical characteristics of metals

- Ability to join fiber- and dispersion-strengthened composites

- Capability for precision production tolerance

- Reproducible and reliable quality control techniques.

An example of the use of brazing for a secondary heat exchanger application is the assembly of a plate fin heat exchanger, which is made by stacking and brazing corrugated sheets (fins) onto flat, separation sheets. This separation sheet is usually an alloy clad with the brazing filler metal, which will melt at a lower temperature than the parent alloy during the brazing process. The heat exchanger is assembled from the stacked sheets, which are fixtured in a vacuum furnace that has ram capability (compressive force) to keep the individual pieces in contact.

The strength and corrosion resistance of the brazed joint must be considered for an SHX. Brazing can cause partial dissolution of the base metal, which will combine with the different composition of the brazing alloy, resulting in diffusion processes that can change the chemical composition at the boundary zone, resulting in phases with differing physical and mechanical properties. A metallurgically complex transitional zone could also be present. In general, the brazed joint strength is high where the nature of the metallic bond will result in strength equal to or greater than that of the as-brazed parent metal. For long term service, the joint assembly will have to be evaluated for resistance to corrosion from the molten salt and the effects of long term aging.

The braze alloy for Alloy N (the chosen alloy for secondary heat exchanger applications) will likely be nickel-base with elements that depress the melting temperature or the brazing alloy such as silicon and phosphorus. Alloy N, was found to have excellent wetting and spreading characteristics in nickelphosphorus brazes (Ambrose et al. 1990). This attribute will allow the braze material to easily fill the brazed joint.

A review paper on the corrosion resistance of brazed joints of Alloy $\mathrm{N}$ to a molten fluoride salt $\left(\mathrm{NaBF}_{4}-8\right.$ Mole Percent NaF) was published by ORNL (Kroger 1972). The tests were performed at $610^{\circ} \mathrm{C}$ in nickel containers. The chemistries of the brazing alloys used in the study are given in Table 2-34. 
Table 2-34. Braze alloys, brazing temperature, and composition.

\begin{tabular}{|c|c|c|c|c|c|c|c|c|c|c|c|c|}
\hline \multirow[b]{2}{*}{ No. } & \multirow[b]{2}{*}{$\begin{array}{l}\text { AWS }- \text { ASTM } \\
\text { classification }\end{array}$} & \multirow{2}{*}{$\begin{array}{c}\text { Brazing } \\
\text { Temperature } \\
\left({ }^{\circ} \mathrm{C}\right)\end{array}$} & \multicolumn{10}{|c|}{ Composition (wt \%) } \\
\hline & & & $\mathrm{Cr}$ & $\mathrm{Fe}$ & $\mathrm{Ni}$ & $\mathrm{P}$ & $\mathrm{C}$ & $\mathrm{Si}$ & $\mathrm{B}$ & $\mathrm{Au}$ & $\mathrm{Cu}$ & $\mathrm{Ag}$ \\
\hline 1 & $\mathrm{BNi}-7$ & 1010 & 13 & & 76.85 & 10 & 0.15 & & & & & \\
\hline 2 & $\mathrm{BNi}-3$ & 1040 & & 3.5 & 89.1 & & & 4.5 & 2.9 & & & \\
\hline 3 & $\mathrm{BAu}-4$ & 1010 & & & 18 & & & & & 82 & & \\
\hline 4 & BAg-8 & 816 & & & & & & & & & 28 & 72 \\
\hline 5 & $\mathrm{BNi}-4$ & 1040 & & & 92.35 & & 0.15 & 4.5 & 3 & & & \\
\hline 6 & $\mathrm{BCu}$ & 1125 & & & & & & & & & 100 & \\
\hline 7 & $\mathrm{BNi}-2^{\mathrm{b}}$ & 1030 & 7 & 3.5 & 82.1 & & & 4.5 & 2.9 & & & \\
\hline 8 & $\mathrm{BNi}-2^{\mathrm{b}}$ & 1040 & 6.5 & 2.5 & 83.35 & & 0.15 & 4.5 & 3 & & & \\
\hline
\end{tabular}

BNi-3 braze alloy was the least corrosion resistant, while $\mathrm{BAg}-8$ and $\mathrm{BCu}$ were the most corrosion resistant. It was concluded that all the braze alloys listed in Table 2-34 were compatible with $\mathrm{NaBF}_{4}-8 \mathrm{~mol} \% \mathrm{NaF}$ at $610^{\circ} \mathrm{C}$.

Another reference (MacPherson 1964) showed results of the exposure of various brazing alloys to a $\mathrm{NaF}-40 \mathrm{~mol} \% \mathrm{ZrF}_{4}-6.5 \mathrm{~mol}^{\circ} \mathrm{UF}_{4}$ at $816^{\circ} \mathrm{C}$. The data shows that the $\mathrm{BCu}, \mathrm{BAu} 4,60 \mathrm{Pd}-40 \mathrm{Ni}, \mathrm{MNi}-3$, BNi-1, and BNi-7 braze alloys would be acceptable for service in the stated conditions.

The available data shows that wetting and spreading ability of Alloy $\mathrm{N}$ with various brazing materials will allow the fabrication of high quality brazed joints. No data was found on the corrosion resistance of various brazing materials to $\mathrm{KF}-\mathrm{ZrF}_{4}$ at $610^{\circ} \mathrm{C}$. However, the available data in other molten fluoride salts suggest that brazing materials that show reasonable corrosion resistance to $\mathrm{KF}^{-} \mathrm{ZrF}_{4}$ is possible.

\subsubsection{Thermodynamic and Kinetic Modeling of Diffusion Welding}

The diffusion welding process can be thermodynamically modeled for metallurgical phase formation at different temperature by the use of ThermoCalc ${ }^{\mathbb{R}}$ and for the diffusion of base metal and welding filler metal elements in the joint by Dictra ${ }^{\circledR}$. The modeling these joints was followed by experimental verification to identify the appropriate diffusion welding parameters. 


\section{Diffusion of Interlayer}

The best results for the diffusion welding of Alloy $800 \mathrm{H}$ were obtained by using a nickel filler metal of electroplated nickel or an insert of $15 \mu \mathrm{M}$ nickel foil (Mizia, R.E, et al, $2010^{\mathrm{e}}$ and Mizia, R.E. et al, $2011^{\mathrm{f}}$ )The $0.5 \mu \mathrm{m}$ nickel electroplating is too thin to resolve in the SEM for quantitative EDS analysis of diffusion. The $15 \mu \mathrm{m}$ foil, however, allows this kind of analysis for model verification. Figure 2-5 shows a diffusion welded joint with a $15 \mu \mathrm{m}$ nickel foil interlayer, and the resulting experimental and modeled composition profiles for elements of interest. It can be seen that the model produced results within 1 to $2 \mathrm{wt} \%$ of the experimentally determined values.

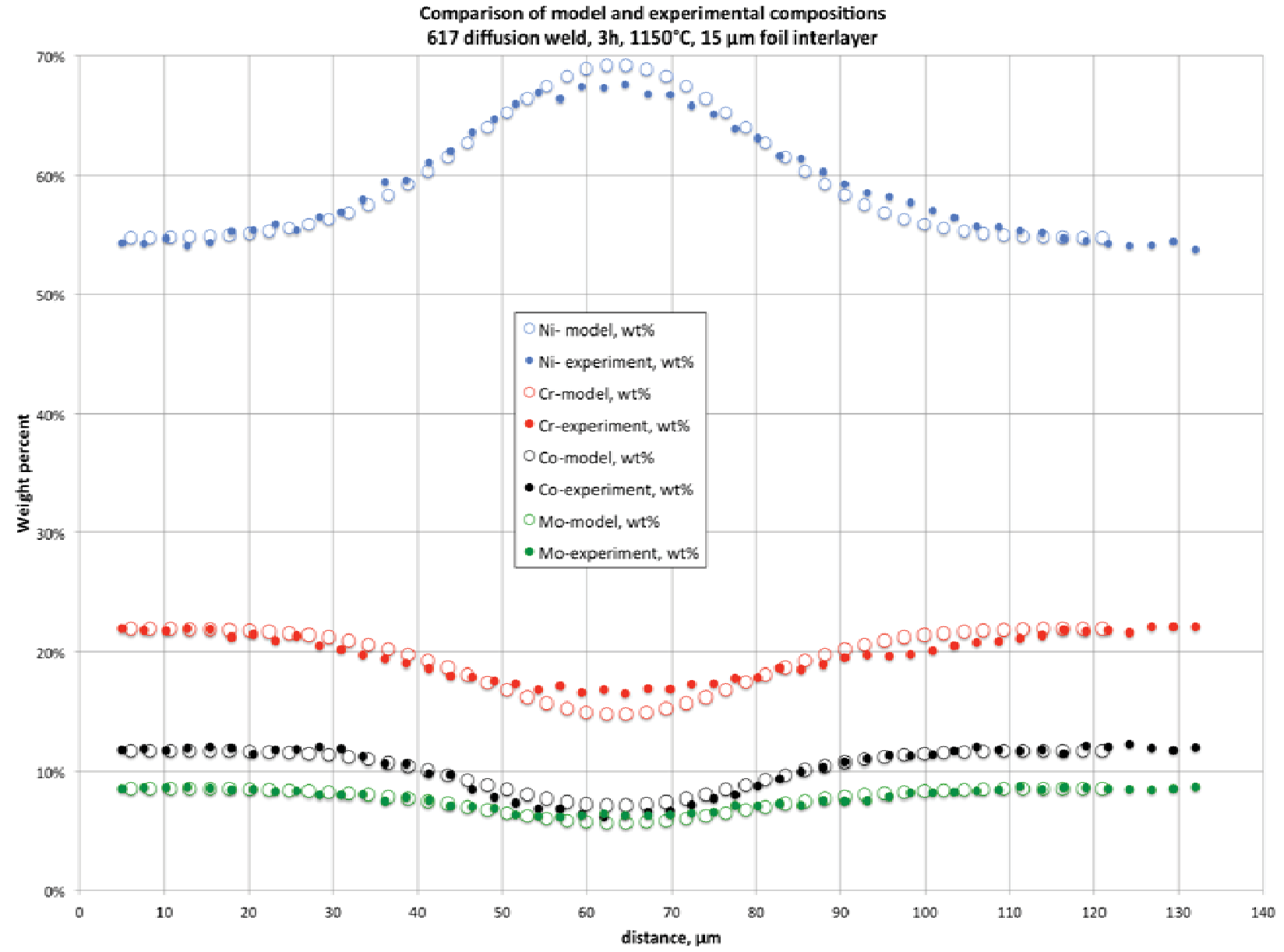

Figure 2-5. Diffusion weld in Alloy 617 with modeled and experimental compositions.

\section{Second Phase Predictions}

Another useful role for modeling is the prediction of the phases that might be present after various times at various temperatures. This is important because the development of detrimental phases in nickel alloys can degrade properties significantly. This can occur either during the welding cycle or after many

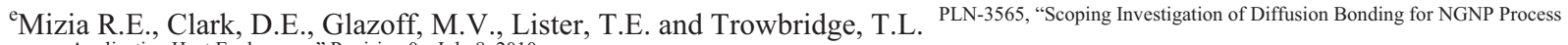
Application Heat Exchangers," Revision 0, July 8, 2010

${ }^{\mathrm{f}}$ Mizia R.E., Clark, D.E., Glazoff, M.V., Lister, T.E. and Trowbridge, T.L, INL/EXT-11-21817, Progress Report for Diffusion Welding of the NGNP Process Application Heat Exchangers, April 2011 
hours at the typically lower service temperatures for the components. Predicted phases were seen microstructurally in diffusion welds.

\section{Dissimilar Metal Welding}

Advanced compact heat exchangers may need to handle more than one fluid: for example, molten salt in one circuit exchanging heat with gaseous helium in another and steam generation using the Rankine Cycle, as discussed later. Environmental testing for performance under these conditions is quite expensive. Even the evaluation of metallurgical microstructures is an expensive process if done purely experimentally, particularly as longer service times are contemplated. Modeling thus serves to indicate which alloys and diffusion welding/service thermal cycles are promising for experimental work.

\subsubsection{Metal/Ceramic Joints}

The metal ceramic joint in a secondary heat exchanger would join a ceramic heat exchanger to metallic piping. Metal to ceramic brazing can be accomplished by the following techniques (Walker and Hodges 2008):

\section{Molybdenum-Manganese/Nickel Plating Method}

The ceramic surface is coated with molybdenum and manganese particles mixed with glass additives and volatile carriers. The coating is fired in a wet hydrogen environment at high temperature, leaving a fired coating that is plated with nickel and finally sintered. The resultant nickel layer can then be brazed to the metallic surface using standard braze filler materials. This is the traditional method for making a metal-to-ceramic joint.

\section{Thin-Film Deposition}

Thin film deposition is another technique that will deposit a metalized layer that can be easily joined to a metallic pipe by brazing. A series of materials are deposited onto the ceramic surface using a physical vapor deposition process such as evaporation or sputtering. The first layer deposited will be a strong, oxide forming element such as titanium, hafnium, zirconium, chromium, or niobium. This layer is typically 0.05 to $0.25 \mu \mathrm{m}$ thick. An intermediate layer may be applied to protect the base layer from interaction with the braze filler metal. The outer layer is usually a noble metal such as gold, platinum, or palladium 0.25 to $1.0 \mu \mathrm{m}$ thick. This layer prevents the underlying layer from oxidizing and the layer is compatible with standard brazing filler materials.

\section{Active Filler Metal Brazing}

Active filler metal brazing that permits the use of standard brazing techniques to join metals to ceramics that does not require metallization of the ceramic surface. The metallic and nonmetallic surfaces are cleaned and the active filler metal paste is positioned or applied to the faying surfaces (surfaces to be joined) of the joint. The braze operation is then performed in an inert or ultrahigh vacuum environment.

\section{Direct-Brazing Method}

The direct-brazing method allows metals to be brazed to ceramics without the use of an active filler metal or metallization coating of the ceramic surface. The process uses standard brazing filler metals. The brazing process is the same as that used for active filler metal brazing. During this process, specific metal substrates and braze filler metal combinations interact to form an adherent metallic oxide layer on the oxide ceramic faying surface.

Based on preliminary design studies for the secondary heat transport system, it is anticipated that a $\mathrm{SiC}$ heat exchanger with an undefined manufacturing process will need to be joined to Alloy $\mathrm{N}$. The 
joining procedure will be developed and qualified to the requirements of ASME BPV Code Section IX (ASME 2011a).

\subsubsection{Other Joining Processes}

Diffusion welding (AWS 2007a) is the baseline process for fabricating compact heat exchangers. Properly done, it produces monolithic microstructures in a variety of alloys suitable for various hightemperature environments.

Diffusion welding can be performed on quite large components, but other joining processes will be required for the assembly of compact heat exchangers into actual energy system hardware. Other joining processes are also candidates for the fabrication of heat exchangers themselves. Compact heat exchangers may be fabricated by other processes, and other types of heat exchangers such as coiled tube or tube-totube sheet heat exchangers can practically be made with other processes.

This section of the report briefly describes some of the other joining processes that have been initially evaluated in the course of the present work.

\subsubsection{Joining Requirements}

It is generally the case that joining is considered rather late in the design process for many systems. Alloy development strives for improved properties in specially processed materials, and, although it is known that welding may be required for the alloy's applications, it is often only later that the degradation of properties, disturbed microstructures, and reduced joint efficiencies associated with welding are taken into account, for example, in construction codes.

\section{High Temperature Regimes}

For efficiency, heat transfer in NGNP applications (as well as in fossil energy and conventional nuclear power) generally occurs at as high a temperature as possible, and material and joining limitations set the upper bound for this temperature. As reflected in the applicable codes, this generally means that welding is the only acceptable method of joining components. Brazing (the use of a lower-temperature filler metal) typically has high-temperature strength and corrosion problems, and mechanical fastening is typically too expensive and unreliable for most joining situations, though there are exceptions to both.

\section{Dissimilar Metal Welding}

It is often necessary to transition from one material to another in energy systems; for example, from the nickel alloys required for high temperature service to the lower-cost low-alloy steels common in steam generation systems. For reasons noted above, welding is the preferred or required method of joining these dissimilar materials. This leads to a number of issues, including problematical microstructures resulting from solidification of the mixed materials, the choice of a filler material compatible with both, the undesirable diffusion of alloy constituents from one side of the joint to the other (either in service or during welding), susceptibility to galvanic corrosion because of the electrochemical potential difference, and differential thermal expansion, which can cause defects during welding and fatigue damage in service.

Dissimilar metal welding is covered in codes based on empirical data, and can also be modeled. Modeling might include diffusion characteristics, and the development of detrimental or desirable minor second phases during joining or in service. 


\subsubsection{Other Joining Processes}

A number of joining processes besides diffusion welding are potentially valuable for heat exchanger applications. They are briefly described below.

\section{Diffusion Brazing}

Sometimes known also as "transient liquid phase bonding," diffusion brazing uses a filler material that lowers the melting point of the materials being joined, often by forming a eutectic (AWS 2007b). Boron is a typical element added for this purpose. At temperature, the boron (or similar constituent) diffused away into the base metal, and solidification occurs at a constant temperature as the constitution of the material at the interface changes - it is essentially "constitutionally supercooled" at the start of the cycle, and then solidifies at is reaches thermodynamic equilibrium.

This process has the advantage of filling in small amounts of surface roughness and providing an active liquid environment for the dissolution of surface oxides or contaminants. Also, compared with diffusion welding, the pressures required for bonding are lower, making lighter weight structures possible. It has the disadvantage of leaving the residual melting point depressant in the matrix, where it could cause further problems in service, or in other kinds of welding performed on the component.

\section{Laser and Electron Beam Welding}

Laser and electron beam welding are high energy density welding processes that can produce narrow, deeply penetrating welds at high speeds (AWS 2007c \& d). They can also control heat input to fabricated parts with great precision, and can weld thin, delicate parts as well as heavier sections. They are similar in operation, except that laser energy is carried by photons and electron beam, energy by electrons in a hard or soft vacuum.

One possible fabrication method for multilayer heat exchangers is to use the penetrating power of these beam processes to weld the sheets together, between any channels that might be cut or etched into them. Numerous geometries are possible, including lightweight assemblies that might not stand up to the pressures and potential high plastic flow typical of diffusion welding. The processes may also hold promise for component-to-component joints, such as header attachment to a diffusion welded stack.

\section{Brazing}

Brazing joins material with a lower-melting brazing filler material that achieves atom-to-atom bonding by thorough wetting of the surfaces to be joined, often with the aid of an active flux (AWS 2007e). Heat can be applied by a moving source such as a fuel/oxygen torch, or the brazing can be done in a controlled furnace environment. As mentioned above, brazing is not code qualified for many joints and service environments, but might be considered for some applications, with proper development and qualification. It is also sometimes used for temporary repair operations.

\section{Arc welding}

Arc welding is a broad and diverse set of distinct processes using an electric arc as the heat source for welding. The most relevant process for heat exchanger fabrication is Gas Tungsten Arc Welding (GTAW, sometimes referred to as TIG, or Tungsten Inert Gas welding) (AWS 2007f). As a common and inexpensive fabrication process, it is well characterized and is perhaps the most likely one to be specified for assembling components such as compact heat exchangers into larger energy systems. It might have limited use in the fabrication of heat exchanger assemblies, although the precision and penetration depth of the high energy density processes might be more appropriate. 


\section{Ultrasonic Welding}

Ultrasonic welding uses large amounts of ultrasonic power to create a joint at an interface between relatively thin materials. A scrubbing action at the interface of the materials to be joined disrupts oxides, promotes highly localized plastic deformation, and a sound joint is formed by atomic bonding across the interface (AWS 2007g). Ultrasonic welding is limited to thin materials (for at least one of the members being joined), typically $<0.1$ in. $(2.5 \mathrm{~mm})$, although successful welding also depends on material and surface condition. It is a possibility for the fabrication of NGNP-scale heat exchangers.

\section{Spray Forming}

Spray forming is a variant of the thermal spray process commonly used to put wear- and corrosionresistant coatings on structural materials (AWS 2007h). Spray forming builds a thicker layer of material, and it is possible to spray form over molds and reverse molds to produce channels and other features that might be useful in heat exchangers. The potential cost of producing complex 3-D objects might thus be lower once production methods are optimized. The disadvantages of the process include limitations on the alloys that can be sprayed, suboptimal microstructures because of the difficulty of controlling the spray environment, and the inclusion of oxides developed during droplet flight.

\section{Friction Stir Welding}

Friction Stir welding moves a rapidly rotating tool through the near-surface (up to $\sim 0.25$ in. deep) zone of a metallic material, with a disc-and-pin geometry that induces severe plastic flow in the material (AWS 2007i). In the case of two pieces of material, the stirred zone becomes the weld. No melting occurs, which is an advantage for materials sensitive to solidification defects or severe segregation. It is possible to use it to outline channels in a way similar to electron beam or laser welding. Friction stir processing is analogous and can, for example, mechanically make alloys in place or refine surface microstructures. A potential disadvantage is that for very high-temperature materials such as those under consideration here, tool requirements are severe, and small-scale processing at the required high temperatures may be inconsistent because of the high heat inputs required for workability.

\section{Explosion Welding}

Explosion welding bonds parallel sheet or plate material by loading the top sheet with explosive, which is detonated on one end, causing the plates to meet at high velocity and an acute angle. Bonding occurs as surface oxides are removed by a plasma jet at the interface, and a wavy mechanical interlocking also occurs that enhances contact (AWS 2007j). Very large sheets (many meters on a side) can be bonded in this way, and dissimilar materials can be joined. Although expensive per shot, the large area produce may make it economical. At this point it is difficult to see how delicate fluid passageways in the heat exchanger might be preserved, but it may be worth considering, at least as a processing step. 


\section{COMPUTATIONAL THERMODYNAMICS MODELING OF HOT CORROSION IN ALLOY 242 AND ALLOY N ALLOYS}

\subsection{Introduction}

The issue of hot corrosion of Alloy 242 and Hastelloy-N alloys in molten salt eutectic mixtures is of significant interest and importance in the problems of designing modern modular nuclear reactors such as AHTRs (Sabharwall et al. 2011, Sohal et al. 2010); solar energy temporary storage (Biello 2009); development of new batteries; corrosion in high temperature fuel cells such as the molten carbonate and solid oxide fuel cells; functioning of spent nuclear waste processing equipment (e.g., apparatuses MarkIV and Mark-V at the INL-FFC); etc. (Phogikaroon 2011). Indeed, the relative compatibility of materials with molten salts, to a significant extent, defines how long equipment might work without experiencing breakdowns or malfunctioning.

Hot corrosion represents a phenomenon of materials degradation when in contact with molten salts and, possibly, aggressive gaseous environment. Most molten salts interact strongly with such environments. In general, this phenomenon has been underappreciated by the nuclear materials community. The problem is exacerbated by the fact that, unlike in aqueous environments with dissolved gases, no Pourbaix diagrams can be constructed for molten salts. ${ }^{\mathrm{g}}$ Pourbaix diagram highlights the importance of taking into account gaseous environment, which is not very relevant to the conditions at which the secondary coolant loop of molten salt nuclear reactors (AHTRs) function (molten salt is supposed to be hermetically pressurized in the loop piping), it is critically important to elucidate the "molten salt - gaseous phase" interactions for other applications.

Oxidation in hot corrosion can be because of either a component of the gas environment or a salt species. In fact, equivalence could be established between the two from a thermodynamics perspective. In turn, this leads to quite different corrosion processes because of the presence of a thin film of salt compared to the same salt present in secondary coolant loops (Shores and Mohanty 2004). Also, the corrosion products (oxides, or fluorides, etc.) are rarely soluble in the salt. Besides, they seldom form any passive films (the importance of $\mathrm{Cr}_{2} \mathrm{O}_{3}$ stability with respect to aggressive is explored in this report). This means that the product layer is porous, easily subjecting it to further attack by molten salt. Consequently, the formation of different diffusion couples across the thickness of the corrosion product near the metal surface could be expected as concentration of different components changes across the interface (Shores 1983). The high temperatures at which molten salts are used also facilitate chemical interactions, leading to increased rates of oxidation (Shores 1983). In superalloys where just a couple of components may contribute to the formation of the ultimate corrosion products, diffusion sometimes leads the formation of a depletion zone immediately below the corrosion product layer (Glazoff 2008).

Another feature typical of molten fluorides is that they can easily dissolve passive oxide layers, while moisture and oxide impurities in fluorides can cause corrosion (oxidation) of the metal alloy. One of the protective measures against these undesirable phenomena is the development of systems for control of coolant chemistry and purification of molten salt materials [Biello 2009; Shores 1983; Shores and Mohanty 2004).

Different methods have been offered to control hot corrosion in AHTR systems: development of advanced, corrosion resistance alloys; control of redox processes by use of metallic beryllium immersed into the molten salt; control of oxide formation by using high purity helium as a cover gas; etc. The

g What a phase diagram is for a metallurgist, a Pourbaix diagram is for a corrosion scientist. It is plotted in the " $\mathrm{pH}-\mathrm{E}(\mathrm{SHE})$ " coordinates (electrochemical potential w/r to standard hydrogen electrode, $\mathrm{vs.} \mathrm{pH}$ ) and allows constructing areas of stability, passivation, and unchecked corrosion attack for a given electrolyte system 
principal idea is to maintain a reducing (low oxidation potential) environment in the salt by imposing rigorous REDOX control upon the system (Ignatiev 2008).

According to previous research, the following materials were assessed as candidates for AHTR designs in different countries: $800 \mathrm{H}$, Alloy N, Hastelloy X, Czech superalloy MONICR (MoNiCr), and a Russian alloy HN80M-VI. The application of many of these materials and silicon carbide (SiC) was explored extensively in a recent $\mathrm{PhD}$ thesis at the University of Wisconsin (Advisor - Prof T. Allen) (Olson 2009). The chemical compositions of these materials, temperature ranges of their exposure to molten salt mixtures of different chemical compositions, and resistance to molten salt corrosion are described in Table 3-1 (Williams, Toth, and Clarno 2008).

Table 3-1. Chemical composition and hot corrosion resistance of the several superalloy materials against hot corrosion (Chartrand and Pelton 2001).

\begin{tabular}{|l|l|l|l|}
\hline \multicolumn{1}{|c|}{ Alloy } & \multicolumn{1}{|c|}{$\begin{array}{c}\text { Alloy Composition } \\
\text { (principal elements) } \\
\text { (wt\%) }\end{array}$} & \multicolumn{1}{c|}{ Resistance to Hot Corrosion } & \multicolumn{1}{c|}{$\begin{array}{c}\text { Working } \\
\text { Temperature } \\
\text { Range }\end{array}$} \\
\hline Alloy N & Ni base; $\sim 17 \% \mathrm{Mo} ; 7 \% \mathrm{Cr} ; 5 \% \mathrm{Fe}$ & Very good & Up to $750^{\circ} \mathrm{C}$ \\
\hline Hastelloy X & $\mathrm{Ni}$ base; $9 \% \mathrm{Mo} ; 20 \% \mathrm{Cr} ; 20 \% \mathrm{Fe}$ & Needs evaluation & Up to $900^{\circ} \mathrm{C}$ \\
\hline Alloy 242 & $\begin{array}{l}\mathrm{Ni}-\text { base; } ~ 25 \% \mathrm{Mo} ; 8 \% \mathrm{Cr} ; \\
1.5 \% \mathrm{Fe}\end{array}$ & $\begin{array}{l}\text { Good resistance to high-T } \\
\text { fluoride-bearing environments }\end{array}$ & Up to $815^{\circ} \mathrm{C}$ \\
\hline HN80M-VI & $\mathrm{Ni}$ - base; $8 \% \mathrm{Mo} ; 12 \% \mathrm{Cr}$ & Very good & High Temperatures \\
\hline MONICR & $\mathrm{Ni}$ - base; $18 \% \mathrm{Mo} ; 7 \% \mathrm{Cr} ; 2 \% \mathrm{Fe}$ & Very good & Up to $750^{\circ} \mathrm{C}$ \\
\hline
\end{tabular}

Based on the results of this and other research projects, it was decided in this work to explore the hot corrosion stability of Alloy 242 and Alloy $\mathrm{N}$ in a molten fluoride mixture of eutectic composition.

While the physical and thermo-physical properties of these materials are known, the issue of hot corrosion, up until recently, has been studied only experimentally (Olson 2009). Experimental studies involving molten salts are very difficult, given the aggressive nature of these materials and high temperature of experimentation. Consequently, any modeling efforts aimed at prescreening of candidate materials from the viewpoint of their thermodynamic, diffusion, and corrosion stability, are of interest to the nuclear engineering community.

Such computational thermodynamic and diffusion work has commenced only within the last 10 years or so. Efforts have been made to assess the behavior of generic superalloys in different eutectic ${ }^{\mathrm{h}}$ molten salt mixtures in order to establish different hot corrosion mechanisms - protection with thin oxide films (typically $\mathrm{Cr}_{2} \mathrm{O}_{3}$ ); formation of volatile salts depleting the contents of metals in superalloys; formation of different salts $\left(\mathrm{CrCl}_{2}, \mathrm{CrF}_{2}, \mathrm{CrCl}_{3}\right.$, and $\left.\mathrm{CrF}_{3}\right)$; and others. While this work is rapidly developing now in different European research centers in Sweden, Germany, Spain, etc., it is still in its infancy. In part, this situation was caused by the lack of reliable ionic liquid, superalloy, pure substances, and solutions databases and insufficient processing speed of computers. However, the situation has changed dramatically with all of these resources available, allowing for conducting reliable single-point, stepping, and mapping thermodynamic calculations of hot corrosion.

The rest of this section is organized as follows: Section 3.2 gives a brief overview of different molten salts typically used for design of AHTRs; Section 3.3 describes thermodynamic properties and phase

$\mathrm{h} \quad$ Eutectic salt mixtures are used in order to reduce the operating temperatures of different processes. Typically, a working temperature of a given process should be at least $100^{\circ} \mathrm{C}$ higher than that of the eutectic point to ensure that a highly undesirable solidification would not take place. 
equilibria in Alloy 242 and Alloy N; Section 3.4 provides the results obtained in this study and their comparison to existing experimental data, mostly generated at ANL, ORNL, and the University of Wisconsin; and Section 5 provides conclusions and recommendations for future computational and modeling research in this area of nuclear engineering.

\subsection{Thermodynamics and Phase Equilibria in Molten Salt Compositions}

For the purposes of the present report, only data for the following three candidate salt systems is discussed: NaF-LiF-KF; KCl-MgCl 2 ; and $\mathrm{KF}-\mathrm{ZrF}_{4}$.

\subsubsection{NaF-LiF-KF Quasi-ternary System}

Of these three systems, NaF-LiF-KF (also known as FLiNaK) has been studied most extensively. The binary phase diagrams for K-F, Li-F, and $\mathrm{Na}-\mathrm{F}$, are presented in Figure 3-1.

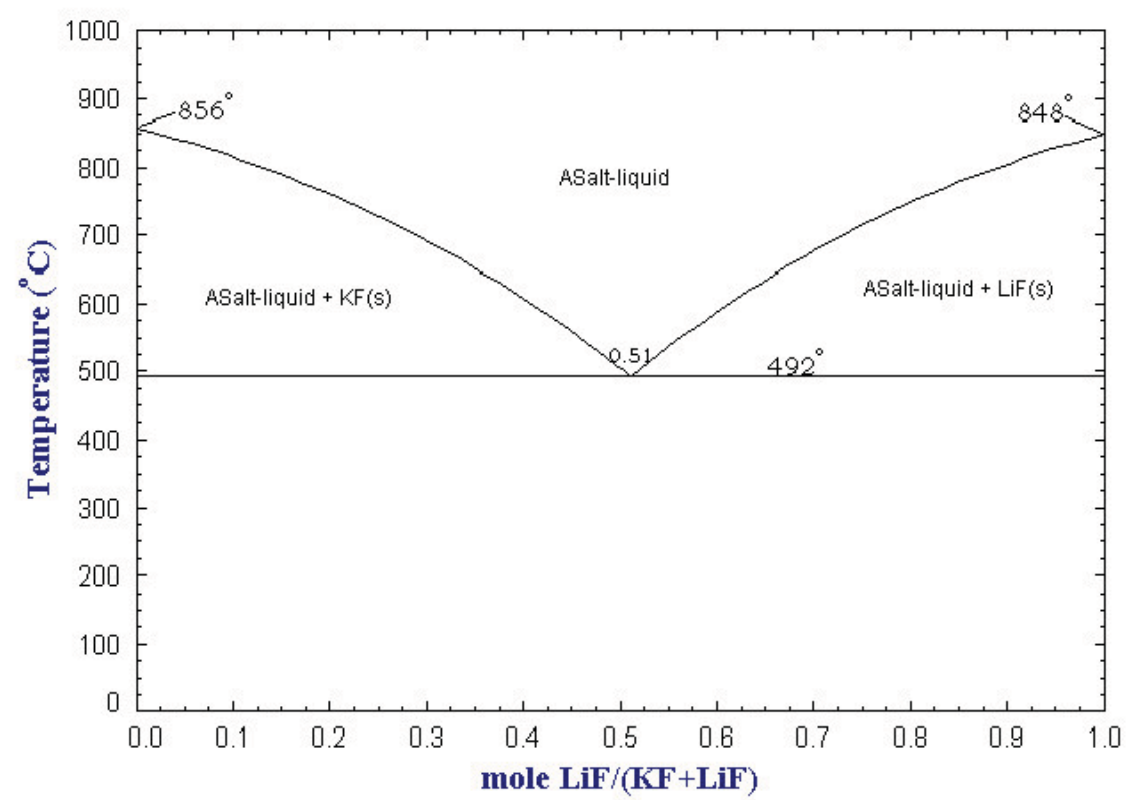

Figure 3-1. Phase diagram LiF-KF, after (Chartrand and Pelton 2001).

\subsubsection{The Quasi-Binary LiF-KF Phase Diagram}

Calculations performed using ThermoCalc and the molten salt thermodynamic database, SALT1, yielded the practically identical result shown in Figure 3-2. The red line(s) represent nonvariant phase transformation lines while tie lines are presented as green lines. While this diagram does not carry any additional information compared to Figure 3-1, it still illustrates the computational thermodynamics capabilities developed at INL over the last year.

Figure 3-2 is of a eutectic type characterized by the absence of mutual solubility of either LiF in KF, or of $\mathrm{KF}$ in $\mathrm{LiF}$. The temperature of nonvariant eutectic transformation is $492^{\circ} \mathrm{C}$ at $0.51 \mathrm{~mol} \%$ of $\mathrm{LiF}$. The liquid phase forming upon melting of these salts is a so-called ionic liquid. As it is typical of molten salts, it is transparent, possesses viscosity similar to that of pure water, and conducts electricity (ionic conductivity). It is this combination of properties that make molten salts so attractive for the applications in different nuclear reactor designs (AHTRs) 


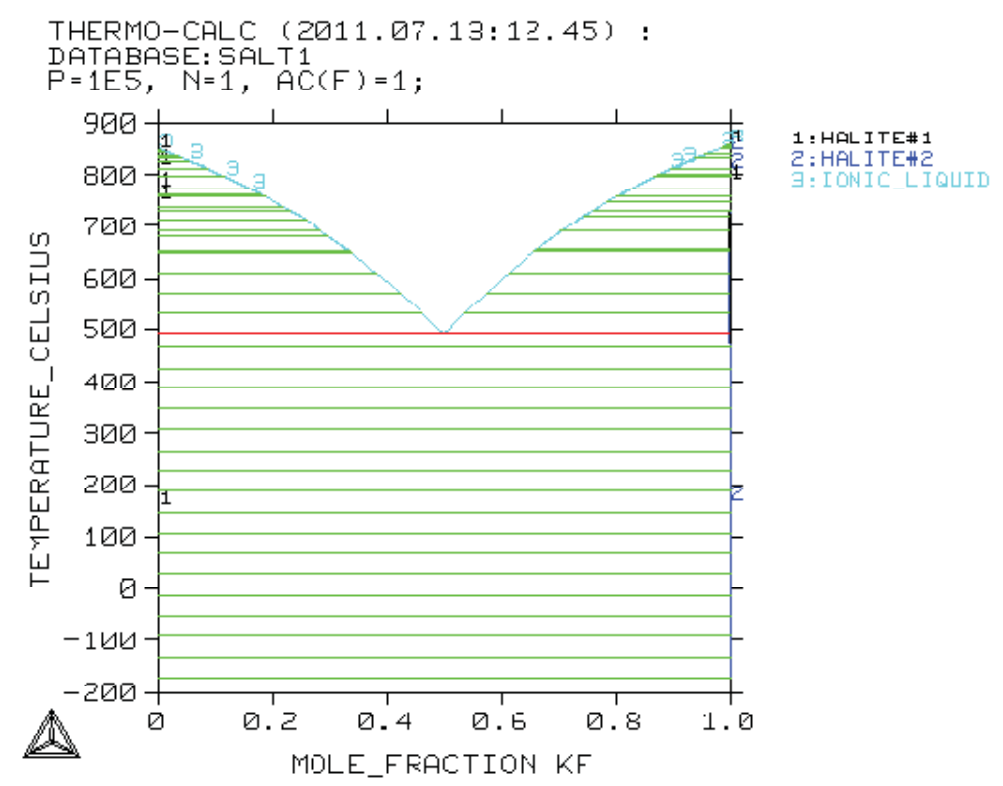

Figure 3-2. Quasi-binary phase diagram LiF-KF. While this diagram does not carry any additional information compared to Figure 3-1, it illustrates the computational thermodynamics capabilities developed at the INL during the last year.

\subsubsection{Quasi-Binary LiF-NaF Phase Diagram}

This phase diagram for LiF-NaF is presented in Figure 3-3 (FactSage 2011).

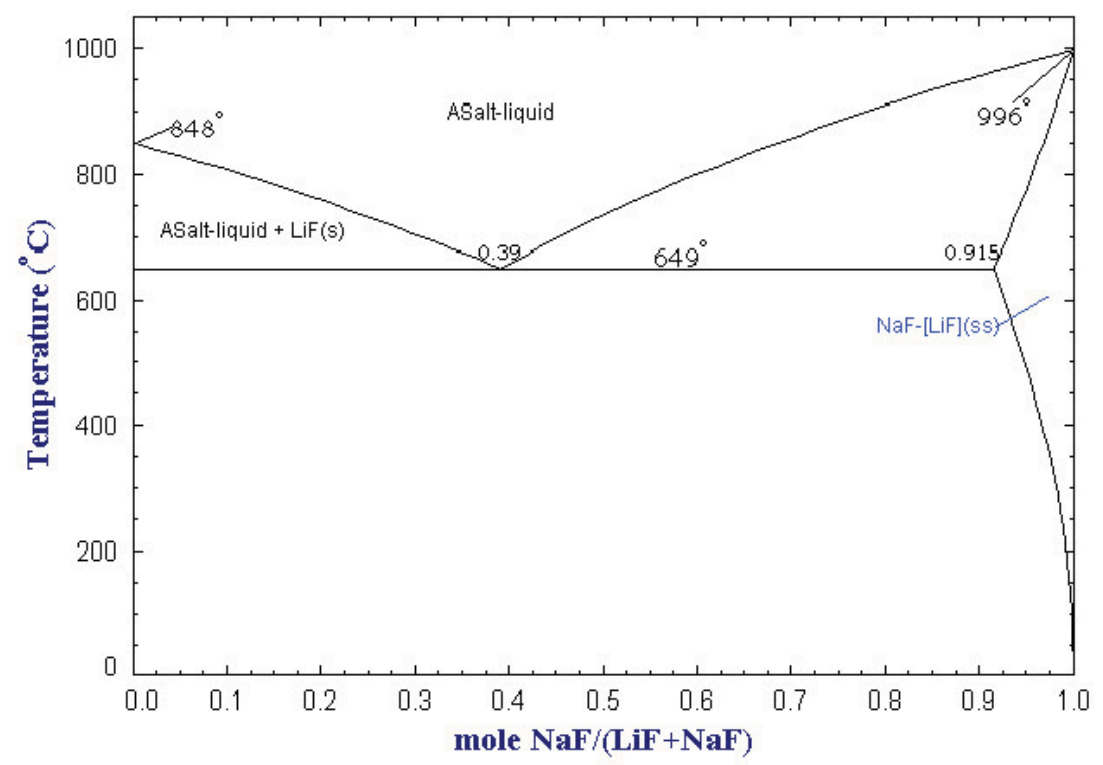

Figure 3-3. Phase Diagram NaF-LiF, after (FactSage 2011).

Similar results were obtained in this work using the ThermoCalc software as shown in Figure 3-4. 
As can be seen from Figure 3-3 and 3-4, there is some solubility of LiF in NaF, but no solubility of $\mathrm{NaF}$ in pure $\mathrm{LiF}$. The nonvariant eutectic transformation takes place at $649^{\circ} \mathrm{C}$, with the eutectic point being at $0.39 \mathrm{~mol} \% \mathrm{NaF}$.

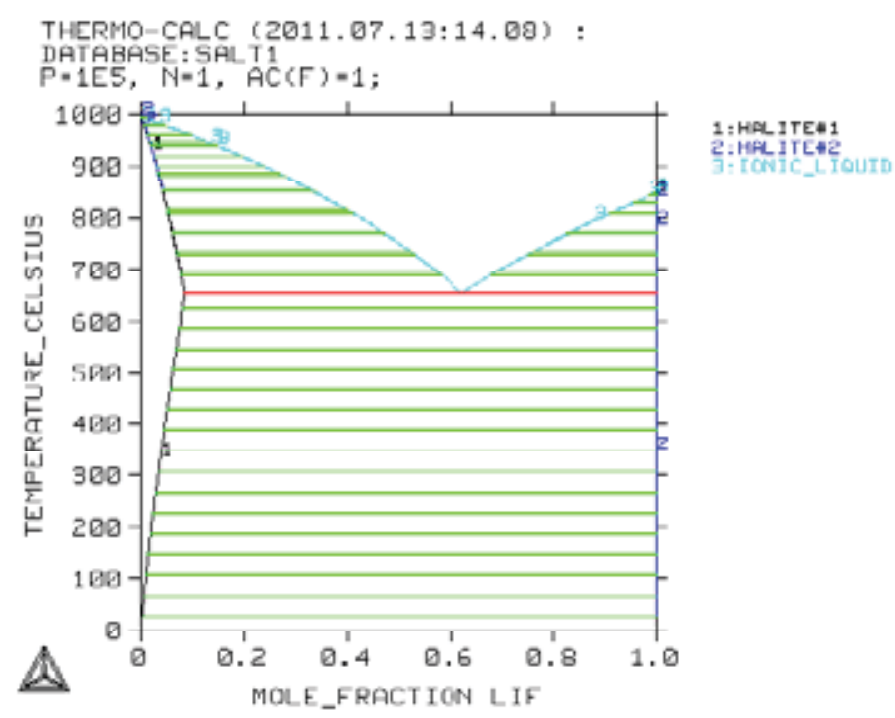

Figure 3-4. ThermoCalc calculations in the present work, NaF-LiF phase diagram. Halites \#1 and \#2 correspond to solid LiF and NaF, respectively. Also see note to Figure 3-2 above.

\subsubsection{Quasi-binary KF-NaF Phase Diagram}

The KF-NaF phase diagram is given in Figure 3-5.

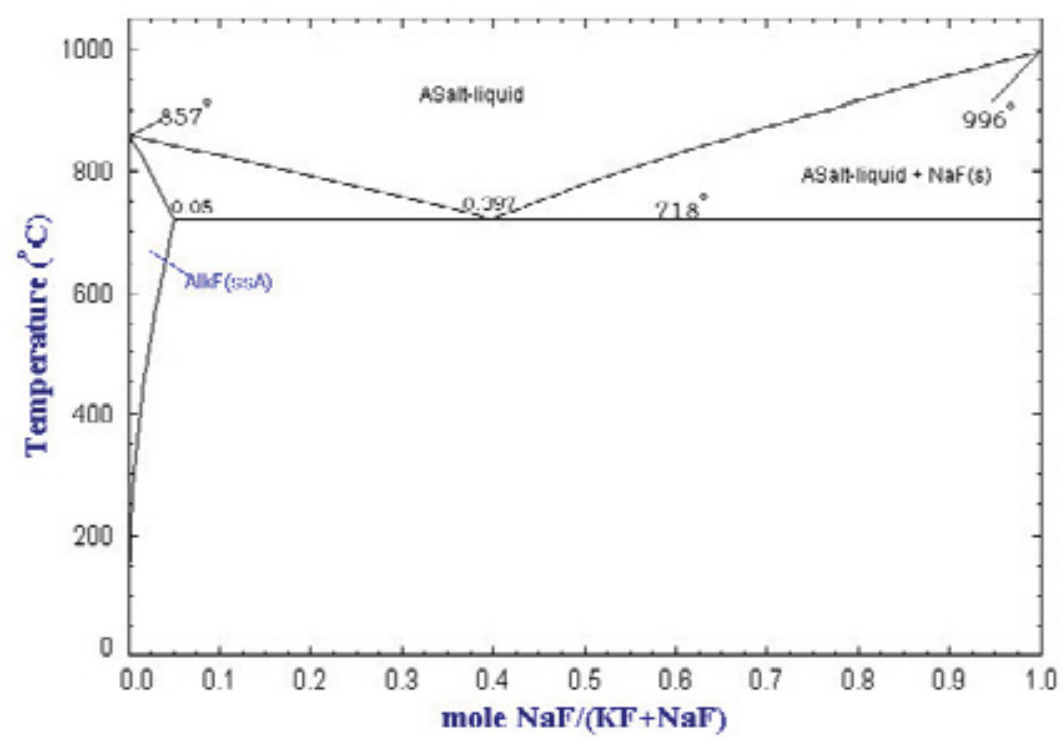

Figure 3-5. The NaF-KF phase diagram, after [FactSage 2011].

ThermoCalc calculations yielded very similar results as shown in Figure 3-6. 


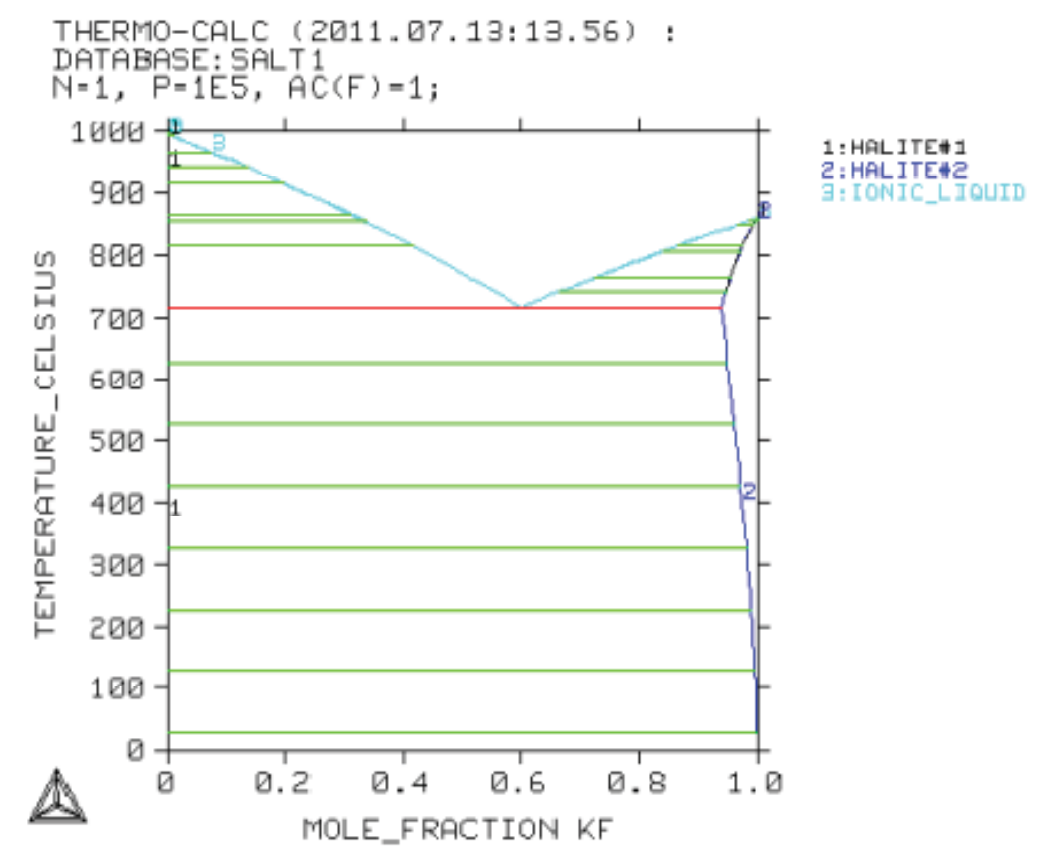

Figure 3-6. ThermoCalc calculations of the NaF-KF phase diagram.

The eutectic temperature is at $718^{\circ} \mathrm{C}$; and the eutectic point corresponds to the 0.397 molar fraction of $\mathrm{NaF}$. Of the three binary diagrams, the eutectic temperature is the highest for the NaF-KF phase. Consequently, the need arises to use a three-component system in which the ternary eutectic temperature will lie lower than in the binary systems considered above.

\subsubsection{Ternary Phase Diagram LiF-KF-NaF}

The ternary diagram for LiF-KF-NaF presented in Figure 3-7 (Chartrand and Pelton 2001) clearly demonstrates the advantage of a ternary system over the corresponding binaries; the ternary eutectic point temperature falls to $457^{\circ} \mathrm{C}$, while the lowest binary eutectic temperature is $492^{\circ} \mathrm{C}$ (for the $\mathrm{KF}$ - $\mathrm{LiF}$ system).

The ternary KF-LiF-NaF system is not assessed in the SALT1 database, so the law of ideal solutions extrapolating from these binaries to the ternary system was tried. Unfortunately, the resulting eutectic point temperature was $\mathrm{T}_{\mathrm{e}}=491{ }^{\circ} \mathrm{C}$, nearly the value coinciding with that of the binary KF-LiF eutectic. Future work on the database development will need to be undertaken for this and other systems of interest. 


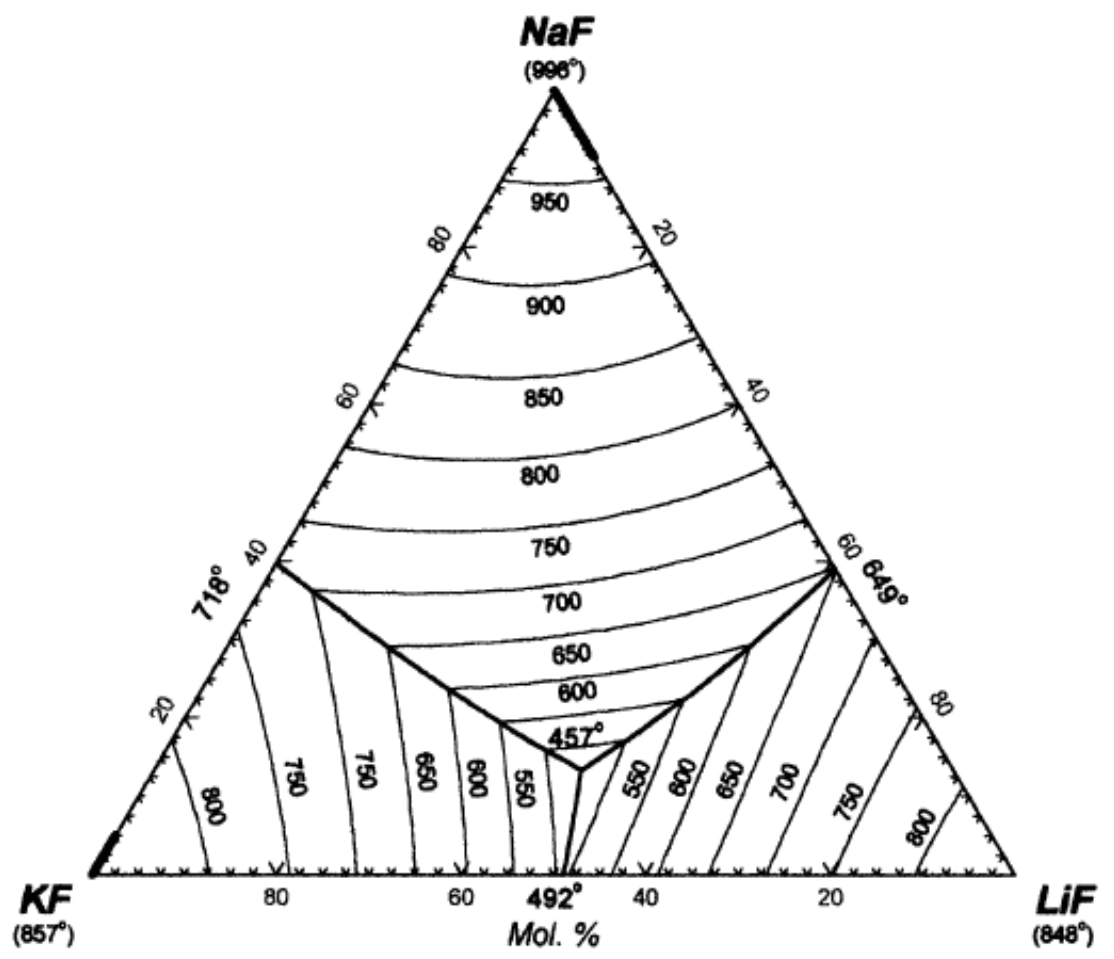

Figure 3-7. Polythermal (liquidus) projection diagram for the LiF-NaF-KF ternary system (Chartrand and Pelton 2001).

\subsubsection{Eutectic $\mathrm{KCl}-\mathrm{MgCl}_{2}$ Binary System}

The phase diagram for the $\mathrm{KCl}-\mathrm{MgCl}_{2}$ system is presented in Figure 3-8 (FactSage 2011). The FTSalt database belonging to FactSage was used in these calculations. 


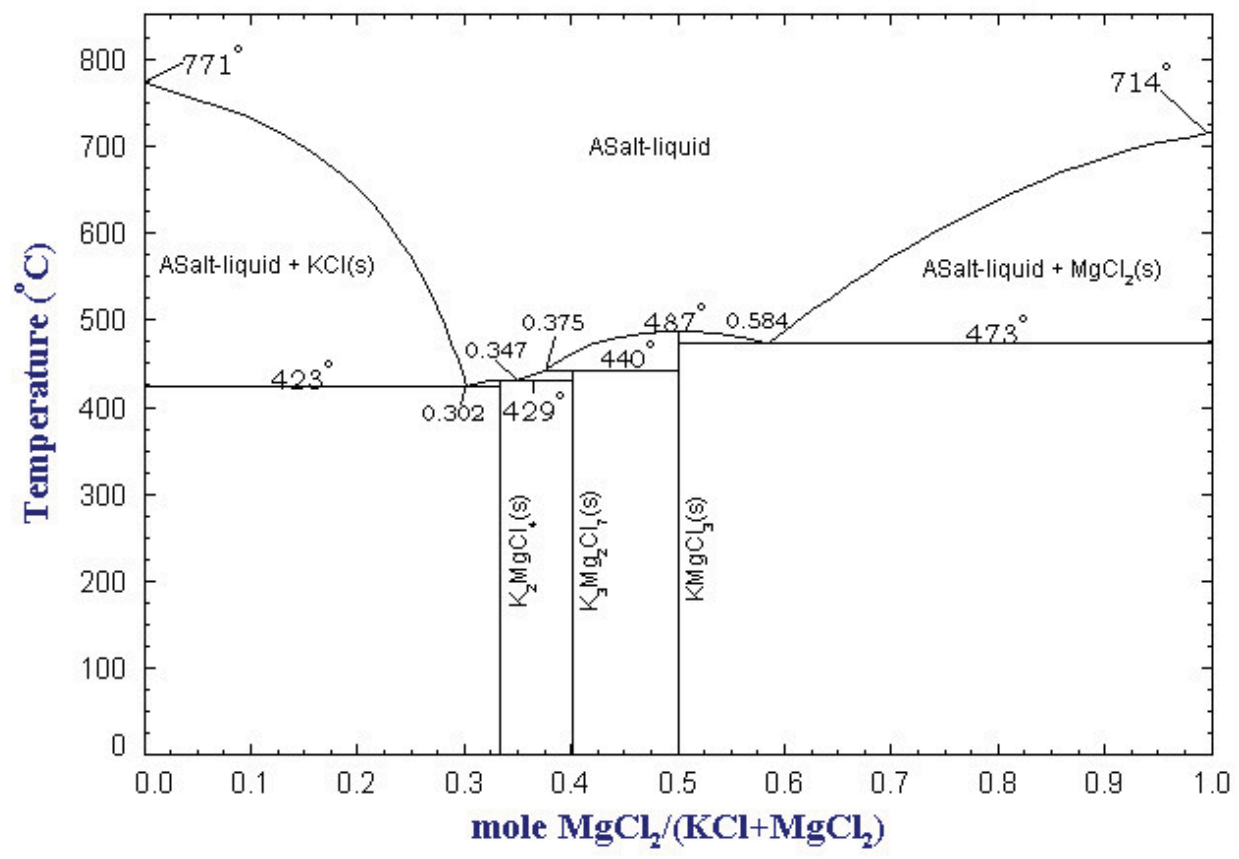

Figure 3-8. Phase diagram of the $\mathrm{KCl}-\mathrm{MgCl}_{2}$ system (FactSage 2011).

As can be seen in this phase diagram, it is characterized by the practically nonexistent solubility of both species $\left(\mathrm{KCl}\right.$ and $\left.\mathrm{MgCl}_{2}\right)$ in each other. Also note the formation of three distinctive compounds: $\mathrm{K}_{2} \mathrm{MgCl}_{4}$ (forms at $429^{\circ} \mathrm{C}$ according to peritectic reaction), $\mathrm{K}_{3} \mathrm{Mn}_{2} \mathrm{Cl}_{7}$ (forms according to peritectic reaction at $440^{\circ} \mathrm{C}$ ), and $\mathrm{KMgCl}_{3}$ (melts congruently at $487^{\circ} \mathrm{C}$ ). Typically, to avoid solidification, the working temperature is kept at least $100^{\circ} \mathrm{C}$ above the onset of solidification. According to Sabharwall et al. (2011), the concentration point for this system was chosen at $68 \mathrm{~mol} \% \mathrm{KCl}$ and $32 \mathrm{~mol} \% \mathrm{MgCl}_{2}$. This is very close to the deep eutectic point $\left(423^{\circ} \mathrm{C} ; 0.302 \mathrm{~mol} \% \mathrm{MgCl}_{2}\right)$. The inlet and outlet temperatures in the reactor design (Sabharwall et al. 2011) are going to be $679^{\circ} \mathrm{C}$ and $587^{\circ} \mathrm{C}$, respectively. The choice of chemical composition is excellent, resulting in a safety cushion of at least $150^{\circ} \mathrm{C}$ above the liquidus line for this composition.

\subsubsection{Phase Diagram KF-ZrF 4 .}

This quasi-binary system is the least studied for AHTR molten salt applications. The corresponding phase diagram was not found in available open literature, and it could not be assessed thermodynamically because of the lack of data in the SALT1 database by ThermoCalc or FSalt database by FactSage. The work on expanding this thermodynamic database to include the assessed $\mathrm{KF}-\mathrm{ZrF}_{4}$ phase diagram has commenced at INL.

\subsubsection{Carbon to Silicon Binary Phase Diagram}

The carbon to silicon phase diagram is presented in Figure 3-9.

According to Hillert (2008), the $\mathrm{SiC}$ intermediate compound is formed at high temperatures (around $2850 \mathrm{~K}$ ) as a result of peritectic reaction between the saturated melt and the graphite phase. It displays no deviations from the 1:1 stoichiometry. The choice of this material for the AHTR designs is dictated by its exceptional chemical inertness and stability. 


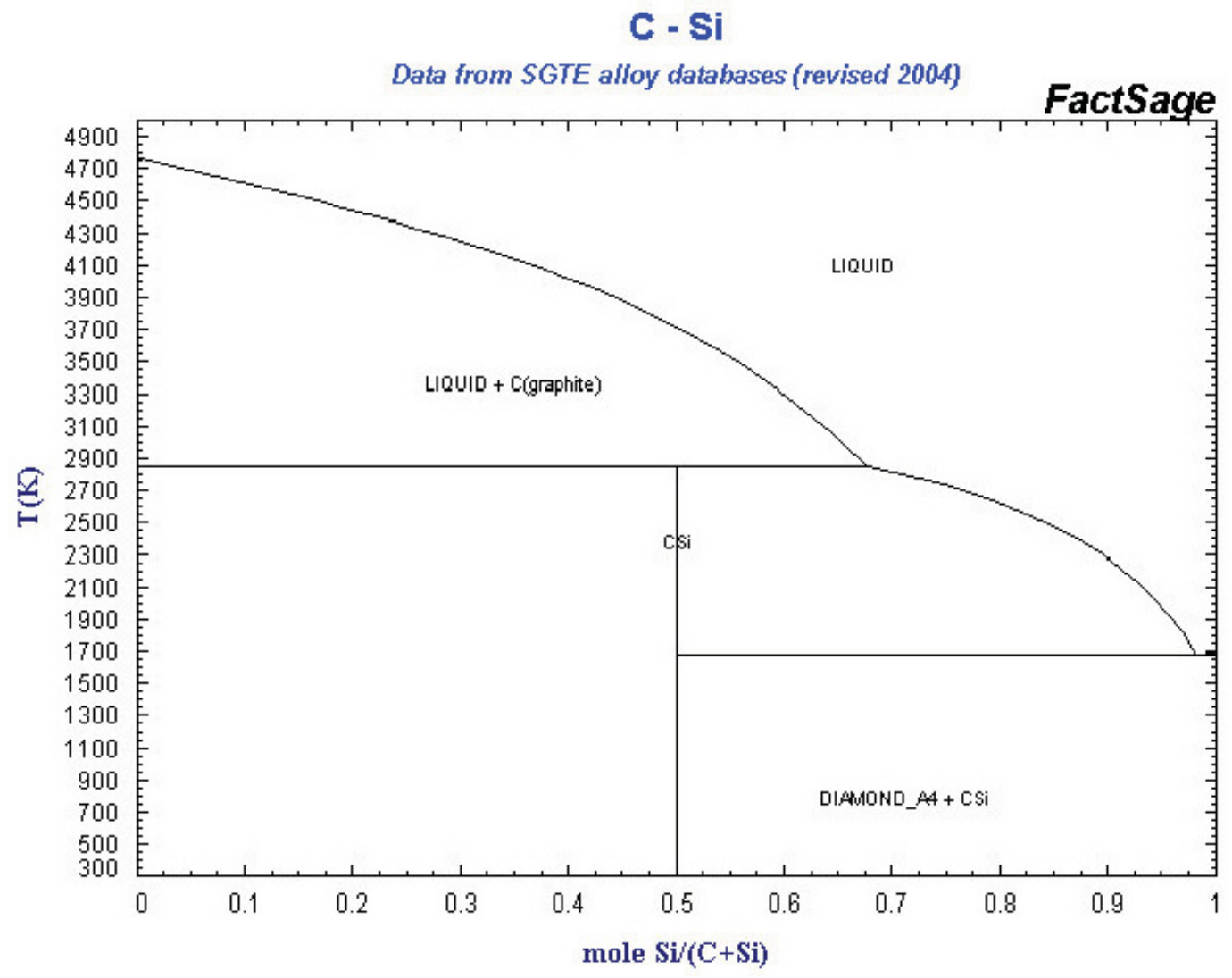

Figure 3-9. Phase diagram of the carbon-silicon system (Hillert 2008).

\subsection{Chemical Compositions and Microstructure of Alloy 242 and Alloy $\mathbf{N}$}

\subsubsection{Alloy 242}

This alloy was developed more than 40 years ago, and its properties, microstructure, and behavior in oxidizing environments have been studied quite extensively (Haynes 2000; Miller et al. 2002). To understand its phase composition as a function of temperature and pressure, typically quasi-binary diagrams (property diagrams) are constructed (Hillert 2008; Lukas, Suzana, and Sundman 2007). Such diagrams can be studied currently using well-regressed thermodynamic databases and fast, efficient algorithms of the global Gibbs energy minimization to establish equilibrium conditions.

In order to probe this alloy's microstructure at temperatures from 600 to $\sim 720^{\circ} \mathrm{C}$, we have constructed the carbon isopleth for Alloy 242 as shown in Figure 3-10. As can be seen in Figure 3-9, this is an austenitic matrix alloy with particles of $\mathrm{Ni}_{2} \mathrm{Me}$ and, depending upon its heat treatment, $\mu$-phase, $\delta$-phase, and $\gamma^{\prime}$-precipitates. 


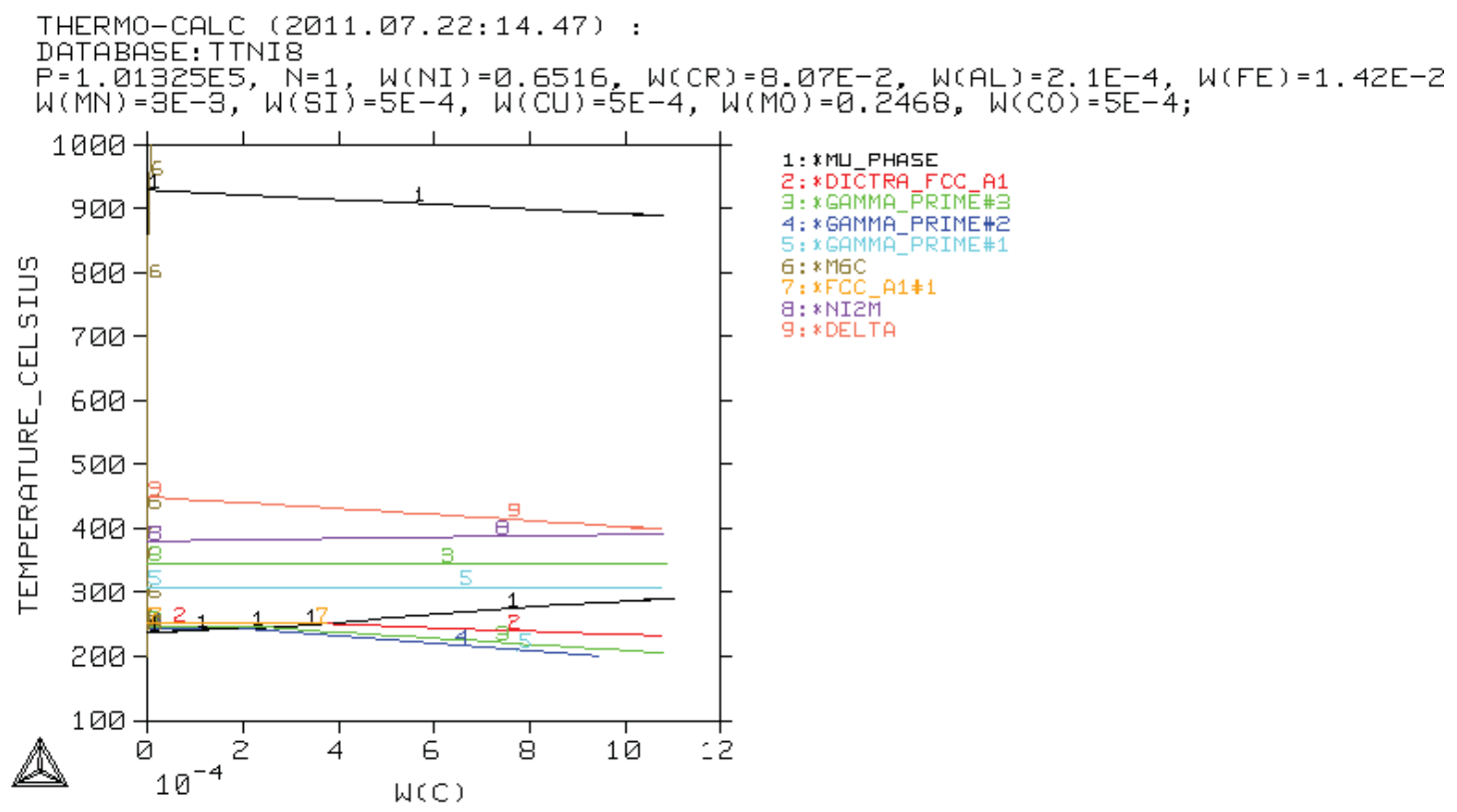

Figure 3-10. Carbon isopleth for Haynes-242.

A microstructural characterization of an Alloy 242 nickel-molybdenum-chromium superalloy was performed (Sabharwall et al. 2011). Molybdenum was found to partition to the lenticular $\mathrm{Ni}_{2}(\mathrm{Mo}, \mathrm{Cr})$ precipitates, whereas iron, aluminum, silicon, manganese and nickel were found to partition to the $\gamma$ matrix. Chromium was not found to partition significantly between the phases. Atom probe tomography and energy-filtered transmission electron microscopy core-loss images revealed boron, molybdenum, chromium, phosphorus, and carbon segregation to the grain boundaries. Despite the size of the precipitates being larger after a two-step heat treatment of 16 hours at $704^{\circ} \mathrm{C}+16$ hours at $650^{\circ} \mathrm{C}$ compared to a one-step heat treatment of 48 hours at $650^{\circ} \mathrm{C}$, no significant differences were found in the mechanical properties or compositions of the phases.

The formation of the $\mathrm{Ni}_{2} \mathrm{M}$ intermetallic phase takes place at somewhat lower temperatures, around $400^{\circ} \mathrm{C}$ as shown in Figure 3-10. However, overall, this is a reasonable set of phases to be expected for Alloy 242 at this temperature range, because the alloy's ultimate microstructure and phase composition will be determined by the heat treatments used during its thermomechanical processing.

\subsubsection{Alloy $\mathbf{N}$}

Alloy $\mathrm{N}$ is a nickel-base alloy invented at Oak Ridge National Laboratories as a container material for molten fluoride salts. Its hot corrosion mechanism has been studied extensively and reported by McKoy, Jr. (1971). It has good oxidation resistance to hot fluoride salts in the temperature range of 1300 to $1600^{\circ} \mathrm{F}\left(704\right.$ to $\left.871^{\circ} \mathrm{C}\right)$.

The carbon isopleth (property diagram) of this alloy was constructed similar to Figure 3-10. Figure 3-11 shows that the equilibrium phases for this alloy are carbide $\mathrm{M}_{6} \mathrm{C}, \gamma^{\prime}$ strengthening precipitates, and $\mu$-phase. This is similar to Alloy 242, but no $\mathrm{Ni}_{2} \mathrm{M}$ formation is expected in this case. 


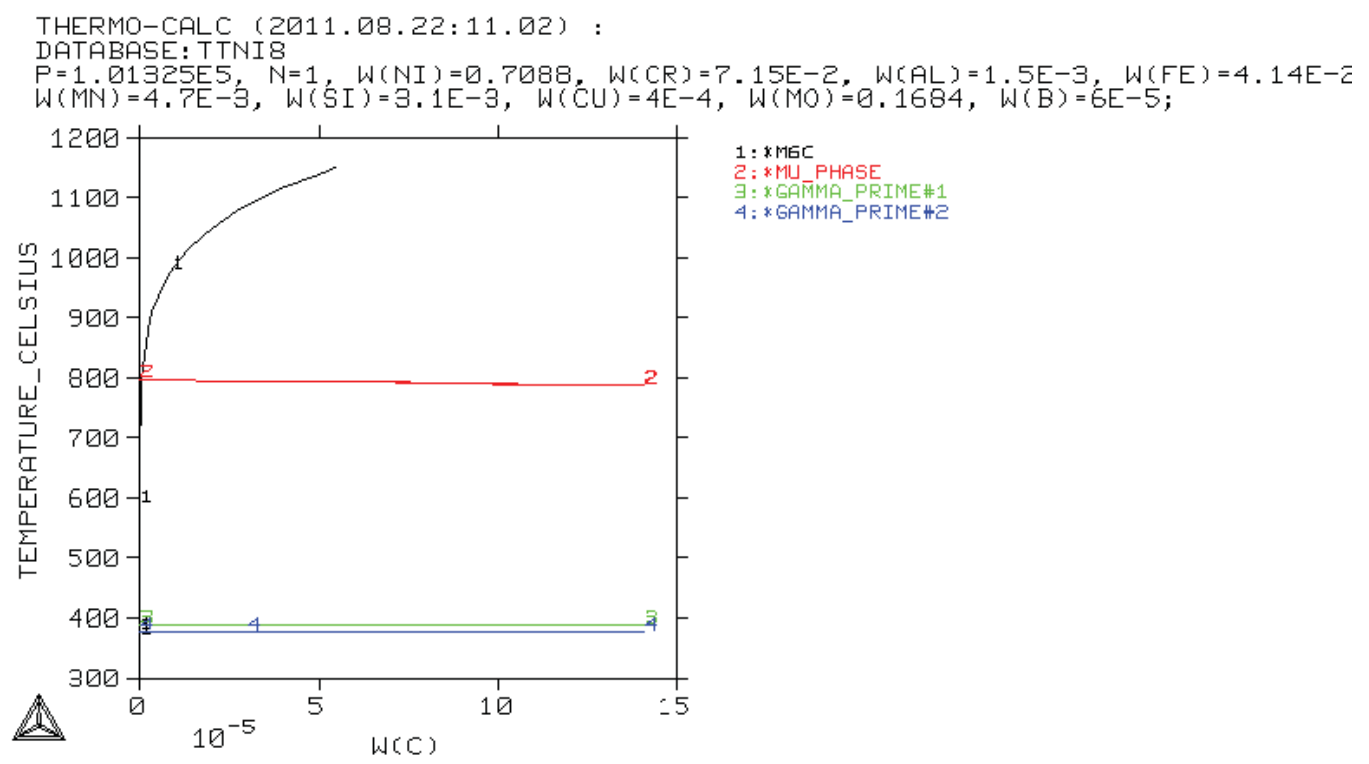

Figure 3-11. Carbtyu5^7hjn isopleth (property diagram) for Hastelloy-N.

\subsection{Modeling of Corrosion Behavior of Haynes-242 and Hastelloy-N in Molten Salt Environment}

As indicated in the introduction to Section 3, the specifics of hot corrosion are in the dissolution of protective oxides that might be formed on the metal surface. It is also very important to realize that the composition of molten salt mixture will strongly depend on the composition of the gaseous phase. Consequently, all of these factors need to be taken into account when modeling hot corrosion phenomena.

Perhaps the most detailed study of hot corrosion of different materials, including Alloy $\mathrm{N}$ and $\mathrm{SiC}$, was given in a recent experimental work by Olson (2009). This researcher studied a mixture of LiF-NaF$\mathrm{KF}$ (46.5-11.5-42 mol\% (commonly referred to as FLiNaK), as well as a molten chloride near eutectic salt, $\mathrm{KCl}-\mathrm{MgCl}_{2}: 6832 \mathrm{~mol} \%$. The following high temperature alloys and materials have been studied in these molten salt environments: Hastelloy-N, Hastelloy-X, Haynes-230, Inconel-617, and Incoloy-800H, $\mathrm{Nb}-1 \mathrm{Zr}$, a nearly pure nickel alloy $\mathrm{Ni}-201$, and a $\mathrm{C} / \mathrm{Si} \mathrm{SiC}$ ceramic. After exposure to molten FLiNaK at $850^{\circ} \mathrm{C}$ for 500 hours in sealed graphite crucibles under argon cover gas corrosion was established to occur predominantly from de-alloying of chromium from the chromium bearing alloys, an effect that was particularly pronounced at the grain boundaries.

Similar conclusions were made by Koger and Litman (1971), who studied compatibility of Hastelloy$\mathrm{N}$ and Haynes Alloy No. 25 in a molten sodium fluoroborate mixture. It was determined in the range from 460 to $605^{\circ} \mathrm{C}$. The cobalt-base alloy (Haynes \#25) was inadvertently incorporated in the Alloy $\mathrm{N}$ thermal convection loop and was exposed to the fluoroborate salt mixture for 3,660 hours. The Haynes 25 alloy suffered damage by selective leaching of cobalt and chromium, which migrated to the Alloy N. The mechanism of corrosive attack was activity gradient and temperature-gradient mass transfer. Haynes 25 alloy is more susceptible to attack by the fluoroborate mixture than Alloy N.

Consequently, special attention has been paid to the issues of chromium leaching from these two alloys, the formation of $\mathrm{Cr}_{2} \mathrm{O}_{3}$ on the surface, which in some cases has been shown to serve as a protective barrier against further hot corrosion attack, and its dissolution under certain harsh environmental conditions. 
It is important to note that, in all of these calculations, oxygen was supposed to be directly present in the gaseous phase (not suspended or rejected phase).

\subsubsection{General Considerations on the Stability of Protective Oxide $\mathrm{Cr}_{2} \mathrm{O}_{3}$ on Alloy 242 and Alloy N Surfaces}

It is an established fact that, in many cases, further oxidation of stainless steel and/or superalloy surfaces can be arrested if $\mathrm{Cr}_{2} \mathrm{O}_{3}$ is formed on the surface. This is also true of other oxides such as $\mathrm{Al}_{2} \mathrm{O}_{3}$. However, under extremely aggressive conditions, the $\mathrm{Cr}_{2} \mathrm{O}_{3}$ layer may be dissolved by the attacking salts, or gases, resulting in an alloy becoming prone to corrosion attacks from oxidizing environments.

In the computational thermodynamics literature (Shi, Engströmand, and Sundman 2008), an example was considered elucidating the behavior of $\mathrm{Cr}_{2} \mathrm{O}_{3}$ in the presence of an aggressive environment comprised of such elements as carbon, hydrogen, nitrogen, oxygen, sulfur, and the molten salt, $\mathrm{NaCl}$. While the exact chemical composition of the gaseous phase will be defined by the conditions of chemical and phase equilibria, it could be hypothesized that it could be comprised of hydrogen $\mathrm{H}_{2} ; \mathrm{SO}_{2}$; nitrogen $\mathrm{N}_{2}$ (from the air); and CO. Such a mixture could represent a contaminated syngas, and the process would then model its interaction with the steel or superalloy surfaces (Shi, Engströmand, and Sundman 2008).

These calculations have been repeated in this work for the temperature range from 200 to $1300^{\circ} \mathrm{C}$, and ambient pressure. The results are presented in Figures 3-12 and 3-13.

In Figure 3-12, the solid green line corresponds to $\mathrm{Cr}_{2} \mathrm{O}_{3}$; the red line to $\mathrm{NaCl}$ (melting begins at around $730^{\circ} \mathrm{C}$ ). Other phases present are the gaseous phase (black line); halite (5, light blue),

orthorhombic (6, dark green) and hexagonal (4, dark brown). It can be seen that chromia remains stable in this very aggressive atmosphere and molten salt up to $\sim 1,000^{\circ} \mathrm{C}$. Beyond this temperature, a rapid $\mathrm{Cr}_{2} \mathrm{O}_{3}$ dissolution process takes place.

Figure 3-13 shows how chromium is distributed among the several thermodynamically stable phases in the system. It shows a growing concentration of chromium-bearing compounds in the gaseous phases (1, black); and the onset of chromium concentration increase in ionic liquid $\left(2\right.$, red) beginning at $\sim 1000^{\circ} \mathrm{C}$ (Shi, Engströmand, and Sundman 2008). 


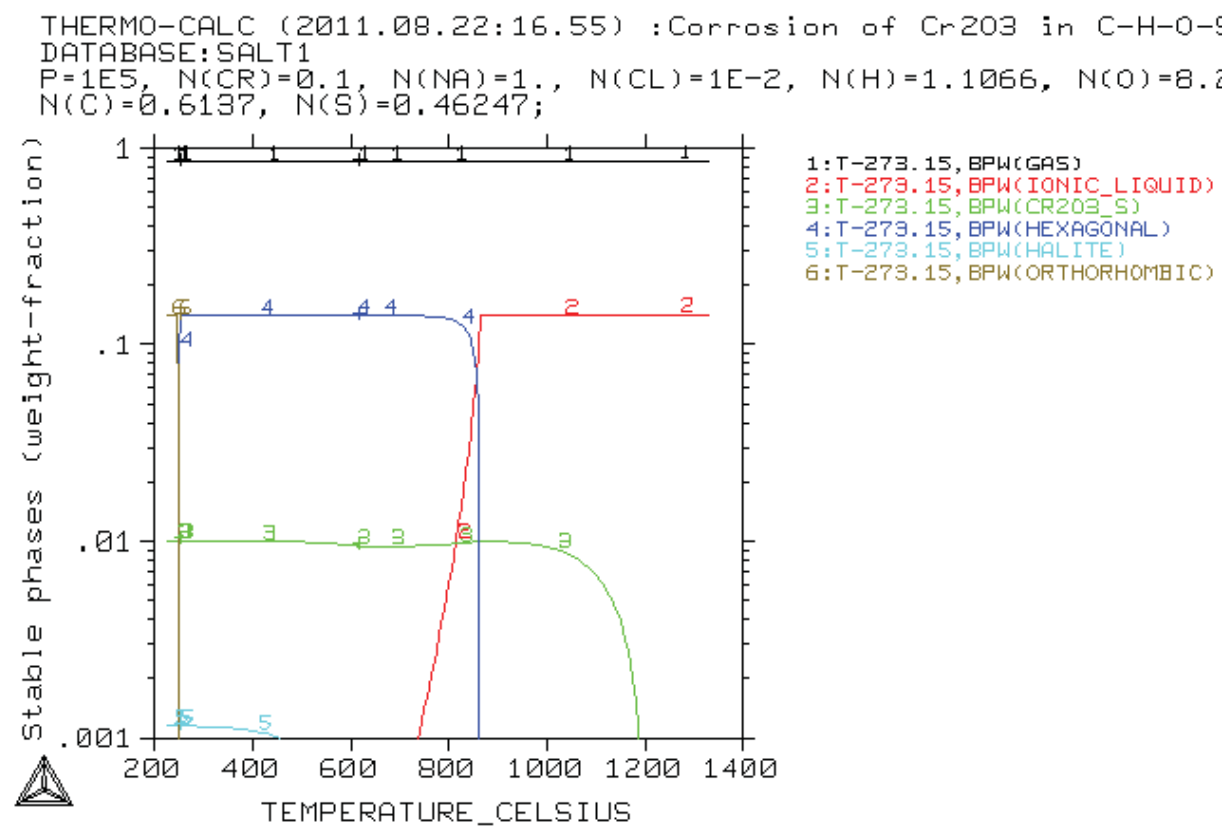

Figure 3-12. Stable phases in the $\mathrm{Cr}_{2} \mathrm{O}_{3}-$ molten salt $\mathrm{NaCl}-\mathrm{C}-\mathrm{H}-\mathrm{O}-\mathrm{N}-\mathrm{S}$ system (Shi, Engströmand, and Sundman 2008).

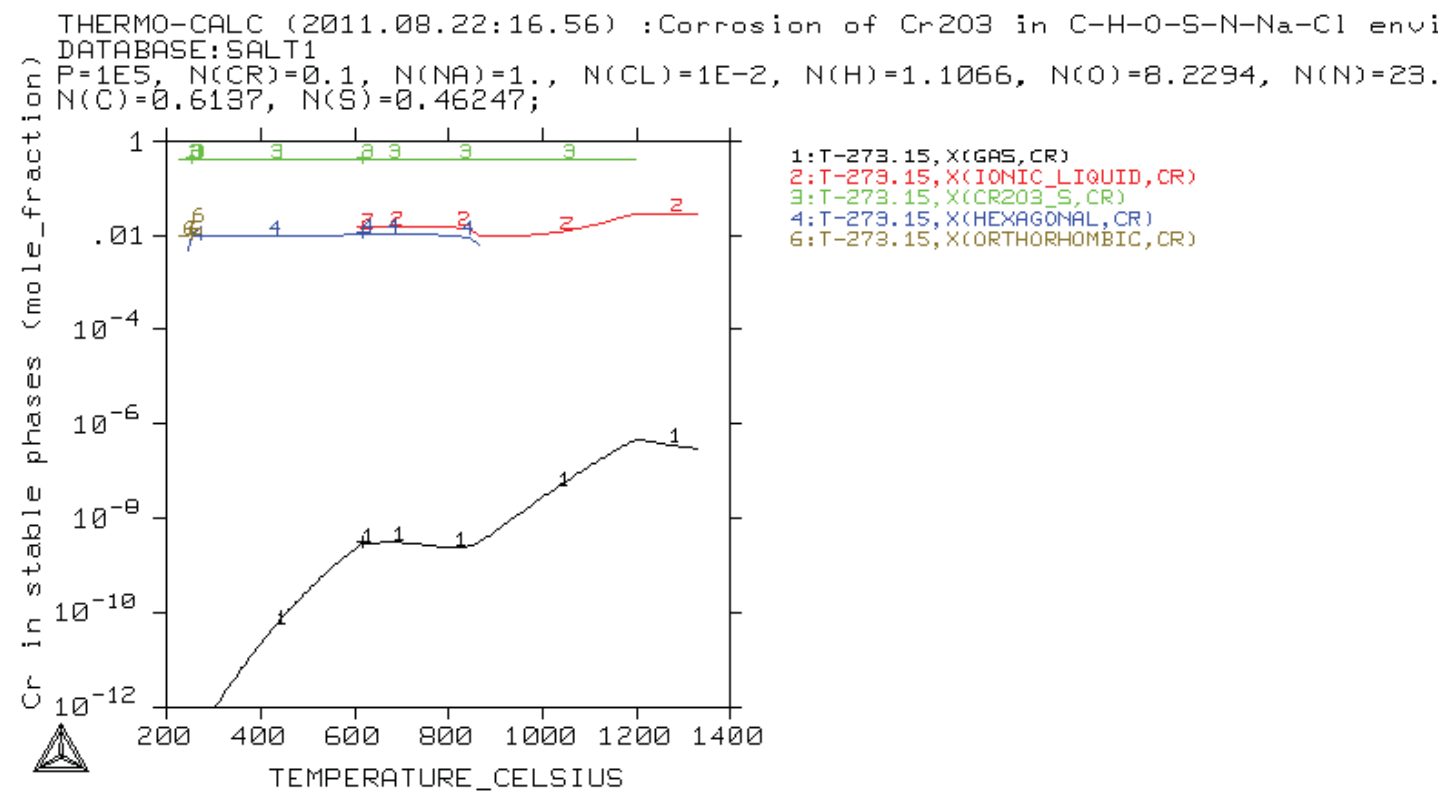

Figure 3-13. Distribution of chromium in stable phases as a function of temperature (Shi, Engströmand, and Sundman 2008).

Overall, these data support the fact that $\mathrm{Cr}_{2} \mathrm{O}_{3}$ could provide a high degree of protection of chromiumbearing Alloy 242 and Alloy N, provided it is deposited upon the surface in a compact in a contiguous way. This conclusion will need to be further evaluated experimentally.

Figure 3-14 illustrates the formation of a protective layer of $\mathrm{Cr}_{2} \mathrm{O}_{3}$ in a generic stainless steel Fe-

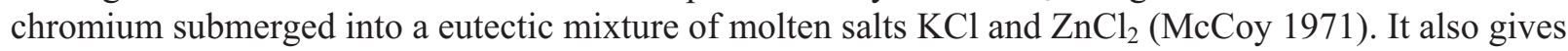


an idea of what modeling techniques are used by the computational thermodynamics community for analysis of hot corrosion phenomena in molten salts.

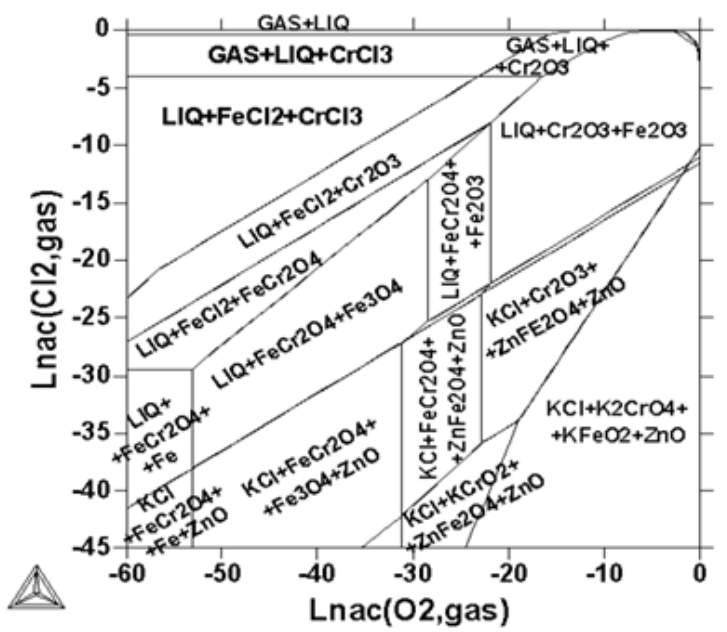

Figure 3-14. The representation of the "Fe-chromium" generic stainless steel in eutectic mixture of salts $\mathrm{KCl}$ and $\mathrm{MgCl}_{2}$ (Shi, Engströmand, and Sundman 2008).

\subsubsection{Hot Corrosion of Nickel-Based High temperature Alloys (Alloy 242 and Alloy $\mathbf{N}$ in FLiNaK)}

The problem of the quantitative assessment of hot corrosion for such complex multi-component alloys as Alloy 242 or Alloy $\mathrm{N}$ is extremely complicated from the computational thermodynamics perspective. The need to work with at least three data bases (TTNI8, SALT1, and SSUB4 (for superalloys, molten salts-ionic liquids, and pure substances) rapidly renders the overall number of competing phases unmanageable. In such a situation, even a high-quality global equilibrium solver may yield unphysical results. To make this problem more tractable, the researcher needs to reduce the number of components in the system without jeopardizing the quality of the results, making reasonable assumptions about phases that might be formed at conditions of interest and a realistic representation of the initial set of phases in the system.

After tedious computer experimentation, it was decided to reduce Alloy 242 and Alloy N to Poor Man's 242 and Poor Man's N," respectively. More specifically, it was assumed that the behavior of multicomponent Alloy 242 can be realistically described using just four components: molybdenum, iron, chromium, and the balance going to nickel. In such a formulation, the composition of Alloy $\mathrm{N}$, in wt\%, is given as follows: $\mathrm{Ch}-7.2 \%$; Mo-16.8\%; Fe- $\sim 0.5 \%$, and the balance-nickel. For Alloy 242, proceeding in a similar fashion, we get: Ch-8.1\%; Mo-24.7\%; Fe-1.4\%; and the balance-nickel (65.2\%).

Since the ternary system KF-LiF-NaF was not assessed in database SALT1, the binary system KF$\mathrm{LiF}$ was used. This assumption seems to be reasonable because the introduction of the third salt, NaF, reduces the temperature of eutectic to $\sim 457^{\circ} \mathrm{C}$, while for the binary system KF-LiF it was assessed as $492^{\circ} \mathrm{C}$. No qualitative changes were expected in the behavior of the whole system as there are not ternary intermediate compounds, or binary compounds in the corresponding phase diagrams.

A simple ThermoCalc script was prepared to model the hot corrosion process at $\sim 600^{\circ} \mathrm{C}$, which is given in Figure 3-15. As can be seen from the script, all calculations were made for 1 mole of the "Alloy $\mathrm{N}+$ molten salt" mixture, and at ambient pressure. 


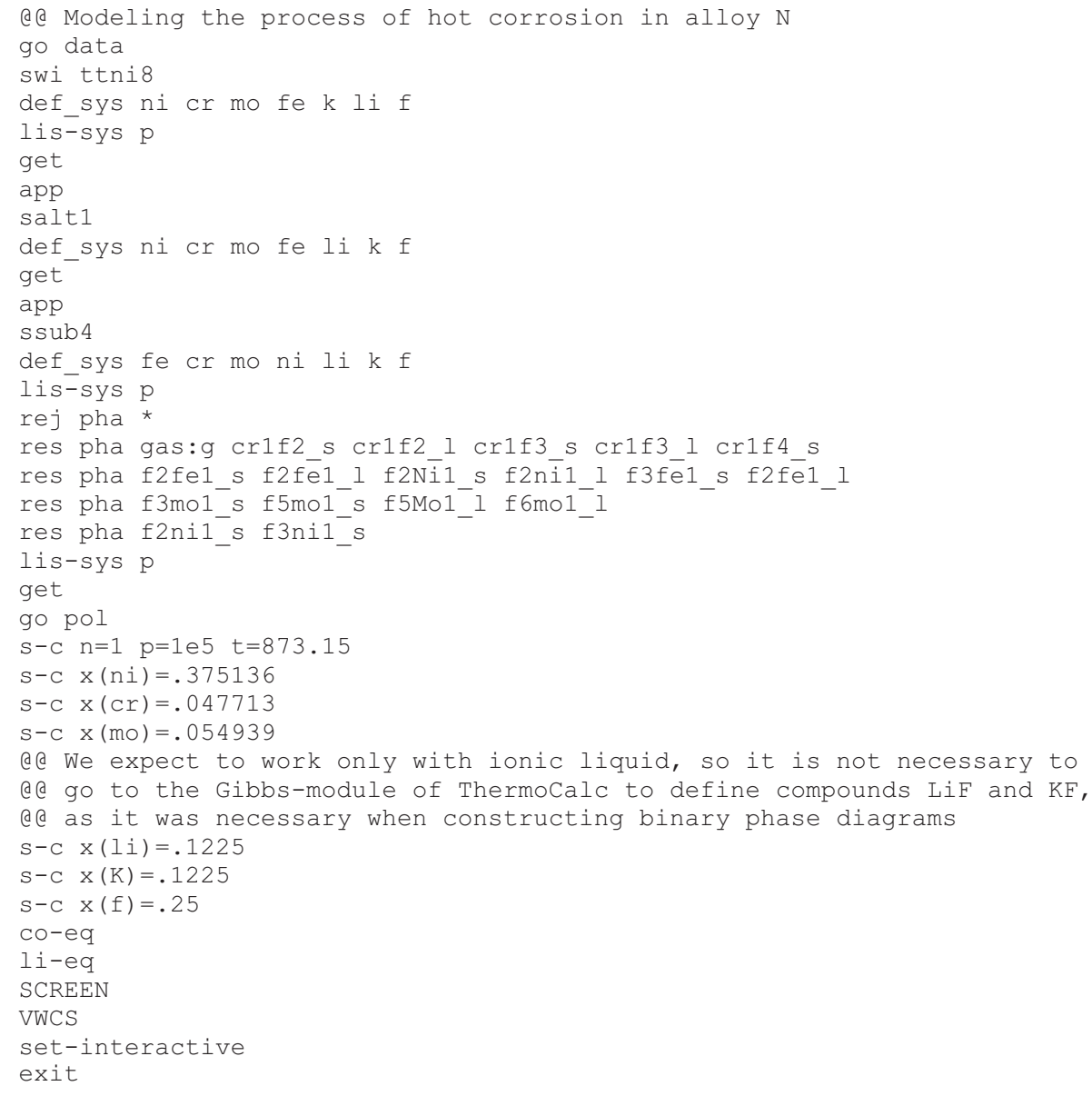

Figure 3-15. ThermoCalc script for assessing hot corrosion of Alloy $\mathrm{N}$ in FLiNaK approximated by a binary mixture LiF-KF.

The results shown in Figure 3-16 were obtained from a so-called "single point" equilibrium calculation. These results provide a very reasonable equilibrium picture for both alloys-FCC-matrix, and a small amount of the $\mu$-phase. There is also an ionic liquid phase and an infinitely small amount of solid $\mathrm{CrF}_{2}$ ( this is denoted with blue oval in Figure 3-16). This latter result is very important because it demonstrates how the process of corrosion of Alloy N could begin by leaching chromium from the alloy's composition.

The next step was to assess how the hot corrosion process might develop if the chemical activity of fluoride varies, so that the severity of hot corrosion attack could be compared for Alloy 242 and Alloy N. This was done by varying the chemical activity of F. However, since it was assumed that there is practically no $\mathrm{F}_{2}$ in the gaseous phase, the status of the $\mathrm{F}_{2}$ gas was set to "suspended" or "dormant" (in the latter case only the driving forces would be computed for this phase, but its amount is assumed to be zero).

Proceeding in a way similar to the oxidation of these two alloys, the following results were obtained. First, conducting a single-point calculation for pure molten salt mixture, the expected results were confirmed after the modeling of oxidizing of Alloy 242 and Alloy N; Alloy 242 is more prone to hot corrosion than Alloy N. This is illustrated by Figure 3-17. 


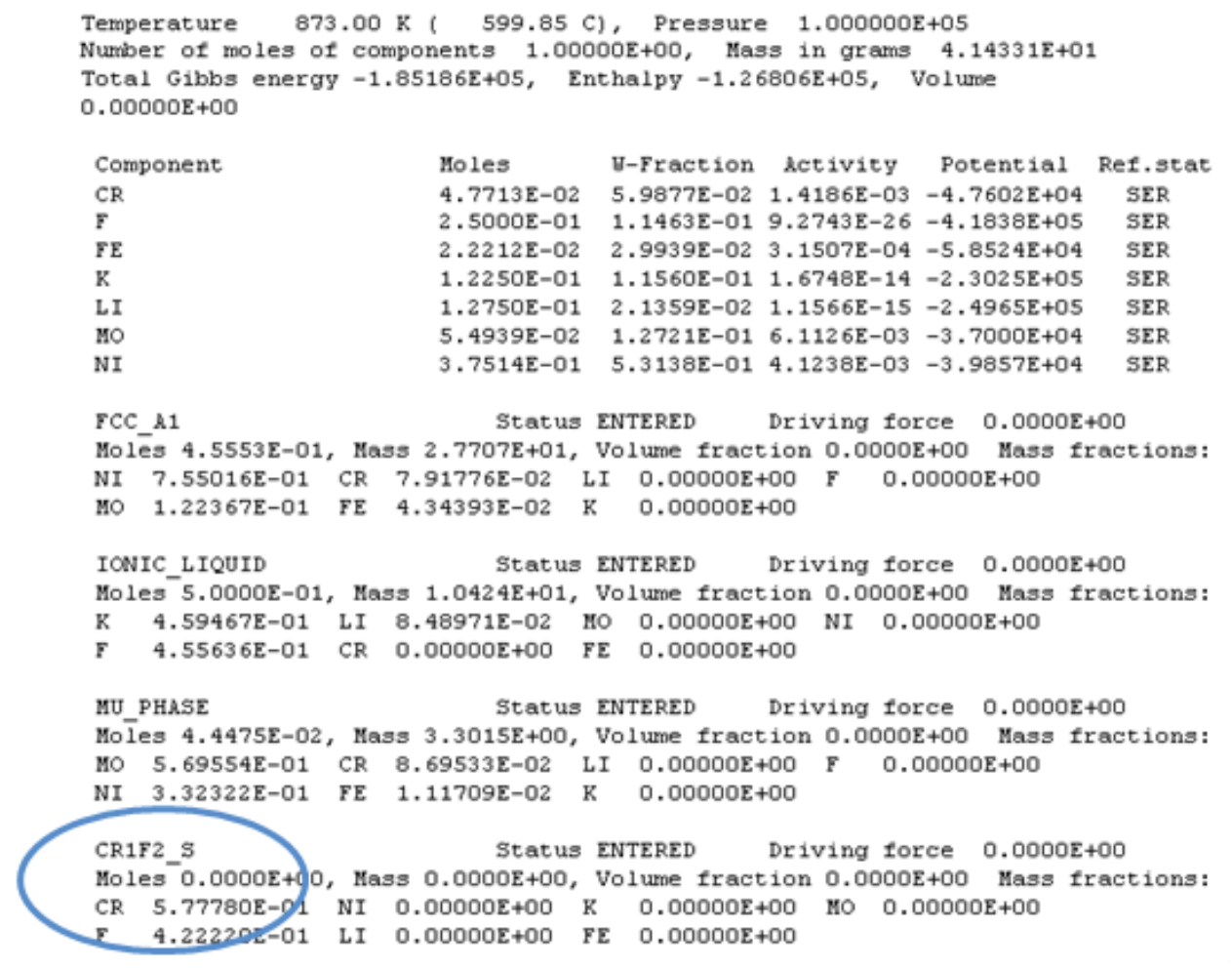

Figure 3-16. The results of a single-point calculation for $\mathrm{T}=600^{\circ} \mathrm{C}$, Alloy $\mathrm{N}$.

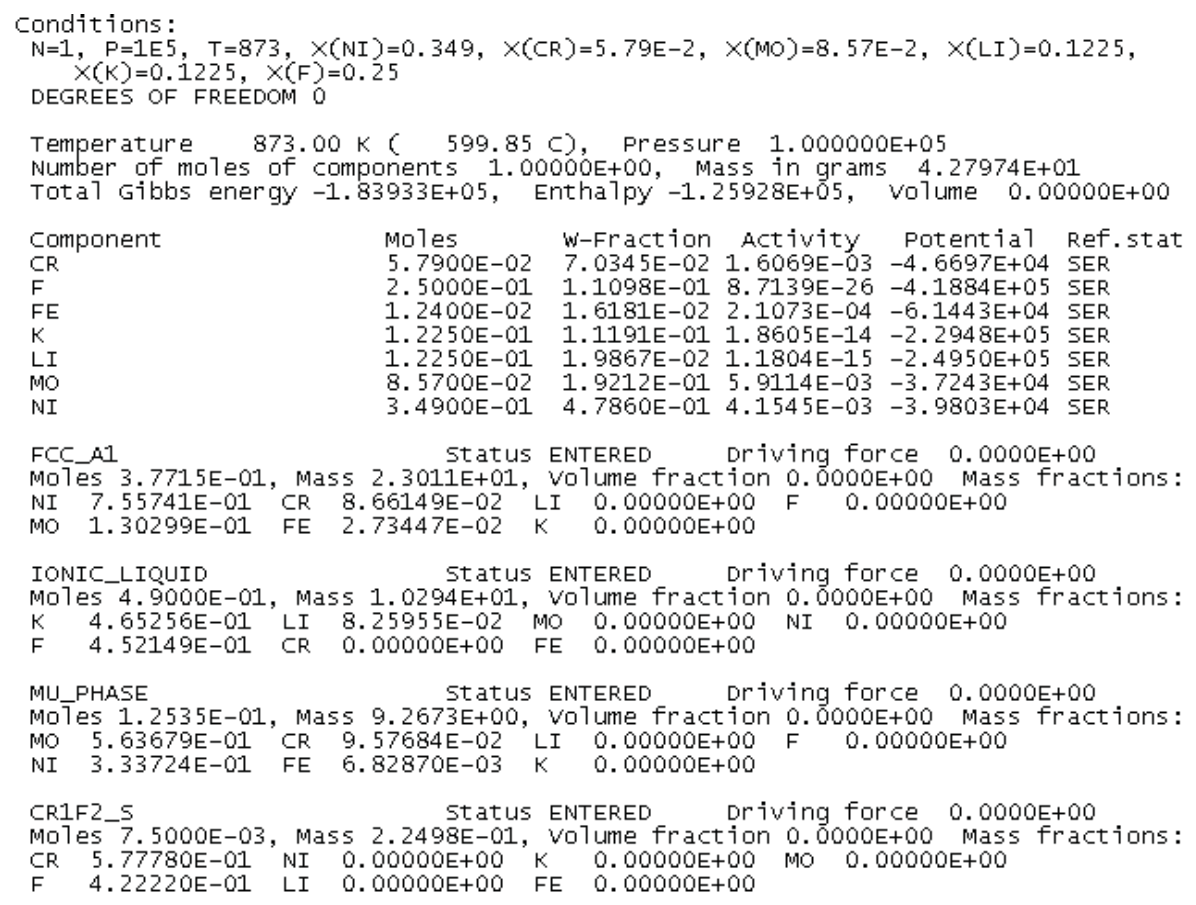

Figure 3-17. The results of a single-point calculation for $\mathrm{T}=600^{\circ} \mathrm{C}$, Alloy 242.

This conclusion is reached because, under similar conditions, Alloy 242 forms more $\mathrm{CrF}_{2}$ than Alloy $\mathrm{N}$-finite, albeit a very small amount (0.7E-3 moles) vs. an infinitesimally small amount of $\mathrm{CrF}_{2}$ for Alloy N. 
For Alloy N, in "mild" and "aggressive" conditions (corresponding to increasing chemical activity of F), the results are illustrated by Figures 3-18 and 3-19.

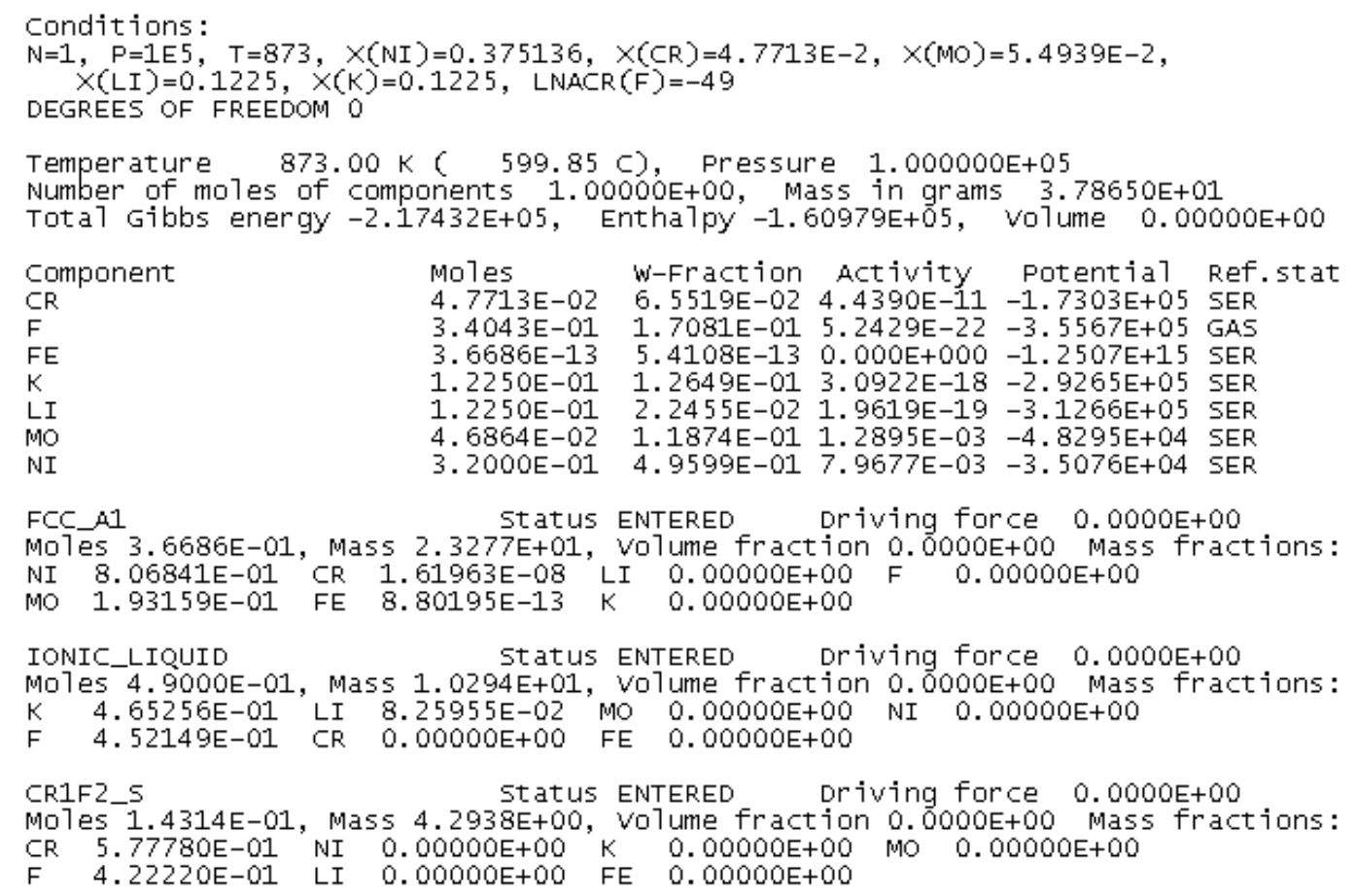

Figure 3-18. Hot corrosion of Alloy $N$ under "mild" conditions $-\ln [a c(F)]=-49$, accompanied by the formation of $\mathrm{CrF}_{3}$.

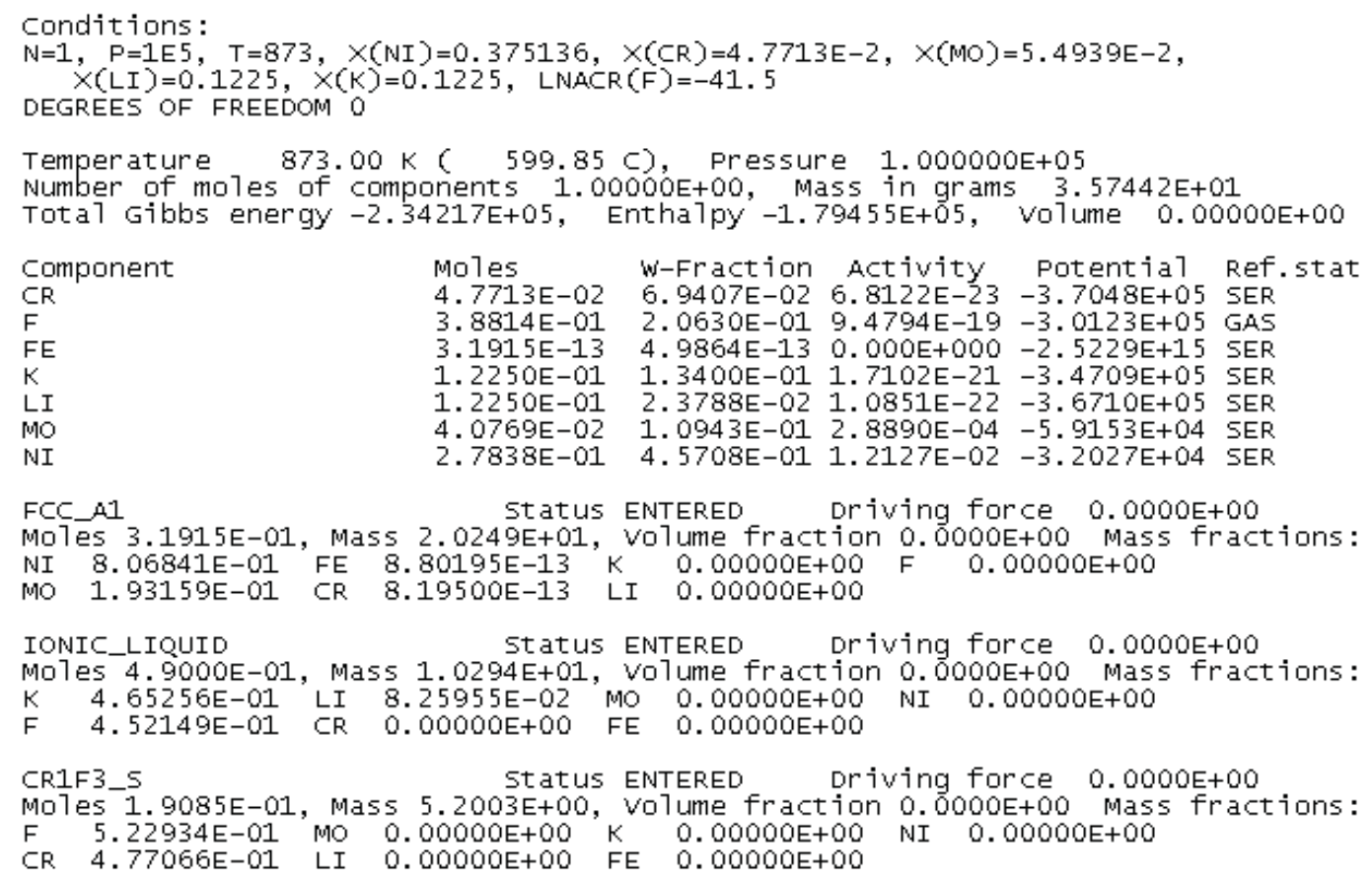

Figure 3-19. Hot corrosion of Alloy $N$ under "aggressive" conditions $-\ln [\operatorname{ac}(F)]=-41.5$, accompanied by the formation of $\mathrm{CrF}_{3}$. 
Similar calculations conducted for Alloy 242 as shown in Figure 3-20 confirm the previous conclusion - it is more prone to hot corrosion, its onset taking place at "mild" conditions around $\ln [\operatorname{ac}(\mathrm{F})]$ $=-57.5$, i.e., practically 10 orders of magnitude weaker hot corrosion conditions than for Alloy N. The formation of a more oxidized $\mathrm{CrF}_{3}$ also takes place in much milder conditions as shown in Figure 3-21.

Thus, we come to the conclusion that the 4-component simple representation of Alloy 242 and Alloy $\mathrm{N}$ was quite reasonable, and we confirm experimental results on the relative stability of these materials in molten salt.

As far as binary salt mixtures are concerned, Figure 3-22 below illustrates that hot corrosion for such system begins with the initial formation of $\mathrm{MoCl}_{4}$, rather than chromium leaching process. These results will need to be verified experimentally in future research efforts.

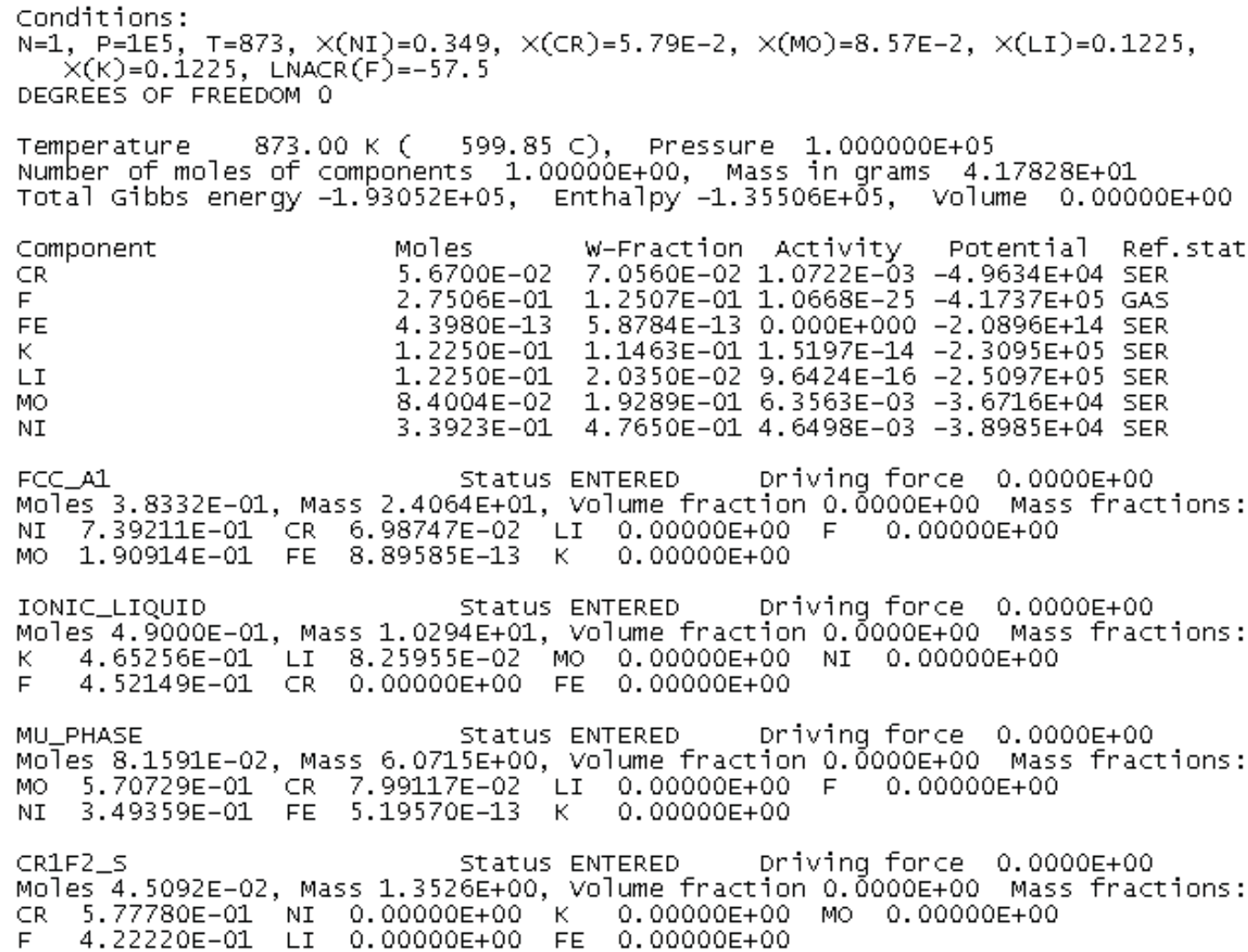

Figure 3-20. Hot corrosion of alloy 242 in "mild" conditions, $\ln [\mathrm{ac}(\mathrm{F})]=-57.5$, accompanied by the onset of formation of $\mathrm{CrF}_{2}$. 


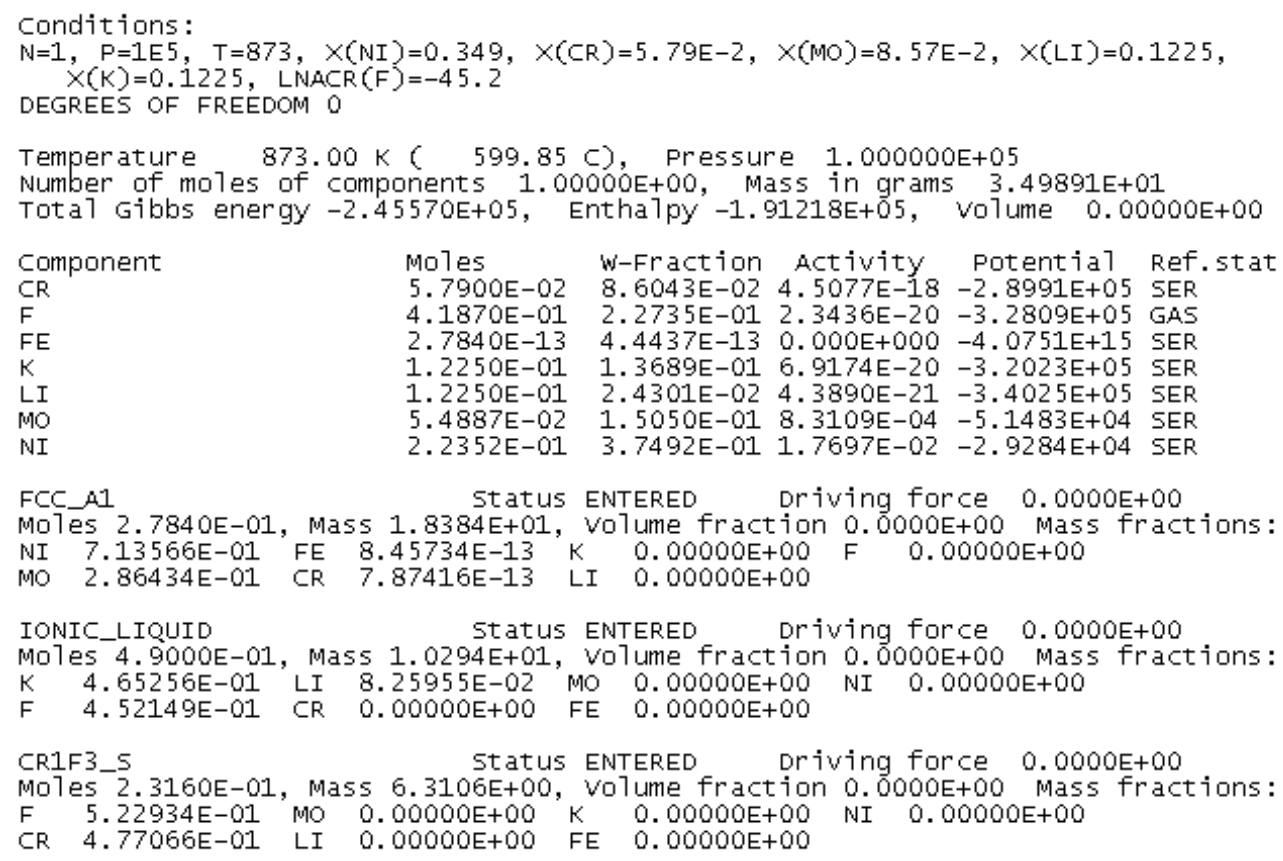

Figure 3-21. Hot corrosion of alloy 242 in "aggressive" conditions, $\operatorname{In}[\mathrm{ac}(\mathrm{F})]=-45.2$, accompanied by the onset of formation of $\mathrm{CrF}_{2}$.

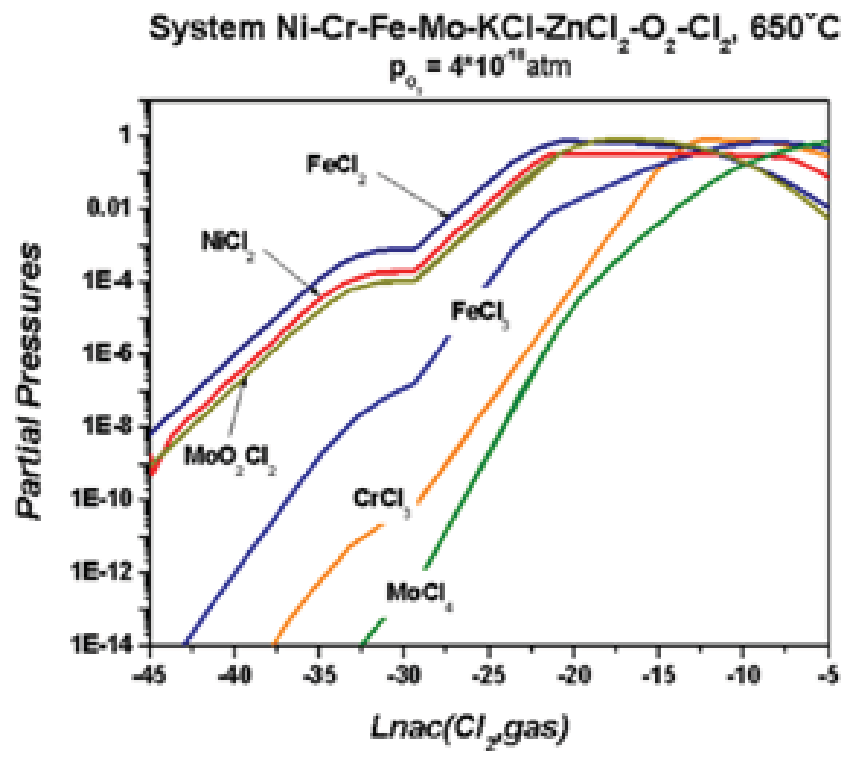

Figure 3-22. Computational assessment of partial pressures of different hot corrosion products for the $\mathrm{KCl}$ $\mathrm{ZnCl}_{2}$ eutectic mixture and generic Ni-Cr-Fe-Mo alloy (Trujillo 2011).

\subsection{Conclusions and Recommendations}

In this computational work, we modeled the behavior of Alloy 242 and Alloy $\mathrm{N}$ in a ternary molten salt eutectic mixture LiF-NaF-KF. It was established that the use of just four principal alloying elements - nickel, chromium, molybdenum, and iron - allows making quite reasonable conclusions about the nature of hot corrosion resistance of these materials. In turn, it probably implies that further alloy composition optimization work could be conducted to further enhance alloy hot corrosion resistance. 
It was established, in complete agreement with earlier experimental studies (Ignatiev et al. 2008; Shi, Engströmand, and Sundman 2008) that the onset of hot corrosion for both alloys is associated with chromium leaching and the formation of $\mathrm{CrF}_{2}$ in relatively mild oxidizing conditions followed by the formation of $\mathrm{CrF}_{3}$ in harsher conditions. However, for Alloy $\mathrm{N}$ the onset of hot corrosion takes place in much harsher conditions than for Alloy 242.

Significant deviations from these conclusions are not expected for binary molten salt mixture $\mathrm{NaCl}-\mathrm{MgCl}_{2}$; or in $\mathrm{NaF}-\mathrm{ZrF}_{4}$. However, thermodynamic data for these systems need to be generated in future research efforts in order to get a clearer picture of the mechanisms of hot corrosion onset.

Because time ran out, work on hot corrosion of silicon carbide was not completed, which will also need to be done later on. However, experimental data indicate (Ignatiev et al. 2008) that the principal mechanism of corrosion for this material is associated with the formation of $\mathrm{SiO}_{2}$, rather than the formation of carbon-bearing oxidation products.

In conclusion, continuing this computational research effort will allow nuclear engineers to approach the problem of down selection of materials for NGNP AHTRs with greater confidence, less effort spent on expensive experimental work, and in shorter periods of time. 


\section{MOLTEN SALT MIXTURE PROPERTIES FOR KF-ZrF 4 AND $\mathrm{KCl}-\mathrm{MgCl}_{2}$}

Molten salt coolants are being investigated as primary coolants for a fluoride high-temperature reactor and as secondary coolants for high temperature reactors such as the next generation nuclear plant. This work provides a review of the thermophysical properties of candidate molten salt coolants for use as a secondary heat transfer medium from a high temperature reactor to a processing plant. The molten salts LiF-NaF-KF, KF- $\mathrm{ZrF}_{4}$ and $\mathrm{KCl}-\mathrm{MgCl}_{2}$ were considered for use in the secondary coolant loop. The thermophysical properties necessary to add the molten salts $\mathrm{KF}-\mathrm{ZrF}_{4}$ and $\mathrm{KCl}-\mathrm{MgCl}_{2}$ to RELAP5-3D were gathered for potential modeling purposes. The properties of the molten salt LiF-NaF-KF were already available in RELAP5-3D. The effect that the uncertainty in individual properties had on the Nusselt number was evaluated. This uncertainty in the Nusselt number was shown to be nearly independent of the molten salt temperature.

\subsection{Introduction}

Molten salt coolants are being investigated as primary coolants for a Fluoride High-temperature Reactor (FHR) and as secondary coolants for High Temperature Reactors (HTRs) such as the Next Generation Nuclear Plant (NGNP) and AHTR. The NGNP project was initiated based on a US Department of Energy (DOE) study aimed at the research and development of a helium-cooled, high temperature gas reactor that could generate both electricity and process heat for the production of hydrogen (Mills, Soto, and Gibbs 2007). The purpose of this work is to provide a review of thermophysical properties of candidate molten salt coolants, which may be used as a secondary heat transfer medium from a High Temperature Reactor (HTR) to a processing plant; for example, a hydrogenproduction plant. Several fluids are under consideration for heat transfer fluids between the HTR, such as the NGNP, and the downstream processes. Applicability of molten salts as heat transferring coolants has been assessed by ORNL researchers (Williams 2006; Williams, Toth, and Clarno 2006). Williams (2006) contended that the coolants must have the following characteristics:

- Chemical stability at high temperatures $\left(500-800^{\circ} \mathrm{C}\right)$

- Freezing (melting) temperatures as low as possible, preferably lower than $525^{\circ} \mathrm{C}$

- Large specific heat and thermal conductivity

- Low vapor pressures that are substantially less than one atmosphere at operating temperatures and are thus not volatile

- Compatibility with high-temperature materials, alloys, graphite, and ceramics.

Molten salts appear to be excellent candidates that meet most of these requirements. However, no single-component salt meets the requirement of low melting temperature; multi-component eutectic mixtures do however meet the melting temperature requirement. Some multi-component eutectic salt mixtures have melting temperatures less than $500^{\circ} \mathrm{C}$. The use of eutectic mixtures ensures compositional and phase stability, and therefore, uniform thermophysical properties in the operating temperature range (Grimes 1967; Grimes et al. 2002; Ingersoll 2007).

Molten salt technology has been used for many decades in industrial process heat transfer, thermal storage, heat treatment, high-temperature electrochemical plating, and other materials processing applications. The potential utility of molten salts as heat transfer agents was also demonstrated for nuclear reactors, as the liquid fuel in the Aircraft Reactor Experiment (ARE) and the Molten Salt Reactor Experiment (MSRE) programs. The behavior and material compatibility of various molten salts was studied extensively by ORNL from the 1950s through the 1970s in support of the MSRE and the Molten Salt Breeder Reactor (MSBR) programs. Several types of molten salt, including LiF-NaF-KF (46.5, 11.5, 
and $52 \mathrm{~mol} \%$, respectively; also known as $\mathrm{FLiNaK}$ ), $\mathrm{LiF}_{-}-\mathrm{BeF}_{2}$ (67 and $33 \mathrm{~mol} \%$, respectively; also known as $\mathrm{FLiBe}$ ), and $\mathrm{KCl}-\mathrm{MgCl}_{2}$ (67 and $33 \mathrm{~mol} \%$, respectively), have been investigated recently by several Japanese and U.S. groups (FLiBe and FLiNaK), as well as the University of Wisconsin (KCl$\mathrm{MgCl}_{2}$ and $\mathrm{FLiNaK}$ ) in support of fusion reactor and HTR concepts, respectively.

In the liquid state, molten salts have viscosity and appearance similar to water. A mixture of sodium and potassium nitrate, with a melting temperature of $\sim 222^{\circ} \mathrm{C}$, is commonly used in solar applications. A primary advantage of molten salt technology is that the molten salt can be heated to $\sim 560^{\circ} \mathrm{C}$, which allows high energy steam to be generated at utility-standard temperatures $\left(11.4 \mathrm{MPa}, 550^{\circ} \mathrm{C}\right)$, achieving high thermodynamic cycle efficiencies of approximately 40 percent in modern steam turbine systems (Sohal et al. 2010).

The molten salts that are being considered as the secondary loop coolants are: $\mathrm{LiF}-\mathrm{NaF}-\mathrm{KF}, \mathrm{KF}-\mathrm{ZrF}$, and $\mathrm{KCl}-\mathrm{MgCl}_{2}$. Property data for these molten salts are being gathered so that they can potentially be added to RELAP5-3D for modeling purposes. The RELAP5-3D code was developed for best-estimate transient simulation of light water reactor coolant systems during postulated accidents. The generic modeling approach permits the simulation of a variety of thermal hydraulic systems and coolants, including molten salts ${ }^{8}$. The properties for LiF-NaF-KF are already included in RELAP5, so its properties will not be discussed. The results of this effort are described in this work.

\subsection{Description of Properties Required by RELAP5-3D}

RELAP5-3D accesses salt thermodynamic properties through tables located in auxiliary files. The required fluid properties include specific volume, $v\left(\mathrm{~m}^{3} / \mathrm{kg}\right)$; specific internal energy, $u(\mathrm{~J} / \mathrm{kg})$; coefficient of thermal expansion, $\beta(1 / \mathrm{K})$; isothermal compressibility, $\kappa(1 / \mathrm{Pa})$; specific heat capacity at constant pressure, $c_{P}(\mathrm{~J} / \mathrm{kg}-\mathrm{K})$; and specific entropy, $s(\mathrm{~J} / \mathrm{kg}-\mathrm{K})$. The coefficient of thermal expansion and isothermal compressibility are defined as

$\beta \equiv \frac{1}{v}\left(\frac{d v}{d T}\right)_{P}=-\frac{1}{\rho}\left(\frac{d \rho}{d T}\right)_{P}$

and

$\kappa \equiv-\frac{1}{v}\left(\frac{d v}{d P}\right)_{T}=\frac{1}{\rho}\left(\frac{d \rho}{d P}\right)_{T}$

where $T$ is the temperature $(\mathrm{K}), P$ is the pressure $(\mathrm{Pa})$, and $\rho$ is the density $\left(\mathrm{kg} / \mathrm{m}^{3}\right)$.

The calculation of these properties for the liquid and vapor phases are described in Section 4.2.1 and 4.2.2 respectively. The calculation of the saturation line is described in Section 4.2.3. The transport properties are described in Section 4.2.4.

\subsubsection{Liquid Thermodynamic Properties}

Table 4-1 shows some of the physical properties of the molten salts. The two molten salts have similar melting points and boiling points, thus they have similar application possibilities.

Table 4-1. Basic physical properties of molten salts.

\begin{tabular}{|c|c|c|c|c|}
\hline Salt & Composition & $\begin{array}{c}\text { Molecular Weight } \\
(\mathrm{g} / \mathrm{mol})\end{array}$ & $\begin{array}{c}\text { Melting Point } \\
\left({ }^{\circ} \mathbf{C}\right)\end{array}$ & $\begin{array}{c}\text { Boiling Point } \\
\left({ }^{\circ} \mathrm{C}\right)\end{array}$ \\
\hline LiF-NaF-KF & $(46.5-11.5-42)$ & 41.3 & 454 & 1570 \\
\hline $\mathrm{KF}-\mathrm{ZrF}{ }_{4}$ & $(58-42)$ & 103.9 & 390 & $\sim 1450$ \\
\hline $\mathrm{KCl}-\mathrm{MgCl}_{2}$ & $(68-32)$ & 81.4 & 426 & $>1418$ \\
\hline
\end{tabular}


The specific volume is calculated as

$v=\frac{1}{\rho}$

where $\rho$ is the fluid density.

The density of the molten salts $\mathrm{KF}-\mathrm{ZrF}_{4}$ and $\mathrm{KCl}-\mathrm{MgCl}_{2}$ are defined in Williams (2006) as

$\rho=3416.0-0.887 \cdot(T-273.15)$

and by Janz et al. (1975) as

$\rho=2000.7-0.45709 \cdot T$

respectively, where temperature, $T$ is in $\mathrm{K}$. The density correlation for $\mathrm{KF}^{-\mathrm{ZrF}_{4}}$ in Equation 4 has an unknown temperature range of applicability and an uncertainty of about $\pm 5 \%$. The density correlation for $\mathrm{KCl}-\mathrm{MgCl}_{2}$ in Equation 5 is applicable for the temperature range of $1030-1140 \mathrm{~K}$ and an uncertainty of $\pm 1.5 \%$.

The heat capacity used for $\mathrm{KF}-\mathrm{ZrF}_{4}$ is based on a predicted value of $1051 \mathrm{~J} / \mathrm{kg} \cdot \mathrm{K}$ and the heat capacity of $\mathrm{KCl}-\mathrm{MgCl}_{2}$ was measured as $1156 \mathrm{~J} / \mathrm{kg} \cdot \mathrm{K}$ (Williams 2006). The heat capacity is assumed constant for the liquid phase.

The liquid specific internal energy is determined from the relation

$\Delta u=\int_{T_{0}}^{T} c_{P} d T-P \Delta v$.

Specific heat is assumed constant for the liquid phase giving

$u=c_{P}\left(T-T_{0}\right)_{P}-P\left(v-v_{1}\right)$

where $T_{0}$ is a reference temperature and $v_{1}$ is evaluated at $T_{0}$.

In Davis (2005), the effect of a reversible, isothermal change in pressure is also accounted for in the internal energy. However it is ignored here, as its effect is small in comparison.

The value of the thermal expansion coefficient can be obtained by evaluating Equation 1 using Equations 4 and 5. The thermal expansion coefficients determined for the salts $\mathrm{KF}-\mathrm{ZrF}_{4}$ and $\mathrm{KCl}-\mathrm{MgCl}_{2}$ are:

$\beta=\frac{1}{3851.18-(T-273.15)}$

and

$\beta=\frac{1}{4377.04-T}$

respectively.

Correlations for the isothermal compressibility $\kappa$ of these two salts were not available, so their values were set arbitrarily to the values that were used in adding LiF-NaF-KF to the RELAP5 software (Davis 2005).

$\kappa=2.3 \times 10^{-11} e^{0.001 T}$. 
The liquid specific entropy is determined from the relation

$S=\int_{T_{0}}^{T} \frac{c_{P}}{T} d T$.

Once again specific heat is constant giving

$s=c_{P} \ln T / T_{0}$.

\subsubsection{Vapor Thermodynamic Properties}

The specific volume of the vapor can be calculated using the ideal gas law

$v=\frac{R T}{P}$

where

$R=\frac{\bar{R}}{M}$

The variable $\bar{R}$ is the universal gas constant, and $M$ is the molecular weight of the mixture.

The method of determining the specific heat capacity of the mixture is documented in Davis (2005). The mass fraction of each component, $x_{i}$, is calculated as

$x_{i}=\frac{X_{i} M_{i}}{M}$

where $M_{i}$ is the molecular weight of the $\mathrm{i}^{\text {th }}$ component in the mixture and $X_{i}$ is the corresponding mole fraction given in Table I.

The mass fraction of each component is then used to calculate the specific heat of the gas as

$c_{P}=\sum x_{i} c_{P i}$

The parameters needed to calculate the specific heat capacity of the vapor are included in Table 4-2.

Table 4-2. Parameters for vapor components. The values for $\tilde{c}_{P i}$ were all evaluated at $1000 \mathrm{~K}$.

\begin{tabular}{|c|c|c|}
\hline Component & $M_{i}(\mathrm{~g} / \mathrm{mol})$ & $\tilde{c}_{P i}(\mathrm{~J} / \mathrm{mol} \cdot \mathrm{K})$ \\
\hline $\mathrm{KF}$ & 58.097 & 37.846 \\
\hline $\mathrm{ZrF}_{4}$ & 167.214 & 105.459 \\
\hline $\mathrm{KCl}$ & 74.5513 & 38.061 \\
\hline $\mathrm{MgCl}_{2}$ & 95.211 & 61.748 \\
\hline
\end{tabular}

The molar specific heat capacity values come from Chase (1988).

The constants that were determined for the vapor mixtures are summarized in Table 4-3.

Table 4-3. Constants for salt vapors.

\begin{tabular}{|lcccc|}
\hline \multicolumn{1}{|c}{ Salt } & Composition & $\mathrm{M}(\mathrm{g} / \mathrm{mol})$ & $\mathrm{R}(\mathrm{J} / \mathrm{kg} \cdot \mathrm{K})$ & $c_{P}(\mathrm{~J} / \mathrm{kg} \cdot \mathrm{K})$ \\
\hline $\mathrm{KF}_{-\mathrm{ZrF}} \mathrm{K}_{4}$ & $(58-42)$ & 103.926 & 79.999 & 637.409 \\
$\mathrm{KCl}-\mathrm{MgCl}_{2}$ & $(68-32)$ & 81.162 & 102.437 & 562.340 \\
\hline
\end{tabular}


The specific internal energy of the vapor is calculated as (Davis 2005)

$u=u_{g 0}+\int_{T_{0}}^{T}\left(c_{P}-R\right) d T=u_{g 0}+\left(c_{P}-R\right)\left(T-T_{0}\right)$

where $u_{g 0}$ is a reference vapor specific energy that is evaluated at a reference pressure and temperature, $P_{0}$ and $T_{0}$.

The thermal expansion coefficient of the vapor can be found by evaluating Equations 1 and 13

$\beta=\frac{1}{T}$.

The isothermal compressibility can be calculated similarly as

$\kappa=\frac{1}{P}$.

The specific entropy of the vapor is calculated as (Davis 2005)

$s=s_{g 0}+\int_{T_{0}}^{T} \frac{c_{P}}{T} d T-\int_{P_{0}}^{P} \frac{R}{P} d P=s_{g 0}+c_{P} \ln T / T_{0}-R \ln P / P_{0}$

where $s_{g 0}$ is a reference vapor specific entropy that is evaluated at a reference pressure and temperature, $P_{0}$ and $T_{0}$.

\subsubsection{Saturation Line}

The calculation of the saturation line for the two molten salts follows the work of Davis (2005). The correlation used in calculating the saturation line is

$P_{\text {sat }}=133.32 \times 10^{\left(A_{\text {sat }}-B_{\text {sat }} / T\right)}$

where $P_{\text {sat }}$ is the saturation pressure at temperature $T$ and $A_{\text {sat }}$ and $B_{\text {sat }}$ are constants that depend on the salt. Values for $A_{\text {sat }}$ and $B_{\text {sat }}$ were unavailable for the molten salts, so 9.04 and 10,500 were assumed respectively as was done previously (Davis 2005).

The saturation line was used to define the triple and critical points. The triple point temperature was set to the melting temperature given in Table 1. The triple point pressure was calculated using Equation 21. The reference values of $T_{0}$ and $P_{0}$ were set to the triple point values.

The critical point values were chosen in the same way that the critical point values of LiF-NaF-KF were chosen in Davis (2005). The values for the triple and critical points are shown in Table 4-4.

Table 4-4. Values for triple and critical points.

\begin{tabular}{|lcccc|}
\hline \multicolumn{1}{|c}{ Salt } & $T_{0}(\mathrm{~K})$ & $P_{0}(\mathrm{~Pa})$ & $T_{\text {crit }}(\mathrm{K})$ & $P_{\text {crit }}(\mathrm{Pa})$ \\
\hline $\mathrm{KF}-\mathrm{ZrF}_{4}$ & 663.15 & $2.145 \mathrm{E}-05$ & 2138.9 & $1.802 \mathrm{E}+06$ \\
$\mathrm{KCl}-\mathrm{MgCl}_{2}$ & 699.15 & $1.402 \mathrm{E}-04$ & 2138.9 & $1.802 \mathrm{E}+06$ \\
\hline
\end{tabular}

The values for $u_{g 0}$ and $s_{g 0}$ were chosen such that the differences between the vapor and liquid values were approximately zero at the critical point.

The saturation line should be avoided, as the results are not reliable in the vapor regions. 


\subsubsection{Transport Properties}

The required RELAP5-3D transport properties include dynamic viscosity $\mu(\mathrm{Pa} \cdot \mathrm{s})$; thermal conductivity $\mathrm{k}(\mathrm{W} / \mathrm{m} \cdot \mathrm{K})$; and surface tension $\sigma(\mathrm{N} / \mathrm{m})$.

Reported correlations for the viscosity of $\mathrm{KF}^{-\mathrm{ZrF}_{4}}$ (Williams 2006) and $\mathrm{KCl}-\mathrm{MgCl}_{2}$ (Janz 1988) are as follows:

$\mu=1.59 \times 10^{-5} e^{3179 / T}$

and

$\mu=1.408 \times 10^{-4} e^{2262.98 / T}$

respectively, where temperature, $T$ is in $\mathrm{K}$. The viscosity correlation for $\mathrm{KF}_{\mathrm{Z}} \mathrm{ZrF}_{4}$ in Equation 22 has an unknown temperature range of applicability and an uncertainty within $\pm 10 \%$. The viscosity correlation for $\mathrm{KCl}-\mathrm{MgCl}_{2}$ in Equation 23 has a temperature range of applicability from $900-1030 \mathrm{~K}$ and an uncertainty within $\pm 15 \%$.

Correlations for the surface tension of $\mathrm{KF}-\mathrm{ZrF}_{4}$ (Darienko 1988) and $\mathrm{KCl}-\mathrm{MgCl}_{2}$ (Janz et al. 1975) are as follows

$\sigma=0.182-7.134 \times 10^{-5} \mathrm{~T}$

and

$\sigma=0.133-0.48 \times 10^{-4} T$

respectively, where temperature, $T$ is in $\mathrm{K}$. The correlation for the surface tension of $\mathrm{KF}^{-\mathrm{ZrF}_{4}}$ was obtained by interpolating between 40 and 45 molar fraction percent $\mathrm{ZrF}_{4}$ in the table provided by Darienko et al. (1988) The surface tension correlation in Equation 24 has a temperature range from 953$1150 \mathrm{~K}$ and an uncertainty of $\pm 1.5 \%$. The surface tension correlation for $\mathrm{KCl}-\mathrm{MgCl}_{2}$ in Equation 25 has a temperature range of applicability from $1020-1135 \mathrm{~K}$ and an uncertainty of $\pm 1 \%$.

The thermal conductivity values for $\mathrm{KF}-\mathrm{ZrF}_{4}$ and $\mathrm{KCl}-\mathrm{MgCl}_{2}$ are based on predicted values of 0.32 $\mathrm{W} / \mathrm{m} \cdot \mathrm{K}$ and $0.39 \mathrm{~W} / \mathrm{m} \cdot \mathrm{K}$ respectively (Williams 2006). Williams (2006) reported that the thermal conductivity of molten salts show a very weak dependence on temperature.

It should be noted that the property correlations given in the section are only valid for a certain range of temperatures, calculating the properties outside of the intended temperature range will result in additional unknown uncertainty in calculations.

\subsection{Effect of Uncertainty in Thermophysical Properties on the Nusselt Number}

The accuracy in the thermodynamic and thermophysical properties is needed to perform design calculations for heat transport, heat exchanger design, and other component calculations. In order to determine the effect of the individual properties (such as density, heat capacity, thermal conductivity, and viscosity) on the Nusselt number, each respective property is varied by the amount of known uncertainty given in the property correlation. The uncertainty in the Nusselt number was evaluated using the DittusBoelter correlation which provides a measure of the uncertainty. It should be noted that the uncertainty associated with the Dittus-Boelter correlation can be up to $25 \%$ or even higher (Sleicher and Rouse 1975). The Dittus-Boelter correlation is given as 
$N u=0.023 \operatorname{Re}^{0.8} \operatorname{Pr}^{0.4}$.

$R e$ is the Reynolds number and is evaluated as

$R e=\frac{\rho V L}{\mu}$

where $V$ is the velocity of the fluid, which was arbitrarily chosen to be $10 \mathrm{~m} / \mathrm{s}$ for this case, and $L$ is the characteristic linear dimension chosen to be $0.1 \mathrm{~m}$ for this calculation.

$\operatorname{Pr}$ is the Prandtl number and is evaluated as

$\operatorname{Pr}=\frac{c_{P} \mu}{k}$.

The uncertainty in the Nusselt number was calculated by first evaluating the relevant properties at $1000 \mathrm{~K}$. Next, the Nusselt number was calculated using the evaluated properties. The variation in the individual properties was then calculated using both the upper and lower bounds of the uncertainty. Using the varied property values, the maximum and minimum Nusselt number values were calculated. Lastly, the maximum and minimum Nusselt number values were compared to the originally calculated Nusselt number to determine the uncertainty.

The resulting maximum deviation (uncertainty) in the Nusselt number given as an indicative value is shown in Table 4-5. All of the properties and uncertainties were calculated at an arbitrarily chosen temperature of $1000 \mathrm{~K}$.

Table 4-5. Maximum deviation in the Nusselt number due to uncertainty.

\begin{tabular}{|c|c|c|}
\hline Salt & Molar Composition & Uncertainty \\
\hline $\mathrm{KF}-\mathrm{ZrF} 4$ & $(58-42)$ & -7.6 to $+8.4 \%$ \\
\hline $\mathrm{KCl}-\mathrm{MgCl}_{2}$ & $(68-32)$ & -6.6 to $+8.0 \%$ \\
\hline
\end{tabular}

The Nusselt number was also evaluated at different temperatures. Changing the temperature showed that the uncertainty in the Nusselt number, was nearly independent of temperature. The uncertainty in the individual properties can result in a large deviation from the calculated Nusselt number. The property correlations are only valid for certain ranges of temperature as well, which can greatly affect heat transfer correlations.

\subsection{Summary}

The necessary property correlations and values needed to add the molten salts $\mathrm{KF}-\mathrm{ZrF}_{4}$ and $\mathrm{KCl}-$ $\mathrm{MgCl}_{2}$ to the RELAP5-3D code were presented. The uncertainty associated with individual properties was shown to change the resulting Nusselt number calculations when varied across the uncertainty range; however the uncertainty in the Nusselt number was nearly independent of the temperature of the molten salt. The uncertainty associated with the calculation of the Nusselt number for $\mathrm{KF}-\mathrm{ZrF}_{4}$ was shown to vary from -7.6 to $+8.4 \%$. The uncertainty associated with the calculation of the Nusselt number for KCl$\mathrm{MgCl}_{2}$ was shown to vary from -6.6 to $+8.0 \%$. This result shows the need of obtaining accurate correlations for individual property values. 


\section{PRELIMINARY (THERMAL/MECHANICAL) DESIGN AND ENGINEERING CALCULATION FOR AHTR SECONDARY HEAT EXCHANGER}

\subsection{INTRODUCTION}

Heat exchangers are devices used for transferring thermal energy from hotter medium to colder medium in a system. According to Sekulic (1990), "heat exchangers are devices that provide for a change of the mutual thermal (energy) levels between two or more fluids in thermal contact without external heat and work interactions." The mechanical power for heat exchanger applications is expended to pump the working fluids through each exchanger by virtue of pressure losses in its ducting or heat exchanger passage. For liquids, this power requirement is relatively less compared to compressible fluids (air or other gaseous). The pumping power is a significant design variable, and its value relative to heat rate transferred is a commonly used measure of the cost of primary energy as explained by Kays and London (1998).

The Next Generation Nuclear Reactors (NGNR) such as high temperature gas-cooled reactor (HTGR) and Advanced High Temperature Reactor (AHTR) are intended to increase energy efficiency in the production of electricity and/or provide high temperature heat for industrial processes. The efficient transfer of energy for industrial applications depends on the ability to incorporate effective heat exchangers between the nuclear heat transport system and the industrial process heat transport system. However, the need for efficiency, compactness, and safety challenge the boundaries of existing heat exchanger technology, giving rise to this study. Various studies have been performed in attempts to update the IHX that is downstream of the primary heat exchanger, mostly because its performance is strongly tied to the ability to employ more efficient conversion cycles, such as the Brayton cycle using supercritical $\mathrm{CO}_{2}$ (Harvego 2006). The liquid-to-liquid primary heat exchanger will come with its own advantages and challenges when compared to the liquid-to-gas IHX. Figure 5-1 presents a framework for heat exchanger selection and design that is dependent on the condition and environment of the application.

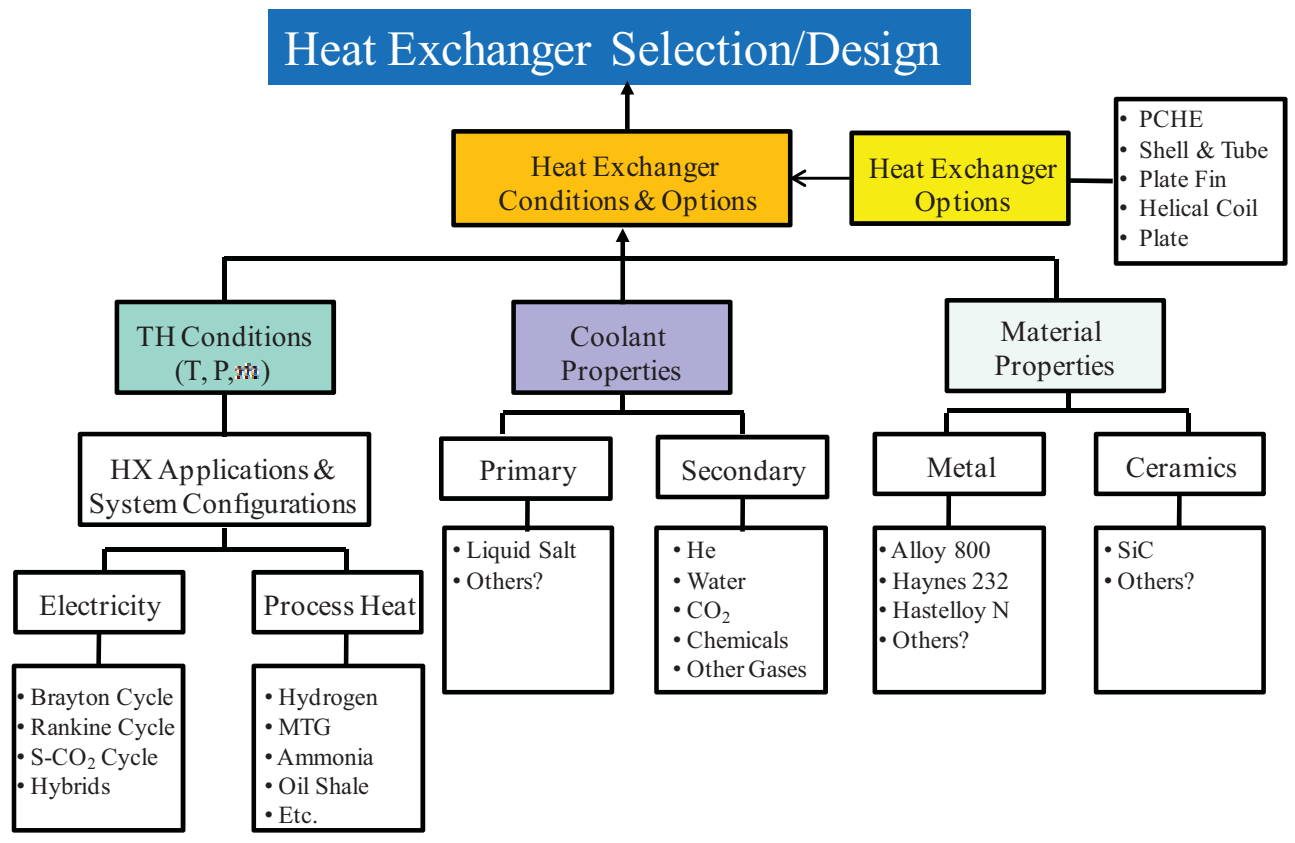

Figure 5-1. Heat exchanger selection framework (Sabharwall et al. (i) 2011). 
Heat exchanger selection is most strongly influenced by the application and operational conditions requirement with its individual requirement for cost, size, reliability, robustness, maintenance, expected life, etc. This is further explained in detail in the evaluation metrics and trade study's methodology section of this report. Irrespective of the type of heat exchanger the performance of the heat exchanger is described by heat transfer coefficient, friction factor relationships, and pressure drop. The thermal design of heat exchangers is to determine channel size, required length, and number of layers or tubes to meet a given thermal duty. With smaller channels and less allowance for corrosion, fouling and corrosion remain major priorities during the life cycle of heat exchangers.

The operation of compact heat exchangers requires a degree of control over conditions that tend to be greater than those exercised with conventional shell-and tube-heat exchangers, as explained by Reay and Hesselgreaves (2001). This arises from the faster transient conditions consequent on the lower fluid inventory of compacts.

This section summarizes the preliminary design activities performed by Idaho National Laboratory (INL) to evaluate AHTR IHX options.

\subsection{AHTR Heat Exchanger Requirements and Related Issues}

\subsubsection{Basic Requirements for the AHTR Heat Exchanger Design}

The operating environment for designing a heat exchanger should be defined as specifically as possible. The heat exchanger of an AHTR is subjected to a unique set of conditions that bring with them several design challenges not encountered in standard heat exchangers. The somewhat corrosive molten salts, especially at temperatures in excess of $700^{\circ} \mathrm{C}$, require specialized materials throughout the system to avoid corrosion, and adverse high-temperature effects such as creep. Alloy $\mathrm{N}$ comprised the entire construction of the primary heat exchanger of the Molten Salt Breeder Reactor (MSBR), each of which was roughly $6.5 \mathrm{ft}$ in diameter and $22 \mathrm{ft}$ in height (Bettis et al. 1964). Alloy $\mathrm{N}$ is a material with limited commercial uses, so it is expected to be very expensive compared to more common stainless steel alloys. A reduction in the amount of material used in that volume is also a vital, and separate calculation that must be made (Sabharwall et al. (i) and (ii) 2011). Table 5-1 summarizes the basic design conditions and requirements for the AHTR SHX:

Table 5-1. SHX design requirements and basic conditions for the AHTR.

\begin{tabular}{|ll|}
\hline \multicolumn{1}{|c|}{ Parameter } & \multicolumn{1}{c|}{ Requirements } \\
\hline Reference System Configuration & AHTR + Supercritical Steam Rankin PCS: \\
Heat Exchanger Type & - Helical Coiled \\
& - Printed Circuit Heat Exchanger \\
Heat Exchanger Duty $(\mathrm{MW})$ & $3400 / 1700 / 1130$ \\
Primary Coolant & $\mathrm{KF}^{-Z \mathrm{rF}_{4}}$ \\
Secondary Coolant & $\mathrm{Water}_{\mathrm{Steam}}$ \\
Primary Temperature $\left(\mathrm{T}_{\text {in }} / \mathrm{T}_{\text {out }}\right)$ & $679 / 587^{\circ} \mathrm{C}$ (supercritical Rankine cycle) \\
& $679 / 586.1^{\circ} \mathrm{C}$ (subcritical Rankine cycle) \\
Secondary Temperature $\left(\mathrm{T}_{\text {in }} / \mathrm{T}_{\text {out }}\right)$ & $251 / 593^{\circ} \mathrm{C}$ (supercritical Rankine cycle) \\
& $241.7 / 550^{\circ} \mathrm{C}$ (supercritical Rankine cycle) \\
Primary Pressure $(\mathrm{MPa})$ & 0.103 \\
Secondary Pressure $(\mathrm{MPa})$ & 25 (supercritical Rankine cycle) \\
& $17.3($ subcritical Rankine cycle) \\
Tube Material & Alloy N \\
Shell Material & Alloy N \\
\hline
\end{tabular}




\subsubsection{Options for Heat Exchanger Types}

Two different types of heat exchangers - helical coiled heat exchanger and printed circuit heat exchanger (PCHE) - are considered possible options for the AHTR SHX based on their available operating conditions and principle features listed in Table 5-2. The general features of these two candidate heat exchangers are described below.

\subsubsection{Helical Coil Shell-and-Tube Heat Exchanger}

Helical coil heat exchangers are shell-and-tube type heat exchangers that consist of tubes spirally wound into bundles and fitted in a shell. The spiral geometry of the tubes transfer heat at a higher rate than straight tubes (Shah and Sekulic 2003). A helical coil heat exchanger is shown in Figure 5-2. Because of the tube bundle geometry, a considerable amount of surface can be accommodated inside the shell. These heat exchangers are used for gas-liquid heat transfer applications primarily when the operating temperature and/or pressure are very high. Cleaning a helical coil heat exchanger is very challenging (Shah and Sekulic 2003).

\subsubsection{Printed Circuit Heat Exchanger}

The PCHE is a relatively new concept, as shown Figure 5-3, that has been commercially manufactured by Heatric ${ }^{\mathrm{TM}}$ since 1985 . PCHEs are robust, combining compactness, low pressure drop, high effectiveness, and the ability to operate with a very large pressure differential between hot and cold sides (Heatric ${ }^{\mathrm{TM}}$ Homepage 2011). These heat exchangers are especially well suited to applications where compactness is important. As the name implies, PCHEs are manufactured by the same technique used to produce standard printed circuit boards for electronic equipment. Individual plates are etched to produce channels. These etched plates are thereafter joined by diffusion welding, resulting in extremely strong all-metal heat exchanger cores. The diffusion welding process includes a thermal soaking period to allow grain growth, thereby enabling an interfacefree joint between the plates, which gives the base material strength and very high pressure containment capability along with the avoidance of corrosion cells, as explained by Hesselgreaves (2001). The fluid passages are semicircular in cross-section, typically being 1.0 to $2.0 \mathrm{~mm}$ wide and 0.5 to $1.0 \mathrm{~mm}$ deep with a hydraulic diameter of 1.5 to $3 \mathrm{~mm}$ (Hesselgreaves 2001). After bonding, any number of core blocks can be welded together to provide the required flow capacity.

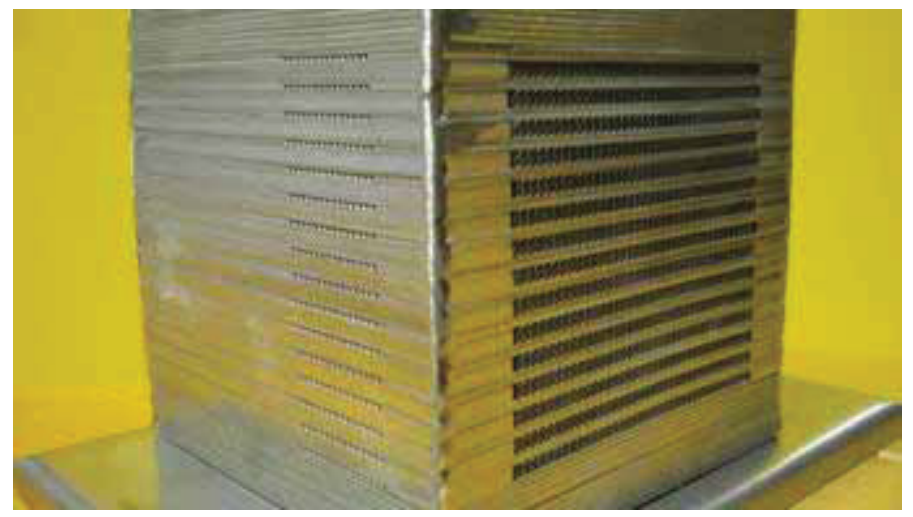

Figure 5-3. Printed Circuit Heat Exchanger (Heatric ${ }^{\mathrm{TM}}$ Homepage 2011)

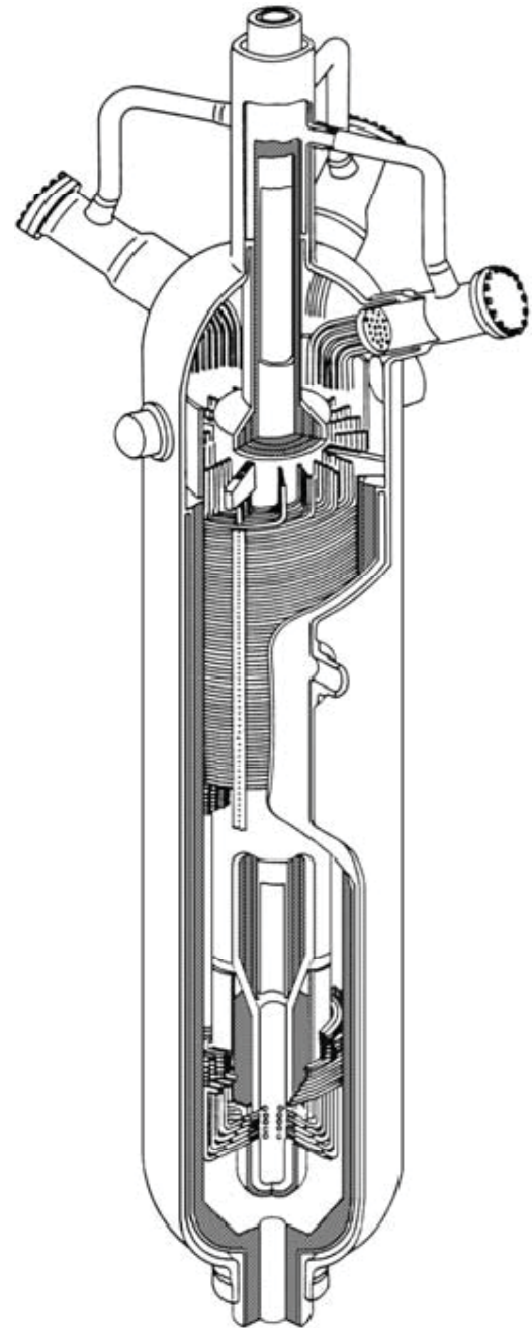

Figure 5-2. Helical coil heat exchanger (Areva 2008) 
Table 5-2. Principal features of several types of heat exchangers (Shah 2003).

\begin{tabular}{|c|c|c|c|c|c|c|c|c|}
\hline HX Type & $\begin{array}{c}\text { Compactness } \\
\left(\mathrm{m}^{2} / \mathrm{m}^{3}\right)\end{array}$ & System Types & Material & $\begin{array}{l}\text { Temperature } \\
\text { Range }(\mathrm{C})^{\mathrm{a}}\end{array}$ & $\begin{array}{c}\text { Maximum } \\
{\text { Pressure }(\mathrm{bar})^{\mathrm{b}}}\end{array}$ & $\begin{array}{l}\text { Cleaning } \\
\text { Method }\end{array}$ & $\begin{array}{l}\text { Multistream } \\
\text { Capability }^{\mathrm{c}}\end{array}$ & $\begin{array}{l}\text { Multipass } \\
\text { Capability }^{\mathrm{d}}\end{array}$ \\
\hline $\begin{array}{l}\text { Shell and Tube } \\
\text { (Helical) }\end{array}$ & $\sim 100$ & $\begin{array}{l}\text { Liquid/Liquid, Gas/Liquid, } \\
\text { 2Phase }\end{array}$ & $\begin{array}{l}\text { s/s, Ti, Incoloy, Hastelloy, } \\
\text { graphite, polymer }\end{array}$ & $\sim+900$ & $\sim 300$ & $\begin{array}{l}\text { Mechanical, } \\
\text { Chemical }\end{array}$ & No & Yes \\
\hline $\begin{array}{l}\text { Plate-and-frame } \\
\text { (gaskets) }\end{array}$ & $\sim 200$ & $\begin{array}{l}\text { Liquid/Liquid, Gas/Liquid, } \\
\text { 2Phase }\end{array}$ & $\begin{array}{l}\text { s/s, Ti, Incoloy, Hastelloy, } \\
\text { graphite, polymer }\end{array}$ & $-35 \sim+200$ & 25 & Mechanical & Yes & Yes \\
\hline $\begin{array}{l}\text { Partially welded } \\
\text { plate }\end{array}$ & $\sim 200$ & $\begin{array}{l}\text { Liquid/Liquid, Gas/Liquid, } \\
\text { 2Phase }\end{array}$ & s/s, Ti, Incoloy, Hastelloy & $-35 \sim+200$ & 25 & $\begin{array}{l}\text { Mechanical, } \\
\text { Chemical }\end{array}$ & No & Yes \\
\hline $\begin{array}{l}\text { Fully welded plate } \\
\text { (Alfa Rex) }\end{array}$ & $\sim 200$ & $\begin{array}{l}\text { Liquid/Liquid, Gas/Liquid, } \\
\text { 2Phase }\end{array}$ & s/s, Ti, Ni alloys & $-50 \sim+350$ & 40 & Chemical & No & Yes \\
\hline Brazed plate & $\sim 200$ & Liquid/Liquid, 2Phase & $\mathrm{s} / \mathrm{s}$ & $-195 \sim+220$ & 30 & Chemical & No & No \\
\hline Bavex plate & $200 \sim 300$ & $\begin{array}{l}\text { Gas/Gas, Liquid/Liquid, } \\
\text { 2Phase }\end{array}$ & $\begin{array}{l}\text { s/s, Ni, Cu, Ti, special } \\
\text { steels }\end{array}$ & $-200 \sim+900$ & 60 & $\begin{array}{l}\text { Mechanical, } \\
\text { Chemical }\end{array}$ & Yes & Yes \\
\hline Platular plate & 200 & $\begin{array}{l}\text { Gas/Gas, Liquid/Liquid, } \\
\text { 2Phase }\end{array}$ & s/s, Hastelloy, Ni alloys & $\sim 700$ & 40 & Mechanical & Yes & Yes \\
\hline Compabloc plate & $\sim 300$ & Liquid/Liquid & s/s, Ti, Incoloy & $\sim 300$ & 32 & Mechanical & Not usually & Yes \\
\hline Packinox plate & $\sim 300$ & $\begin{array}{l}\text { Gas/Gas, Liquid/Liquid, } \\
\text { 2Phase }\end{array}$ & s/s, Ti, Hastelloy, Inconel & $-200 \sim+700$ & 300 & Mechanical & Yes & Yes \\
\hline Spiral & $\sim 200$ & Liquid/Liquid, 2Phase & s/s, Ti, Incoloy, Hastelloy & $\sim 400$ & 25 & Mechanical & No & No \\
\hline Brazed plate fin & $800 \sim 1500$ & $\begin{array}{l}\text { Gas/Gas, Liquid/Liquid, } \\
\text { 2Phase }\end{array}$ & $\mathrm{Al}, \mathrm{s} / \mathrm{s}, \mathrm{Ni}$ alloy & $\sim 650$ & 90 & Chemical & Yes & Yes \\
\hline $\begin{array}{l}\text { Diffusion bonded } \\
\text { plate fin }\end{array}$ & $700 \sim 800$ & $\begin{array}{l}\text { Gas/Gas, Liquid/Liquid, } \\
\text { 2Phase }\end{array}$ & $\mathrm{Ti}, \mathrm{s} / \mathrm{s}$ & $\sim 500$ & $>200$ & Chemical & Yes & Yes \\
\hline Printed circuit & $200 \sim 5000$ & $\begin{array}{l}\text { Gas/Gas, Liquid/Liquid, } \\
\text { 2Phase }\end{array}$ & $\mathrm{Ti}, \mathrm{s} / \mathrm{s}$ & $-200 \sim+900$ & $>400$ & Chemical & Yes & Yes \\
\hline $\begin{array}{l}\text { Polymer (e.g. } \\
\text { channel plate) }\end{array}$ & 450 & Gas/Liquid & PVDF, PP & $\sim 150$ & 6 & Water Wash & No & No \\
\hline Plate and shell & - & Liquid/Liquid & $\mathrm{s} / \mathrm{s}, \mathrm{Ti}$ & $\sim 350$ & 70 & $\begin{array}{l}\text { Mechanical, } \\
\text { Chemical }\end{array}$ & Yes & Yes \\
\hline \multicolumn{9}{|c|}{ 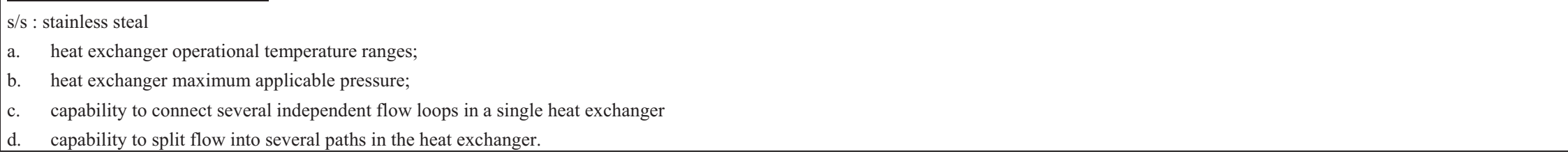 } \\
\hline
\end{tabular}


Compact heat exchangers like PCHEs offer the combination of compactness (hydraulic diameter of the order of $1 \mathrm{~mm}$ ) and great structural integrity (because of diffusion welding), as explained by Hesselgreaves (2001).

The fundamental parameter describing compactness is the hydraulic diameter $\left(d_{h},\right)$, which can be defined as

$d_{h}=\frac{4 A_{f} L}{A_{s}}$.

where

$$
\begin{array}{ll}
A_{f} & : \text { flow area }\left(\mathrm{m}^{2}\right) \\
A_{s} & : \text { surface area }\left(\mathrm{m}^{2}\right) \\
L & : \text { channel length }
\end{array}
$$

For surfaces where the flow area $\left(A_{f}\right)$ varies with flow length, hydraulic diameter can be defined as

$d_{h}=\frac{4 V_{s}}{A_{s}}$

where $V_{s}$ is the enclosed wetted volume. Equation (2) enables ??? to link hydraulic diameter to the surface area density $(\beta)$, which is $A_{s} / V$, also known as measure of compactness (Hesselgreaves 2001).

Overall surface volume ' $\mathrm{V}$ ' is related to the surface porosity $(\forall)$ by

$\forall=\frac{V_{s}}{V}$.

Therefore, the surface area density becomes

$\beta=\frac{A_{s}}{V}=\frac{4 \forall}{d_{h}}$.

Modern compact heat exchangers can provide compactness - a measure of the ratio of surface areato-volume of a heat exchanger - approaching $2,500 \mathrm{~m}^{2} / \mathrm{m}^{3}$ for the most advanced designs. Commonly accepted lower threshold value for $\beta$ is $300 \mathrm{~m}^{2} / \mathrm{m}^{3}$, which for a typical porosity of 0.75 gives $d_{h}$ of $10 \mathrm{~mm}$ as shown by Hesselgreaves (2001). For high temperature and high pressure containment, high Ni alloys are necessary for construction, and diffusion welding is the preferred welding (joining) technique. Typical values reported by Hesselgreaves (2001) for porosity of diffusion bonded exchangers are from 0.5 to 0.6 , having a strong effect on surface density and exchanger weight.

For a given heat load $(\dot{Q})$ and temperature difference $(\Delta T)$, the exchange volume required is proportional to the inverse square of the hydraulic diameter for laminar flows as (Hesselgreaves 2001)

$\dot{Q}=\frac{4 \forall V N u K \Delta T}{d_{h}^{2}}$.

where
$\mathrm{Nu} \quad$ : Nusselt Number
$K \quad$ : Thermal conductivity of the fluid (W/m K)
$\Delta \mathrm{T} \quad$ : Temperature difference between hot and cold sides $(\mathrm{K})$ 


\section{Options for Heat Exchanger Arrangement}

As shown in Table 1, the total thermal duty of the AHTR heat exchangers is $3,400 \mathrm{MW}_{\mathrm{t}}$. In this study, the following three different options were taken into consideration for preliminary design as heat exchanger arrangements:

- Option 1: A single heat exchanger transfers all the heat $\left(3,400 \mathrm{MW}_{\mathrm{t}}\right)$ from the intermediate heat transfer loop to the power conversion system or process plants.

- Option 2: Two heat exchangers share heat to transfer total heat of 3,400 $\mathrm{MW}_{\mathrm{t}}$ from the intermediate heat transfer loop to the power conversion system or process plants. Each exchanger transfers 1,700 $\mathrm{MW}_{\mathrm{t}}$ with a parallel configuration.

- Option 3: Three heat exchangers share heat to transfer total heat of 3,400 $\mathrm{MW}_{\mathrm{t}}$ from the intermediate heat transfer loop to the power conversion system or process plants. Each exchanger transfers 1,130 $\mathrm{MW}_{\mathrm{t}}$ with a parallel configuration.

\section{Existing Challenges for Fluoride Salt Process Heat Exchanger}

Using molten salt as coolant requires lots of challenges for designing and operating heat exchangers (Sabharwall et al., (i) 2011, Wilson 2010). Some of existing challenges are:

- High melting point temperature:

- Prevent or accommodate freezing in heat exchangers and piping

- Materials and corrosion control strategies needed:

- Fluoride salts remove oxide layers from metals, enhancing corrosion

- $\quad$ Reactions with metal ions occur $\left(\mathrm{HF}+\right.$ metal $\rightarrow$ metal fluoride $\left.+\mathrm{H}_{2}\right)$

- Minimum chromium but sufficient to provide oxidation resistance

- Limited aluminum, titanium, and carbon contents minimize fabrication and corrosion problems

- $\quad$ Limited Boron content prevents weld cracking

- Development needs in fabrication and joining technology is a must (thin sections, grain size effects, etc.)

- Maintenance and inspection issues with compact heat exchangers

- High uncertainty in data at high temperatures

- Impurities in salts must be controlled

- Oxidation potential (redox control) of salts can influence material performance (embrittlement of material)

- Mass transfer:

- Oxidation at high temperature and deposition at lower temperature

- Differences in chemical activities of different metals (dissimilar materials)

- Salt to gas transfer issues:

- Pressure differentials between the primary and secondary systems are large (the pressure difference is about 17 and $25 \mathrm{MPa}$ for subcritical and supercritical Rankine cycle, respectively)

- Increase in gas velocities or large surface areas to compensate for low thermal conductivity of the gas

- Enhance material performance, thin walls are problematic for high pressure differences and corrosion 
- High temperature alloys and ceramics with required mechanical and fluoride salt corrosion resistance properties

\subsection{Design and Analysis Method}

The following summarizes the design and analysis methods used in this study. The mechanical design method describes how this study determined tube, shell, and plate geometrical dimension in order to satisfy operating and temperature requirements. Thermal design method describes how this study determined overall heat exchanger geometries and sizes.

\subsubsection{Mechanical Design}

\subsubsection{Helical Coiled Heat Exchanger: Determination of Tube-and-Shell Thickness}

This study assumed that loading is only due to pressure (internal and external) and it is loaded axisymmetrically. It also assumed that the tube and shell are thick-walled cylinders (wall thickness is greater than one-tenth of inner radius).

\section{General Case}

In the case of a thick wall cylinder subjected to uniform internal and external pressure the radial $\left(\sigma_{r}\right)$ and tangential $\left(\sigma_{\theta}\right)$ stresses are defined as (Ugural 2003):

$\sigma_{r}=\frac{R_{i}^{2} P_{i}-R_{o}^{2} P_{O}}{R_{o}^{2}-R_{i}^{2}}-\frac{\left(P_{i}-P_{o}\right) R_{i}^{2} R_{o}^{2}}{\left(R_{o}^{2}-R_{i}^{2}\right) r^{2}}$

$\sigma_{\theta}=\frac{R_{i}^{2} P_{i}-R_{o}^{2} P_{O}}{R_{O}^{2}-R_{i}^{2}}+\frac{\left(P_{i}-P_{O}\right) R_{i}^{2} R_{o}^{2}}{\left(R_{o}^{2}-R_{i}^{2}\right) r^{2}}$

where:

$$
\begin{aligned}
& R_{i}=\text { Inside radius } \\
& P_{i}=\text { Internal pressure } \\
& R_{o}=\text { Outside radius } \\
& P_{o}=\text { External pressure } \\
& r \quad=\text { radius }
\end{aligned}
$$

From Equation (6), the maximum numerical value of radial stress is at $\mathrm{r}=R_{i}$ (if $P_{i}$ is greater than $P_{o}$ ). If $P_{o}$ is greater than $P_{i}$, the maximum radial pressure occurs at $r=R_{o}$ and it is equal to the external pressure $\left(P_{o}\right)$.

\section{Internal Pressure Dominant}

In a special case where the cylinder is exposed to dominant internal pressure, from Equation (6) and (7), the radial $\left(\sigma_{r}\right)$ and tangential $\left(\sigma_{\theta}\right)$ stresses are defined as

$\sigma_{r}=\frac{R_{i}^{2} P_{i}}{R_{o}^{2}-R_{i}^{2}}\left(1-\frac{R_{o}^{2}}{r^{2}}\right)$

and

$$
\sigma_{\theta}=\frac{R_{i}^{2} P_{i}}{R_{o}^{2}-R_{i}^{2}}\left(1+\frac{R_{O}^{2}}{r^{2}}\right)
$$


From Equations (8) and (9), it is obvious that the magnitude of the tangential stress is greater than the radial stress. Note that the radial stress is compressive (negative) for all $r$ values except when $r$ is equal to the outside radius. In this case, the radial stress is zero. The tangential stress $\left(\sigma_{\theta-\max }\right)$ is always positive (tensile) for all the $r$ values and it is maximum at $r$ equal to inner radius expressed as

$\sigma_{\theta-\max }=\frac{\left(P_{i}+P_{o}\right) R_{i}^{2}}{\left(R_{o}^{2}-R_{i}^{2}\right)}$.

\section{External Pressure Dominant}

In the case of presence of dominant external pressure, from Equation (8) and (9), the radial $\left(\sigma_{r}\right)$ and tangential $\left(\sigma_{\theta}\right)$ stresses are defined as

$\sigma_{r}=-\frac{R_{o}^{2} P_{o}}{R_{o}^{2}-R_{i}^{2}}\left(1-\frac{R_{i}^{2}}{r^{2}}\right)$

and

$$
\sigma_{\theta}=-\frac{R_{O}^{2} P_{o}}{R_{o}^{2}-R_{i}^{2}}\left(1+\frac{R_{i}^{2}}{r^{2}}\right)
$$

The maximum radial stress occurs at $r=R_{o}$ (always compressive/negative). As it can be seen from Equations (11) and (12), the numerical value of the tangential stress is greater than the radial stress. The maximum tangential stress (compressive/negative, $\sigma_{\theta-\max }$ ) occurs at $r=R_{\mathrm{i}}$ and is expressed as

$\sigma_{\theta-\max }=-\frac{2 R_{o}^{2} P_{o}}{R_{o}^{2}-R_{i}^{2}}$

\subsubsection{Printed Circuit Heat Exchanger: Determination of Channel Pitch and Plate Thickness}

Diffusion welding strength of compact PCHE is believed to be that of the parent metal, because of the crystal grain growth across the interface during bonding. A simple stress analysis was preformed for the IHX assuming that it is a compact heat exchanger of the type designed by Heatric (Dewson and Thonon 2003). The design of the heat exchanger channel is defined by the channel diameter, $d$, and plate thickness, $\mathrm{t}_{\mathrm{p}}$, as illustrated in Figure 5-4. Each plate contains either hot or cold fluid, but not both. Adjacent plates contain the other fluid. Following the method used by Dostal et al. (2004), the minimum wall thickness between channels, $t_{f}$, can be approximated as

$t_{f} \geq \frac{p}{\frac{\sigma_{D}}{\Delta P}+1}$

where $\sigma_{\mathrm{D}}$ is the allowable stress and $\Delta \mathrm{P}$ is the differential pressure between the hot and cold streams. Expressing Eq. (9) in terms of pitch-to-diameter ratio yields

$$
\frac{p}{d} \geq 1+\frac{\Delta P}{\sigma_{D}} \text {. }
$$

The required plate thickness can also be calculated based on the method of Dostal et al. (2004). The plate is assumed to be a thick-walled cylinder, with an inner radius $\left(R_{i}\right)$ of $\mathrm{d} / 2$ and an outer radius $\left(R_{o}\right)$ of $\mathrm{t}_{\mathrm{p}}$. Equations (10) and (15) can be used to calculate the thickness-to-diameter and pitch-to-diameter ratio for the IHX as a function of allowable stress and various pressures of the hot and cold streams. 

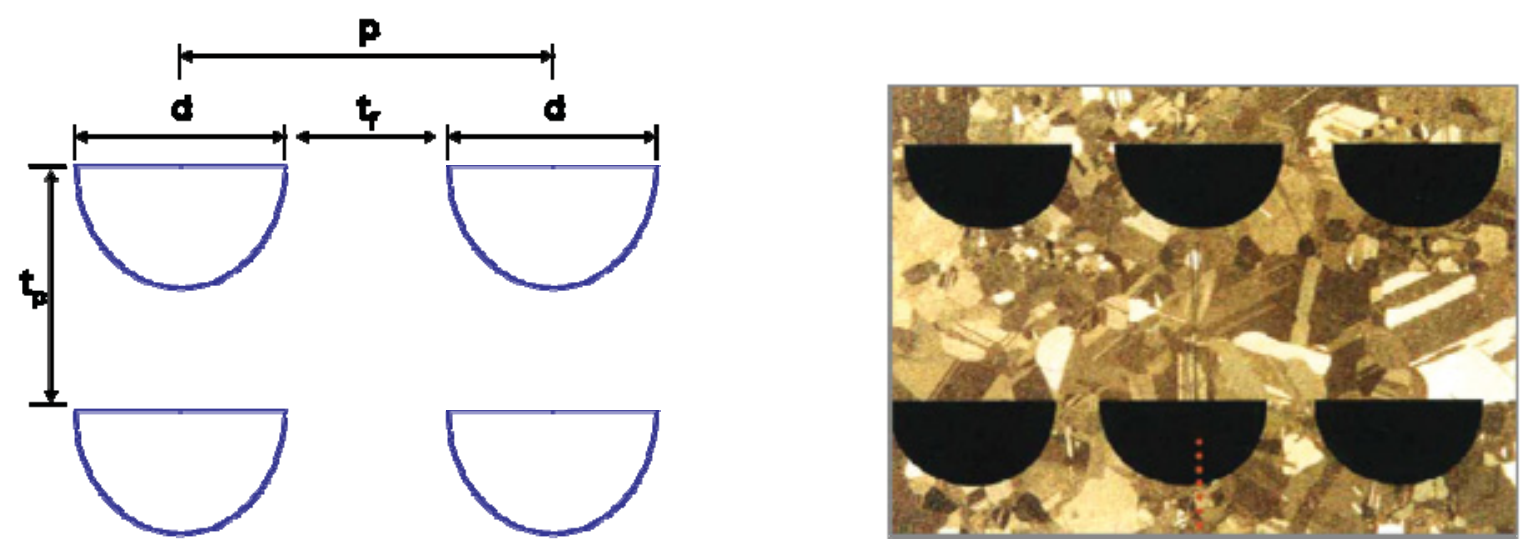

Figure 5-4. PCHE channel layout.

\subsubsection{Thermal Design (General Method)}

This study provides a general description followed by thermal design analysis for both helical coil heat exchanger and PCHE. The function of the process/SHX is to recuperate heat from the secondary salt for supercritical/subcritical Rankine cycle. Very high efficiency heat conversion is desired for the heat exchanger, as any heat that is not transferred to the process side is a direct detriment to overall plant efficiency. Compact heat exchangers can provide significant reductions in volume and material usage. With tightly packed channels making adjacent streams able to effectively translate temperatures across their boundaries, approach temperatures (the difference between the outlet temperature of one fluid stream and the inlet temperature of the opposing fluid stream at their common header location) closer to $1{ }^{\circ} \mathrm{C}$ are possible with compact heat exchangers. Shell-and-tube heat exchangers are often closer to $12^{\circ} \mathrm{C}$ in approach temperature, another demonstration of their inferior performance (Kandlikar et al. 2006). Compact heat exchangers are an intriguing technology that could provide MSRs, and nuclear reactors in general, with a means to reduce capital costs.

The aim of design or selection calculations is to determine the heat exchange surface area as a function of inlet and outlet temperatures of hot and cold fluids, fluid flow rates, flow direction, and pressure drop. Based on the flow direction of hot and cold fluids, heat exchangers are termed as concurrent (or parallel) flow, with both fluids moving in the same direction; counterflow, with fluids flowing in the opposite directions; and crossflow, with fluids flowing perpendicular to each other.

The temperature difference between hot and cold fluids is continuously changing. Therefore, an effective difference needs to be calculated to determine heat flow through the wall separating the two fluids. This effective temperature difference is termed as Log Mean Temperature Difference (LMTD, $\left.\Delta T_{m}\right)$. For the same inlet and exit temperature values of two fluids, $\Delta T_{m}$ attains a larger magnitude for countercurrent flow than the parallel flow, as explained by Singh (2004). Thus, the counterflow configuration is more effective in transferring heat than the parallel-flow arrangement and has been used further for thermal design study. Since the temperature difference varies along the length of the heat exchanger, it has to be weighted to obtain a mean value for single-point determination of heat-transfer area. The LMTD represents this weighted value, as explained by Mukherjee (1998).

A specified heat load $(\dot{Q})$, is given by the heat transfer and rate equations for either side as

$\dot{Q}=\dot{m} c_{p} \Delta T$. 
The basic effect of the surface on thermal design can be shown by (for details refer Hesselgreaves 2001)

$j=\frac{d_{h}}{4 L} \operatorname{Pr}^{2} / 3 N$

and

$\frac{G^{2}}{2 \rho \Delta P}=\frac{j / f}{\operatorname{Pr}^{2} / 3 N}$

where, $j$ is the dimensionless factor and is expressed as $j=\frac{N u}{\operatorname{Re} \operatorname{Pr}^{\frac{1}{3}}}=S t \operatorname{Pr}^{\frac{2}{3}}, N$ is NTU (number of thermal units), $G$ is the mass velocity, i.e., $\frac{\dot{m}}{A_{f}}$, and $f$ is the fanning friction factor.

The above equations infer that flow length decreases as hydraulic diameter decrease and flow area is largely independent of hydraulic diameter.

Both $j$ and $f$ are functions of $R e$, but $j / f$ is not strongly $R e$ number sensitive. The ratio of $j / f$ shows that $R e$ number is close to directly proportional to the hydraulic diameter. It could be further explained with the following example given by Hesselgreaves (2001):

"A non compact exchanger surface with hydraulic diameter of $25 \mathrm{~mm}$ for a given thermal duty would operate at Re number of about 25 times that of compact surface of $1 \mathrm{~mm}$ hydraulic diameter, this has important implications for surface selection: typically a $1 \mathrm{~mm}$ hydraulic diameter surface would operate in developing or fully developed laminar for, whilst for the same duty a $25 \mathrm{~mm}$ surface would be in high transitional or turbulent flow."

Two methodologies are commonly used to carry out thermal design for the heat exchanger: LMTD method, and Effectiveness - Number of Transfer Units $(\varepsilon-N T U)$ method. Both methods are equivalent to each other. This analysis used the LMTD method. The analysis carried out here is appropriate for the preliminary design analysis (for scoping and comparison purposes). In order to make the design of a heat exchanger an infinitely more manageable task, the following assumptions must be made for preliminary designs:

- The fluid properties are constant throughout the exchanger and are evaluated at the respective mean temperature

- Heat transfer coefficients of both sides are constant along the exchanger

- Flows in heat exchanger experience abrupt contractions at the entry and expansions at the exit, from the headers or ducts. In this analysis entry and exit losses are neglected

- Flow is assumed to be steady-state in order to hold true in order to avoid the complications of making transient calculations in preliminary studies

- Two cases area individually analyzed:

- Supercritical Rankine Cycle (25 MPa)

- Subcritical Rankine Cycle (17 MPa).

Rewriting equation (16) in terms of hot and cold fluids is expressed as

$\dot{Q}=\dot{Q}_{h}=\dot{m}_{h} c_{p, h}\left(T_{h, \text { in }}-T_{h, \text { out }}\right)$

and 
$\dot{Q}=\dot{Q}_{c}=\dot{m}_{c} c_{p, c}\left(T_{c, \text { out }}-T_{c, \text { in }}\right)$

where $Q_{h}$ is equal to $Q_{c}$ because the heat lost by the heating medium is equal to the heat gained by the cold fluid. Product of $\left(m c_{p}\right)$ is called as heat capacity rate and is denoted by ' $\mathrm{C}$ ', the highest and lowest between hot and cold streams being ' $\mathrm{C}_{\max }$ ' and ' $\mathrm{C}_{\min }$ '. If the ratio of $\mathrm{C}_{\min }$ to $\mathrm{C}_{\max }$ is unity, the exchanger is said to be balanced.

The maximum possible heat exchanged between the streams, can be expressed as

$\dot{Q}_{\max }=C_{\min }\left(T_{h, \text { in }}-T_{c, \text { in }}\right)$

which represents the idealized performance with infinite surface area, as explained by Hesselgreaves (2001). Maximum heat transferred is obtained when stream of lowest heat capacity rate has an outlet temperature equal to the inlet temperature (for a counterflow configuration) of the other stream. For parallel flow arrangement, the state is reached when both streams attain the same temperature at outlet. In all cases, the state corresponds to a theoretically infinite surface area. The point of equal temperatures, called pinch point, ideally corresponds to zero temperature difference, but in general it refers to the minimum temperature difference in the heat exchanger.

After defining maximum possible heat transfer, heat exchanger effectiveness can be defined as

$\varepsilon=\frac{\dot{Q}}{Q_{\max }}=\frac{C_{h}\left(T_{h, \text { in }}-T_{h, \text { out }}\right)}{C_{\min }\left(T_{h, \text { in }}-T_{c, \text { in }}\right)}=\frac{C_{C}\left(T_{c, \text { out }}-T_{c, \text { in }}\right)}{C_{\min }\left(T_{h, \text { in }}-T_{c, \text { in }}\right)}$

where, $C_{c}$ and $C_{h}$ are the cold and hot stream heat capacity rates.

The overall heat transfer coefficient is now determined followed by the calculation of LMTD. These values and the Q calculated above will finally be used to determine the surface area through which heat transfer takes place.

Heat exchanger performance is normally evaluated by the overall heat transfer coefficient $U$ that is defined by the equation

$\dot{Q}=F\left(U A_{s}\right) \Delta T_{m}$

where, $\Delta T_{m}$ is the LMTD between the streams, multiplied by $F$, which is the correction factor (depends on the flow configuration), and $U A_{s}$ is the product of the overall heat transfer coefficient and reference area, also known as heat transfer conductance as

$\Delta T_{m}=\frac{\Delta T_{2}-\Delta T_{1}}{\ln \left(\frac{\Delta T_{2}}{\Delta T_{1}}\right)}$

where $\Delta T_{2}=T_{h, \text { out }}-T_{c, \text { out }} ; \Delta T_{1}=T_{h, \text { in }}-T_{c, \text { in }}$.

Also, as described by Hesselgreaves (2001), the number of transfer units (NTU) can be defined as

$N T U=\frac{U A_{s}}{C_{\min }}$

which is a measure of the thermal length of the exchanger.

For liquid/gas exchangers, the gas side heat transfer coefficient is low and dominates the total heat conductance. If the required effectiveness is high (i.e. $\varepsilon>0.8$ ) a counter flow configuration will usually be the most economic design Hesselgreaves (2001). 
The overall conductance $\left(\mathrm{UA}_{\mathrm{s}}\right)$ can be written in terms of individual heat transfer coefficients; surface films and metallic wall pose a resistance to heat flow. Resistance of surface films and metallic wall can be considered in series, which allows their addition to obtain the total resistance (Singh 2004). Assuming no fouling on both sides (as fouling could pose additional resistance to heat flow from the medium to the product side), the overall heat transfer conductance can be written as

$\frac{1}{U A}=\frac{1}{\left(E_{S} h A_{S}\right)_{h}}+R_{W}+\frac{1}{\left(E_{S} h A_{s}\right)_{c}}$

where, $E_{s}$ is the surface effectiveness and $R_{w}$ is the wall resistance

$R_{w}=\frac{\ln \left(\frac{d_{o}}{d_{i}}\right)}{2 \pi K_{w} L N_{T}}($ for a circular tube $)$

where, $d_{o}$ and $d_{i}$ are the outer and inner tube diameters, $L$ is the tube length and $N_{T}$ is the number of tubes in the exchanger. For thin walled tubes, Equation (26) can be approximated by

$R_{w}=\frac{t_{w}}{K_{m} A_{m}}$

where, $t_{w}$ is the tube wall thickness $\left(\mathrm{t}_{\mathrm{w}}=\left(\mathrm{d}_{\mathrm{o}}-\mathrm{d}_{\mathrm{i}}\right) / 2\right)$ and $A_{m}$ is the area evaluated at the arithmetic mean diameter $\left(\mathrm{A}_{\mathrm{m}}=\pi L N_{T} \frac{\left(d_{o}+d_{i}\right)}{2}\right)$.

The resistance of the largest stream dominates the overall resistance. For a gas stream, conductance is likely to be the lowest and resistance the highest. Further details on the effect of resistances are out of the present scope of work, so will not be covered further. A lower heat transfer coefficient is usually compensated for by an increase in surface area on that side to obtain a balance design.

The surface heat transfer coefficient ' $h$ ' values, depends upon the fluid's thermal properties, flow properties (Newtonian or non-Newtonian nature, viscosity, power-law parameters, etc.), flow condition (Grashof number for free convection and Reynolds number for forced convection), heat exchanger's geometrical characteristics (e.g., smooth plate, plate with ripples, cylindrical shape, presence of fins and baffles, etc.), and roughness of the heat exchange surface, as explained by (Singh 2004).

Table 5-3. Range of heat transfer coefficient values for different flow situations (Kakac and Liu 1998).

\begin{tabular}{lc}
\hline Fluid & $\boldsymbol{h}\left(\mathbf{W} / \mathrm{m}^{2} \mathbf{K}\right)$ \\
\hline $\begin{array}{lc}\text { Gases (natural convection) } \\
\text { Engine oil (natural convection) }\end{array}$ & $3-25$ \\
$\begin{array}{l}\text { Flowing superheated steam or air } \\
\text { Flowing nonmetallic liquids }\end{array}$ & $30-60$ \\
$\begin{array}{l}\text { Flowing metallic liquids } \\
\text { Boiling water }\end{array}$ & $100-10,000$ \\
(water pressure 5 bar abs, $\Delta T=25 \mathrm{~K})$ & $5,000-250,000$ \\
$\begin{array}{l}\text { Boiling water } \\
\text { (water pressure 5-100 bar abs, } \Delta T=20 \mathrm{~K})\end{array}$ & $5,000-10,000$ \\
Film boiling & $4,000-15,000$ \\
$\begin{array}{l}\text { Film condensation on horizontal } \\
\text { tubes at } 1 \text { atm }\end{array}$ & $300-400$ \\
$\begin{array}{l}\text { Film condensation on vertical } \\
\text { surfaces at } 1 \text { atm }\end{array}$ & $9,000-25,000$ \\
Dropwise condensation & $4,000-11,000$ \\
\hline
\end{tabular}

After obtaining the respective values for $\dot{Q}$, overall heat transfer coefficient (U) and LMTD $\left(\Delta T_{m}\right)$ can be the value of ' $A$ ' and further the size and number of plates/tubes could be obtained. Dividing it further with inner cylinder's circumference could yield the required tube length needed for the heat exchanger for the given heat duty. 
Thermal design methods and correlations for helical coiled heat exchangers and PCHEs are described in more detail in Appendixes A and B. 


\section{EVALUATION METRICS FOR SHX CONCEPTS}

This section describes the method for AHTR heat exchanger evaluation and selection based on Multicriteria Decision Analysis (MCDA), as mentioned in the INL feasibility study (Sabharwall et al. 2011).

\subsection{Evaluation Methodology: Analytical Hierarchy Process (AHP)}

In the previous sections, major alternatives and criteria for the AHTR secondary heat exchangers are mentioned. This section describes how these criteria and the alternatives are evaluated. This study uses the analytical hierarchy process (AHP) to evaluate candidate heat exchangers. It is a structured technique developed for multicriteria decision making and currently among the most widely used multicriteria decision analysis (MCDA) techniques. The AHP helps decision makers find the best option that suits the goal and understanding of a problem. The AHP was first developed at Wharton School of Business by Thomas L. Saaty in the 1970s based on mathematics and psychology (Saaty 1980), and has been extensively studied and refined since then. It provides a comprehensive and rational framework for structuring a decision problem, representing and quantifying its elements, relating those elements to overall goals, and evaluating alternative solutions.

AHP allows for the application of data, experience, insight, and intuition in a logical way. AHP enables decision-makers to derive ratio-scale priorities or weights as opposed to arbitrary assigning values. AHP not only supports decision-makers by enabling them to structure complexity and exercise judgment, it allows them to incorporate both objective and subjective considerations into the decision process.

In the AHP method, weights and scores are done by structuring complexity as a hierarchy and by deriving ratio-scale measures through pairwise relative comparisons. The pairwise comparison process can be performed using words, numbers, or graphical bars, and typically incorporates redundancy, resulting in a reduction of measurement error as well as producing a measure of consistency of the comparison judgments. This method is based on the fact that humans are much more capable of making relative rather than absolute judgments. The use of redundancy permits accurate priorities to be derived from verbal judgments even though the words are not very accurate. The weights or priorities are therefore not arbitrarily assigned in the AHP method.

The AHP involves the mathematical synthesis of numerous judgments about the decision problem at hand. It is not uncommon for these judgments to number in the dozens or even the hundreds. While the math is pretty straight forward, it is far more common to use one of several computerized methods for entering and synthesizing the judgments.

The procedure for using the AHP can be summarized as listed below (Satty 1996; Forman 2001; Hallowell 2007; Bhushan 2004).

1. Identify and describe the problem.

2. Set up the final goal and objective.

3. Select alternatives.

4. Identify and list criteria.

5. Model the problem as a hierarchy containing the decision goal, the alternatives for reaching it, and the criteria for evaluating the alternatives. 
6. Establish priorities among the elements of the hierarchy by making a series of judgments based on pairwise comparisons of the elements. For example, when comparing potential real-estate purchases, the investors might say they prefer location over price and price over timing.

7. Synthesize these judgments to yield a set of overall priorities for the hierarchy. This would combine the investors' judgments about location, price, and timing for properties A, B, C, and D into overall priorities for each property.

8. Check the consistency of the judgments.

9. Come to a final decision based on the results of this process.

\subsection{Goal, Alternatives, and Criteria for AHTR SHX Selection}

The goal of this study is to evaluate and select the best heat exchanger type for the AHTR SHX. Using the screening process described in the previous section, the two heat exchanger types identified as possible SHX options that meet the base requirements are:

- $\quad$ Shell-and-tube (helical coiled)

- PCHE.

Table 6-1 summarizes the criteria for the AHTR heat exchanger evaluation and selection. Details are explained in the subsections below.

Table 6-1. Criteria for AHTR heat exchanger selection.

\begin{tabular}{|ll|}
\hline \multicolumn{1}{|c|}{ Criteria } & Sub-criteria \\
\hline & High Heat Transfer Performance (heat transfer / pumping power) \\
Thermal Performance & High Effectiveness \\
Structural Performance (Evaluated by & Mechanical Stress \\
ASME B\&PV Design rules) & Thermal Stress \\
& Vibration \\
& Geometry (heat exchanger wall thickness) \\
Material Performance & Corrosion Allowance in Design (Uniform Corrosion) \\
& Localized Corrosion/Environmental Cracking \\
& Fluid Compatibility \\
Technology Readiness & Material \\
& Fabrication Method \\
System Integration & ASME B\&PV Code Status \\
Tritium Permeation & Industrial Experience \\
Inspection & Size \\
Maintenance & Adaptability \\
& Material \\
Initial Cost & Geometry (Total Heat Transfer Area+ Wall thickness) \\
& Ease of Inspection (geometry) and field access \\
& Cleaning \\
& Waste \\
& Repairing \\
& Material \\
& Fabrication \\
&
\end{tabular}




\begin{tabular}{|lll|}
\hline & Criteria & Sub-criteria \\
\hline & & \\
Operability & Installation & \\
& Reliability & \\
& Operating \& Maintenance & \\
\hline
\end{tabular}

\subsubsection{Thermal Performance}

Thermal performance is the primary criterion for most of the heat exchanger selection process because effective heat transfer is the main purpose of the heat exchanger. Thermal performance consists of the following subcriteria:

- High Heat Transfer Performance: Heat transfer performance is highly affected by heat exchanger types because they have different channel geometries and configurations. Generally, a smaller channel size provides a better heat transfer coefficient for the same flow-rates. However, it causes higher frictional losses.

- Effectiveness: When heat is transferred, the system requires minimizing loss of useful thermal energy (exergy). Therefore, the heat exchanger's effectiveness is generally considered a very important design parameter. Higher effectiveness means the heat exchanger design is closer to the ideal. Typical values for the effectiveness are 0.7 to 0.9 for conventional shell-and-tube design, and 0.9 to 0.98 for the compact heat exchanger design.

- Fouling: Fouling can significantly degrade the thermal performance of a heat exchanger, especially for liquid coolants. To compensate for fouling, an oversized heat exchanger design is required and cleaning strategies are needed for specific applications.

\subsubsection{Structural Performance}

Structural performance is one of the most important criteria for AHTR heat exchangers so they can be operated safely at high temperature and large pressure differences for long plant lifetimes. Heat exchanger integrity can be categorized primarily by how it operates under steady-state and transient conditions. AHTR is mainly exposed to two different stresses: mechanical and thermal. Vibration is also an important heat exchanger criterion because it could degrade the integrity of the heat exchanger. Thus, a heat exchanger less prone to vibration instabilities is preferred. Since the heat exchanger is operated for long periods of time at high temperatures, creep and fatigue are also important issues that should be considered.

Validating the effects of system pressure and temperature on the integrity of the joints (diffusion bonding, brazing, and welding) in a molten salt environment under steady-state and transient conditions is necessary and would enable a better selection of the heat exchanger. Bonds are subjected to static and dynamic loading while the heat exchanger is operating; the one with better performance will be ranked higher. Brazed constructed heat exchangers are appropriate at lower temperatures, but there are potential mechanical integrity problems at higher temperatures with temperature cycling (Tatara 1997). The heat exchanger with proven joining techniques will be preferred when compared with unproven techniques.

The materials being considered for the heat exchanger (alloys 617, 230,800H, and Alloy N) all spontaneously form chromium rich oxide scales, which will present problems in making diffusion bonds. The diffusion bonding process needs to be further developed and bonding process parameters and controls identified. Technical literature addresses microstructure and mechanical properties, but not the parameters used to perform the bonding. Techniques such as mating surface pickling, nickel plating, or a nickel foil interlayer will have to be investigated. Mechanical testing of the diffusion bonded joints will be needed to identify promising joining parameters, such as temperature, applied pressure, and hold time for 
optimization. In addition to optimizing process parameters and inspecting diffusion bonds, other specific concerns must be addressed:

- Microstructural stability during the high temperature exposure associated with diffusion bonding

- Production of large components is limited by the size of the bonding equipment used

- Design and demonstration of adequately representative specimens because the real components will require joining of thin walls and complex stress conditions.

Creep-fatigue is mainly influenced by peak stresses because of the stress concentration effects of the coolant channels. Creep-fatigue combined with high temperature influences in AHTR environments makes the creep-fatigue characterization very complicated. Creep data at these high temperatures will be needed for the selected material in order to develop a creep-fatigue interaction diagram.

In this study, the mechanical performance consists of the following subcriteria:

- Mechanical stress: In the AHTR, the SHX is exposed to large pressure difference at high temperature between the primary and the secondary sides, depending on the integrated systems. Therefore, mechanical stress is an important consideration in heat exchanger evaluation and selection.

Mechanical stress in a heat exchanger is significantly affected by channel/tube configuration, size, and geometry. The bonding method is also very important to the mechanical integrity of a heat exchanger, which should be able to withstand the mechanical stresses in the given environment.

- Thermal stress: Thermal stress should be considered because large temperature gradient exists in the heat exchanger. Thermal stress is affected by heat exchanger configurations and geometries. Therefore, the thermal stress should be minimized in the heat exchanger design.

- Vibration: Vibration is one of the major failure mechanisms of the heat exchanger tube or channel. It is highly affected by heat exchanger geometry and configuration. Therefore, the vibration should be minimized in the heat exchanger design.

\subsubsection{Material Performance}

Corrosion is an important criterion for the AHTR heat exchanger, because of corrosive features of the fluoride salt at high temperature. A factor in the lifetime of a heat exchanger will be its resistance to corrosion in the AHTR environment. Corrosion resistance will be a function of the materials of construction, as well as the thickness of various sections. Design features of the heat exchanger and the material of construction will also impact corrosion. Corrosion is resisted by using special alloys in construction. If the selected material cannot effectively prevent corrosion, a better or a preferred option will be for the heat exchanger to have thicker walls (more forgiving) and more corrosion allowance incorporated into its design when compared with other heat exchangers. The subcriteria are:

- Geometry

- Corrosion allowance in design (uniform corrosion)

- Localized corrosion/environmental cracking

- Fluid compatibility.

\subsubsection{Technology Readiness}

Technology readiness is an important consideration for AHTR heat exchanger selection. A technology may look promising in the industrial applications but still need to be demonstrated under the AHTR operating conditions and environment. The sub-criteria selected for technology readiness are: 
- Material: The material used in manufacturing an AHTR heat exchanger is a major issue because of its high temperature and highly corrosive environment. The technology readiness of these materials is an important considered in heat exchanger evaluation.

- Fabrication method: Some heat exchanger types, such as PCHEs, use unique fabrication methods such as photochemical etching and diffusion bonding. Readiness for the fabrication method should be evaluated for a certain candidate materials.

- $\quad A S M E B P V$ Code status: The material used in manufacturing the heat exchanger should be supported by the ASME B\&PV code, even though it may exhibit excellent thermomechanical and chemical performances. The readiness of the ASME B\&PV code should be considered in the heat exchanger evaluation process.

- Industrial experience: Experience with A proven technology is always recommended for nuclear systems applications because of low uncertainty.

\subsubsection{System Integration}

The main role of the SHX in the AHTR is to integrate the nuclear reactor with the power conversion system and process application plant. Therefore, integrating the heat exchanger with both systems should be considered. The subcriteria are:

- Size: Size of the heat exchanger is important for integrating the heat exchanger with both systems. A smaller size is generally preferred.

- Adaptability: Adaptability is considered important to heat exchanger selection, dependent on the system selected for integration with the heat exchanger.

\subsubsection{Tritium Permeation}

Tritium is mainly generated in the AHTR core by ternary fission and various neutron reactions. A major concern is tritium permeation through the high temperature metallic surfaces because it is so small. Since this tritium is radioactive isotope, it can eventually radioactively contaminate the industrial system and products. Less heat transfer surface area and thicker heat exchangers are preferred in the design to mitigate tritium permeation. The subcriteria are:

- Material: Tritium permeation of the heat exchanger is significantly affected by the type of tube or channel materials. It is also highly affected by existing oxide-layers produced by chemical reactions between metals and steam/water or oxygen.

- Geometry: Total tritium permeation through the heat transfer surface is affected by heat exchanger geometrical parameters such as heat transfer area and wall thickness. Tritium permeation is proportional to the heat transfer area and inversely proportional to the wall thickness.

\subsubsection{Inspection}

Inspection should be easily accomplished to determine the state of the equipment. Compact heat exchangers will be difficult to inspect. A heat exchanger design that allows joints to be examined and cracks and crack growth to be more easily identified over its operational lifetime is preferred.

Nondestructive evaluation (such as eddy current testing, ultrasonic testing, radiography, and pressure leak testing) may be used to evaluate the structural integrity of heat exchanger components. It is not possible to offer more insight because of the lack of historical inspection and operation data for the heat exchangers being considered. 


\subsubsection{Maintenance}

The ease of maintenance such as cleaning, repair, and serviceability is an important characteristic for a successful AHTR heat exchanger. All heat exchangers should be chemically cleanable, which is more effective and efficient than dismantling and physically cleaning them. The heat exchanger should also have provision for replacing any components subject to corrosion, unless it is more economical to replace the whole unit (Shah 2003). Thus, a heat exchanger with these capabilities is preferred. The subcriteria are:

- Cleaning: The heat exchanger should be cleaned regularly to decrease the probability of fouling inside the channel or tube. Generally, it can be cleaned by physical, chemical, or both, depending on the heat exchange type.

- Waste: When cleaning and repairing a heat exchanger, some waste is discharged, which should also be considered in the evaluation process.

- Repairing: The heat exchanger should be easily repairable if tube rupture or other problems occur. Easiness in repair is highly dependent on the heat exchanger types.

\subsubsection{Initial Cost}

In one respect, the life-cycle cost for a given heat exchanger can serve as a single criterion for comparison. Such aspects as development, design, fabrication, installation, and maintenance costs can be included in the life-cycle cost. However, at this point in the project, the heat exchanger concepts are not sufficiently developed to provide accurate cost information on which to base these comparisons. Therefore, the cost comparisons will be qualitatively addressed. The cost could be characterized as:

- Fabrication Cost: cost associated with fabrication. Complicated designs might cost more to fabricate than simpler designs. In order to increase the surface area density of the heat exchanger, the fluid channel diameter (or effective diameter) is reduced, which generally increases the net fabrication cost. The fabrication method has to be acceptable and meet all the requirements imposed by ASME. The heat exchanger designs for the NGNP are still in the development phase, so fabrication cost values are rough estimates. The equivalent (same thermal duty) heat exchanger will be compared based on the net fabrication cost; the one with the highest value for a specific thermal load in $\mathrm{kW}$ (quantitatively measured as Heat Load (Q) in $\mathrm{kW}$ per dollar (\$) spent) per money spent will be ranked higher than the others.

- Materials Cost: Cost associated with construction materials. More material volume will be required for heavier heat exchanger, thus increasing the cost.

- Installation Cost: Cost associated with installing the heat exchanger could potentially be higher for conventional designs when compared with compact designs.

\subsubsection{Operability}

The subcriteria for operability are:

- Reliability

- Operating and maintenance.

\subsection{Modeling of the AHTR Heat Exchanger Selection Problem}

The AHP hierarchy for the AHTR heat exchanger selection is shown in Figure 6-1, which is developed based on criteria in Table 6-1 and alternatives. 


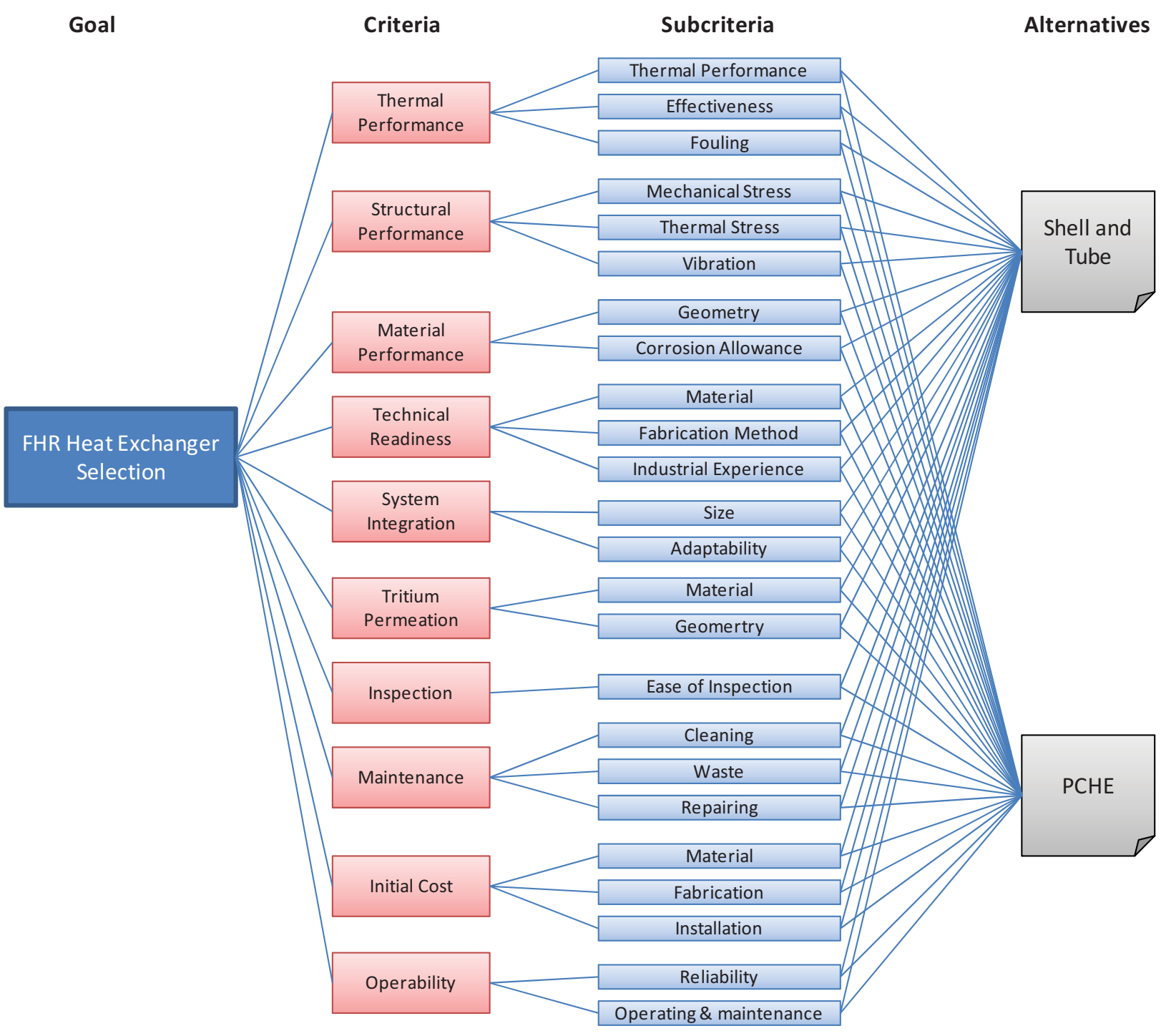

Figure 6-1. Decision hierarchy for AHTR heat exchanger selection.

\subsection{Pairwise Comparisons}

Once the AHP hierarchy has been constructed, the participants analyze it through a series of pairwise comparisons that derive numerical scales of measurement for the nodes. The criteria are pairwise compared against the goal for importance. The alternatives are pairwise compared against each of the criteria for preference. The comparisons are processed mathematically, and priorities are derived for each node. Table 6-2 shows the fundamental scale for pairwise comparison recommended in the AHP (Forman 2001). 
Table 6-2. Fundamental scale for pairwise comparison in AHP (Forman 2001).

\begin{tabular}{|c|l|l|}
\hline \multicolumn{3}{|c|}{ The Fundamental Scale for Pairwise Comparisons } \\
\hline $\begin{array}{c}\text { Intensity of } \\
\text { Importance }\end{array}$ & \multicolumn{1}{|c|}{ Definition } & \multicolumn{1}{c|}{ Explanation } \\
\hline 1 & Equal importance & $\begin{array}{l}\text { Two elements contribute equally to the } \\
\text { objective }\end{array}$ \\
\hline 3 & Moderate importance & $\begin{array}{l}\text { Experience and judgment slightly favor } \\
\text { one element over another }\end{array}$ \\
\hline 5 & Strong importance & $\begin{array}{l}\text { Experience and judgment strongly favor } \\
\text { one element over another }\end{array}$ \\
\hline 7 & Very strong importance & $\begin{array}{l}\text { One element is favored very strongly } \\
\text { over another, its dominance is } \\
\text { demonstrated in practice }\end{array}$ \\
\hline 9 & Extreme importance & $\begin{array}{l}\text { The evidence favoring one element } \\
\text { over another is of the highest possible } \\
\text { order of affirmation }\end{array}$ \\
\hline $\begin{array}{l}\text { Intensities of } 2,4,6, \text { and } 8 \text { can be used to express intermediate values. Intensities } \\
1.1,1.2,1.3, \text { etc. can be used for elements that are very close in importance. }\end{array}$ \\
\hline
\end{tabular}

\subsection{AHP Software (for Evaluation of Model): MakeltRational}

This study uses MakeItRational software for evaluation and selection of the AHTR heat exchanger. MakeItRational is well-known, Web-based, multicriteria decision making software based on the AHP method that uses pairwise comparisons for weighting and rating preferences. This software provides group decision evaluations and sensitivity analysis results. Figure 6-2 shows a screenshot of this software. Currently, all goals, alternatives, criteria, and subcriteria are implemented into the software with the hierarchy structure shown in Figure 6-1. This setup will be finally used for evaluation and selection of the AHTR heat exchanger in the next stage with adequate feasibility studies. 


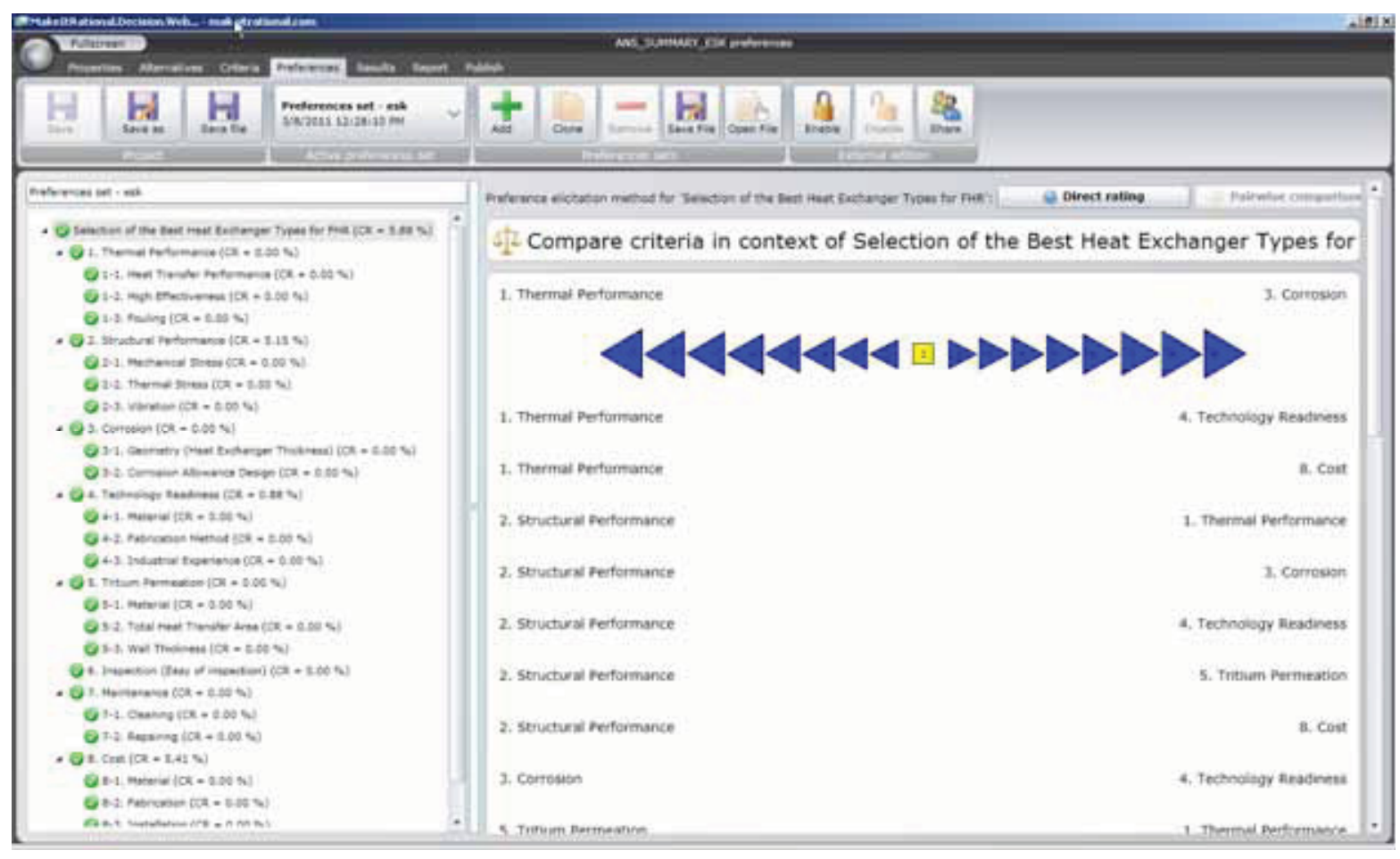

Figure 6-2. Screenshot of MakeltRational.

\subsection{Results for AHTR Secondary Heat Exchanger Evaluation}

Based on scores and weights obtained from pair wise comparisons, final priorities of the alternatives were evaluated with respect to the goal. Figure 6-3 and Table 6-2 show the subcriteria weight. Structural performance (CR2), material performance (CR3), operability (CR10), and technology readiness (CR4) were weighted as the important criteria for the AHTR SHX. Tritium permeation (CR6), initial cost (CR9), inspection (CR7), and maintenance (CR8) were weighted relatively low. Figure 6-4 and Table 6-2 show evaluated ranking of the two alternatives: helical coiled heat exchanger (A1) and PCHE (A2). The helical coiled heat exchanger shows higher overall rating than the PCHE. The rate of the PCHE is 43.75 and the rate of the helical coiled heat exchanger is 56.25 . These ratings were estimated using the scores obtained from the pair-wise comparisons. The detailed evaluation methodology can be referred to the book by Saaty (1996). Figure 6-5 compares the two alternatives for various criteria, giving the following results:

- Thermal Performance: PCHEs have better heat transfer performance and are more effective because they are more compact than the helical coiled heat exchangers.

- Structural Performance: PCHEs handle mechanical stress better than helical coiled heat exchangers because they are diffusion bonded and have relatively larger thickness-to-diameter ratios. They are also prone to less vibration than the helical coiled heat exchangers, which have lots of flow tubes.

- Material Performance: Helical coiled heat exchangers have thicker walls than PCHEs, making them preferable in corrosion environments. PCHEs are generally constructed of a single material, while shell-and-tube heat exchangers consist of several materials for their different components.

- Technology Readiness: Helical coiled heat exchangers have a much higher technical readiness level than PCHEs. 
- Tritium Permeation: PCHEs have a smaller heat transfer area than shell-and-tube heat exchangers, which is preferable for reducing tritium permeation, but they have thinner walls, which is not preferred. Thus, the PCHE and helical coiled heat exchanger have a similar tritium permeation rating.

- Inspection: Helical coiled heat exchangers are much easier to inspect than PCHEs, mainly because they are larger.

- Maintenance: Helical coiled heat exchangers are much easier to maintain (clean and repair) than PCHEs. Shell-and-tube heat exchangers can be cleaned either physically and chemically, while PCHEs can only be chemically cleaned.

- Initial Costs: Helical coiled heat exchangers cost less to fabricate, operate, and maintain. However, they cost more to manufacture and install because they are larger. In this study, cost was included in the evaluations. However, in the complex decisions, the AHP usually sets the cost aside until the benefits of the alternatives are evaluated.

- Operability: Helical coiled heat exchangers are more reliable and easier to operate and maintain than PCHEs.

Overall, the helical coiled heat exchanger is preferred for its material performance (corrosion), technology readiness, system integration, inspection, maintenance, and operability, while the PCHE is preferred for its thermal and structural performance.

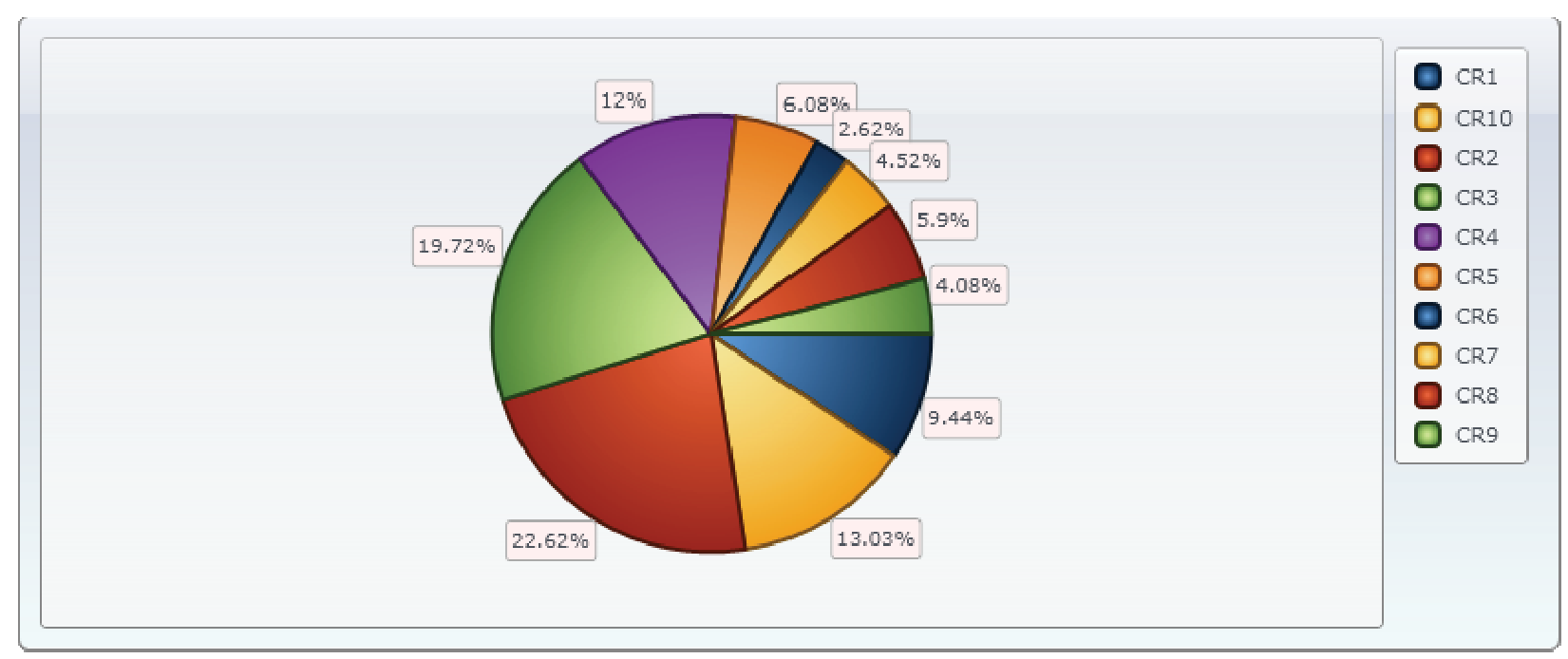

Figure 6-3. Subcriteria weight.

Table 6-2. Subcriteria Weight.

\begin{tabular}{|c|c|c|}
\hline & Criteria & Scores \\
\hline CR1 & Thermal Performance & 9.44 \\
\hline CR2 & Structural Performance (Evaluated by ASME B\&PV Design Rules) & 22.62 \\
\hline CR3 & Material Performance & 19.72 \\
\hline CR4 & Technology Readiness & 12 \\
\hline CR5 & System Integration & 6.08 \\
\hline CR6 & Tritium Permeation & 2.62 \\
\hline CR7 & Inspection & 4.52 \\
\hline CR8 & Maintenance & 5.9 \\
\hline
\end{tabular}




\begin{tabular}{|lll|}
\hline CR9 & Initial Cost & 4.08 \\
CR10 & Operability & 13.03 \\
Total & & 100.0 \\
\hline
\end{tabular}

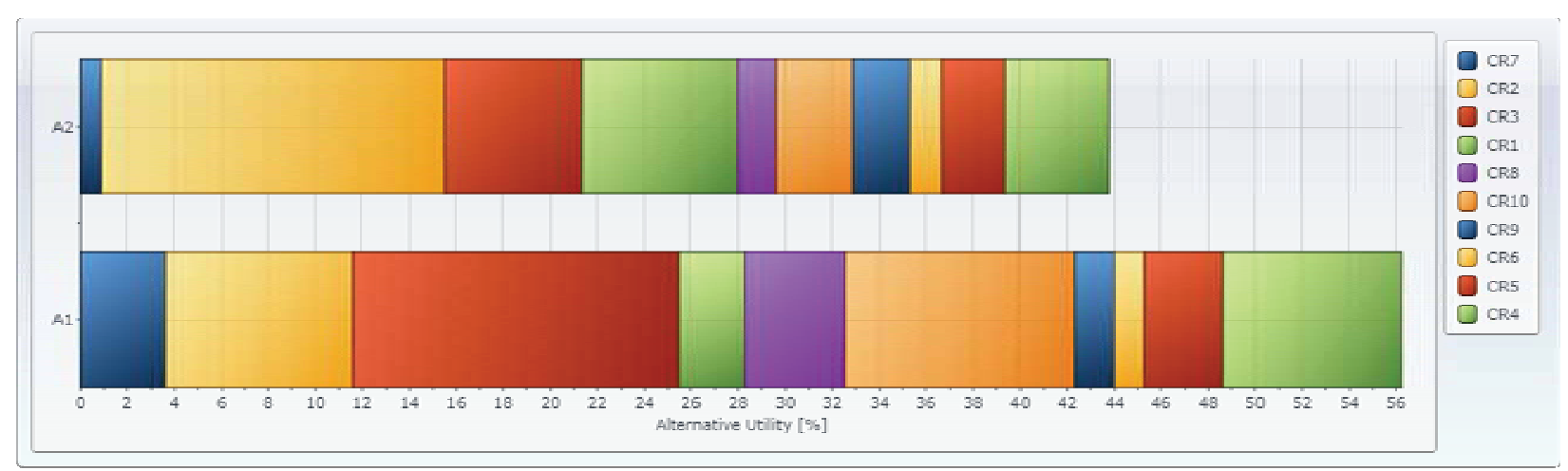

Figure 6-4. Alternatives ranking.

Table 6-3. Alternatives ranking.

\begin{tabular}{|c|c|c|c|}
\hline & Criteria & $\begin{array}{c}\text { A1 } \\
\text { (Helical Coiled) }\end{array}$ & $\begin{array}{c}\mathrm{A} 2 \\
\text { (PCHE) }\end{array}$ \\
\hline CR1 & Thermal Performance & 2.79 & 6.65 \\
\hline CR2 & Structural Performance (Evaluated by ASME B\&PV Design Rules) & 7.99 & 14.62 \\
\hline CR3 & Material Performance & 13.89 & 5.83 \\
\hline CR4 & Technology Readiness & 7.62 & 4.38 \\
\hline CR5 & System Integration & 3.34 & 2.73 \\
\hline CR6 & Tritium Permeation & 1.31 & 1.31 \\
\hline CR7 & Inspection & 3.62 & 0.9 \\
\hline CR8 & Maintenance & 4.26 & 1.64 \\
\hline CR9 & Initial Cost & 1.66 & 2.42 \\
\hline CR10 & Operability & 9.77 & 3.26 \\
\hline Total & & 56.25 & 43.75 \\
\hline
\end{tabular}




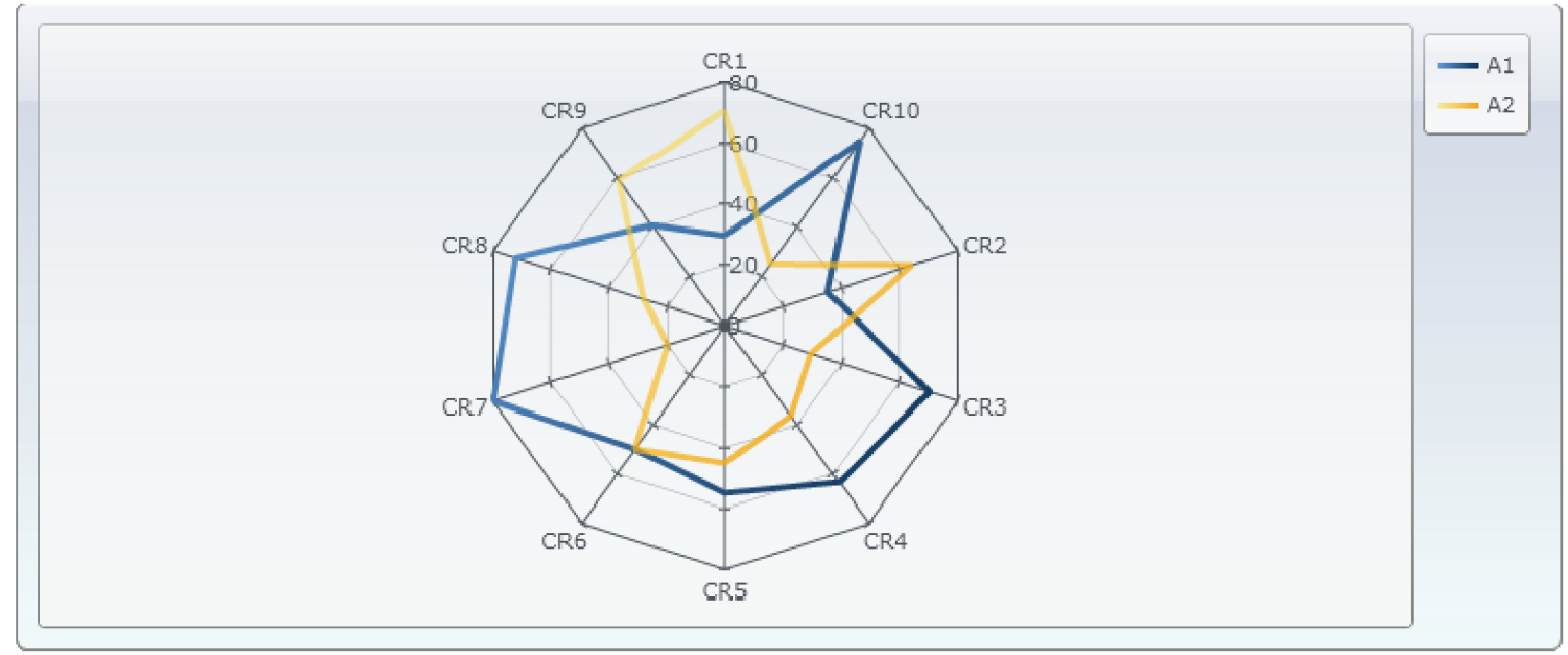

Figure 6-5. Alternatives comparisons. 


\section{THERMAL CONSIDERATIONS FOR TRADE STUDY OF MOLTEN SALT STEAM GENERATORS AND STEAM PLANT}

\subsection{Overview}

The objective of this study is to explore the challenges associated with adapting a steam power cycle to a molten salt reactor to identify future trade studies and research to obtain additional information required to design an actual plant and operate it from essentially room temperature to full operating temperature under steady-state load and changing loads. This study involves conceptualizing two steam power cycles based on existing fossil and nuclear plant designs, identifying components beyond existing designs that would be required for the molten salt, and listing the reasons for the additional components.

The adaptation of a steam power cycle to a working molten salt fluid with its high freezing temperature presents a number of challenges. This study conceptualizes two generic supercritical plant designs and describes the general considerations and characteristics of the systems and components anticipated to be required to couple a very high pressure and temperature (supercritical) Rankine steam cycle to a 3,400 $\mathrm{MW}_{\mathrm{t}}$ molten salt reactor. It includes lists of trade studies that should be conducted to conceptually define the plant and estimate its cost.

Two proposed generic supercritical steam plant configurations form case studies to illustrate concepts, components, and further areas to be considered in trade studies. The major difference between the two is reheating steam from the high pressure turbine by a steam-to-steam reheater, or a salt-to-steam reheater as discussed later. The study explores the application of off-the-shelf components, such as those used supercritical steam cycles currently being used in fossil plants, and modifications to accommodate a molten salt nuclear plant. It is anticipated that the steam generator and reheaters will be the most challenging design aspects.

Four sketches, Figures 7-1 through 7-4, illustrate the two designs. For each design there is a simplified and a more detailed sketch. Each shows general flow paths and components. In the actual plant there will generally be more than one of each component. For example, one steam generator is shown but there might be several. The same applies to pumps, feedwater heaters, and other components. 


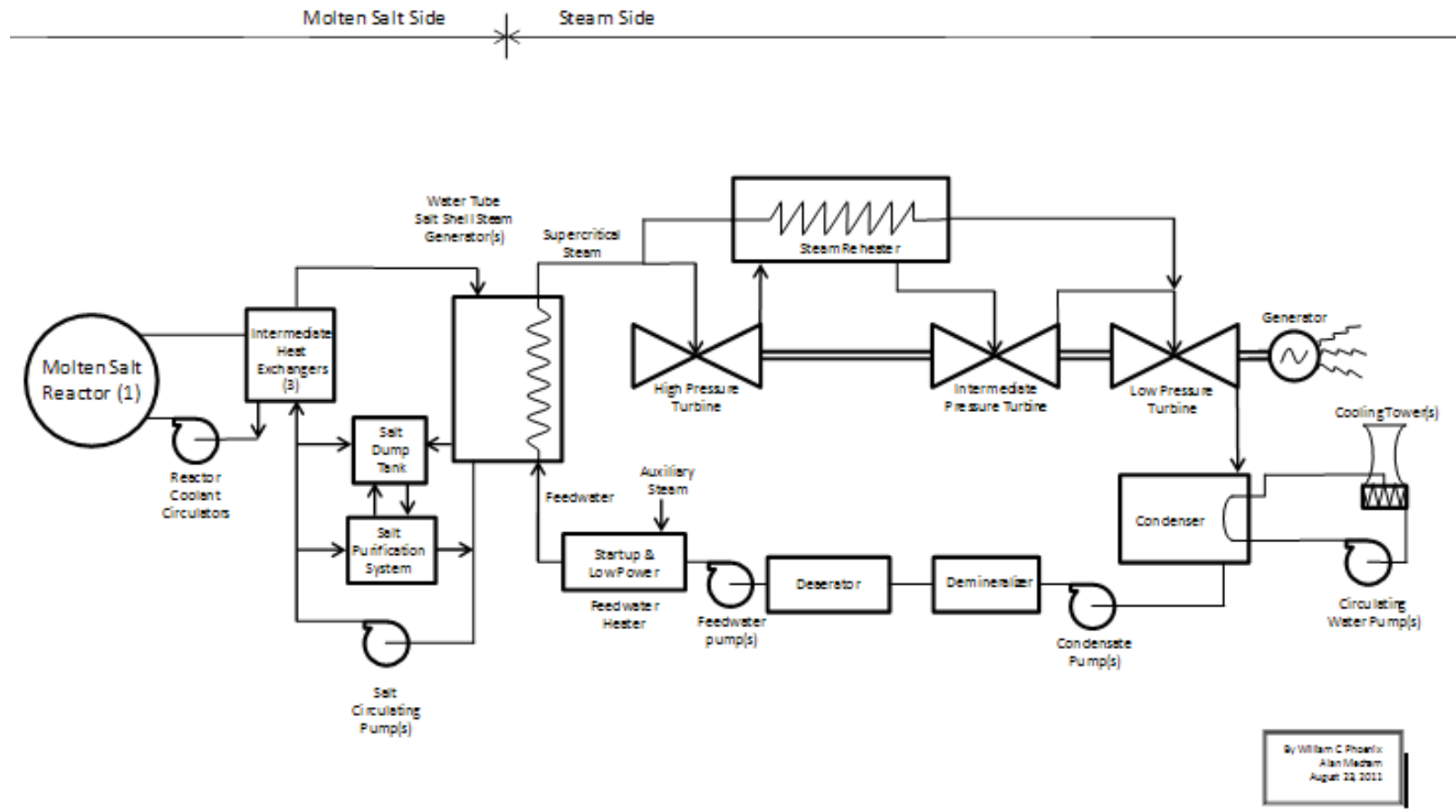

Figure 7-1. Simplified molten salt nuclear reactor conceptual Rankine supercritical steam cycle with steamto-steam reheat

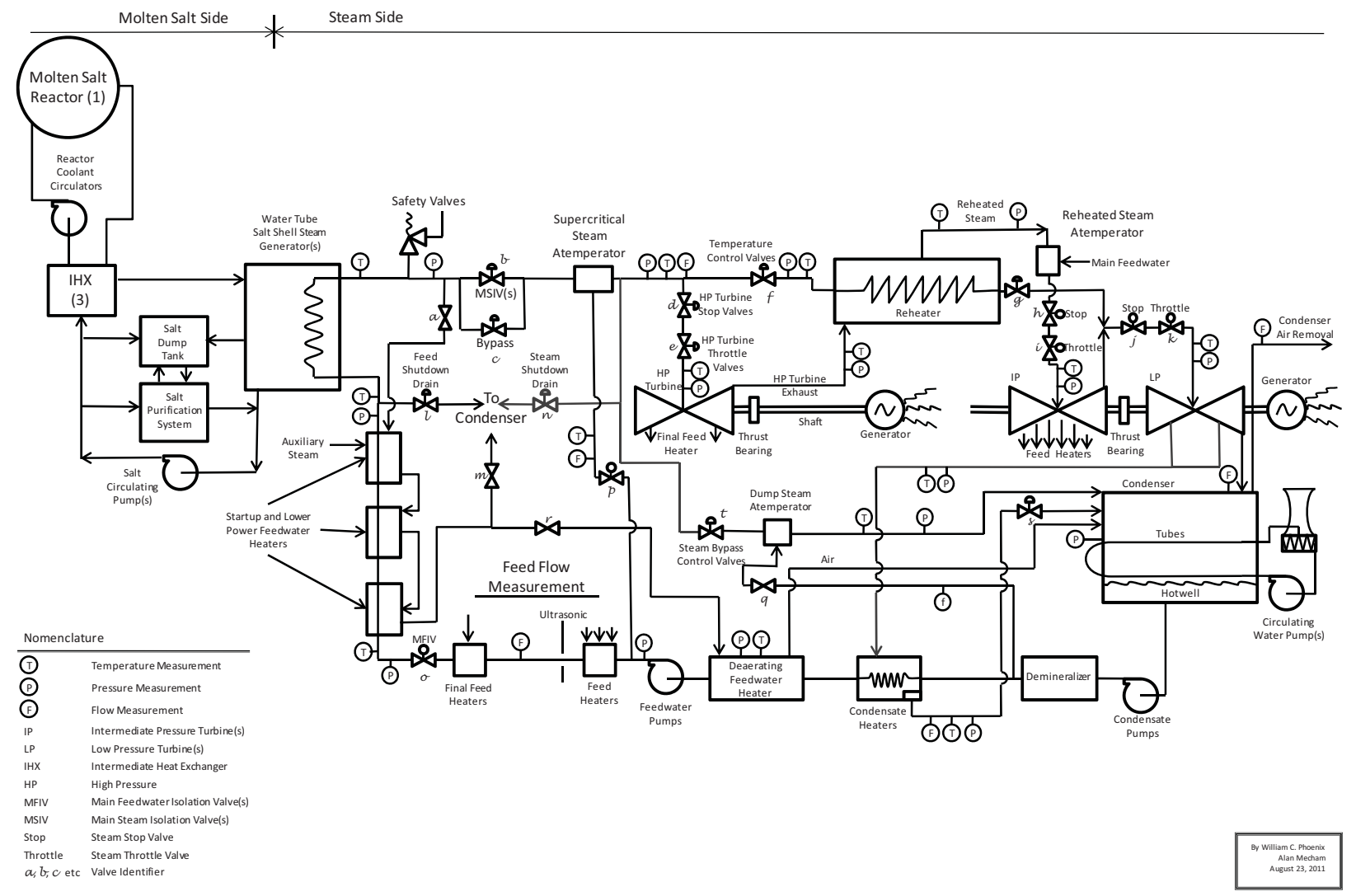

Figure 7-2. Detailed molten salt nuclear reactor conceptual Rankine supercritical steam cycle with steam-tosteam reheat. 


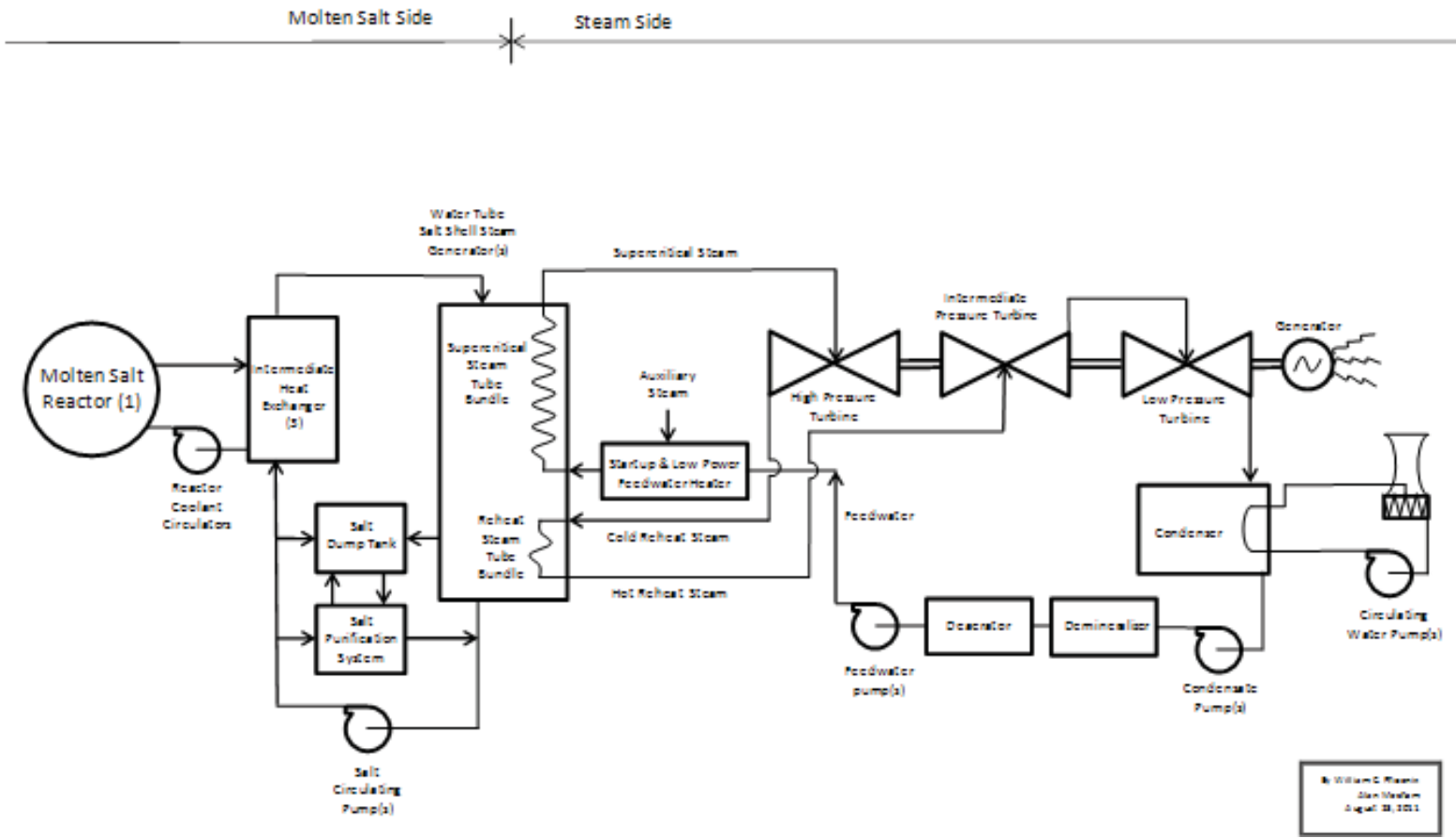

Figure 7-3. Simplified molten salt nuclear reactor conceptual Rankine supercritical steam cycle with salt reheat.

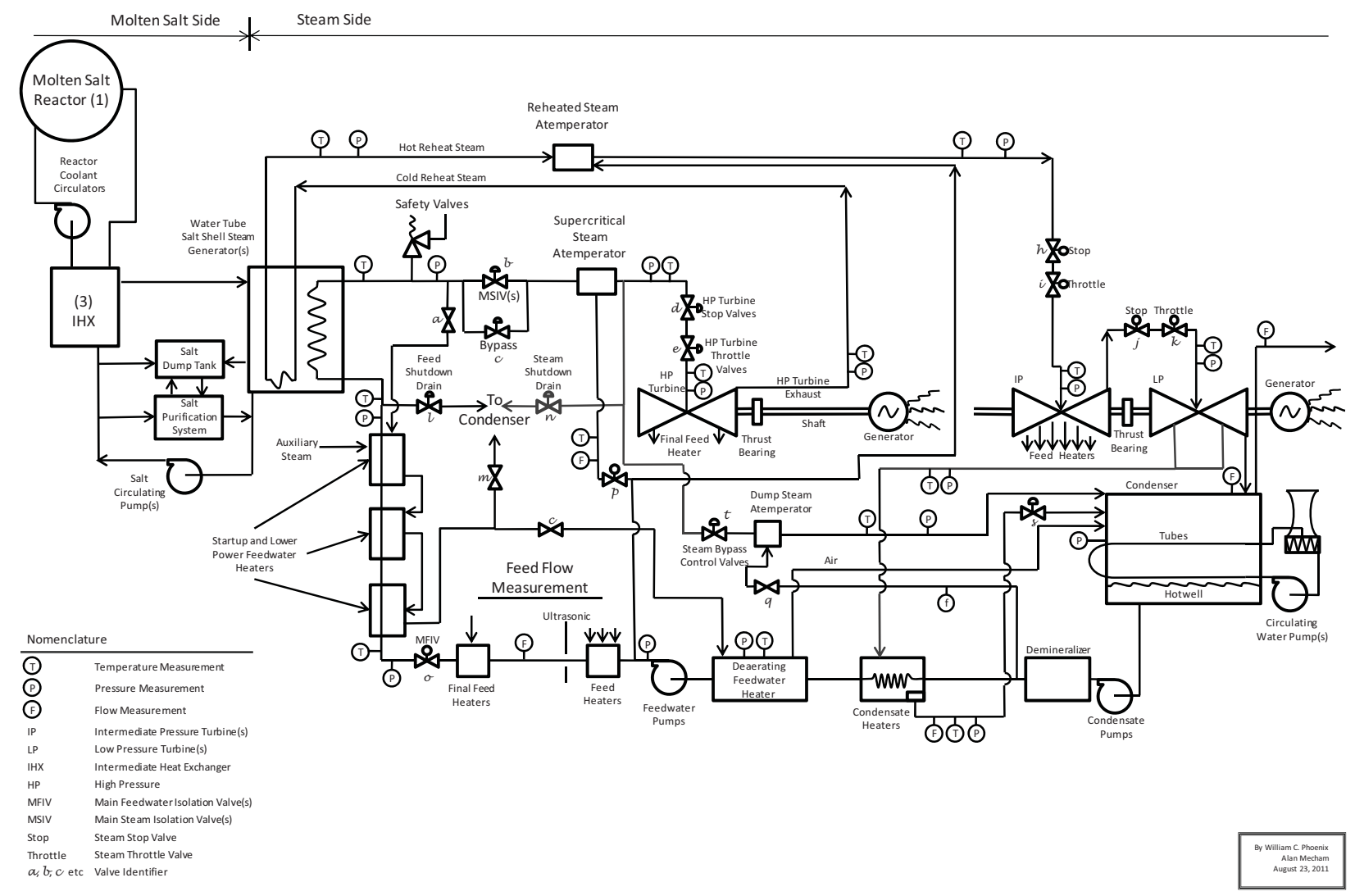

Figure 7-4. Detailed molten salt nuclear reactor conceptual Rankine supercritical steam cycle with salt reheat. 


\subsection{List of Future Trade Studies}

For convenience, trade studies are listed in this section with a short summary of the problems requiring them. Later sections provide background information, discuss the two plant concept in greater detail, and further justify the trade studies.

\subsubsection{High Salt Freezing Temperatures and Steam Generator Fatigue Life Usage}

The freezing point of salts, for example $390^{\circ} \mathrm{C}\left(794^{\circ} \mathrm{F}\right)$ for $\mathrm{KF} \mathrm{ZrF}_{4}$, is higher than the critical temperature for water, which is $373.94^{\circ} \mathrm{C}\left(705.4^{\circ} \mathrm{F}\right)$ at $22.06 \mathrm{MPa}(3208.2 \mathrm{psia})$ (ASME 1967). Obtaining this high temperature requires either a supercritical steam cycle or a superheated steam cycle where the majority of superheating is conducted in the steam generator and a portion of the steam is then used to heat and evaporate the incoming feedwater in a separate steam generator. It is anticipated that a supercritical steam cycle with once-through steam generators will be selected because the supercritical steam is denser and has higher cycle efficiency.

The current practical upper steam temperature limit for supercritical fossil fired plants is $621^{\circ} \mathrm{C}$ $\left(1150^{\circ} \mathrm{F}\right)$ although advanced materials show promise of $649^{\circ} \mathrm{C}\left(1200^{\circ} \mathrm{F}\right)$. The limit is imposed by the current metallurgy of boiler tubes, hot reheat steam lines, and high pressure and intermediate turbine blades. There are about 200 supercritical plants operating world-wide today (PDHengineer.com 2011) with the first having been operated since the mid-1950s.

Plants using supercritical, superheated, or saturated steam cycles preheat feedwater to varying degrees in feedwater or condensate heaters whose heat source is steam that has been extracted from the turbines or the main steam lines. Using steam avoids the possibility of freezing and freeze/thaw cycles in the steam generators, which could quickly consume fatigue life and lead to cracking.

One of the trade studies is to study the effect of salt freezing on the steam generator tubes and feedwater and steam headers, and particularly freeze/thaw cycles. The high freezing temperature of the salt will undoubtedly require much higher feedwater temperatures than any other steam cycle. The effects of freezing must therefore be studied.

Because of the extremely high pressures and temperatures of the water, it is assumed that water will be on the tube side of a tube-and-shell steam generator and the shell (salt) side will be essentially atmospheric pressure. Feedwater would enter the steam generator via a nozzle and be distributed to a number of tubes via a header or a tube sheet. The tubes might be spiral, straight, or have some other configuration. They might also have a single wall, or a double wall to contain hot water and steam in case of a leak. The tubes would converge on a header or a tube sheet where the supercritical steam would be discharged. Trade studies are required to identify the configuration and materials of the steam generator's components.

The high freezing temperature of the salt poses the prospect of extreme temperature changes and associated high fatigue usage. Many materials can be damaged or fatigued by changes in pressure, temperature, or mechanical loads. The amount of cycling from all sources before a material cracks is generally called 'fatigue life,' which is consumed by cycling. Some operations produce small changes and consume small amounts of fatigue life, while others consume large amounts. It is conceivable that a component could experience only a few very large extreme cycles before its fatigue life was completely consumed and it must be replaced. For example, sudden large temperature changes typically consume far more fatigue life than many small gradual cycles.

It is postulated that freezing salt on the feedwater header, where feedwater enters the steam generator and where steam generator tubes are attached, will significantly reduce heat transfer to the water inside 
the header and tubes, since the solid salt adds another layer of thermal resistance. This in turn leads to colder water further downstream in the tubes, possibly accompanied by salt freezing on additional tubing. The propagation of cold water inside the tubes and subsequent freezing of salt outside might suddenly and sharply cool the steam header and steam piping and lead to other problems such as excessive fatigue usage.

Significant thermal cycles can be postulated if the salt sloughs off or cracks, thereby allowing hot molten salt to contact the cold metal. The molten salt could freeze, then slough off, and the cycle could repeat, perhaps quickly. The cycle could be repeated. Each cycle might consume a small amount of fatigue usage and in time result in cracking.

Normal operation of the plant will probably require supplemental heating of the feedwater. Typically, the greatest challenges in actually operating a plant occur in bringing the plant from ambient conditions where maintenance has been performed to approximately $20 \%$ power. These challenges should be identified and evaluated beginning in the conceptual design stage. It is likely that substantial heating of feedwater downstream of the final feedwater heaters will be required. This additional, or supplemental, heat could be supplied by an auxiliary steam boiler, electric heaters, main steam, or another source. There is precedence for supplemental heating; it was used at Experimental Breeder Reactor II (EBR-2), a liquid metal fast breeder with steam generators (Koch 2008).

Trade studies are required to:

- Determine the extent of supplemental feedwater heating required during low power operation and plant startup and shutdown, and the temperature and power level at which supplemental feedwater heating is not required

- Calculate the resulting thermal efficiency of the plant (for example 20,50, 70\%, and full power)

- Evaluate using one or more supplemental heaters with cascading drains to reduce thermal stresses on the heaters

- Identify materials for the tubes and shells of the heaters

- Evaluate designs to circulate heated water to the feedwater inlet plenum - either recycle it for further heating or dump it to the condenser

- Evaluate and limit the rate and magnitude of thermal cycling of the condenser where the steam is dumped so the condenser will operate for the life of the plant

- Identify ways to limit damaging thermal shock and water impingement from the preheating system on the condenser

- Identify candidate materials for steam generator and steam and feedwater piping

- Include the cost of materials in estimating the cost of the plant.

\subsubsection{Steam Generators}

The steam generators design must consider the characteristics of the coolants including pressures, corrosion, temperatures, density, viscosity, heat capacity, and their materials, maintenance, operation under normal, off-normal, emergency conditions, and transportation to the site and placing them in their operating location. Steam generators are often designed with a lifetime exceeding the rest of the plant, although they are often replaced at least once during a plant's lifetime. The plant and coolant piping must be designed to support the steam generators and facilitate their replacement.

The extreme pressure differences between the water and salt sides and the high freezing temperature of salt offer the opportunity for different configurations than currently considered for light water reactor, 
liquid metal, and gas cooled reactors. Evolutionary advancements in tube-and-shell, once-through, spiraltube steam generator(s) might produce a robust design of steam generator based on the existing body of knowledge. Compact heat exchangers are likely to require significantly greater development than tube and shell steam generators with particular attention to freezing and thawing of salt, thermal cycles, and pressure cycles of the secondary fluid.

Supercritical steam generators are typically once-through, meaning the feedwater enters in one location called a feedwater header, and a large number of tubes extend through the shell to another location called a steam header, which is much hotter than the feedwater heater. In contrast, superheated and saturated steam generators typically recirculate the water through a portion of a boiler, remove the saturated steam, and either send it to another bank of tubes for superheating or directly to a turbine.

A tube-and-shell heat exchanger has several components. The lower pressure fluid can be in the shell to reduce stresses on the shell and permit faster changes in temperature. Shells with moderate to high pressure fluids typically are quasi-cylindrical with hemispherical heads. The relatively small diameter tubes are better able to withstand very high pressure fluid, compared to the shell.

The number of steam generators likely will be influenced by their size and weight, which in turn affects the ability to transport and erect them. The size and weight will in turn be affected by the thermal properties of the two coolants.

Trade studies are required to:

- Define design considerations for selecting the number and design of steam generators, including the configuration of their internals

- Determine the number of steam generators based on thermodynamics and operational concerns such as shutting down and restarting an idle steam generator

- Determine the internal configuration of the steam generators such as materials, thickness, joining and bonding techniques, and configuration to avoid creep-fatigue and other degradation mechanisms.

Also, joining techniques to dissimilar materials and the feedwater and steam headers; and spiral tubes, concentric steam tube to limit leakage into the salt, as found in the Experimental Breeder Reactor 2 steam generators (pages 3-35 and 3-36 of Koch 2008) based on thermal fatigue of metallic components and freezing of the salt

- Identify and quantify differential thermal and pressure-induced growth within the steam generator and designs to enhance the ability to withstand temperature and pressure cycles and stress corrosion cracking

- Determine water and steam chemistry requirements

- Define feedwater and steam pipe materials, and dimensions for single and multiple steam pipes

- Select materials with particular attention to withstanding stress corrosion cracking

- Define the configuration of secondary plant components such as deaerating feedwater heaters and oxygen addition to preserve metallic oxide films, and steam generator feedwater and steam headers to minimize sudden temperature changes and avoid stress corrosion cracking

- Develop criteria for high pressure components to accommodate nondestructive testing such as eddy current and other inspection, cleaning, and plugging

- Define and minimize salt and water flow patterns within the steam generators to reduce the possibility of stagnant low temperature areas where freezing could begin and propagate, particularly along the tubes, and conditions and operation to encourage thawing of frozen salt, particularly in low temperature areas around main feedwater inlet 
- Define the configuration of the steam generator(s) to avoid damage and loss of heat transfer from frozen salt, and encourage thawing by liquid salt flowing through the heat exchanger

- Identify and if necessary, develop instrumentation and algorithms for protection such as detecting low temperatures and stagnant flow in cold regions, particularly where freeze/thaw cycles could lead to unacceptable fatigue life usage

- Develop instrumentation and control and operating schemes to allow the plant to be started up and shut down, operated at full power, and operated during anticipated transients without adverse affects from freezing and to limit fatigue usage

- Configure and operate supplemental startup and low power feedwater heaters to maintain incoming water above a temperature that results in substantial freezing using induction heaters to avoid freezing and thaw frozen salt

- Determine the need for a salt dump tank to quickly remove salt from the steam generator(s) in case of significant tube or header leakage (in addition to overcooling or water contamination discussed later)

- Consider using another thermodynamic cycle such as Brayton using helium or other gas, if the trade studies indicate that supplemental heating will result in relatively low efficiency above power levels where the plant is anticipated to operate, say $70 \%$ power, or significant fatigue usage occurs that might require frequent replacement of the steam generators.

\subsubsection{Frozen and Liquid Salt Properties-Conductive Heat Transfer and Volumetric Changes}

The design of the steam generator(s) and feedwater preheating will depend on properties of frozen and liquid salt, including the volumetric change from liquid to salt upon freezing, as temperature changes, and as a function of water contamination. The limited existing information on salt properties, including heat transfer and heat capacity of molten salts, must be expanded. Considerably more information will be required.

\subsubsection{Frozen and Liquid Salt Properties-Water Absorption}

In the steam generators, large steam-to-salt differential pressures and creep fatigue and other degradation of the tubes, feedwater, and steam headers might allow water to enter the salt. The water might encourage corrosion of the steam generator tubes, shell, and feedwater and steam headers, salt loop components, such as piping and pumps, and the IHX. Information is therefore required on the:

- Corrosion of steam generator materials, loop materials and components, and the IHX.

- Changes in salt properties such as liquid and frozen heat transfer, density, viscosity, and freezing point as a function of water content.

Trade studies are required to:

- Determine salt chemistry, including moisture limits over the operating range of the plant such as cold shutdown to hot full power with particular attention to contamination of the salt because of leakage from the secondary side of pure water and water with the maximum allowable levels of impurities

- Determine water side operating chemistry requirements, including oxygen and other contaminants from cold layup (not operating at room temperature), hot layup (at operating temperature but zero power), and flowing at the full range of operation

- Define and develop instrumentation to directly measure the content of water and other contaminants in the salt 
- Identify the events and conditions that might require dumping the salt to a tank to limit corrosion or damage to the salt circuit

- Develop design requirements and conceptually design a salt purification system.

\subsubsection{Salt Circuit from IHX(s) to Steam Generator(s) and Steam Generator(s)}

The balance of the salt circuit from the IHX(s) to one or more steam generator(s) is anticipated to include piping, any expansion tank and inert gas overpressure supply and control systems, piping and component heating and piping insulation, the type and size of any isolation valves if one or more salt loops to supply a single steam generator, and the type and size of salt pump(s).

Trade studies are required to identify:

- The number, type and size of salt circulating pumps

- The type and size of associated salt loop isolation valves

- The material and configuration of the piping system, including an inerting gas storage, processing, and cleanup system

- The cost of the salt circuit.

\subsubsection{Water Chemistry Requirements and Secondary Plant Design}

Supercritical steam cycles require extremely pure water to prevent chemical attack of the components, and deposits of impurities on the turbine blades. Supercritical plants always include a demineralizer in the condensate system to remove impurities.

Impurities enter the condenser via: leaks in the condenser tubes at the points where the tubes enter the tube sheet (the flat piece of metal with many holes for each of the thousands of tubes); various fluid streams that discharge into the condenser because of erosion/corrosion of plant piping and components; water that is added to replace normal and abnormal leakage; and maintenance activities when the piping systems, turbine, and condenser have been opened. Leakage of circulating water from inside the condenser tubes into the condenser can bring substantial amounts of chloride; sodium; dirt; small but measurable amounts of copper, mercury, and other metals; organics such as sand; and inorganics.

The impurities must be removed before they can initiate and accelerate corrosion or coat heat transfer surfaces and turbine blades. A demineralizer typically consists of large vessels of resins that adsorb impurities. Typically, all of the condensate passes through the demineralizer, which, in this case, is called a full flow demineralizer. A polisher is another name for a demineralizer.

In addition to demineralizers, the materials in the condensate and feedwater systems from the condenser to the steam generator, and the steam system from the steam generator to the condenser must be chosen to limit the generation of metals or metal oxides by erosion/corrosion and eliminate metals such as mercury and copper that are incompatible with other metals, particularly at elevated temperatures and pressures. The extreme changes in pressures and temperatures throughout the plant require careful selection of materials. Bimetallic welds must be evaluated. The potential for galvanic corrosion between piping sections and components such as valve and pump bodies must also be evaluated.

Careful control of the oxygen content of the feedwater is also required to maintain protective oxide films on the materials. Air typically enters portions of the steam cycle that are below atmospheric pressure (subatmospheric) at such locations as valve stem seals (typically called packing), flanges, vents and drain valves, and the rotating shafts of low pressure turbines. 
Deaerating feedwater heaters, also known as deaerators, are typically capable of reducing oxygen during normal operation to parts-per-billion levels. Deaerators are typically large tanks downstream of the condensate pumps, demineralizers, and low pressure feedwater. The warm water entering them is sprayed into a steam environment and thereby heated. The combination of spray and higher temperature causes the water to release its oxygen and other noncondensibles such as nitrogen and argon, the other main components of air.

The metals downstream of the deaerators might require a low level of oxygen to preserve the protective oxide film. Instruments that can measure very low levels of oxygen and an oxygen injection systems might be required. Chemistry conditions to preserve materials during low power or shutdown conditions must also be considered and accommodated.

Trade studies are required to:

- Determine chemistry requirements from shutdown through full power operation of the various materials at a level to determine the requirements for condensate polisher/demineralizers and deaerators

- Identify materials in the secondary plant, if not already identified by earlier trade studies.

\subsection{Secondary Plant Configuration}

It appears likely that existing plant designs for the secondary plant can inform the design and cost of the supercritical plant downstream of the main steam isolation valves through the final extraction-heated feedwater heaters. A number of modern natural gas-fired supercritical plants have been installed, particularly in the Mideast. The decisions involve one or more sets of steam turbines on a single or more shafts, turbine speeds, and other issues. In the past, nuclear plants were among the lowest in cost generation because their limitations were mainly operated as base load at $100 \%$ power.

Trade studies are required to estimate:

- Fatigue life usage with cycling

- Overall general cost of the steam cycle in steady-state full power and cycling.

\subsubsection{Overall Estimated Plant Cost}

The overall cost of the salt circuit and secondary plant is anticipated to be generated from the studies mentioned above, although a preliminary cost estimate of the SHX is presented in Section 8.

\subsection{Thermodynamic Cycles and Limitations of a Molten Salt Steam Generator}

Supercritical fossil steam electric power plants have been in operation for about 60 years. Almost 200 are currently operating world-wide so there are decades of operating experience in a wide variety of environments.

It might be possible for the molten salt reactor to modify an existing supercritical design. One of the main modifications to accommodate the nuclear plant is the ability to route relatively large amounts of steam to the condenser during low power operation while the reactor is stabilized. Another is reheating the exhaust from the high pressure turbine with a steam-to-steam or salt-to-steam heat exchanger. Finally, significant preheating of feedwater might be required. 


\subsubsection{Example of Fossil Fired Supercritical Plant - Eddystone}

The Eddystone Unit 1 station is a supercritical plant upon which the thermodynamic cycle of the conceptual supercritical plant is based. It incorporates the fundamentals of the typical supercritical steam cycle explored in this section. The reader may wish to consult the Eddystone Station, $325 \mathrm{MW}$ Generating Unit 1, a Brief History (ASME 2011b) for additional details about its design, construction, and operation.

A properly designed and operated supercritical plant can have an extremely long life (in excess of 57 years) of highly efficient operation as demonstrated by the Eddystone supercritical coal-fired plant that has operated from 1954 until 2011. For most of its life, Eddystone was one of the most efficient plants in the world with a net output of $325 \mathrm{MW}$ and a heat rate of $8,320 \mathrm{BTU} / \mathrm{net} \mathrm{kWh}$ or about $41 \%$, including allowance for fuel used in the auxiliary boilers. The Eddystone Station, $325 \mathrm{MW}$ Generating Unit 1, a Brief History (ASME 2011) provides considerable information about this plant.

The Eddystone supercritical plant featured two turbine generator shafts and two stages of reheat, as shown in Figures 8 and 12 of Reference 7.4. The first was a high speed $(3,600 \mathrm{rpm})$ tandem compound shaft with a super pressure, a very high pressure, and a high pressure turbine. The other shaft had one intermediate turbine and two low pressure turbines operating at 1,800 rpm for a $60 \mathrm{~Hz}$ grid. The lower operating speed reduced the stresses on the 44-inch-long, last-stage blades of the low pressure turbines. The final stage blades of modern turbines can be even longer and more efficient, but they still must operate at relatively low speeds of $1,800 \mathrm{rpm}$ to generate $60 \mathrm{~Hz}$.

The supercritical steam conditions of Eddystone's 1957 vintage supercritical turbine's first turbine shaft, with its first stage reheater could be operated with $\mathrm{KF}-\mathrm{ZrF}_{4}$ with its freezing point of $794^{\circ} \mathrm{F}$ $\left(390^{\circ} \mathrm{C}\right)$. The super pressure turbine received high pressure supercritical steam at 5,000 psi (approximately $34.5 \mathrm{MPa}$ ) and $1200^{\circ} \mathrm{F}$ (approximately $649^{\circ} \mathrm{C}$ ) and discharge superheated steam at 2300 psia $(15.9 \mathrm{MPa})$ and $1001^{\circ} \mathrm{F}\left(538^{\circ} \mathrm{C}\right)$ to the very high pressure turbine. The very high pressure turbine's exhaust was reheated in the first stage of reheating from $790^{\circ} \mathrm{F}\left(421^{\circ} \mathrm{C}\right)$ to $1050^{\circ} \mathrm{F}\left(565.6^{\circ} \mathrm{C}\right)$ at 1,133 psia $(80.7 \mathrm{MPa})$ and supplied to the high pressure turbine. The high pressure turbine exhausted to the second reheater at $283 \mathrm{psia}(1.95 \mathrm{MPa})$ and $705^{\circ} \mathrm{F}\left(373.9^{\circ} \mathrm{C}\right)$. The second reheater discharged to a compound flow intermediate turbine and two low pressure turbines on an 1,800 rpm shaft.

The final stage of feedwater heaters, which had the highest temperature, was supplied superheated steam from the very high pressure turbine at $786^{\circ} \mathrm{F}(418.9 \mathrm{C})$. The final feedwater temperature exiting the feedwater pump was $574^{\circ} \mathrm{F}\left(301^{\circ} \mathrm{C}\right)$, far below the freezing point of salt. Coupling the Eddystone design to a molten salt reactor would require additional feedwater heating.

Eddystone had nine feedwater heater stages. The feedwater heaters were upstream of the final feedwater pump, probably to avoid thermal stresses and very thick feedwater tubes.

Since power plants make electricity by steam flowing through turbines, the loss of the steam to steam turbine stages downstream of the extraction point will reduce electrical output and reduce cycle efficiency. Heating feedwater somewhat compensates, but there will be a net reduction in cycle efficiency.

The use of very high pressures required the super pressure turbine to use more expensive materials and be quasi-spherically shaped to accommodate the pressure. It had an austenitic stainless steel (chromium content of 12 to $18 \%$ ) inner shell and casing, and a ferritic steel outer casing. Its outer shell had a shape that approached a sphere whose material composition was conventional $2 \%$-chromium, $1 \%$ molybdenum-V.

Like all once-through steam generators, Eddystone's feedwater required extremely low levels of impurities. Maximum total dissolved solids in the steam were $50 \mathrm{ppb}$ with $2 \mathrm{ppb}$ maximum for silica 
$\left(\mathrm{SiO}_{2}\right)$. Such low levels require a condensate polisher/demineralizer in the design of the molten salt reactor and careful attention to piping systems to avoid generating additional metals and oxides from erosion/corrosion.

\subsubsection{Load Following}

The advent of large amounts of intermittent, nondispatchable renewable generation, such as wind and solar, may require most future plants to load follow or accommodate the renewable's sudden increases and decreases in generation to maintain essentially constant grid frequency. Load following, or load cycling, is varying the generation of a plant to match the existing instantaneous load on the grid to maintain essentially constant grid frequency. In the United States, the frequency of the grid is tightly regulated. Future plants, including nuclear, can be expected to load follow to some extent as long as the current laws require the grid to accept all generation from renewable sources.

If a preferred source of generation such as wind increases its generation, the frequency of the grid increases unless other forms of generation reduce their output. The pressures and temperatures within the steam turbines change with changes in generation, sometimes very rapidly with the rates of increase and decrease (known as ramp rates) associated with large amounts of wind generation. Rapid load changes, with associated rapid temperature changes, have been shown to rapidly consume fatigue life of the turbine and other plant components.

A plant is called dispatchable if the grid operator can direct the plant to increase and decrease generation at a controlled rate. Wind, particularly, tends to operate at around $25 \%$ of full capacity until a storm; it then quickly ramps to full capacity and decreases to $25 \%$ after the storm passes. Large wind turbine farms can have a full generating capacity of 1,000 MW(e) or more, approximately equal to one large nuclear plant. A storm can increasing the farm's output from $25 \%$ to full generation in a few minutes, remain at full generation for an hour or so, then decrease to calm or return to $25 \%$ in tens of minutes. The grid operates with quasi-constant frequency and large changes in one form of generation require another to be reduced.

The Columbia nuclear generating station in eastern Washington State is in an area with abundant hydro and wind power. It routinely reduces load from $100 \%$ to $85 \%$ on weekday evenings and to $65 \%$ on weekends.

Gas fired cogeneration plants that were designed as base load have updated their control systems and developed operating schemes to cope with renewable energy. Large amounts of wind turbines in Texas left the Sim Gideon combined cycle gas turbine/steam turbine plant, with no option but cycling. It was retrofitted with revised controls and management of steam temperatures using, among other things, attemperation (spraying relatively cold water into steam) with the goal of preserving thermally sensitive portions of the plant and reducing fatigue life consumption (Key 2010). The proposed molten salt design incorporates several attemperators for the same reason.

\subsubsection{Supercritical Steam Cycle and Superheated Steam Cycle}

Figures 7-5, 7-6, and 7-7 illustrate the thermodynamic cycle for the molten salt reactor and supercritical steam plant, and a superheated steam plant.

Figure 7-5 illustrates a temperature versus entropy diagram to help visualize the steam cycle. The diagram is divided into two areas. At the saturation curve steam and water are at the same pressure and temperature, and one value, either temperature or pressure, defines the other properties, including steam and water densities, energies, and enthalpies. The saturation curve makes a dome. Inside the dome, under the saturation curve is an inner area where saturated steam and water co-exist as a two phase mixture ranging from pure water on the left-hand side to pure steam on the right-hand side. The density, energy, 
and enthalpy of the mixture depend on the ratio of water and steam. Lower temperatures in the lower portion of the area are typically where steam condenses to water by rejection of heat.

Boiling and condensation typically occur at essentially one temperature and pressure. In a boiler or steam generator, subcooled water on the left hand side of the saturation curve is heated to saturation temperature for the existing pressure at the left hand portion of the curve. At saturation temperature, steam and water coexist and additional heat produces more steam from the water until eventually all of the water has been converted to steam on the right hand side of the saturation curve. On a temperature versus Entropy curve (T, s curve), boiling is an essentially horizontal line.

Outside the saturation curve, superheated steam exists on the right hand side and compressed water to the left. Additional heat will superheat the saturated steam.

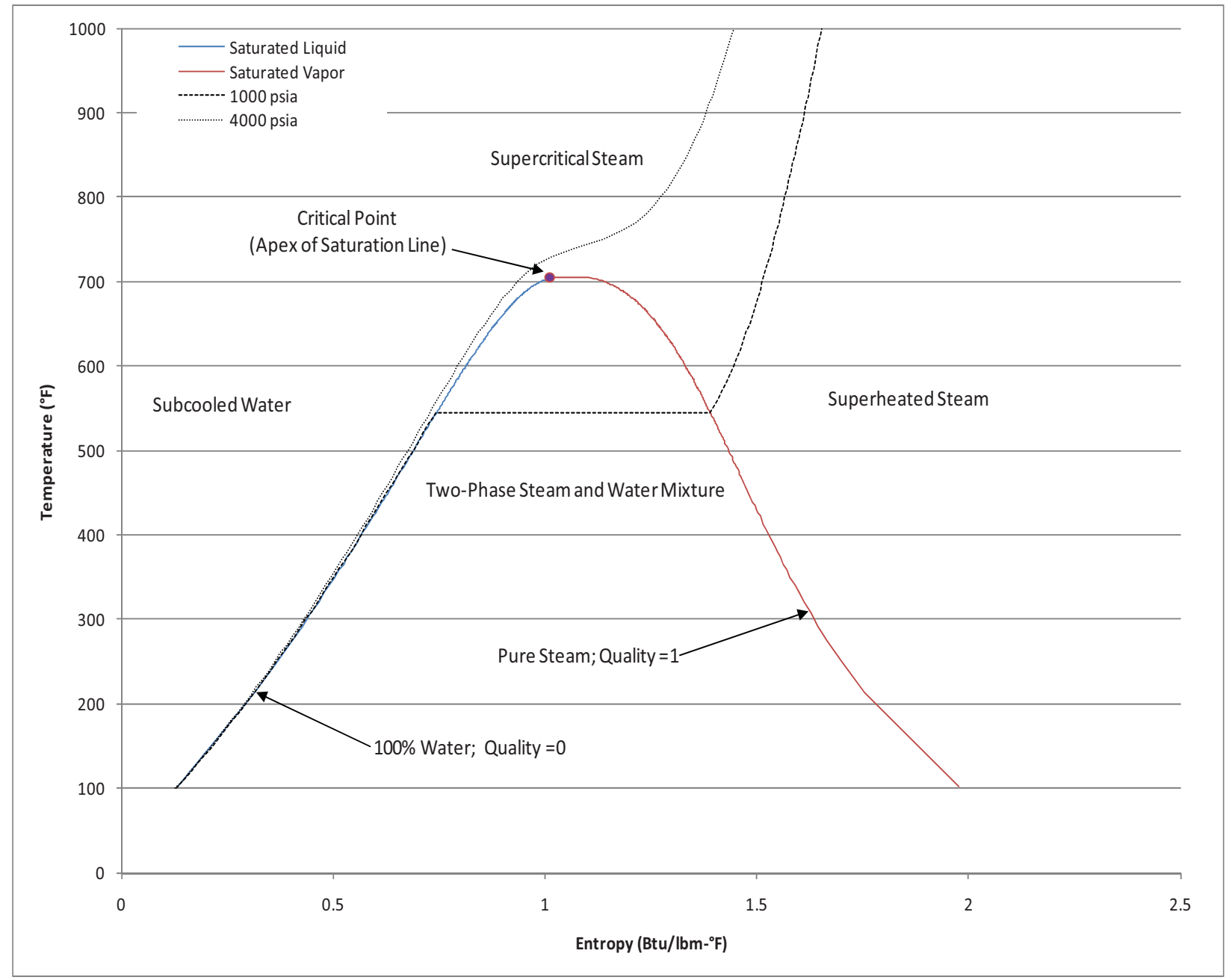

Figure 7-5: Sketch of diagram of temperature in ${ }^{\circ} \mathrm{F}$ or ${ }^{\circ} \mathrm{C}$ versus entropy, s, in BTU/lbm- ${ }^{\circ} \mathrm{F}$ (illustration only - not to scale). 


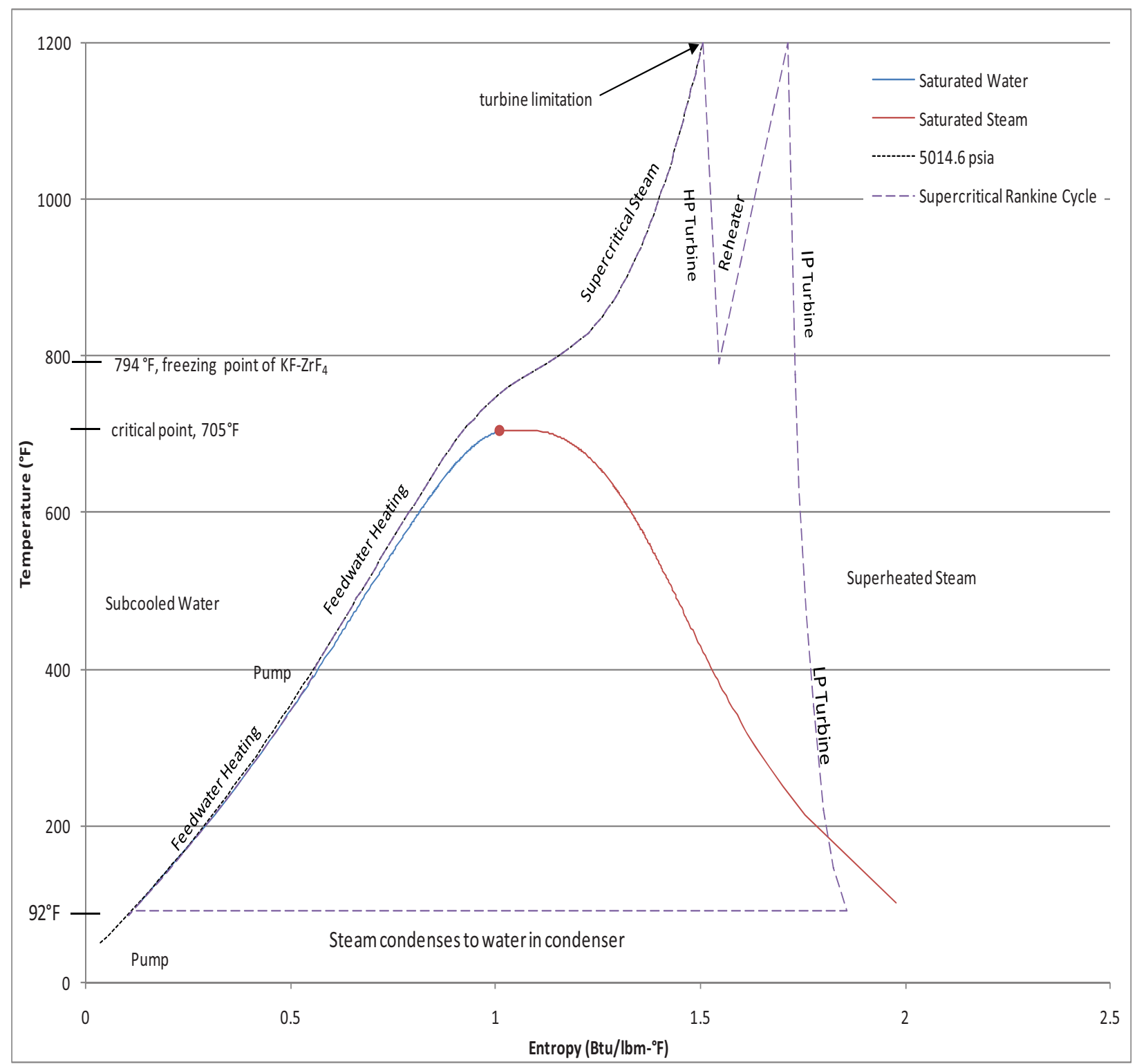

Figure 7-6. Sketch of diagram of temperature in ${ }^{\circ} \mathrm{F}$ or ${ }^{\circ} \mathrm{C}$ versus entropy, $\mathrm{s}$, in $\mathrm{BTU} / \mathrm{lbm}-{ }^{\circ} \mathrm{F}$ for supercritical

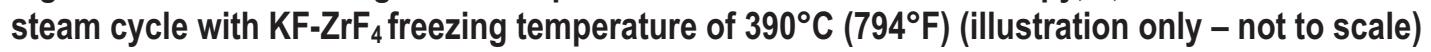




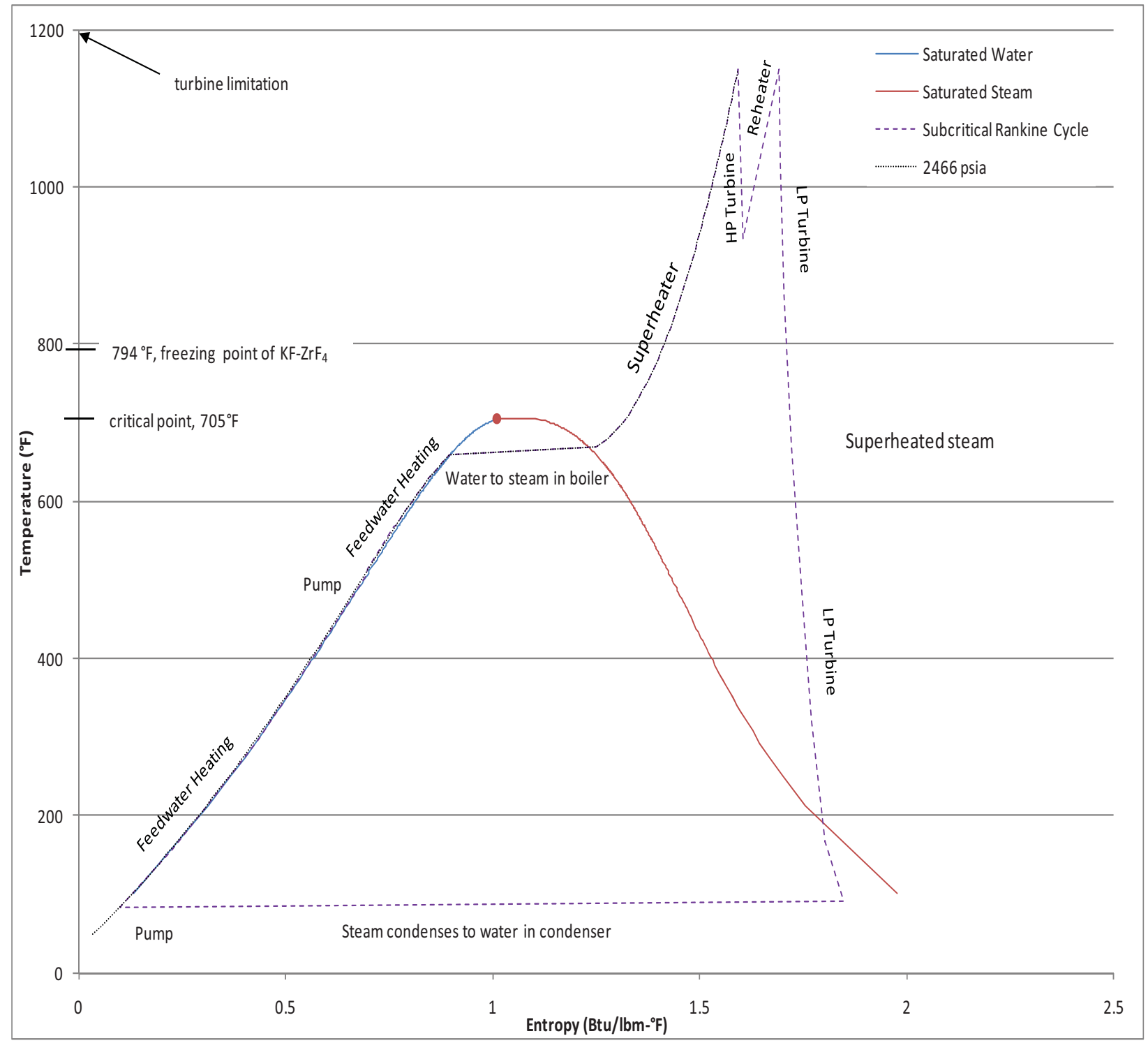

Figure 7-7. Sketch of diagram of temperature in ${ }^{\circ} \mathrm{F}$ or ${ }^{\circ} \mathrm{C}$ versus entropy, $\mathrm{s}$, in $\mathrm{BTU} / \mathrm{lbm}-{ }^{\circ} \mathrm{F}$ for superheated

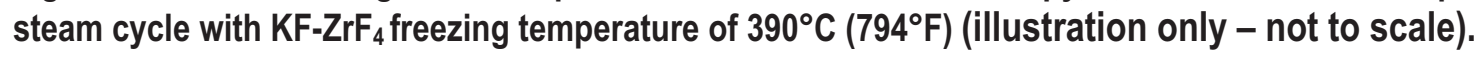

The apex of the saturation curve is the critical point of water - a unique combination of pressure and temperature above which water is converted to steam. The critical temperature for water of $373.946^{\circ} \mathrm{C}$ $\left(705.4^{\circ} \mathrm{F}\right)$ is at $22.060 \mathrm{MPa}(3208.2 \mathrm{psia})$ (ASME 1967). The conversion of water to steam occurs without a two phase mixture above the critical point and at ever-increasing temperatures for a constant pressure, as shown in Figure 7-6. The water is subcooled until it reaches critical temperature, and then it changes to supercritical steam. Further heat addition results in additional heating of the already supercritical steam.

The supercritical steam cycle results in resultant greater enthalpy changes than the superheated steam cycle. Electrical output of the generator is proportional to the mass flowing through the turbine and the total difference in temperature and enthalpy between the highest pressure turbine's inlet and lowest pressure turbine's exhaust to the condenser.

Reheating the steam from the high pressure turbine significantly increases the total enthalpy change and increases efficiency, as well as delaying the onset of condensation and resulting wet steam in the 
turbine. The rejection temperature of the condenser for a typical condensing steam cycle, as discussed here, is relatively constant. Therefore, the higher the inlet temperature and the more reheating, the higher the generation for a given amount of heat and the more efficient the plant.

For comparison with a supercritical cycle, Figure 7-7 is included for a superheated plant to illustrate that the high temperatures in the upper portion of the area are typically where water is converted to steam in a steam generator by addition of heat. The steam is then superheated in a separate portion of the boiler called a superheater. Because the incoming feedwater is at less than critical pressure, this cycle can only produce superheated steam.

\subsection{Intermediate Salt Loop}

The molten salt reactor will have one or more primary loops, each containing a salt-to-salt IHX to transfer heat. The secondary side of the salt-to-salt IHXs is connected to the intermediate salt loop. Each intermediate salt loop contains an IHX to transfer heat to one or more salt-to-steam generator(s) and possibly steam reheater(s), pumps to circulate the salt, and one or more salt dump tank and salt purification system. The same intermediate salt loop concept applies to both steam cycle concepts as shown in Figures 7-1 through 7-4 (above).

It is anticipated that the intermediate salt loop will operate at low pressures, close to atmospheric, which allows for a large salt dump tank. The loop piping and components will undoubtedly be insulated and heat traced to avoid freezing, or to thaw frozen salt following maintenance or prolonged loss of offsite and onsite power sources. The intermediate salt loop might also have an inert cover gas system to minimize contact with the atmosphere and its moisture and oxygen.

The salt dump tank serves several purposes. Under normal operation it stores salt to accommodate the volumetric expansion and contraction of the salt and piping in the intermediate salt loop resulting from temperature changes. Under emergency conditions such as significant leakage of water from a steam generator it provides a large volume to quickly remove the salt from the system and limit further contamination of the salt. It also provides a recirculation flow path for the Salt Circulating Pump(s) in case recirculation piping (not shown in the drawings) is blocked by frozen salt. It is anticipated to have cooling coils in case the salt requires cooling, and the coils could also remove the heat added by the pump and to cool salt following dumping the salt in the intermediate loop during an upset or emergency. Finally, it is connected to the salt purification system for constant purification and chemical conditioning. It will be heated, perhaps using heat trace, to maintain salt in molten condition and have its own circulation pumps to mix the tank and transfer salt to the salt purification system, and an inert cover gas to minimize air contamination of the salt.

The salt purification system is intended to remove water and other contaminants. Depending on the characteristics of the salt and the required level of purity, it might be batch or continuous processing, although, because of the high freezing temperature, continuous operation and continuous flow might present fewer control problems and much less thermal cycling of components and piping. It will require instruments to automatically and manually measure the contaminants in the salt, and provisions to manually obtain samples for chemical analysis. The salt purification system might also contain the system(s) to store and maintain an inert cover gas for the intermediate salt. It will be heat traced to maintain salt above freezing.

The salt circulating pump(s) circulate the intermediate coolant salt, $\mathrm{KF}^{-} \mathrm{ZrF}_{4}$, between the IHX(s) and the steam generator(s) and provide a pressure to drive fluid to the salt dump tank and salt purification system. They are anticipated to be either centrifugal or centrifugal/axial pump(s) with shaft seals and a motor driven by variable frequency drives (VFDs). The VFDs make it easier to obtain a variety of 
differential temperatures across the IHX to limit temperature changes and associated thermal stresses, and a means controlling the supercritical steam temperature over a variety of power levels.

\subsection{Steam Generator(s)}

The solidification temperature of $390^{\circ} \mathrm{C}\left(794^{\circ} \mathrm{F}\right)$ of the $\mathrm{KF}-\mathrm{ZrF}_{4}$ heat transport coolant presents novel operating restraints on the plant as a whole, but particularly the steam generators. The solidification temperature of the salt is higher than liquid metal coolants, which had high thermal conductivity in molten and solid states. As discussed earlier, unless special heaters are installed to ensure the water entering the steam generator, relatively cold feedwater could result in solidification below a given power level. In this case, salt might freeze on the outside of the tubes and the feedwater header. If the thermal heat transfer of frozen salt is low, frozen salt might effectively insulate the tube. Freezing would begin at the inlet side and could progress until essentially all of the tubes were covered with frozen salt.

The high freezing temperature of the $\mathrm{KF}-\mathrm{ZrF}_{4}$ coolant places a number of restrictions on potential steam generators and presents opportunities to explore different configurations of final feedwater heaters, steam generator(s), and reheater(s) used in the nuclear industry. Heat exchangers generally operate on the principle of fluids flowing through them to lose or gain energy. A frozen or stationary fluid can only transfer heat via conduction. Frozen salt might have significantly reduced heat transfer compared to flowing salt. A study will be required to determine if freezing, once started, will propagate so most or perhaps the entire steam generator tubes will be covered by frozen salt, and if so, how to thaw the generator.

There are many potential steam generator design options, including compact or more conventional tube-and-shell, single or double tube, vertical or horizontal, additional economizers (heat transfer surfaces specifically designed to preheat water), spiral or u-tube, and top, side, and bottom steam and water plenums. The differential pressure between the water and salt will influence the design of the water and steam headers and inlet and discharge plenums, and the tubes. While the high pressure water and steam will require thick-walled and therefore heavy components, the various pieces might be small and light enough to transport by road, in additional to rail, barge, and other traditional means. A number of smaller components might be required to reduce thermal expansion and thermal cycling.

There could be one steam generator, if there is no safety requirement for the steam generators to operate as is the case with the current fleet of pressurized water reactors, to cool the plant to the point where the shutdown cooling system can operate and if the thermal, stress, and flow distributions allow. The steam and feedwater headers would be very large, allowing them to be under considerable stress. Several steam generators might be more practical, say one per IHX loop.

Once-through steam generators typically have very little water inventory and operate at relatively high to very high pressure. A steam generator tube rupture or cracked header could very quickly empty the inventory of the steam generator into the salt. As discussed elsewhere there may be much more water in the steam and feedwater lines associated with each steam generator and consequently a need to isolate the steam generator and dump the water and steam to the condenser.

At first glance, the standard tube-and-shell design of liquid metal and gas cooled reactor steam generators appear to be preferred because of decades of good and bad experience. However, compact heat exchangers might be used if they can tolerate high differential pressures and temperatures and salt freezethaw cycles. 


\subsection{Supercritical Steam Cycle including Turbine and Associated Equipment}

The proposed nuclear supercritical steam cycle is based on a generic fossil supercritical steam cycle. A generic fossil supercritical steam cycle and the proposed variations on a nuclear supercritical steam cycle are discussed in this section.

\subsubsection{Generic Fossil Supercritical Steam Cycle}

A quasi-standard fossil plant supercritical steam cycle has several design considerations that are anticipated to be used in the molten reactor. Conceptual designs shown in Figures 7-1 through 7-4 are roughly based on a supercritical fossil plant with accommodations for nuclear.

In a fossil design, the pressure of feedwater entering the steam generator is far higher than the critical pressure. The feedwater has been moderately preheated in feedwater heaters that use extraction steam. Very high temperature and pressure supercritical steam exits the steam generator and is routed through thick-walled tubing to the highest pressure and temperature turbine. The temperature of the supercritical steam is limited by the materials in the boiler and supercritical steam tubing and the turbine stationary and rotating inlet blades. The design of high pressure stop and throttle valves and the shaft seals on the turbine must limit the flow of very high temperature and pressure steam to limit damage to the shaft and surrounding metal because of flow and the loss of energy from the cycle.

In typical superheated fossil boilers, radiant heat from burning fuel heats water in the boiler's waterwall tubes to saturation and boils a considerable amount of the saturated water. The saturated steam is separated from the saturated water in a long narrow tube called a steam drum. Saturated water is mixed with incoming feedwater in the steam drum and returned through u-shaped downcomer tubes to the bottom of the boiler, then through the waterwall tubes as it recirculates. The superheated steam is then routed to superheater section where high temperature combustion gasses superheat the steam. The hot gas then continues to a reheat sections where lower pressure steam from the exhaust of the high pressure turbine, called cold reheat, is reheated to essentially the same temperature as main steam. The reheated steam, called hot reheat, is finally routed to the intermediate pressure turbine and then to the low pressure turbine. Gas temperature is always far above its freezing point, which is far below ambient temperature.

In supercritical fossil boilers, the water makes one pass and exits the boiler. It is therefore called a once-through system.

The highest pressure and temperature turbine typically reduces steam pressure below supercritical so its discharge is superheated. The superheated steam can then be routed to either a high pressure turbine or as cold reheat returned to the boiler for the first stage of reheating, which adds energy to heat the steam so the temperature of the superheated steam is nearly equal to the original temperature of the supercritical steam. The temperature of the superheated steam is again limited by piping and turbine materials. The reheated superheated steam is then expanded through a high pressure turbine and often returned to the boiler for a second stage of reheating.

Many supercritical plants have two turbine shafts that rotate at different speeds, each with an electrical generator. For a two shaft plant, the relatively small diameter blades and shafts on the very high pressure and high pressure turbines allow the turbines to rotate at 3,600 rpm-synchronous speed for a two pole generator. The intermediate and low pressure turbines are then on another lower speed $(1,800$

$\mathrm{rpm}$ ) shaft with a four-pole generator. The differential expansion of the shafts and thrust bearing, the fixed point between the shafts and their shells, is an important aspect of the design. 
The turbines, boilers, and reheaters operate at very high pressures and temperatures. Sudden large changes in temperature can consume fatigue life. Temperature control systems and temperature control devices in the piping called desuperheaters or attemperators are located at strategic locations. They operate by spraying feedwater or condensate into the steam to reduce downstream steam temperature.

Because of their higher efficiencies, supercritical and superheated plants reject less heat to the environment so have lower requirements for cooling water. Their condensers are generally smaller in proportion to the electrical output than a nuclear plant. However, they must accommodate high temperature, high pressure dumps from feedwater heaters and steam compared to nuclear plants.

\subsubsection{Nuclear Supercritical Steam Cycle with Steam-to-Steam Reheater}

It is anticipated that a supercritical steam plant for a molten salt plant will be based on existing supercritical and superheated turbine plants. The major differences will be the (1) addition of supplemental feedwater heaters at least for startup, shutdown, and low power operation, and perhaps also for high power operation; (2) steam reheater between the high pressure and intermediate pressure turbines (two options considered here are steam-to-steam or salt-to-steam); and (3) greater turbine bypass capability to accommodate low power operation of the reactor prior to spinning the turbine and synchronizing the electrical generator.

\subsubsection{Supplemental Feedwater Heating}

Supplemental feedwater heating will undoubtedly be required for low power operation and for plant startup and shutdown. Once at power, it is anticipated that considerable heat transfer will be external to the steam generator in condensate heaters and feedwater heaters that are heated by extraction from the turbines and cascading from higher pressure heaters and supplemental heat exchangers supplied with energy from outside the steam cycle such as steam from an auxiliary source or electric heaters.

\subsubsection{Attemperators}

The conceptual nuclear plant includes several attemperators. The supercritical steam attemperator on the main steam line controls the temperature to the very high pressure/high pressure turbines and the reheater. An additional attemperator on the reheated steam line controls steam temperature to the intermediate and low pressure turbines in addition to the temperature control valves that route supercritical steam to the reheater tubes. Finally, a dump steam attemperator reduces steam pressure and temperature to acceptable levels for the condenser.

\subsubsection{Condenser}

Steam from the low pressure turbine(s) is condensed to water in the condenser, a large hollow tank may be in several sections, typically one for each low pressure turbine. The condenser is a large vessel and significant thermal cycles, particularly is concentrated in a small area, can significantly damage it. It must accept the entire power of the reactor at low power levels, and the steam being exhausted from the turbine during full power operation. The two extremes could have very different steam conditions and heat loads that, for a molten salt reactor, will probably be much different than light water reactors.

The condensers are generally the only very large tanks in a plant that are braced to endure a high vacuum, typically a pressure of 1 to 3 psia. Wet steam enters the entire top portion of the condenser from the turbine's last stage exhaust. It travels downward over tubes. The tubes are cooled by circulating water that in turn is cooled by cooling towers, ponds, a river, or the ocean. The tubes are arranged so steam flows into them from all directions toward the center. The steam condenses on the tubes and falls into the lower portion of the tank called a hot well where it accumulates. 
The center of the tube bundle contains a perforated tube that is connected to the condenser air removal system, whose lower pressure removes air. Air typically enters the condenser from the deaerating feedwater heater and a variety of subatmospheric sources such as shaft seals of the low pressure turbines, leaking shaft seals of valves that operate below atmospheric pressure, and makeup water to the condenser.

The condenser's tubes can be damaged by excessive thermal cycling, vibration, or impingement of water through drains from a variety of sources. The tubes are long, straight, and attached on either end to a flat plate called a tube sheet. The tube sheets can also be damaged by thermal cycling. Damaged tubes or tube sheets allow impure circulating water to enter the high purity condensate.

Water from drains, and steam from turbine bypass and other sources enters the condenser above the tubes so they are a concentrated heat source as opposed to the low pressure turbine's steam, which is much more diffuse. The steam and water entering above the tubes allows the circulating water to cool the steam; if it were introduced below the water level of the hot well, there would be no cooling and the water would rapidly heat without any real means of cooling.

The turbine typically requires 7 to $15 \%$ power to bring it from rest to synchronous speeds, conduct checks of the turbine's control and protection systems, and check the electrical generator prior to connecting the generator to the grid (called synchronization) and accepting a block of load, typically 5\% of full power to ensure stable generation. The molten salt reactor is expected to follow current light water reactor practice of bringing the reactor to 10 to $15 \%$ power and stabilizing the plant, including the steam generator, by dumping steam from the steam generators to the condenser. Although a considerable amount of steam would be routed to the startup and lower power feedwater heaters to heat the incoming feedwater, the remaining steam would be cooled through the supercritical steam attemperator and the dump steam attemperator before being introduced to the condenser. The drain from the lowest temperature startup and lower power feedwater heaters, which might consist of steam and condensate, would also be dumped to the condenser. During plant startup, the steam lines, the reheater, and other equipment would be warmed and the resulting condensate and steam would be dumped to the condenser. The total heat load might be substantial and localized in several areas, and the condenser must be designed for it.

Furthermore, for flexible operation, the condenser and attemperators would be required to accept between 15 to $20 \%$ reactor power equivalent in steam originating auxiliary sources. If it was not possible to supply nuclear-generated steam, steam from an auxiliary source would be used. Condensate would likely be returned to the auxiliary source. The chemistry of the auxiliary source must be compatible with the supercritical steam cycle.

The plant must accommodate a rupture of a steam generator tube or steam or feedwater header, even if it could be very infrequent. In order to minimize contamination of the intermediate loop salt and minimize pressurizing of the intermittent loop, the steam generator, feedwater lines downstream of the main feedwater isolation valves (shown as 'o' in Figures 7-2 and 7-4) and upstream of the main steam isolation valves and their bypass valves (shown as b and c, respectively in Figures 7-2 and 7-4) would probably be dumped to the condenser through valves ' 1 ' and ' $n$ ', or to the atmosphere if the thermal shock to the condenser and water velocities were too great.

\subsubsection{Condensate System}

Several multistage condensate pumps are connected to the bottom of the condenser. They pressurize low temperature (nominally $70^{\circ} \mathrm{F}$ to $120^{\circ} \mathrm{F}$ ) water and supply the full flow condensate polisher/ demineralizers that remove impurities, including rust and chemicals that have entered the condenser from the circulating water that cools the condenser, from scale and rust on the pipe, wear particles, and other sources. 
The purified condensate then flows through the condensate heaters. The feedwater and condensate heaters are typically long cylindrical hollow shells filled with tubes containing feedwater, a design called tube and shell. Extraction steam from the turbines or other sources enters the top of the feedwater heaters and is condensed while heating the water inside the tubes. The condensate then enters a drain cooler that can be either a lower part of the feedwater heater, as shown in the diagrams, or separate. Water flowing through tubes in the drain cooler is heated as the condensate is cooled. The lowest pressure feedwater heaters then route the cooled condensate to the condenser for recycling,

\subsubsection{Deaerator}

The low pressure condensate heaters increase the thermodynamic cycle efficiency and preheat water to aid the deaerating feedwater heater in removing air. In the deaerating feedwater heater, the condensate is sprayed into a tank and heated with incoming steam. A slight vacuum is established by a connection to the main condenser. Air leaves the condensate because of the elevated temperature and low pressure and is routed to the condenser. Deaerating feedwater heaters can be extremely effective in reducing dissolved oxygen to ppb levels. The preservation of the passive oxide films on downstream piping may require injecting a small amount of oxygen downstream of the deaerator.

The deaerator also serves as reservoir of warmed water for the feedwater pumps, which typically take suction on the deaerator. This reservoir facilitates reliable plant operation by somewhat decoupling the condensate system and feedwater system and providing a relatively long time, sometimes minutes, for condensate pumps to be returned to service if one or more trip. The reservoir of warm pressurized water allows plants with deaerating feedwater heaters to have far fewer condensate and feedwater-related trips than those without deaerators.

\subsubsection{Feedwater Pumps and Feedwater Heaters}

The feedwater pumps might consist of several stages. They typically have thick casings to contain the pressure, perhaps up to 5,000 psia (345 MPa) for 4,500 psia (310 MPa) feedwater at the steam generators. They are subject to moderate temperature changes but still must be slowly warmed, which normally occurs as the plant is brought to power.

Feedwater heaters in supercritical plants are typically upstream of the final feedwater pumps, whereas with light water reactors they are upstream and downstream. Because they are typically supplied by steam that has been extracted from the intermediate pressure and high pressure turbines, their discharge temperature is always considerably colder than main steam. They also cascade from the higher temperature and pressure heaters to lower temperature and pressure heaters, and the final feedwater heater would drain to the attemperator or a low pressure feedwater heater.

Feedwater from the main feedwater line would be routed to the condenser as the feedwater line was being warmed sufficiently to not freeze the salt in the steam generator as the plant is being started up. The feed shutdown drain, shown as valve "i" on drawings 4-2 and 4-4, serves as a way to dump feedwater in case of a tube leak, and also as a flow path for warming the feedwater. This flow path undoubtedly would require cooling upstream of the connection to the condenser.

\subsubsection{Startup and Low Power Feedwater Heaters}

The startup and low power feedwater heaters must be able to accommodate extremely high temperature changes as steam is introduced to them. They would therefore be rather small and there would be several of them to make the cascade from higher pressure and temperature to lower pressure and temperature more efficient and to accommodate thermal expansion of the heaters and the feedwater lines. At very low power levels, the temperature of the feedwater could be as low as $80^{\circ} \mathrm{F}\left(27^{\circ} \mathrm{C}\right)$ and it must be discharged into the steam generators at approximately $794^{\circ} \mathrm{F}\left(390^{\circ} \mathrm{C}\right)$. 


\subsubsection{Steam Generators}

The steam generators, discussed in detail earlier, are called salt shell and water tube because they are, in fact, a tube-and-shell heat exchanger with the low pressure high temperature salt on the shell side, and high pressure water and steam on the tube side.

\subsubsection{Supercritical Steam Lines to Very High Pressure and High Pressure Turbines}

The supercritical steam lines are likely to be very thick and require considerable time to warm. They will undoubtedly require ASME code safety valves and valves called main steam isolation valves to limit flow of steam from the turbines and main steam line into the steam generator(s) in the event of a tube rupture. The design and operation of supercritical fossil plants may provide valuable guidance in design and operation.

\subsubsection{Very High Pressure and High Pressure Turbines}

The very high pressure and high pressure turbines, shown on one shaft on Figures 7-2 and 7-4, are intended to be very similar to existing supercritical fossil turbines. The conceptual sketches of Figures 7-1 and 7-3 show only one shaft, and supercritical plants have been constructed with all of the turbines on one shaft.

\subsubsection{Reheaters-Steam-to-Steam and Salt-to-Steam}

The steam from the very high pressure and high pressure turbines must be reheated to improve thermodynamic efficiency and delay condensing in the low pressure turbine. If non-reheated steam was introduced directly into the intermediate turbine, the large moisture content would quickly wear away and destroy the blades.

One reheating steam possibility is steam-to-steam, where cold reheat passes over a bank of finned tubes. Steam from the supercritical main steam line would be on the inside of the tubes. The existing light water reactors have very large steam-to-steam moisture separator reheaters that resemble the proposed steam-to-steam reheater. Considerable experience in designing and operating light water reactor moisture separator reheaters might be useful in designing the molten salt reactor's reheater.

The approach of incorporating the supercritical steam and reheating sections in the same boiler, in this case steam generator, could be followed, but it is probably precluded because of the high freezing point of salt. An alternative is to reheat the steam in a separate heat exchanger with a separate loop that includes a salt circulating pump. The distance from the turbines to the intermediate salt loop may require long expensive lines and preclude this option.

\subsubsection{Intermediate and Low Pressure Turbines}

The intermediate and low pressure turbines, shown on one shaft on the drawings, are intended to be very similar to existing supercritical fossil turbines.

\subsection{Interfacing Steam Plant with Steam Generator-Valves, Lines, and Instruments}

A great deal of the interfacing equipment, including high temperature and pressure valves, piping, instruments, and other equipment, might exist for supercritical units and require little modification for nuclear use. 
The control systems have been well developed for fossil supercritical steam plants and might be incorporated into a nuclear supercritical plant with little modification.

\subsection{Summary}

The coupling of a molten salt nuclear power plant to a supercritical steam cycle can likely be simplified by applying lessons from decades of successful operation of fossil supercritical plants. These include the materials of the piping, turbine, and other components, and the components such as condensate demineralizers and deaerators to protect them.

The relatively high freezing point of molten salt appears to be best suited to a supercritical steam cycle. Given the very high steam generator pressure of the supercritical steam cycle, water tube and salt shell steam generators will be used as the technology baseline for the SHX.

Many trade studies will be required to design a conceptual plant and estimate its cost, including the number of steam generators. Significant modifications will be required to existing supercritical designs, including equipment for substantial preheating of feedwater to a sufficient temperature to prevent the salt in the steam generators from freezing, and either steam-to-steam reheaters for steam exiting the high pressure turbine, or salt-to-steam reheaters.

The intermediate salt loop transfers heat from the reactor coolant loop to the steam cycle. It will require at least one salt cleanup system to remove water and other impurities in case of steam generator tube leaks. It will also require a salt dump tank to receive salt in case of a steam generator tube rupture or certain operational occurrences such as a prolonged loss of electrical power. 


\section{EQUIPMENT COST OF STEAM GENERATOR OF A POWER CONVERSION UNIT FOR A MOLTEN SALT COOLED REACTOR}

\subsection{Background and Approach}

This study calculates the cost of steam generators considered for a supercritical Rankine power cycle. The heat for the cycle is supplied by a molten salt cooled reactor. The steam generators considered are shell-and-tube heat exchangers and PCHEs.

The heat exchangers analyzed had to have a total duty of $3400 \mathrm{MW}_{\mathrm{t}}$. This duty is supplied in one of three ways: a single heat exchanger, the duty is split between two heat exchangers, or the duty is divided between three heat exchangers. The preliminary thermal and mechanical design specifications of the heat exchangers can be found in the Appendix. The heat exchangers are made of Alloy N.

The cost of the shell-and-tube heat exchangers was developed using the cost for a boiler of a supercritical Rankine power conversion unit (PCU) that uses combustion of pulverized coal for the heat source (Klara 2007). It is assumed that the boiler would cost the same, whether the heat source is from molten salt or pulverized coal for the same duty. The pulverized coal case includes the cost of an ammonia scrubber for cleaning the combusted gases and material suitable for the high temperatures. The molten salt boiler has material that must be suitable. It was assumed that the engineering and manufacturing cost are about the same for both cases, assuming the same duty specification. Table 8-1 compares characteristics of the boilers between the pulverized coal and the molten salt cases. As can be seen by the table, except for duty, the characteristics between the heat exchangers are very similar.

Table 8-1. Comparison of molten salt and pulverized coal heated boilers for supercritical Rankine PCUs.

\begin{tabular}{|lcccc|}
\hline & & \multicolumn{3}{c|}{ Molten Salt } \\
\cline { 3 - 5 } & Pulverized Coal & 1 HX & 2 HX & 3 HX \\
\hline Heat exchanger duty $\left(\mathrm{MW}_{\mathrm{t}}\right)$ & 1231 & 3400 & 1700 & 1133 \\
Water inlet temperature $\left({ }^{\circ} \mathrm{C}\right)$ & 292 & 251 & 251 & 251 \\
Steam Outlet Temperature $\left({ }^{\circ} \mathrm{C}\right)$ & 593 & 593 & 593 & 593 \\
Steam Pressure $(\mathrm{MPa})$ & 24 & 24 & 24 & 24 \\
Primary Coolant & Combustion gases & Molten Salt & Molten Salt & Molten Salt \\
Primary pressure $(\mathrm{MPa})$ & 0.101 & 0.101 & 0.101 & 0.101 \\
\hline
\end{tabular}

Table 8-2 lists the cost of the boiler of the pulverized coal case for the supercritical Rankine cycle. This cost includes the boiler, scrubber system, balance of plant items, major component rigging, and boiler foundation. The cost is based on 2006 dollars. The cost was adjusted to 2010 dollars using the Chemical Engineering's Plant Cost Index: the indices are 499.6 and 550.8 for the years 2006 and 2010 respectively. The cost of the shell-and-tube heat exchangers for the molten salt reactor was calculated using the six-tenths factor rule

$$
C_{2}=C_{1}\left(\frac{q_{2}}{q_{1}}\right)^{n}
$$

where $C_{1}$ is the cost of the boiler for the pulverized coal unit, $q_{1}$ is the duty of that boiler, $\mathrm{C}_{2}$ is the cost of the shell-and-tube heat exchanger for the molten salt unit, and $\mathrm{q}_{2}$ is the duty of the that heat exchanger. The total cost for heat exchange with respect to the shell-and-tube heat exchangers was calculated by multiplying the number of units with the cost per unit. 
Table 8-2. Comparison of cost of pulverized coal and molten salt heated shell-and-tube heat exchangers

\begin{tabular}{|ccccc|}
\hline Boiler Heated by Pulverized Coal & $\begin{array}{c}\text { Duty } \\
\left(\mathrm{MW}_{\mathrm{t}}\right)\end{array}$ & $\begin{array}{c}\text { Cost } \\
(2006 \$)\end{array}$ & $\begin{array}{c}\text { Cost } \\
(2010 \$)\end{array}$ \\
\hline $\begin{array}{c}\text { Shell-and-tube Heat Exchanger } \\
\text { Heated by Molten Salt }\end{array}$ & 1231.2 & $\$ 148,766,000$ & $\$ 164,012,000$ & \\
\hline & 1 & $\begin{array}{c}\text { Duty } \\
\left(\mathrm{MW}_{\mathrm{t}}\right)\end{array}$ & $\begin{array}{c}\text { Cost per unit } \\
(2010 \$)\end{array}$ & $\begin{array}{c}\text { Total Cost } \\
(2010 \$)\end{array}$ \\
\hline & 2 & 3400 & $\$ 301,693,000$ & $\$ 301,693,000$ \\
& 3 & 1700 & $\$ 199,043,000$ & $\$ 398,086,000$ \\
& Number of units & 1130 & $\$ 155,785,000$ & $\$ 467,354,000$ \\
\hline
\end{tabular}

The masses of the shell-and-tube heat exchangers are determined by calculating the solid volumes of the shells and tubes and multiplying that volume by the density of Alloy N. The material costs of each of these heat exchangers are estimated by the product price of Alloy N (Tuff 2011) and the mass of each. Fabrication cost factors are calculated for each heat exchanger by dividing the cost of each heat exchanger by their material costs.

Table 8-3 lists preliminary design specifications for the shell-and-tube heat exchanger. Details of these specifications can be found in the Appendix. The solid volume of the tubes is calculated by

$N \pi\left(D_{i, t u b e}+t_{\text {tube }}\right) L_{\text {tube }} t_{\text {tube }}$

where $N$ is the number of tubes, $D_{i, \text { tube }}$ is the tube inside diameter, $t_{\text {tube }}$ is the tube thickness, and $\mathrm{L}_{\text {tube }}$ is the tube length.

The solid volume of the shell is calculated as

$\frac{\pi}{4} D_{i, \text { shell }}^{2} L_{\text {shell }}+\pi t_{\text {shell }}\left(D_{o, \text { shell }}+t_{\text {shell }}\right) L_{\text {shell }}+\frac{\pi}{2} D_{o, \text { shell }}^{2} t_{\text {shell }}$

where $D_{i, s h e l l}$ is the inner shell diameter, $L_{\text {shell }}$ is the shell length, $t_{\text {shell }}$ is the shell thickness, and $D_{o, \text { shell }}$ is the outer shell diameter. The density and price of Alloy $\mathrm{N}$ is $8860 \mathrm{~kg} / \mathrm{m}^{3}$ and $\$ 56 / 1 \mathrm{bm}$ respectively.

Lower bounded costs of the PCHEs were calculated based on the material costs and then multiplied by the fabrication cost factors of the shell-and-tube heat exchangers. Fabrication cost factors are also calculated, assuming that the costs of the PCHEs are identical to the shell-and-tube costs.

The solid volumes of PCHEs are estimated based on a unit cell shown in Figure 8-1. Channels are also found flowing from the left to the right of Figure 8-1 between the channels shown. The preliminary design parameters for the PCHE module are listed in Table 8-4. The unit void volume is calculated as

$\frac{\pi}{4} D_{\text {channel }}^{2} P_{\text {channel }}$

where $\mathrm{D}_{\text {channel }}$ is the diameter of the semicircular cross section and $\mathrm{P}_{\text {channel }}$ is the pitch between the channels. The total unit volume is found by

$P_{\text {channel }}^{2} t_{\text {plate }}$ 
Table 8-3. Preliminary design specifications for shell-and-tube heat exchangers.

\begin{tabular}{|lccc|}
\hline \multicolumn{1}{|c}{ Number of Heat Exchangers } & 1 & 2 & 3 \\
\hline Duty $\left(\mathrm{MW}_{\mathrm{t}}\right)$ & 3400 & 1700 & 1130 \\
Tube thickness $(\mathrm{mm})$ & 3.21 & 2.3 & 1.84 \\
Shell inside diameter $(\mathrm{m})$ & 3 & 2 & 1.6 \\
Tube inside diameter $(\mathrm{m})$ & 0.03 & 0.03 & 0.03 \\
Tube pitch $(\mathrm{m})$ & 0.05 & 0.05 & 0.05 \\
Shell outside diameter $(\mathrm{m})$ & 7 & 5 & 4 \\
Shell thickness $(\mathrm{mm})$ & 3.21 & 2.3 & 1.84 \\
Height of tube bundles $(\mathrm{m})$ & 1 & 0.7 & 0.6 \\
Number of tubes & 800 & 420 & 288 \\
Heat transfer surface area $\left(\mathrm{m}^{2}\right)$ & 4874 & 2677 & 1724 \\
Tube Length $(\mathrm{m})$ & 58.4 & 62.8 & 59.8 \\
Number of tube rotations & 3.71 & 5.71 & 6.80 \\
Length of shell $(\mathrm{m})$ & 3.72 & 4.00 & 4.08 \\
Solid volume of tubes $\left(\mathrm{m}^{3}\right)$ & 15.6 & 6.16 & 3.17 \\
Solid volume of shell $\left(\mathrm{m}^{3}\right)$ & 26.8 & 12.8 & 8.35 \\
Mass of heat exchangers $(\mathrm{kg})$ & 376,000 & 168,000 & 102,000 \\
Material cost of heat exchangers & $\$ 46,400,000$ & $\$ 20,700,000$ & $\$ 12,600,000$ \\
Fabrication cost factor & 6.50 & 9.60 & 12.4 \\
\hline
\end{tabular}

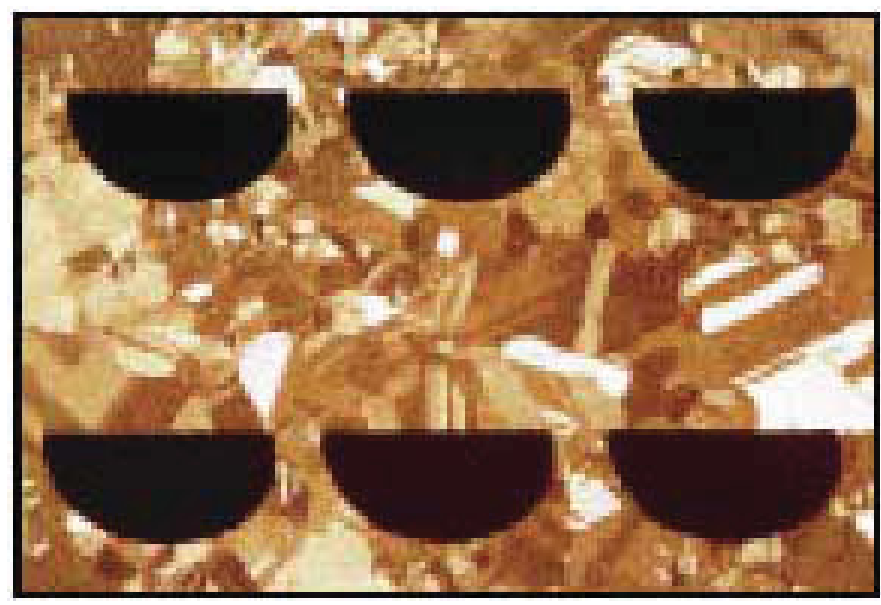

Figure 8-1. Cross section view of the semicircular passages of a PCHE.

Where $t_{\text {plate }}$ is the thickness between the top of one channel to the top of the one just below. The solid volume unit volume is the difference between the total unit volume and the void unit volume. A ratio of solid to total volume is calculated by dividing the solid unit volume by the total unit volume. The ratio for this PCHE unit is 33\%. The width, length, and height of a PCHE module are given in Table 8-4. Using the ratio of solid to total volume, the module solid volume is estimated. Table 8-5 lists the PCHEs with their corresponding duties, number of PCHE modules, total solid volumes, total masses, and material costs. It also includes the price of each heat exchanger if material costs are multiplied by shell-and-tube fabrication cost factors. Finally the fabrication cost factors are shown if one assumes that the PCHEs have identical costs as the shell and tube for the same duties. If one assumes the same cost factors as the shell 
and tube. The cost of the $3,400 \mathrm{MW}_{\mathrm{t}} \mathrm{PCHE}$ is $38 \%$ of the cost of the shell and tube. Fabrication costs are likely higher for the PCHE, but it is unlikely that the fabrication cost factors are as high as 16.8. This analysis shows that the PCHE may be a less expensive heat exchanger than the shell-and-tube design.

Table 8-4. Preliminary design specification for PCHE module

\begin{tabular}{|ll|}
\hline \multicolumn{2}{|c|}{ PCHE Design Specifications } \\
\hline Channel Diameter $(\mathrm{m})$ & $3.00 \mathrm{E}-03$ \\
Channel Pitch $(\mathrm{m})$ & $3.33 \mathrm{E}-03$ \\
Plate Thickness $(\mathrm{m})$ & $3.17 \mathrm{E}-03$ \\
Unit Volume $\left(\right.$ void + solid volume) $\left(\mathrm{m}^{3}\right)$ & $3.52 \mathrm{E}-08$ \\
Unit Void Volume $\left(\mathrm{m}^{3}\right)$ & $2.35 \mathrm{E}-08$ \\
Unit Solid Volume $\left(\mathrm{m}^{3}\right)$ & $1.16 \mathrm{E}-08$ \\
Ratio of Solid Volume to Total Volume & $33.0 \%$ \\
Module width $(\mathrm{m})$ & 0.600 \\
Module length $(\mathrm{m})$ & 0.850 \\
Module height $(\mathrm{m})$ & 0.600 \\
Module volume $\left(\mathrm{m}^{3}\right)$ & 0.306 \\
Module solid volume $\left(\mathrm{m}^{3}\right)$ & 0.101 \\
\hline
\end{tabular}

Table 8-5. Mass, material cost, and total costs of PCHEs.

\begin{tabular}{|c|c|c|c|}
\hline Number of Heat Exchangers & 1 & 2 & 3 \\
\hline Heat Duty $\left(\mathrm{MW}_{\mathrm{t}}\right)$ & 3400 & 1700 & 1133 \\
\hline Number of modules & 162 & 81 & 54 \\
\hline Total Solid Heat Exchanger Volume $\left(\mathrm{m}^{3}\right)$ & 16.4 & 8.19 & 5.46 \\
\hline Mass of heat exchanger $(\mathrm{kg})$ & 145,000 & 72,600 & 48,400 \\
\hline Material cost & $\$ 17,900,000$ & $\$ 8,960,000$ & $\$ 5,970,000$ \\
\hline $\begin{array}{l}\text { Fabrication cost factors from shell and tube } \\
\text { heat exchangers }\end{array}$ & 6.50 & 9.60 & 12.4 \\
\hline Cost of Heat Exchanger & $\$ 116,000,000$ & $\$ 86,000,000$ & $\$ 73,800,000$ \\
\hline Cost to exchange $3400 \mathrm{MW}_{\mathrm{t}}$ of heat & $\$ 116,000,000$ & $\$ 172,000,000$ & $\$ 221,000,000$ \\
\hline $\begin{array}{l}\text { Fabrication cost factors if costs of PCHE } \\
\text { are identical to shell and tube }\end{array}$ & 16.8 & 22.2 & 26.1 \\
\hline
\end{tabular}




\section{SUMMARY AND CONCLUSIONS}

The need for efficiency, compactness, and safety challenge the boundaries of existing heat exchanger technology, giving rise to this thermal design study. The descriptions of potential heat exchanger configurations or designs (such as printed circuit, spiral or helical coiled, ceramic, plate and fin, and plate type) were covered in an earlier report (Sabharwall et al. 2011a, INL/EXT-11-21584). Material options being considered for SHX are:

- Type 316 stainless steel

- Incoloy alloy $800 \mathrm{H}$

- Inconel alloy 617

- Alloy N

- Alloy 242

- $\mathrm{SiC}($ ceramic)

However, Alloy $\mathrm{N}$ is used as the construction material for the thermal design study of SHX.

In materials computational work, the behavior of Alloy 242 and Alloy $\mathrm{N}$ in a ternary molten salt eutectic mixture LiF-NaF-KF was modeled. It was established that the use of just four principal alloying elements - nickel, chromium, molybdenum, and iron — allows making quite reasonable conclusions about the nature of hot corrosion resistance of these materials.

The diffusion welding process for Alloy $800 \mathrm{H}$ has been completed. The appropriate welding time, temperature, contact pressure, atmosphere and filler metal have been identified. The results of this work will be applied to the diffusion welding of Alloy N.

For the thermal design study, preliminary heat exchanger design has been performed in this report to provide basic information to evaluate the AHTR secondary heat exchangers. The AHTR secondary heat exchanger transfer heat from the molten salt intermediate loop to the power conversion system based on steam Rankine cycles. Helical coiled heat exchangers and PCHEs were determined to be the possible heat exchanger options capable of satisfying design requirements. The total thermal requirement of the heat exchanger was $3400 \mathrm{MW}_{\mathrm{t}}$. Three different options for the number of heat exchangers were considered for effectively sharing the total thermal duty in the system.

For evaluation of candidate heat exchangers, this study selected the analytical hierarchy process (AHP), which is a structured technique developed for multicriteria decision making and currently among the most widely used multicriteria decision analysis (MCDA). AHP allows for the application of data, experience, insight, and intuition in a logical way. The major characteristics included in evaluation of the heat exchanger are: thermal hydraulic performance, structural performance, material performance, technology readiness, system integration, tritium permeation, inspection, maintenance, initial cost, and operability.

Further challenges associated with adapting a steam power cycle to a molten salt reactor were explored and few suggestions/recommendations were made along with cost comparisons. Development of the integration methodology, feasibility study along with research and development needs is ongoing tasks that will be covered in the future reports as work progresses. Many trade studies will be required to design a conceptual plant and these should be linked to design decisions for the SHX. Therefore, development of a detailed technology development roadmap is recommended for the SHX that incorporates development of materials, fabrication techniques, single effects experimentation and integral tests. To the extent practical, the roadmap should be integrated with similar work for other heat transfer system components such as the IHX, valves, piping, pumps and instrumentation. 


\section{REFERENCES}

2010 ASME Boiler \& Pressure Vessel Code, 2011a Addenda, Section IX, Qualification Standard For Welding and Brazing Procedures, Welders, Brazers, and Welding and Brazing Operators, July 1, 2011.

316/316L Stainless Steel, 2007, Publication Number PD-140 7180-0127, AK Steel Corporation.

Ambrose, J. C., M. G. Nichols, N. Young, and S. L. Jenkins, 1990, "Wetting and Spreading of Ni-P brazes: Effects of Workpiece and Braze Composition," Materials Science and Technology, Volume 6, October 1990

Ambrose, J. C., M. G. Nichols, N. Young, and S. L. Jenkins, 1990, "Wetting and Spreading of Ni-P brazes: Effects of Workpiece and Braze Composition," Materials Science and Technology, Volume 6, October 1990.

American Welding Society, 2007a, "Diffusion Welding and Diffusion Brazing," Chapter 12, pp. 421-450, Welding Handbook, $9^{\text {th }}$ Ed, Vol. 3.

American Welding Society, 2007b, Diffusion Welding and Diffusion Brazing, Chapter 12, pp. 421-450, Welding Handbook, $9^{\text {th }}$ Ed, v. 3, 2007, American Welding Society.

American Welding Society, 2007c, Diffusion Welding and Diffusion Brazing, Chapter 12, pp. 437-442, Welding Handbook, $9^{\text {th }}$ Ed, v. 3, 2007, American Welding Society.

American Welding Society, 2007d, Electron Beam Welding, Chapter 13, pp. 451-502, Welding Handbook, $9^{\text {th }}$ Ed, v. 3, 2007, American Welding Society.

American Welding Society, 2007e, Laser Beam Welding, Cutting and Associated Processes, Chapter 14, pp. 503-559, Welding Handbook, $9^{\text {th }}$ Ed, v. 3, 2007, American Welding Society.

American Welding Society, 2007f, Brazing, Chapter 12, pp. 501-556, Welding Handbook, $9^{\text {th }}$ Ed, v. 2 , 2007, American Welding Society.

American Welding Society, 2007g, Gas Tungsten Arc Welding, Chapter 3, pp. 103-145, Welding Handbook, $9^{\text {th }}$ Ed, v. 2, 2007, American Welding Society.

American Welding Society, 2007h, Ultrasonic Welding, Chapter 8, pp. 263-301, Welding Handbook, $9^{\text {th }}$ Ed, v. 3, 2007, American Welding Society.

American Welding Society, 2007i, Thermal Spraying and Cold Spraying, Chapter 11, pp. 367-419, Welding Handbook, $9^{\text {th }}$ Ed, v. 3, 2007, American Welding Society.

American Welding Society, 2007j, Friction Stir Welding, Chapter 7, pp. 211-253, Welding Handbook, $9^{\text {th }}$ Ed, v. 3, 2007, American Welding Society.

American Welding Society, 2007k, Explosion Welding, Chapter 9, pp. 303-330, Welding Handbook, $9^{\text {th }}$ Ed, v. 3, 2007, American Welding Society.

ASM, 1983, ASM Handbook, Volume 6, "Welding, Brazing, and Soldering."

ASME BPV Code, 2001, Addenda, II, “Properties (Metric) Materials,” July 2001.

ASME, 1967, "Steam Table 1, Properties of Saturated Steam and Saturated Water (Temperature)," American Society of Mechanical Engineers (ASME).

ASME, 2007, “Old Plant, New Mission,” Power Engineering Magazine, June 15, 2007. http://www.powermag.com/marmaduke/Old-plant-new-mission 299 p2.html (Retrieved August 8, 2011). 
ASME, 2011a, 2010 ASME Boiler \& Pressure Vessel Code, 2011a Addenda, Section IX, "Qualification Standard for Welding and Brazing Procedures, Welders, Brazers, and Welding and Brazing Operators," July 1, 2011.

ASME, 2011b, Eddystone Station, 325 MW Generating Unit 1, a Brief History, ASME Historical Mechanical Engineering Heritage Site, http://files.asme.org/ASMEORG/Communities/History/Landmarks/1500.pdf, retrieved August 8, 2011.

AWS, 2007a, "Diffusion Welding and Diffusion Brazing," Chapter 12, pp. 421-450, Welding Handbook, $9^{\text {th }}$ Ed, v. 3, 2007, American Welding Society

AWS, 2007b, Diffusion Welding and Diffusion Brazing, Chapter 12, pp. 437-442, Welding Handbook, $9^{\text {th }}$ Ed, v. 3, 2007, American Welding Society

AWS, 2007c, "Electron Beam Welding," Chapter 13, pp. 451-502, Welding Handbook, $9^{\text {th }}$ Ed, v. 3, 2007, American Welding Society

AWS, 2007d, "Laser Beam Welding, Cutting and Associated Processes," Chapter 14, pp. 503-559, Welding Handbook, $9^{\text {th }}$ Ed, v. 3, 2007, American Welding Society

AWS, 2007e, "Brazing," Chapter 12, pp. 501-556, Welding Handbook, $9^{\text {th }}$ Ed, v. 2, 2007, American Welding Society

AWS, 2007f, Gas Tungsten Arc Welding, Chapter 3, pp. 103-145, Welding Handbook, $9^{\text {th }}$ Ed, v. 2, 2007, American Welding Society

AWS, 2007g, Ultrasonic Welding, Chapter 8, pp. 263-301, Welding Handbook, $9^{\text {th }}$ Ed, v. 3, 2007, American Welding Society

AWS, 2007h, Thermal Spraying and Cold Spraying, Chapter 11, pp. 367-419, Welding Handbook, $9^{\text {th }}$ Ed, v. 3, 2007, American Welding Society

AWS, 2007i, Friction Stir Welding, Chapter 7, pp. 211-253, Welding Handbook, $9^{\text {th }}$ Ed, v. 3, 2007, American Welding Society

AWS, 2007j, Explosion Welding, Chapter 9, pp. 303-330, Welding Handbook, $9^{\text {th }}$ Ed, v. 3, 2007, American Welding Society

Bettis, C. E., Braatz, R. J., Cristy, G. A., Dyslin, D. A., Kelly, O. A., Pickel, T. W., et al. "Design Study of a Heat-Exchange System for One MSBR Concept, ” Oak Ridge, TN: Oak Ridge National Laboratory, 1964

Bhushan, Navneet; Kanwal Rai (January 2004). Strategic Decision Making: Applying the Analytic Hierarchy Process. London: Springer-Verlag. ISBN 1-8523375-6-7.

Biello, D., "How to Use Solar Energy at Night," Scientific American, February 18, 2009.

Bott, T. R., "Fouling of Heat Exchangers," Chemical Engineering Monograph, vol. 26, Elsevier Science, Amsterdam, 1995

Chartrand, P., and A. D. Pelton, 2001, "Thermodynamic Evaluation and Optimization of the LiF-NaF$\mathrm{KF}-\mathrm{MgF}_{2}-\mathrm{CaF}_{2}$ System Using the Modified Quasi-Chemical Model," Metallurgical and Materials Transactions A, Volume 32A, Issue 6, June 2001, pp.1385-1396

Chase, M. W., 1988, "NIST-JANAF Thermochemical Tables," Fourth Edition, Journal of Physical and Chemical Reference Data, Monograph No. 9.

Cowell, T. A., and D. A. Cross, "Airside Fouling of Internal Combustion Engine Radiators," SAE Transactions, Vol.89, pp3179-3188, 1981 
Dewson, S. J and B. Thonon, 2003, “The Development of High Efficiency Heat Exchangers for Helium Gas CooledReactors," Paper 3213, International Congress on Advances in Nuclear Power Plants 2003

Darienko, S. E., V. I. Desyatnik, S. F. Katyshev, and Y. F. Chervinskii, 1988, "Density and Surface Tension of Melts of the KF-KCl-ZrF 4 System," Journal of Atomic Energy, Vol. 65, pp. 785-787.

Davis, C. B. 2005, Implementation of Molten Salt Properties into RELAP5-3D/ATHENA, INEEL/EXT05-02658, Idaho National Engineering and Environmental Laboratory.

Dynamic Systems Inc. 2011, Welcome to Gleeble.com, http://www.gleeble.com/, visited 9/22/2011.

FactStage, 2011, "FSalt Thermodynamic database for molten salt applications."

Forman, E. H., and S. I. Gass, 2001-07. "The analytical hierarchy process—an exposition," Operations Research, Vol. 49, Issue 4, pp. 469-487.

Forsberg, C. W., P. F. Peterson, and H. Zhao, 2004, "An Advanced Molten Salt Reactor Using HighTemperature Reactor Technology,” Paper 4152, Proceedings of ICAPP '04, Pittsburg, PA. June 2004.

Glazoff, M. V., 2008, unpublished research.

Grimes, W. R., 1967, Chemical Research and Development for Molten-Salt Breeder Reactors, ORNLTM-1853, Oak Ridge National Laboratory.

Grimes, W. R., E. G. Bohlmann, A. S. Meyer, and J. M. Dale, 1972, "Fuel Can Coolant Chemistry," Chapter 5 in M. W. Rosenthal, P. N. Haubenreich, and R. B. Briggs, The Development Status of Molten-Salt Breeder Reactors, ORNL-4812, Oak Ridge National Laboratory.

Hallowell, David L. (January 2005). "Analytical Hierarchy Process (AHP) - Getting Oriented". SixSigma.com. Retrieved 2007-08-21.

Harvego, E. A. "Evaluation of Next Generation Nuclear Power Plant (NGNP) Intermediate Heat Exchanger (IHX) Operating Conditions," Idaho Falls, Idaho: Idaho National Laboratory, 2006

Hastelloy N Alloy, 2002, Data Document H-2052B, Haynes International, Inc.

Haynes 242 Alloy, 2000, “Technical Description,” Haynes International, Kokomo, Ind., publication H3079E.

Haynes International. (n.d.). Hastelloy $N$ alloy, http://www.haynesintl.com/pdf/h2052.pdf, Retrieved from Haynes International, Inc.

Heat Transfer International, 2011, “Homepage,” http://heatxfer.com, accessed 10 March 2011.

Heatric, 2011, General heat exchanger overview, http://www.heatric.com/diffusion bonded exchangers.html, visited 9/22/2011.

Hesselgreaves, J. E., “Compact Heat Exchangers: Selection, Design and Operation,” Pergamon Press, 2001.

Hillert, M., 2008, Phase Equilibria, Phase Diagrams, and Phase Transformations; Their Thermodynamic Basis, $2^{\text {nd }}$ Edition, Cambridge University Press, Cambridge, UK.

Holcomb, D. E., S. E. Cetiner, G. F. Flanagan, F. J. Peretz, and G. L. Yoder, 2009, An Analysis of Testing Requirements for Fluoride Salt-Cooled High Temperature Reactor Components, ORNL/TM2009/297, Oakridge National Laboratory, November 2009.

Ignatiev, V., et al. 2008, Nuclear Technology, Vol. 164, p. 130.

Incoloy Alloy 800H and 800HT, 2004, Publication Number SMC-047, Special Metals Corp., September 2004. 
Inconel Alloy 617, 2005, Publication Number SMC-029, Special Metals Corp., March 2005.

Ingersoll, D. T., C. W. Forsberg, and P. E. MacDonald, 2007, Trade Studies on the Liquid-Salt-Cooled Very High-Temperature Reactor: Fiscal Year 2006 Progress Report, ORNL/TM-2006/140, Oak Ridge National Laboratory.

Ingersoll, D. T., C. W. Forsberg, L. J. Ott, D. F. Williams, J. P. Renier, D. F. Wilson, S. J. Ball, L. Reid, W. R. Corwin, G. D. Cul, P. F. Peterson, H. Zhao, P. S. Pickard, E. J. Parma, and M. Vernon, 2004, "Status of Preconceptual Design of the Advanced High-Temperature Reactor (AHTR)," ORNL/TM2004/104, May 2004.

Janz, G. J., 1988, “Thermodynamic and Transport Properties for Molten Salts: Correlation Equations for Critically Evaluated Density, Surface Tension, Electrical Conductance, and Viscosity Data," Journal of Physical and Chemical Reference Data, Vol. 17. Issue 2, p. 1.

Janz, G. J., R. P. T. Tomkins, C. B. Allen, J. R. Downey, Jr., G. L. Gardner, U. Krebs, and S. K. Singer, 1975, "Molten Salts: Volume 4, Part 2, Properties of Chlorides and Mixtures," Journal of Physical and Chemical Reference Data, Vol 4, Issue 4, pp. 871-1178.

Kakac, S. and Liu, H., "Heat Exchangers Selection, Rating and Thermal Design," CRC Press: Boca Raton, FL, 1998

Kanaris, A. G., K. A. Mouza, and S. V. Paras, 2004, "Designing Novel Compact Heat Exchangers for Improved Efficiency Using a CFD Code," 1st Internal Conference "From Scientific Computing to Computational Engineering." Athens, Greece: IC-SCCE.

Kandlikar, S. G., S. Garimella, D. Li, S. Colin, and M. R. King, 2006, Heat Transfer and Fluid Flow in Minichannels and Microchannels, Kidlington, Oxford: Elsevier Ltd.

Katoh, K., D. F. Wilson, and C. W. Forsberg, 2007, Assessment of Silicon Carbide Composites for Advanced Salt-Cooled Reactors, ORNL/TM-2007/168, Revision 1, September 2007.

Kays, W. M., and London, A. L., “Compact Heat Exchangers," Krieger Publishing Company, Florida, 1998.

Kays, W. M., and London, A. L., 1984, “Compact Heat Exchangers,” New York, NY: McGraw-Hill, 1984.

Key, P., 2010, Philadelphia Business Journal, Exelon to delay closing of units in Phoenixville, Eddystone, http://www.bizjournals.com/philadelphia/stories/2010/03/01/daily26.html, Retrieved August 11, 2011.

Klara, J., August 2007, Cost and Performance Baseline for Fossil Energy Plants Study, Volume 1: Bituminous Coal and Natural Gas to Electricity, DOE/NETL-2007/1281, National Energy Technology Laboratory/Department of Energy.

Koch, L. U., 2008, "EBR-II, Experimental Breeder Reactor - II, An Integrated Experimental Fast Reactor Nuclear Power Station," American Nuclear Society.

Koger, J. W., and A. P. Litman, 1971, Mass Transfer Between Hastelloy N and Haynes Alloy 25 in a Molten Sodium Fluroborate Mixture, ORNL-'I'M-3488, October 1971.

Kroger, J. W., 1972, Compatibility of Brazing Alloys and the Molten Salt NaBF4-8 Mole Percent NaF at $610^{\circ} \mathrm{C}$ ORNL -TM-4272, December 1972.

Kroger, J. W., 1972, Compatibility of Brazing Alloys and the Molten Salt NaBF ${ }_{4} 8$ Mole Percent NaF at $610^{\circ} \mathrm{C}$, ORNL-TM-4272, December 1972.

LeBlanc, D., 2010, "Molten Salt Reactors: A New Beginning for an Old Idea," Nuclear Engineering and Design, Vol. 240, pp. 1644-1656. 
LeBlanc, D., 2010, "Molten Salt Reactors: A New Beginning for an Old Idea," Nuclear Engineering and Design, Vol. 240, pp. 1644-1656.

Lippy, M.S., 2011, "Development of Minichannel Compact Primary Heat Exchanger for a Molten Salt Reactor," Masters' Thesis, Virginia Polytechnic Institute and State University, April 28, 2011.

Lukas, H. L., S. G. Fries, and B. Sundman, 2007, Computational Thermodynamics, The CALPHAD Method, Cambridge University Press, Cambridge, UK.

MacPherson, H. G., 1985, “The Molten Salt Reactor Adventure," Nuclear Science and Engineering, pp. 374-380, 15 March 1985.

MacPherson, H. G., 1964, "Molten Salt Reactors," Reactor Handbook, Second Edition, Volume IV Engineering, ed. By S. McLain and J. H. Mortens, Interscience, New York.

McCoy, H. E., Jr., 1971, An Evaluation Of The Molten-Salt Reactor Experiment Hastelloy N Surveillance Specimens - Fourth Group, ORNL/TM-3063, March 1971.

McCoy, H. E., Jr., 1978, "Status of Materials Development for Molten-Salt Reactors, ORNL/TM-5920, January 1978.

Miller, M. K., I. M. Anderson, L. M. Pike, and D. L. Klarstrom, 2002, Mat. Sci. and Eng. A, Vol. 327, Issue 1, pp. 89-93.

Mills, P., R. Soto, and G. Gibbs, 2007, Next Generation Nuclear Plant Pre-Conceptual Design Report, INL/EXT-07-12967, Idaho National Laboratory.

Mizia, R., 2011, Personal Communication, L. Tuff, Haynes International to R. Mizia, Idaho National Laboratory, August 23, 2011.

Morton, D. S., "Thermal Design of Heat Exchangers," Industrial and Engineering Chemistry, Cleveland, Ohio, April 1960

Mukherjee, R., "Effectively Design Shell-and-Tube Heat Exchangers," Chemical Engineering Progress, February 1998

National Institute of Standards and Technology (NIST) Property Data Summary, 2011, "Sintered Silicon Carbide (SiC)," available online at http://www.ceramics.nist.gov/srd/summary/scdscs.htm accessed on August 3, 2011.

Oh C. H., and E. S. Kim, Heat Exchanger Design Options and Tritium Transport Study for the VHTR System, INL/EXT-08-14799, September 11, 2008.

Oh, C. H., Development and Verification of Tritium Analyses Code for a Very High Temperature Reactor, INL/EXT-09-16743, September 16, 2009.

Oh, C. H., E. S. Kim, and M. W. Patterson, 2011, "Tritium Permeation and Transport in the Gasoline Production System Coupled with High Temperature Gas-Cooled Reactors (HTGRS)," Proceeding of the ASME/JSME 2011 8th Thermal Engineering Joint Conference, sponsored by ASME/JSME, Honolulu Hawaii, March 2011.

Olson, L. C., 2009, Materials Corrosion in Molten LiF-NaF-KF Eutectic Salt, Ph.D. Dissertation (Advisor - Prof. T. R. Allen) University of Wisconsin-Madison.

PDHengineer.com, 2011, Advanced Boiler Cycles, Course No. M-1009, http://www.pdhengineer.com/Course $\% 20 \mathrm{Web} /$ Mechanical\%20Courses/advanced boiler cycles.htm, Retrieved August 8, 2011.

Phogikaroon, S., 2011, Molten Salt Technology, University of Idaho, January 2011. 
Reay, D. A., 1995, "Fouling of Compact Heat Exchangers," Proc. Seminar, "Developments in Energy Efficient Technologies for the Refining and Petrochemicals Industries," Institute of Petroleum, London.

Reay, D. A., and J. E. Hesselgreaves, 2011, "Compact Heat Exchangers in Practice," Compact Heat Exchangers: Selection, Design and Operation, Pergamon Press.

RELAP5-3D, 2005, RELAP5-3D Code Manual, Vol. I, Rev. 2.4, INEEL-EXT-98-00834, Idaho National Engineering and Environmental Laboratory.

Saaty, T. L., 1996, The Analytic Hierarchy Process, New York, N.Y., McGraw Hill, 1980, reprinted by RWS Publication, Pittsburgh.

Sabharwall, P., E. S. Kim, M. McKellar, N. Anderson, and M.W. Patterson, 2011, Process Heat Exchanger Options for the Advanced High Temperature Reactor, INL-11-21584, June 2011.

Sabharwall, P., E. S. Kim, and N. A. Anderson, 2011a, "Evaluation Metrics for Intermediate Heat Exchangers for Next Generation Nuclear Reactors," Proceedings of the 2011 National American Nuclear Society Conference, Hollywood, Florida, June 26th to 30th.

Sekulic, D. P., "A Reconsideration of the Definition of a Heat Exchanger," Int. J. Heat Mass Transfer, Vol. 33, No 12, pp. 2748-2750.

Shah, R. K., and D. P. Sekulic, 2003, Fundamentals of Heat Exchanger Design, Hoboken, NJ: John Wiley \& Sons, 2003

Shah, R. K., McDonald, C. F., \& Howard, C. P., 1980, "Compact Heat Exchangers - History, Technological Advancement and Mechanical Design Problems," New York, NY: American Society of Mechanical Engineers.

Shi, P., A. Engströmand, and B. Sundman, 2008, "ThermoCalc Calculations for Materials in Corrosive Environments," SINTEF Symposium, Trondheim, Norway, May 2008.

Shores, D. A., 1983, "New Perspectives on Hot Corrosion Mechanisms," Proc. Intl. Conf. on High Temperature Corrosion, Ed., R. A. Rapp, N. A. C. E. , Houston, p. 493.

Shores, D. A., and B. P. Mohanty, 2004, "Role of Chlorides in High Temperature Corrosion of Fe-Cr-Ni Cast Alloy, Part II: Thermochemical Model Studies," Corr. Sci., Vol. 46, p. 2909.

Singh, P. P. 2004, “Thermal Design of Heat Exchangers.” Encyclopedia of Agricultural, Food, and Biological Engineering, Ed: D. R. Heldman, Marcel Dekker, NY.

Sleicher, C. A., and M. W. Rouse, 1975, "A Convenient Correlation for Heat Transfer to Constant and Variable Property Fluids in Turbulent Pipe Flow," International Journal of Heat and Mass Transfer, Vol. 18, pp. 677-683.

Snead, L. L., T. Nozawa, Y. Katoh, T. S. Byun, S. Kondo, and D. A. Petti, 2007, "Handbook of SiC Properties for Fuel Performance Modeling," Journal of Nuclear Materials, Vol. 371, pp. 329-377.

Sohal, M. S., M. A. Ebner, P. Sabharwall, P. Sharpe, 2010, Engineering Database of Liquid Salt Thermophysical and Thermochemical Properties, INL/EXT-10-18297, Idaho National Laboratory.

Sohal, M. S., P. Sabharwall, P. Calderoni, A. K. Wertsching, B. S. Grover, and P. Sharpe, 2010, Conceptual Design of Forced Convection Molten Salt Heat Transfer Testing Loop, September 2010, INL-10-19908, September 2010.

Sommers, A., Q. Wang, X. Han, C. T'Joen, Y. Park, and A. Jacobi, 2010, "Ceramics and ceramic matrix composites for heat exchangers in advanced thermal systems - A review," Applied Thermal Engineering, doi:10.1016/j.applthermaleng.2010.02.018. 
Stepanoff, A. J., 1948, Centrifugal and Axial Flow Pumps, John Wiley, New York.

Sullivan, N., Personal Communication, Colorado School of Mines.

Taborek, J., G. F. Hewitt, and N. Afgan, 1983, Heat Exchangers Theory and Practice, Hemisphere Publishing Corporation.

Tatara, R., 1997, Heat Exchangers: An Overview of Maintenance and Operations, Duke Engineering and Services, EPRI.

TEV-1160, 2011, "Fluoride High Temperature Reactor Integration with Industrial Process Application," P. Sabharwall and E. Kim, Idaho National Laboratory, March 29, 2011.

Trujillo, F. J. P., 2011, Surface Engineering and Nanostructured Materials, UCM \#910627, Madrid, Spain.

Tuff, L., 2011, “Price quote,” Haynes International, Inc., August 24, 2011.

Velocys Inc., 2011, Microchannel Reactors, http://www.velocys.com/ocge02.php, visited 9/22/2011.

Walker, C. A. and V. C. Hodges, 2008, “Comparing Metal-Ceramic Brazing Methods,” Welding Journal, October 2008.

Walker, C. A., and V. C. Hodges, 2008, “Comparing Metal-Ceramic Brazing Methods,” Welding Journal, October 2008.

Wang, X., Q. Lv, X. Sun. R. N. Christensen, T. E. Blue, G. Yoder, D. Wilson, and P. Sabharwall, 2011, "A Modular Design of a Direct Reactor Auxiliary Cooling System for AHTRs," Proceedings of the 2011 National American Nuclear Society Conference, Hollywood, Florida, June 26th to 30th, 2011.

Williams, D. F., 2006, Assessment of Candidate Molten Salt Coolants for the NGNP/NHI Heat-Transfer Loop, ORNL/TM-2006/69, Oak Ridge National Laboratory.

Williams, D. F., L. M. Toth, and K. T. Clarno, 2006, Assessment of Candidate Molten Salt Coolants for the Advanced High-Temperature Reactor (AHTR), ORNL/TM-2006/12, Oak Ridge National Laboratory.

Wilson 2010 


\section{Appendix A}

Thermal Design of Helical Coiled Heat Exchanger for AHTR 


\section{Appendix A \\ Thermal Design of Helical Coiled Heat Exchanger for AHTR}

\section{Thermal Design of Helical Coil Heata Exchnager for AHTR}

A simple thermal design of the helical coil heat exchanger has been conducted for AHTR Figure 1 and 2 show schematics of the reference helical coil heat exchangers and the tube bundles used in this design. This heat exchanger is a intermediate heat exchanger for HTGR IHX (Kato et al,, 2007).

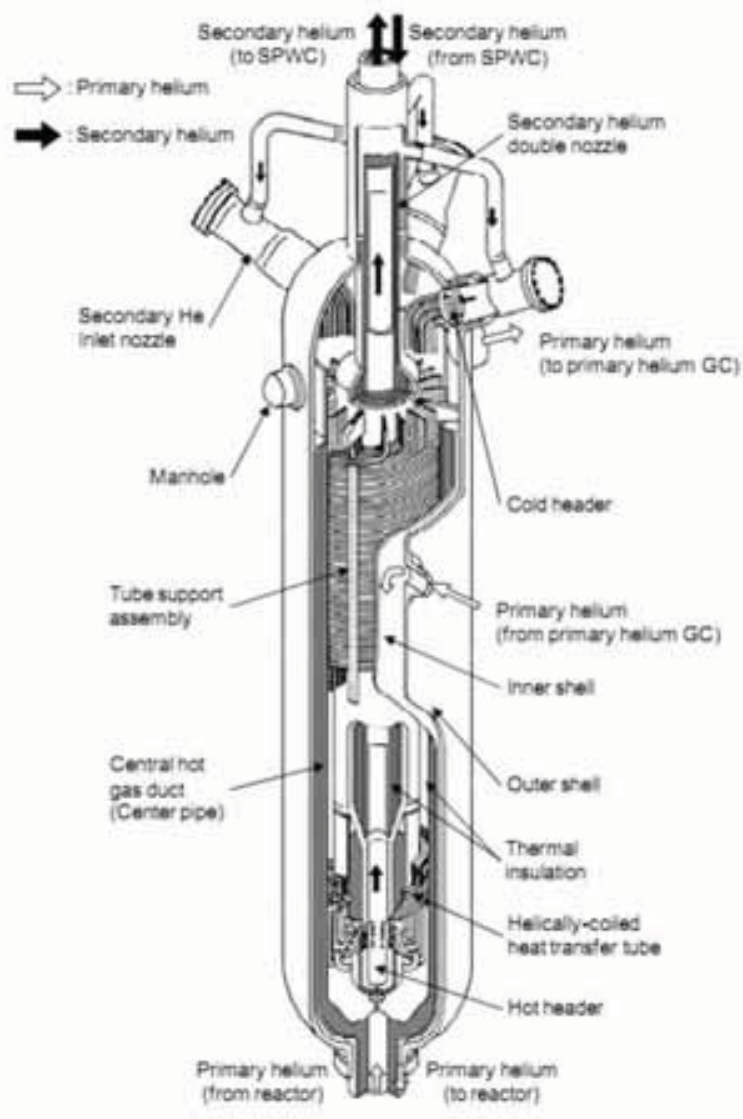

Figure 1. Schematics of HTTR IHX.

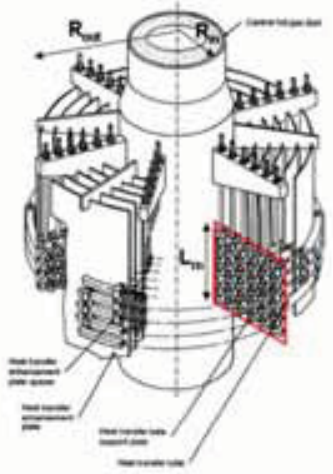

Figure 2. Structural diagram of heat transfer tube bundle of HTTR. 


\section{A. Design Input Parameters:}

The basic input parameters used for the heat exchnager design are summarized below:

Heat Exchanger Operating Conditions:

The following is the heat exchanger operating conditions:

Heat Transfer Duty:

$$
\mathrm{Q}:=3400 \mathrm{MW}
$$

In this design, the primary side is an intermediate heat transfer loop. In this loop, the operating conditions are as follows:

\begin{tabular}{|c|c|c|}
\hline Prim temperatu & Prim temperature outlet: & Prim. Pressure \\
\hline $\mathrm{Tp}$ in $:=679^{\circ} \mathrm{C}$ & $\mathrm{Tp}$ out $:=587^{\circ} \mathrm{C}$ & $\mathrm{Pp}:=0.1 \mathrm{MPa}$ \\
\hline
\end{tabular}

In this design, the secondary side is a power conversion system based on steam/water rankin cycle. In this loop, the operating conditions are as follows:

Sec. temperature inlet: $\quad$ Sec. temperature outlet: Sec. Pressure:
Ts_in : $=251^{\circ} \mathrm{C}$
Ts_out : $=593^{\circ} \mathrm{C}$
Ps : $=24 \mathrm{MPa}$

\section{Heat Exchanger Geometrical Parameters:}

The following summarizes the basic geometrical input parameters:

$\begin{array}{cl}\frac{\text { Shell outer radus: }}{\text { Rout }:=3.5 \mathrm{~m}} & \frac{\text { Shell inner radus: }}{\text { Rin }:=1.5 \mathrm{~m}} \quad \frac{\text { Tube bundle length: }}{\mathrm{Lm}:=1 \mathrm{~m}} \\ \frac{\text { Tube inner diameter: }}{\mathrm{di}:=0.03 \mathrm{~m}} & \frac{\text { Tube pitch: }}{\mathrm{p}:=0.05 \mathrm{~m}} \\ \frac{\text { Tube thickness: }}{\text { th }:=0.001754 \mathrm{~m}} & \frac{\text { Tube outer diameter: }}{\mathrm{do}:=\mathrm{di}+2 \cdot \mathrm{th}=0.034 \mathrm{~m}}\end{array}$




\section{B. Properties:}

For desinging heat exchangers, fluid and structure properties should be defined first. The following summarizes the detail.

\section{Fluide Properties:}

In this heat exchanger design, the primary coolant is molten salt and the secondary coolant is water/steam. The following summarizes the basic properites of the coolant.

\begin{tabular}{|c|c|c|}
\hline & Molten Salt & Water (average) \\
\hline Density = & P_salt $:=2800 \frac{\mathrm{kg}}{\mathrm{m}^{3}}$ & P_water $:=337 \frac{\mathrm{kg}}{\mathrm{m}^{3}}$ \\
\hline Thermal Conductivity = & $\kappa$ _salt $:=0.45 \frac{\mathrm{W}}{\mathrm{m} \mathrm{K}}$ & $\kappa \_$water $:=0.29 \frac{\mathrm{W}}{\mathrm{m} \mathrm{K}}$ \\
\hline Heat Capacity = & Cp_salt $:=1046.7 \frac{\mathrm{J}}{\mathrm{kg} \cdot \mathrm{K}}$ & Cp_water $:=6510 \frac{\mathrm{J}}{\mathrm{kg} \cdot \mathrm{K}}$ \\
\hline Viscosity $=$ & $\mu$ salt $:=0.051$ poise & $\mu \_$water $:=5.23 \cdot 10^{-4}$ poise \\
\hline
\end{tabular}

\section{Structure Properties:}

In this study, Hastelloy $\mathrm{N}$ was selected to be the heat exchanger tube material. The following is the property of the material.

$$
\kappa \_ \text {wall }:=23.5 \frac{\mathrm{W}}{\mathrm{m} \cdot \mathrm{K}} \mathrm{N} \text { ) }
$$




\section{Other Parameters:}

In this type of heat exchanger, the number of tubes (Nt) in the bundle can be determined as follows (See Figure 2):

$$
\mathrm{Nt}:=\frac{(\text { Rout }-\mathrm{Rin})}{\mathrm{p}} \cdot \frac{\mathrm{Lm}}{\mathrm{p}}=800
$$

Other design parameters will be determined after heat exchanger designs.

In this study, the primary coolant (molten salt) flows in the tube side and the secondary coolant (water) flows in the shell side. Therefore, the tube and shell side coolants can be defined as follows:

Tube:

$$
\begin{aligned}
& \rho_{-} \text {tube }:=\rho_{-} \text {water }=337 \frac{\mathrm{kg}}{\mathrm{m}^{3}} \\
& \kappa \text { _tube }:=\kappa_{-} \text {water }=0.29 \frac{\mathrm{m} \cdot \mathrm{kg}}{\mathrm{K} \cdot \mathrm{s}^{3}} \\
& \text { Cp_tube }:=\text { Cp_water }=6.51 \times 10^{3} \frac{\mathrm{m}^{2}}{\mathrm{~K} \cdot \mathrm{s}^{2}} \\
& \mu_{-} \text {tube }:=\mu_{\text {_water }}=5.23 \times 10^{-5} \frac{\mathrm{kg}}{\mathrm{m} \cdot \mathrm{s}} \\
& \rho \_ \text {shell }:=\rho \_ \text {salt }=2.8 \times 10^{3} \frac{\mathrm{kg}}{\mathrm{m}^{3}} \\
& \kappa \_ \text {shell }:=\kappa \_ \text {salt }=0.45 \frac{\mathrm{m} \cdot \mathrm{kg}}{\mathrm{K} \cdot \mathrm{s}^{3}} \\
& \text { Cp_shell }:=\text { CP_salt }=1.047 \times 10^{3} \frac{\mathrm{m}^{2}}{\mathrm{~K} \cdot \mathrm{s}^{2}} \\
& \mu \_ \text {shell }:=\mu \text { _salt }=5.1 \times 10^{-3} \frac{\mathrm{kg}}{\mathrm{m} \cdot \mathrm{s}}
\end{aligned}
$$

Primary and secondary mass flow rates for the heat exchanger can be estimated as follows:

\section{Mass flow in the primary side}

(shell):

$$
\mathrm{Mp}:=\frac{\mathrm{Q}}{\mathrm{Cp} \text { shell } \cdot(\mathrm{Tp} \text { in }-\mathrm{Tp} \text { _out })}=3.531 \times 10^{4} \frac{\mathrm{kg}}{\mathrm{s}}
$$

\section{Mass flow in the secondary side (tube):}

$$
\mathrm{Ms}:=\frac{\mathrm{Q}}{\text { Cp_tube }(\mathrm{Ts} \text { _out }-\mathrm{Ts} \text { in })}=1.527 \times 10^{3} \frac{\mathrm{kg}}{\mathrm{s}}
$$




\section{Flow Parameters}

Based on the heat exchanger design conditions and input parameters, flow parameters of the heat exchanger can be estimated as follows:

Coolant velocity in the tube side:

$$
\mathrm{Vt}:=\frac{\frac{\mathrm{Ms}}{\mathrm{Nt}}}{\rho \text { tube } \cdot\left(\frac{\pi}{4} \cdot \mathrm{di}^{2}\right)}=8.013 \frac{\mathrm{m}}{\mathrm{s}}
$$

Coolant velocity in the shell side:

$$
\text { Vs }:=\frac{\mathrm{Mp}}{\rho \_ \text {shell } \cdot \pi \cdot\left(\text { Rout }^{2}-\mathrm{Rin}^{2}\right) \cdot\left(1-\frac{\mathrm{do}}{\mathrm{p}}\right)}=1.217 \frac{\mathrm{m}}{\mathrm{s}}
$$

Reynolds number in the tube side:

$$
\text { Re_t }:=\frac{\rho \text { tube } \cdot V t \cdot d i}{\mu \_ \text {tube }}=1.549 \times 10^{6}
$$

Reynolds number in the shell side:

$$
\text { Re_s }:=\frac{\rho \_ \text {shell } \cdot V s \cdot d o}{\mu \_ \text {shell }}=2.239 \times 10^{4}
$$

PrandtI number in the tube side:

$$
\text { Pr_t }:=\frac{\text { Cp_tube } \cdot \mu \_ \text {tube }}{\kappa \text { tube }}=1.174
$$

Prandtl number in the shell side:

$$
\text { Pr_s : }=\frac{\text { Cp shell } \cdot \mu \text { shell }}{\kappa \_ \text {shell }}=11.863
$$




\section{E. Heat Transfer Correlations}

In this part, heat transfer for the helical coiled heat exchanger will be estimated.

\section{Tube side:}

In the tube side, heat transfer correlatations are based on the heat transfer in the helical coiled tubes. To estimate it, some geometrical features should be defined first as follows:

$$
\begin{array}{ll}
\text { Radius of Tube: } & \mathrm{a}:=\frac{\mathrm{di}}{2}=0.015 \mathrm{~m} \\
\text { Radius of Curvature: } & \text { R_eff }:=\frac{(\text { Rin }+ \text { Rout })}{2}=2.5 \mathrm{~m}
\end{array}
$$

Based on that, Nesselt number for the helical coiled tube can be estimated as follows (Shah et al. 1987):

Nusselt number for straight pipe (Dittus-Boelter (Kays and Crawford 1981))

$$
\mathrm{Nu} 0:=0.022 \cdot \operatorname{Re}_{-} t^{0.8} \cdot \operatorname{Pr} t^{0.5}=2.135 \times 10^{3}
$$

Nusselt number for helical coil (shah et al. 1987)

$$
\mathrm{Nu} t:=\mathrm{Nu} 0 \cdot\left[1.0+3.6\left[1-\left(\frac{\mathrm{a}}{R_{\text {_eff }}}\right)\right] \cdot\left(\frac{\mathrm{a}}{\mathrm{R}_{-} \text {eff }}\right)^{0.8}\right]=2.262 \times 10^{3}
$$

From the above equation, heat transfer correlation in the tube side can be estimated as follows:

$$
h_{-} t:=\text { Nu_t } \cdot \frac{\kappa \_ \text {tube }}{\mathrm{di}}=2.187 \times 10^{4} \frac{\mathrm{kg}}{\mathrm{K} \cdot \mathrm{s}^{3}}
$$




\section{Shell side:}

In the tube side, heat transfer correlatations are based on heat transfer in inline tube bundles in smooth pipes show in Figure 3 (Zukauskas, 1987):

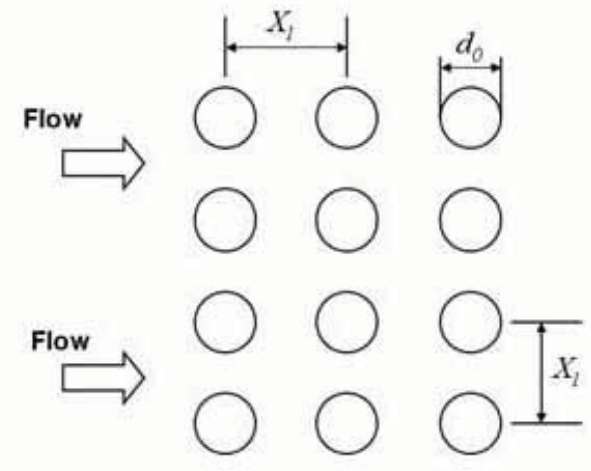

Figure 3 . Tube bundle arrangement (inline array).

To estimate the heat transfer in the inline tube bundles, some parameters should be defined such as the correction factor for the tube rows and the prandt number for wall temperature.

Correction Factor. $\mathrm{Cn}:=1$ (for large number of tubes)

Prandtl Number for a tube wall: $\quad \mathrm{Pr}_{-} \mathrm{W}:=\mathrm{Pr}_{-} \mathrm{s}=11.863$

( ${ }^{*}$ In this estimation, the prandt number for a tube wall was assumed to be the same as the bulk phase)

Nusselt number for the shell can be estimated as follows (zukauskas, 1987)

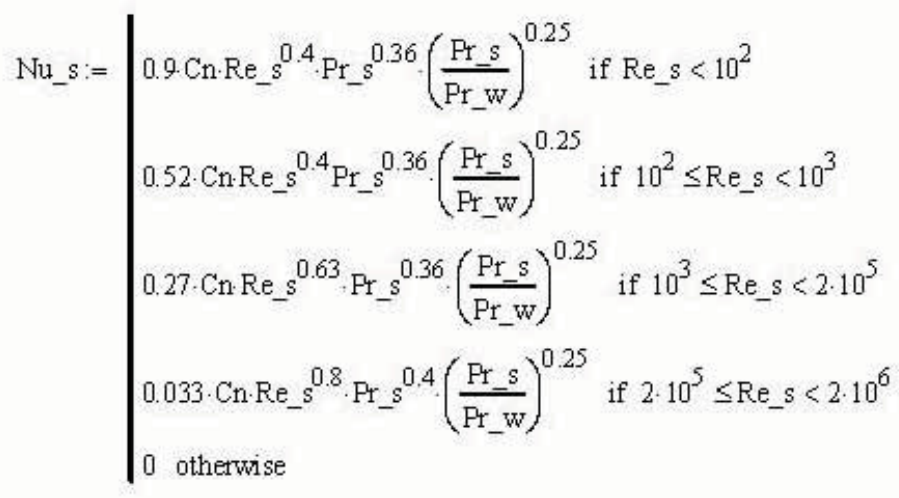


From the above equation, the heat transfer coefficient for the shell can be estimated as follows:

$$
\begin{aligned}
& \text { Nu_s }=361.88 \\
& \text { h_s }:=N u \_s \cdot \frac{\kappa \_s h e l l}{\text { do }}=4.86 \times 10^{3} \frac{\mathrm{kg}}{\mathrm{K} \cdot \mathrm{s}^{3}}
\end{aligned}
$$

\section{Overall Heat Transfer:}

In this part, the overal heat transfer coefficient for the helical coiled heat exchanger is estimated. Since the tube thickness is small, effect of heat transfer resistance at the wall has been neglected.

\section{Overall Heat Transfer Coefficient:}

$$
\mathrm{U}:=\frac{1}{\frac{1}{\mathrm{~h}_{-} \mathrm{t}}+\frac{1}{\mathrm{~h}_{-} \mathrm{s}}}=3.976 \times 10^{3} \frac{\mathrm{kg}}{\mathrm{K} \cdot \mathrm{s}^{3}}
$$

Log Mean Temperature Difference (LMTD):

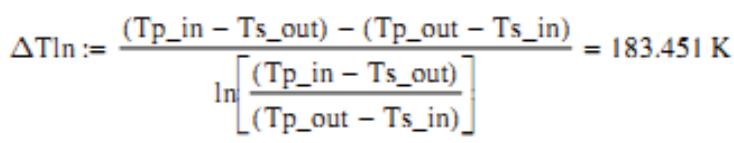

\section{Heat Transfer Surface Area:}

$$
\text { As }:=\frac{\mathrm{Q}}{\mathrm{U} \cdot \Delta \mathrm{Tln}}=4.661 \times 10^{3} \mathrm{~m}^{2}
$$

Tube Length:

$$
\text { Lt_middle }:=\frac{\mathrm{As}}{\pi \cdot\left(\frac{\mathrm{di}+\mathrm{do}}{2}\right) \cdot \mathrm{Nt}}=58.405 \mathrm{~m}
$$

Number of rotations of the tube bundle:

$$
\mathrm{Nb}:=\frac{\text { Lt_middle }}{\pi \cdot(\text { Rin }+ \text { Rout })}=3.718
$$

The shell length is calculated as follows:

$$
\mathrm{Ls}:=\mathrm{Lm} \cdot \mathrm{Nb}=3.718 \mathrm{~m}
$$




\section{F. Pressure Drop}

In this part, pressure drop in the shell and the tubes are estimated for the helical coiled heat exchanger:

\section{Tube Side:}

Pressure drop in the tube side can be estimated by the following equations (Kakac and Liu, 2002):

Friction Factor in the Helical Coiled Tubes:

$$
\mathrm{f}=\left[0.0084 \cdot\left[\operatorname{Re}_{-} \mathrm{t} \cdot\left[\frac{\frac{(\text { Rin }+ \text { Rout })}{2}}{\mathrm{a}}\right]^{-2}\right]^{-0.2} \cdot\left[\frac{\frac{(\text { Rin }+ \text { Rout })}{2}}{\mathrm{a}}\right]^{-0.5}\right]=2.911 \times 10^{-4}
$$

Pressure Drop in the Helical Tube Side:

$$
\Delta P_{-} \text {tube }=4 \cdot \mathrm{f} \cdot \frac{\mathrm{Lt}_{-} \text {middle }}{\mathrm{di}} \cdot \rho_{-} \text {tube } \cdot \frac{\mathrm{Vt}^{2}}{2}=2.453 \times 10^{4} \mathrm{~Pa}
$$

\section{Shell Side:}

Pressure drop in the tube bundles in cross flow can be estimated by the folowing equations (Martin (2002), Shah \& Sekulic (2003)):

Pitch-to-Diameter Ratio:

$$
\text { P_ratio }=\frac{P}{d_{0}}=1.492
$$

Hagen Number for Inline Tube Bundles (Martin, 2002):

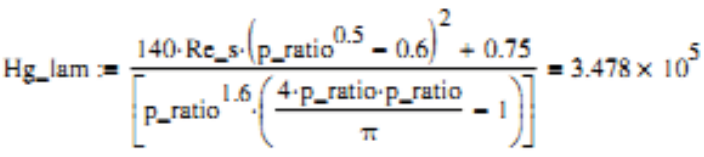

$$
\begin{aligned}
& \mathrm{Hg}_{-} \text {tub }:=\left[0.11+\frac{0.6 \cdot\left(1-\frac{0.94}{P_{-} \text {ratio }}\right)^{0.6}}{\left(\text { P_ratio }_{-0.85)^{1.3}}^{1.3}\right.} \cdot 10^{0.47 \cdot(-0.5)}+0.015 \cdot\left(\text { P_ratio }^{-1)^{2}}\right] \cdot \text { Re_s }^{1.9}\right. \\
& \mathrm{Hg}:=\mathrm{Hg}_{\text {_lam }}+\mathrm{Hg}_{\mathbf{S}} \mathrm{tub}=7.577 \times 10^{7}
\end{aligned}
$$

\section{Number of Effecitve Tube Bundles:}

$$
n_{-} \operatorname{tr}=N b \cdot\left(\frac{L m}{P}\right)=74.364
$$

Pressure Drop in the Shell Side:

$$
\Delta P_{-} \text {shell }=\frac{\mu_{-} \text {shell }}{P_{-} \text {shell }} \cdot \frac{n_{-} \text {tr }}{\text { do }^{2}} \cdot H_{g}=4.662 \times 10^{4} \mathrm{~Pa}
$$




\section{References}

Kato, R., Nishihara, T., Kumitomi, K., 2007, "Design of the Intermediate Heat Exchanger for the High Temperature Gas-cooled Reactor Hydrogen Cogeneration System," Japanese Nuclear Society, Vo. 6, No. 2, pp. 141148.

Martin, $H$., The generalized Leveque equation and its practical use for the prediction of heat and mass transfer rates from pressure drop, Chemical Engineering Science, 57, pp. 3217-3223, 2002.

Shah, R. K. and Joshi, S. D., 1987, Convective Heat Transfer in Curved Pipes, in Handbook of Single-Phase Convective Heat Transfer, Kakac, S., Shah, R. K., and Aung, W. Eds., John Wiley \& Sons, NewYork, Ch. 5.

Kays, W. M. and Crawford, M. E., 1981, Convective Heat and Mass Transfer, 2nd ed., McGraw-Hill, NewYork, 1981.

Kakac, S., Liu, H., 2002, Heat Exchangers: Selection, Rating, and Thermal Design, CRC Press, ISBN 0-8493-0902-6.

Zukauskas, A. A., 1987, "Convective Heat Transfer in Cross Flow," in Handbook of Single-Phase Convective Heat Transfer, Kakac, S., Shah, R. K., and Aung, W., Eds., John Wiley \& Sons, New York, 1987, Ch.5 
Appendix B

\section{Thermal Design of PCHE for AHTR}




\section{Thermal Design of Printed Circuit Heat Exchanger (PCHE)}

A simple thermal design of the printed circuit heat exchanger (PCHE) has been conducted for AHTR. Figure 1 and 2 show pictures of general PCHE channels and stackes. Figure 3 shows the channel configuration and arrangement of the PCHEs.

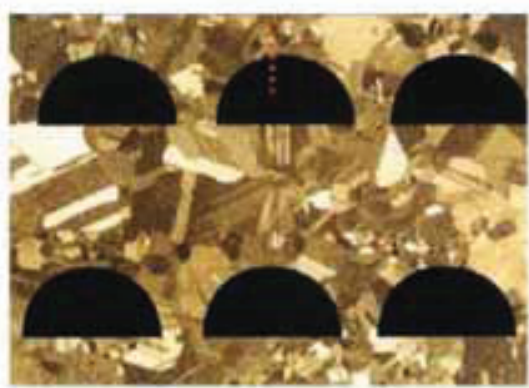

Figure 1. Channels of PCHE.

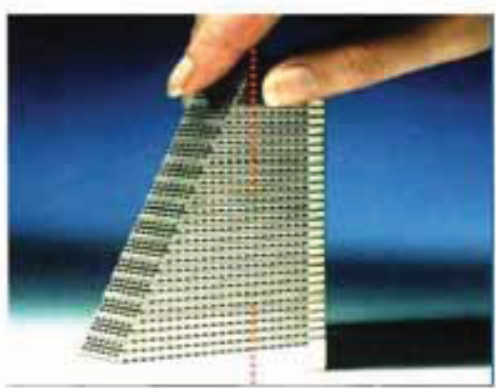

Figure 2. Printed Circuit Heat Exchanger.

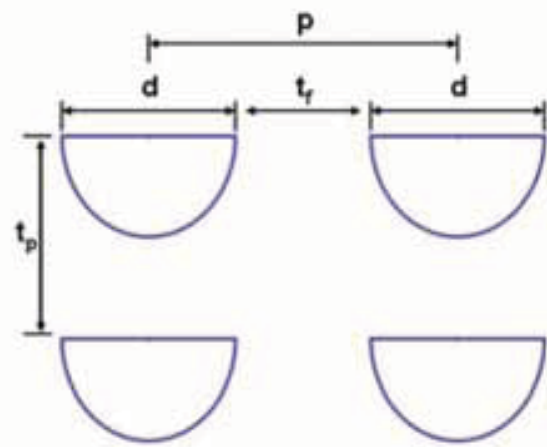

Figure 3. Channel Arrangement of PCHE. 


\section{A. Design Input Parameters:}

The basic input parameters used for the heat exchnager design are summarized below:

\section{Heat Exchanger Operating Conditions:}

The following is the heat exchanger operating conditions:

Heat Transfer Duty:

$$
\mathrm{Q}:=3400 \mathrm{MW}
$$

In this design, the primary side is an intermediate heat transfer loop. In this loop, the operating conditions are as follows:

$$
\begin{aligned}
& \text { Prim. temperature inlet: Prim temperature outlet: Prim. Pressure: } \\
& \mathrm{Tp} \text { in }:=679^{\circ} \mathrm{C} \quad \mathrm{Tp} \text { out }:=587^{\circ} \mathrm{C} \quad \mathrm{Pp}:=0.1 \mathrm{MPa}
\end{aligned}
$$

In this design, the secondary side is a power conversion system based on steam/water rankin cycle. In this loop, the operating conditions are as follows:

Sec. temperature inlet: Sec. temperature outlet: Sec. Pressure:
Ts_in : $=251^{\circ} \mathrm{C}$
Ts_out $:=593^{\circ} \mathrm{C}$
Ps $:=25 \mathrm{MPa}$

\section{Heat Exchanger Geometrical Parameters:}

The following summarizes the basic geometrical input parameters:

$\begin{array}{ccc}\text { Channel diameter: } & \frac{\text { Chennel pitch: }}{\mathrm{d}:=0.003 \mathrm{~m}} \quad \frac{\text { Plate thickness: }}{\mathrm{p}:=0.0033 \mathrm{~m}}:=0.00317 \mathrm{~m}\end{array}$

Channel horizontal distance: $\quad$ Surface area desnsity:

$$
\text { tf }:=\mathrm{p}-\mathrm{d}=3 \times 10^{-4} \mathrm{~m} \quad \beta:=\frac{0.5 \cdot \pi \cdot \mathrm{d}+\mathrm{d}}{(\mathrm{d}+\mathrm{tf}) \cdot \mathrm{tp}}=737.252 \frac{1}{\mathrm{~m}}
$$

Ratio of free flow area to frontal area Effective diameter:

$$
\sigma:=\frac{\frac{1}{2} \cdot \frac{\pi}{4} \cdot d^{2}}{(d+t f) \cdot t p}=0.338 \quad \text { de }:=\frac{4 \cdot \frac{\pi}{8} \cdot d^{2}}{\frac{\pi \cdot d}{2}+d}=1.833 \times 10^{-3} \mathrm{~m}
$$




\section{B. Properties:}

For desinging heat exchangers, fluid and structure properties should be defined first. The following summarizes the detail.

\section{Fluide Properties:}

In this heat exchanger design, the primary coolant is molten salt and the secondary coolant is water/steam. The following summarizes the basic properites of the coolant.

\begin{tabular}{|c|c|c|}
\hline & Molten Salt & Water (average) \\
\hline Density = & $\rho_{-}$salt $:=2800 \frac{\mathrm{kg}}{3}$ & $\rho \_$water $:=337 \frac{\mathrm{kg}}{3}$ \\
\hline
\end{tabular}

Thermal Conductivity $=$

$$
\kappa \_ \text {salt }:=0.45 \frac{\mathrm{W}}{\mathrm{mK}}
$$$$
\text { K_water : }=0.29 \frac{\mathrm{W}}{\mathrm{m} \mathrm{K}}
$$

Heat Capacity $=$

$$
\text { Cp_salt }:=1046.7 \frac{\mathrm{J}}{\mathrm{kg} \cdot \mathrm{K}}
$$$$
\text { Cp_water }:=6510 \frac{\mathrm{J}}{\mathrm{kg} \cdot \mathrm{K}}
$$

Viscosity $=$

$$
\mu \_ \text {salt }:=0.051 \text { poise }
$$

$\mu_{\text {_water }}:=5.23 \cdot 10^{-4}$ poise

\section{Structure Properties:}

In this study, Hastelloy $\mathrm{N}$ was selected to be the heat exchanger tube material. The following is the property of the material.

$$
\text { k_wall : }=23.5 \frac{\mathrm{W}}{\mathrm{m} \cdot \mathrm{K}} \stackrel{\mathrm{N}}{\text { ) }} \text { (Thermal Conductivity of Hastelloy }
$$




\section{Other Parameters:}

In this study, the primary coolant (molten salt) flows in the tube side and the secondary coolant (water) flows in the shell side. Therefore, the hot side and cold side coolants can be defined as follows:

Hot Channel:

$$
\begin{aligned}
& \rho_{-} \mathrm{h}:=\rho_{-} \text {salt }=2.8 \times 10^{3} \frac{\mathrm{kg}}{\mathrm{m}^{3}} \\
& \kappa \_h:=\kappa_{-} \text {salt }=0.45 \frac{\mathrm{m} \cdot \mathrm{kg}}{\mathrm{K} \cdot \mathrm{s}^{3}} \\
& \text { CP_h }:=\text { CP_salt }=1.047 \times 10^{3} \frac{\mathrm{m}^{2}}{\mathrm{~K} \cdot \mathrm{s}^{2}} \\
& \mu \_\mathrm{h}:=\mu \text { salt }=5.1 \times 10^{-3} \frac{\mathrm{kg}}{\mathrm{m} \cdot \mathrm{s}} \\
& \rho_{-} \mathrm{c}:=\rho_{-} \text {water }=337 \frac{\mathrm{kg}}{\mathrm{m}^{3}} \\
& \kappa \_c:=\kappa_{-} \text {water }=0.29 \frac{\mathrm{m} \cdot \mathrm{kg}}{\mathrm{K} \cdot \mathrm{s}^{3}} \\
& \text { CP_c }:=\text { Cp_water }=6.51 \times 10^{3} \frac{\mathrm{m}^{2}}{\mathrm{~K} \cdot \mathrm{s}^{2}} \\
& \mu \_c:=\mu_{-} \text {water }=5.23 \times 10^{-5} \frac{\mathrm{kg}}{\mathrm{m} \cdot \mathrm{s}}
\end{aligned}
$$$$
\text { Cold Channel: }
$$

Primary and secondary mass flow rates for the heat exchanger can be estimated as follows:

Mass flow in the primary side (hot channel):

$$
\mathrm{Mp}:=\frac{\mathrm{Q}}{\mathrm{Cp} \_\mathrm{h} \cdot\left(\mathrm{T} p \_ \text {in }-\mathrm{Tp} \_ \text {out }\right)}=3.531 \times 10^{4} \frac{\mathrm{kg}}{\mathrm{s}}
$$

Mass flow in the secondary side (cold channel):

$$
\text { Ms }:=\frac{\mathrm{Q}}{\text { Cp_c } \cdot(\text { Ts_out }-\mathrm{Ts} \text { in })}=1.527 \times 10^{3} \frac{\mathrm{kg}}{\mathrm{s}}
$$

\section{Define Total Flow Area:}

$$
\text { Ah }:=13 \mathrm{~m}^{2} \quad \text { Ac }:=6.5 \mathrm{~m}^{2}
$$

"PCHE channel arrangement is two hot channels + one cold channel." 


\section{Flow Parameters}

Based on the heat exchanger design conditions and input parameters, flow parameters of the heat exchanger can be estimated as follows:

Coolant velocity in the hot channel:

$$
\mathrm{Vh}:=\frac{\mathrm{Mp}}{\rho \_\mathrm{h} \cdot \mathrm{Ah}}=0.97 \frac{\mathrm{m}}{\mathrm{s}}
$$

Coolant velocity in the cold channel:

$$
V c:=\frac{\mathrm{Ms}}{\rho \_c \cdot A c}=0.697 \frac{\mathrm{m}}{\mathrm{s}}
$$

Reynolds number in the hot channel:

$$
\text { Re_h }:=\frac{\rho \_h \cdot V h \cdot d e}{\mu \_h}=976.178
$$

Reynolds number in the cold channel:

$$
\text { Re_c : }=\frac{\rho \_c \cdot V c \cdot d e}{\mu \_c}=8.234 \times 10^{3}
$$

Prandtl number in the hot channel:

$$
\operatorname{Pr} \mathrm{h}:=\frac{\mathrm{Cp} \_\mathrm{h} \cdot \mu \_\mathrm{h}}{\kappa \_\mathrm{h}}=11.863
$$

Prandtl number in the cold channel:

$$
\operatorname{Pr} \_:=\frac{C p \_c \cdot \mu \_c}{\kappa \_c}=1.174
$$




\section{E. Heat Transfer Correlations}

In this part, heat transfer for the compact heat exchanger will be estimated. In this preliminary design, the channel is assumed to be straight throught the flow paths.

\section{Hot Channel:}

In the hot channel, heat transfer correlatations are based on the heat transfer in the straight pipe as follows:

Nusselt number for straight pipe (Welty et al. (1984))

$$
\text { Nu_h }:=\mid \begin{aligned}
& 3.657 \text { if } \operatorname{Re} \_h<2300 \\
& 0.023 \cdot \operatorname{Re} \mathrm{h}^{0.8} \cdot \operatorname{Pr} \mathrm{h}^{0.33} \text { if } \operatorname{Re} \mathrm{h} \geq 2300
\end{aligned}
$$

Nu_h $=3.657$

From the above equation, heat transfer correlation in the hot side can be estimated as follows:

$$
\mathrm{h} \_\mathrm{h}:=\mathrm{Nu} \_\mathrm{h} \cdot \frac{\kappa \mathrm{h}}{\mathrm{de}}=897.768 \frac{\mathrm{kg}}{\mathrm{K} \cdot \mathrm{s}^{3}}
$$

\section{Cold Channel:}

In the cold side, heat transfer correlatations are based on the heat transfer in the straight pipe as follows:

Nusselt number for straight pipe (Welty et al. (1984))

$$
\begin{aligned}
& \text { Nu_c }:=\mid \begin{array}{l}
3.657 \text { if } \operatorname{Re} \_c<2300 \\
0.023 \cdot \operatorname{Re} c^{0.8} \cdot \operatorname{Pr} c^{0.4} \text { if } R e \_c \geq 2300
\end{array} \\
& N u_{-} c=33.274
\end{aligned}
$$

From the above equation, heat transfer correlation in the hot side can be estimated as follows:

$$
\mathrm{h} \_\mathrm{c}:=\mathrm{Nu} \_\mathrm{c} \cdot \frac{\kappa \_\mathrm{c}}{\mathrm{de}}=5.264 \times 10^{3} \frac{\mathrm{kg}}{\mathrm{K} \cdot \mathrm{s}}
$$




\section{Overall Heat Transfer:}

In this part, the overal heat transfer coefficient for the helical coiled heat exchanger is estimated.

Heat Transfer Resistance in Heat Transfer Wall:

$$
\mathrm{Rw}:=\frac{\mathrm{tf}}{\mathrm{k}_{\text {wwall }}}=1.277 \times 10^{-5} \frac{\mathrm{K} \cdot \mathrm{s}^{3}}{\mathrm{~kg}}
$$

\section{Overall Heat Transfer Coefficient:}

$$
\mathrm{U}:=\frac{1}{\frac{1}{\mathrm{~h} \_\mathrm{h}}+\mathrm{Rw}+\frac{1}{\mathrm{~h} \_\mathrm{c}}}=759.53 \frac{\mathrm{kg}}{\mathrm{K} \cdot \mathrm{s}^{3}}
$$

Log Mean Temperature Difference (LMTD):

$$
\Delta \mathrm{T} \ln :=\frac{\left(\mathrm{Tp} \_ \text {in }-\mathrm{Ts} \text { _out }\right)-\left(\mathrm{T} p \_ \text {out }-\mathrm{Ts} \text { in }\right)}{\ln \left[\frac{(\mathrm{Tp} \text { in }-\mathrm{Ts} \text { out })}{(\mathrm{T} \text { _out }-\mathrm{Ts} \text { _in })}\right]}=183.451 \mathrm{~K}
$$

\section{Heat Transfer Surface Area:}

$$
\text { As }:=\frac{Q}{U \cdot \Delta T h n}=2.44 \times 10^{4} \mathrm{~m}^{2}
$$

Number of Channels:

$$
\mathrm{Nh}:=\frac{\mathrm{Ah}}{\frac{\pi}{8} \cdot \mathrm{d}^{2}}=3.678 \times 10^{6} \quad \mathrm{Nc}:=\frac{\mathrm{Ac}}{\frac{\pi}{8} \cdot \mathrm{d}^{2}}=1.839 \times 10^{6}
$$

Heat Exchanger Channel Length:

$$
\begin{aligned}
& \text { Length_h: }=\frac{\mathrm{As}}{\left(\frac{\pi}{2} \cdot \mathrm{d}+\mathrm{d}\right) \cdot \mathrm{Nh}}=0.86 \mathrm{~m} \quad \text { (hot channel length) } \\
& \text { Length_c }:=\frac{\mathrm{As}}{\left(\frac{\pi}{2} \cdot \mathrm{d}+\mathrm{d}\right) \cdot \mathrm{Nc} \cdot 2}=0.86 \mathrm{~m} \quad \text { (cold channel length) }
\end{aligned}
$$




\section{F. Pressure Drop}

In this part, pressure drop in the hot side and cold side are estimated for the straight pipe:

\section{Hot Side:}

Pressure drop in the tube side can be estimated by the following equations (Kakac and Liu, 2002):

Friction Factor in the straight pipe:

$$
\begin{aligned}
& \text { f_ht }(x):=\frac{1}{\sqrt{x}}-4 \cdot 0 \cdot(\log (\operatorname{Re} h \cdot \sqrt{x})-0.40) \\
& \text { f_h }:=\mid \begin{array}{ll}
\frac{16}{\operatorname{Re} h} \text { if } \operatorname{Re} \_ & =2300 \\
\operatorname{root}\left(f \_h t(x), x, 1\right) \text { if } \operatorname{Re} h \geq 2300 &
\end{array}=0.016
\end{aligned}
$$

\section{Pressure Drop in the Hot Channel:}

$$
\Delta \mathrm{P} \_\mathrm{h}:=4 \cdot \mathrm{f} \_\mathrm{h} \cdot \frac{\text { Length_h }}{\mathrm{de}} \cdot \rho \_\mathrm{h} \cdot \frac{\mathrm{Vh}^{2}}{2}=4.053 \times 10^{4} \mathrm{~Pa}
$$

\section{Cold Side:}

Pressure drop in the tube bundles in cross flow can be estimated by the following equations (Martin (2002), Shah \& Sekulic (2003)):

Friction Factor in the straight pipe:

$$
\begin{aligned}
& \text { f_ct }(x):=\frac{1}{\sqrt{x}}-4 \cdot 0 \cdot\left(\log \left(\operatorname{Re} \_c \cdot \sqrt{x}\right)-0.40\right) \\
& x:=0.001 \\
& \text { f_c }:=\mid \begin{array}{l}
\frac{16}{\operatorname{Re} h} \text { if } \operatorname{Re} \_c<2300 \\
\operatorname{root}\left(f \_c t(x), x\right) \text { if } \operatorname{Re} \_c \geq 2300
\end{array}=9.894 \times 10^{-3}
\end{aligned}
$$

\section{Pressure Drop in the Hot Channel:}

$$
\Delta P_{-} \mathrm{c}:=4 \cdot f_{-} \mathrm{c} \cdot \frac{\text { Length_c}}{\mathrm{de}} \cdot \rho_{-} \mathrm{c} \cdot \frac{\mathrm{Vc}^{2}}{2}=1.521 \times 10^{3} \mathrm{~Pa}
$$




\section{References}

Kato, R., Nishihara, T., Kumitomi, K, 2007, "Design of the Intermediate Heat Exchanger for the High Temperature Gas-cooled Reactor Hydrogen Cogeneration System," Japanese Nuclear Society, Vo. 6, No. 2, pp. 141148.

Martin, H., The generalized Leveque equation and its practical use for the prediction of heat and mass transfer rates from pressure drop, Chemical Engineering Science, 57, pp. $3217-3223,2002$.

Shah, R. K. and Joshi, S. D., 1987, Convective Heat Transfer in Curved Pipes, in Handbook of Single-Phase Convective Heat Transfer, Kakac, S., Shah, R. K., and Aung, W. Eds., John Wiley \& Sons, NewYork, Ch. 5.

Kays, W. M. and Crawford, M. E., 1981, Convective Heat and Mass Transfer, 2nd ed., McGraw-Hill, NewYork, 1981.

Kakac, S., Liu, H., 2002, Heat Exchangers: Selection, Rating, and Thermal Design, CRC Press, ISBN 0-8493-0902-6.

Zukauskas, A. A., 1987, "Convective Heat Transfer in Cross Flow," in Handbook of Single-Phase Convective Heat Transfer, Kakac, S., Shah, R. K., and Aung, W., Eds., John Wiley \& Sons, New York, 1987, Ch.5. 


\section{Appendix C}

\section{Mechanical Design of Heat Exchanger}




\section{Appendix C \\ Mechanical Design of Heat Exchanger}

This appendix describes a simple mechanical design procedure for helical coiled heat exchangers and printed circuit heat exchangers shown in heat exchanger thermal design section.

\section{C-1. Helical Coiled Heat Exchanger \\ C-1.1 Basic Assumptions and Input Parameters}

- Tube inner radius $\left(r_{i}\right): 0.015 \mathrm{~m}$ (assumption)

- Shell inner radius $\left(R_{i}\right): 3.5 \mathrm{~m}$ (based on thermal design)

- Tube inside pressure $\left(P_{t}\right): 2.4 \times 10^{7} \mathrm{~Pa}$ (based on supercritical Rankine cycle)

- Shell inside pressure $\left(P_{s}\right): 1.01 \times 10^{5} \mathrm{~Pa}$ (based on molten salt intermediate loop)

- Shell outside pressure $\left(P_{e}\right): 1.01 \times 10^{5} \mathrm{~Pa}$ (based on environment)

- Maximum allowable stress $\left(\sigma_{\max }\right): 2.18 \times 10^{8} \mathrm{~Pa}$ (Yield stress for Alloy $\mathrm{N}$ at $700^{\circ} \mathrm{C}$ )

\section{C-1.2 Determination of Tube Thickness}

In this case, tube inside pressure is much higher than the outside. Therefore, the tube outer radius $\left(\mathrm{r}_{\mathrm{o}}\right)$ can be estimated by the following equation:

$$
\frac{r_{0}}{r_{i}} \geq \sqrt{\frac{\sigma_{\max }+P_{t}}{\sigma_{\max }+2 P_{s}-P_{t}}} .
$$

Therefore, the tube thickness $\left(t_{t}\right)$ can be estimated by

$t_{t}=r_{0}-r_{i}$

\section{C-1.3 Determination of Shell Thickness}

In this case, shell is also exposed to the internal load in which the internal pressure slightly exceeds the external pressure. Therefore, the shell outer radius can be calculated by

$$
\frac{R_{0}}{R_{i}} \geq \sqrt{\frac{\sigma_{\max }+P_{s}}{\sigma_{\max }+2 P_{e}-P_{s}}} .
$$

Therefore, the shell thickness (ts) can be estimated by

$$
t_{s}=R_{0}-R_{i} \text {. }
$$




\section{C-2. Printed Circuit Heat Exchanger (PCHE) C-2.1 Basic Assumptions and Input Parameters}

- Channel diameter $\left(d_{i}\right): 0.003 \mathrm{~m}$ (assumption)

- Primary channel pressure $\left(P_{p}\right): 2.4 \times 10^{7} \mathrm{~Pa}$ (based on supercritical Rankine cycle)

- Secondary channel pressure $\left(P_{s}\right): 1.01 \times 10^{5} \mathrm{~Pa}$ (based on molten salt intermediate loop)

- Shell outside pressure $\left(P_{e}\right): 1.01 \times 10^{5} \mathrm{~Pa}$ (based on environment)

- Maximum allowable stress $\left(\sigma_{\max }\right): 2.18 \times 10^{8} \mathrm{~Pa}$ (Yield stress for Alloy $\mathrm{N}$ at $700^{\circ} \mathrm{C}$ ).

\section{C-2.2 Determination of Channel Pitch ( $p)$}

Based on Heatric (Dewson and Thonon 2003), the pitch ( $p$ ) of the channels can be estimated by

$$
p \geq d_{i} \cdot\left(1+\frac{\left(P_{p}-P_{s}\right)}{\sigma_{\max }}\right) \text {. }
$$

\section{C-2.3 Determination of Plate Thickness $\left(t_{p}\right)$}

In the PCHE, the plate can be assumed to be a thick-walled cylinder with an inner radius of $d / 2$ and an outer radius of $t_{p}$. Therefore, the thickness of the plate $\left(t_{p}\right)$ can be estimated by

$$
\frac{t_{p}}{d / 2} \geq \sqrt{\frac{\sigma_{\max }+P_{p}}{\sigma_{\max }+2 P_{s}-P_{p}}} .
$$

